
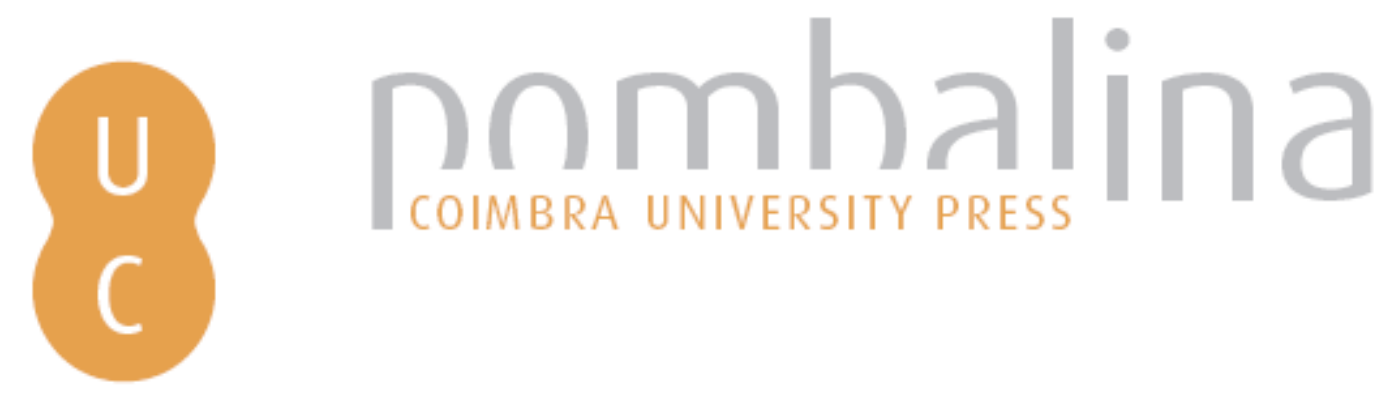

\title{
História, tecnologias digitais e mobile learning: ensinar História na era digital
}

Author(s: $\quad$ Dias-Trindade, Sara; Carvalho, Joaquim Ramos de

Published by: Imprensa da Universidade de Coimbra

Persistent URL: URI:http://hdl.handle.net/10316.2/47406

DOI: $\quad$ DOI:https://doi.org/10.14195/978-989-26-1705-3

Accessed : $\quad$ 6-Feb-2020 18:14:25

The browsing of UC Digitalis, UC Pombalina and UC Impactum and the consultation and download of titles contained in them presumes full and unreserved acceptance of the Terms and Conditions of Use, available at https://digitalis.uc.pt/en/terms_and_conditions.

As laid out in the Terms and Conditions of Use, the download of restricted-access titles requires a valid licence, and the document(s) should be accessed from the IP address of the licence-holding institution.

Downloads are for personal use only. The use of downloaded titles for any another purpose, such as commercial, requires authorization from the author or publisher of the work.

As all the works of UC Digitalis are protected by Copyright and Related Rights, and other applicable legislation, any copying, total or partial, of this document, where this is legally permitted, must contain or be accompanied by a notice to this effect. 


\section{HISTÓRIA, \\ TECNOLOGIAS DIGITAIS \\ E MOBILE LEARNING .}

ENSINAR HISTÓRIA NA ERA DIGITAL

SARA DIAS-TRINDADE

JOAQUIM RAMOS DE CARVALHO
IMPRENSA DA

UNIVERSIDADE

DE COIMBRA

COIMBRA

UNIVERSITY

PRESS 
O livro "História, Tecnologias Digitais e Mobile Learning: ensinar História na era digital" nos apresenta um conjunto de reflexões em torno da relação História, Educação e Tecnologias, com particular atenção ao ensino de História por meio das tecnologias móveis. São reflexões atuais, importantes e necessárias, especialmente quando consideramos as condições que temos experienciado no contexto de cultura digital. Com base em estudo teórico-experimental, os amigos e pesquisadores Sara Dias-Trindade e Joaquim Carvalho nos oferecem uma primorosa análise crítico-reflexiva e propositiva sobre algumas possibilidades de incorporação das tecnologias digitais de informação e comunicação no processo de ensino-aprendizagem na área de História. Trata-se da coroação de um intenso trabalho e empenho dos autores para contribuir tanto para a área de Educação e Tecnologias quanto para a sua área base: a História. Certamente, com este fruto dos seus esforços, a comunidade científica e educacional ganhou bastante. 


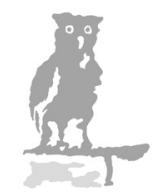

$\begin{array}{lllllllllllll}\text { I } & \mathrm{N} & \mathrm{V} & \mathrm{E} & \mathrm{S} & \mathrm{T} & \mathrm{I} & \mathrm{G} & \mathrm{A} & \mathrm{C} & \tilde{\mathrm{A}} & 0\end{array}$

$\underbrace{}_{\substack{\text { IMPRENSA DA INIERSIDADE DE COIMBRA } \\ \text { COIMBRA LNIVERSITY PRESS }}}$

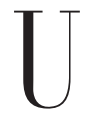




\section{EDIÇÃo}

Imprensa da Universidade de Coimbra

Email: imprensauc@ci.uc.pt

URL: http//www.uc.pt/imprensa_uc

Vendas online: http://livrariadaimprensa.uc.pt

Ceis 20

COORDENAÇÃo EDITORIAL

Imprensa da Universidade de Coimbra

CONCEÇÃO GRÁFICA

Imprensa da Universidade de Coimbra

INFOGRAFIA DA CAPA

Mickael Silva

PRÉ-IMPRESSÃo

Jorge Neves

PRINT BY

KDP

ISBN

978-989-26-1704-6

ISBN DIGITAL

978-989-26-1705-3

DOI

https://doi.org/10.14195/978-989-26-1705-3

C SETEMBRO 2019, IMPRENSA DA UNIVERSIDADE DE COIMBRA

TRINDADE, Sara Dias, 1978-

História, tecnologias digitais e mobile learning : ensinar História na era digital / Sara Dias Trindade, Joaquim Ramos de Carvalho. - (Investigação)

ISBN 978-989-26-1704-6 (ed. impressa)

ISBN 978-989-26-1705-3 (ed. eletrónica)

I - CARVALHO, Joaquim Ramos de, 1958

CDU 37 


\section{HISTÓRIA,}

TECNOLOGIAS DIGITAIS

E MOBILE LEARNING

ENSINAR HISTÓRIA NA ERA DIGITAL 
(Página deixada propositadamente em branco) 


\section{Í N D I C E}

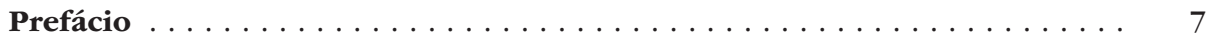

DANIEL MILL

Introdução

PARTE I - HISTÓRIA, TECNOLOGIAS DIGITAIS

E MOBILE LEARNING

1. As tecnologias digitais na educação

2. As tecnologias digitais na era mobile

3. Complexidade em história .

PARTE II - ENSINAR HISTÓRIA NA ERA DIGITALS

4. O estudo de caso: metodologia

5. O estudo de caso

Conclusão 
(Página deixada propositadamente em branco) 
DANIEL MILL

Universidade Federal de São Carlos (UFSCar)

Grupo Horizonte (Grupo de Estudos e Pesquisas sobre Inovação em Educação, Tecnologias e Linguagens)

\section{P R E F Á C I O}

O livro "História, Tecnologias Digitais e Mobile Learning: ensinar História na era digital" nos apresenta um conjunto de reflexões em torno da relação História, Educação e Tecnologias, com particular atenção ao ensino de História por meio das tecnologias móveis. São reflexões atuais, importantes e necessárias, especialmente quando consideramos as condições que temos experienciado no contexto de cultura digital. Com base em um estudo teórico-experimental, os amigos e pesquisadores Sara Dias-Trindade e Joaquim Carvalho nos oferecem uma primorosa análise crítico-reflexiva e propositiva sobre algumas possibilidades de incorporação das tecnologias digitais de informação e comunicação no processo de ensino-aprendizagem na área de História. Trata-se da coroação de um intenso trabalho e empenho dos autores para contribuir tanto para a área de Educação e Tecnologias quanto para a sua área base: a História. Certamente, com este fruto dos seus esforços, a comunidade científica e educacional ganhou bastante.

Numa feliz exploração e articulação entre literatura, projetos político-educacionais e experimento (estudo de caso), os autores realizam com acuidade e perspicácia, ao longo do livro, diversos movimentos reflexivos, tais como:

- fazem aprofundada revisão de literatura com foco na incorporação de tecnologias no seio educacional, lançando mão de estudos atuais e clássicos;

- analisam projetos e documentos oficiais - referentes a várias iniciativas de integração das tecnologias de informação e comunicação na Edu- 
cação -, implementados no contexto português e europeu nas últimas décadas;

- apresentam e discutem abordagens pedagógicas mais adequadas para a Era Digital, como o conectivismo, a aprendizagem em rede e a educação rizomática; e

- destacam a importância conquistada pelas tecnologias móveis, em meio às muitas outras tecnologias digitais, analisando seu emprego no contexto educacional - e buscando definir o Mobile Learning (ou Educação Móvel, como costuma traduzir a literatura brasileira).

Só essa contribuição já seria suficiente justificativa para leitura do presente livro. Todavia, os autores não se contiveram e ainda propõem e apresentam, neste livro, uma investigação realizada para identificar e validar a aplicabilidade da educação móvel no contexto da História e nos apresentam o estudo e seus resultados. Caracterizada como um minucioso estudo de caso, a sua pesquisa foi norteada pela seguinte questão: Que impacto têm os novos dispositivos móveis (como os tablets e os ambientes tecnológicos que lhe estão associados) no envolvimento e na aprendizagem dos alunos nas aulas de História? Entre os importantes elementos e achados da investigação, os autores destacam que o decorrente maior envolvimento ("engagement"), melhor acesso às fontes, melhor organização dos materiais e possibilidade de recriação dos conteúdos podem promover um salto qualitativo no processo de ensino-aprendizagem, inclusive no campo da História. Outras conclusões do estudo e considerações dos autores, apresentadas ao final do livro também merecem a atenção do leitor.

Desta forma, registro aqui as múltiplas e ímpares riquezas da obra que temos em mãos. As análises registradas neste livro tornam a obra primorosa àqueles que se interessam pela temática, especialmente por evidenciar elementos importantes para discussões sobre a relação entre Educação e Tecnologias, não se restringindo à disciplina de História. Certamente, temos em mãos um conjunto de reflexões de grande interesse para pesquisadores e estudantes interessados nas interfaces entre Educação e Tecnologia em geral.

Aos leitores, fica o convite para leitura das linhas e entrelinhas deste livro. Estou certo de que, na leitura, encontrarão diversos elementos para fomen- 
tar reflexões essenciais ao crescimento da área. Desejo uma boa jornada aos leitores!

Deixo, por fim, os meus parabéns e agradecimentos aos autores pela contribuição e pela consideração para leitura em primeira mão do seu livro.

Com um grande abraço,

DANIEL MILL 
(Página deixada propositadamente em branco) 


\section{N T R O D U Ç Ã O}

A introdução das Tecnologias Digitais da Informação e da Comunicação (TDIC1) nas Escolas é, desde há vários anos, um facto consumado. Cada vez são mais os casos de aposta na introdução das mais variadas experiências com o digital, apostando numa interação entre o mundo a que os jovens nativos digitais estão habituados a viver e as potencialidades que estas estratégias podem trazer ao mundo da educação.

Por outro lado, a disciplina de História afigura-se como um caso específico no contexto de informatização do ensino. Sendo os conteúdos desta disciplina muitas vezes complexos e não lineares, torna-se, com frequência, necessária a criação de mecanismos que combatam o desinteresse de que a disciplina, frequentemente, é alvo, fruto de abordagens muitas vezes exclusivamente expositivas. Para além disso, é importante encontrar formas de auxiliar os alunos na desconstrução dos conhecimentos que lhes são ensinados, para que consigam ultrapassar as dificuldades que podem surgir na relação de diferentes conteúdos históricos, sobretudo quando confrontados com a provisoriedade da História, ou seja, com a existência de múltiplas perspectivas face a um mesmo acontecimento. Isabel Barca (2001a) refere que

esta é a característica fascinante da produção histórica, que devemos passar aos alunos sem cair no relativismo de considerar que todas as respostas sobre o passado têm a mesma validade. [...] Tarefas em torno de materiais históricos concretos, que

${ }^{1}$ Nota dos autores: apesar de inicialmente se utilizar a terminologia TIC - Tecnologias da Informação e da Comunicação - optamos por, sempre que nos referimos às tecnologias digitais da informação e da comunicação, usar o acrónimo TDIC. 
veiculem de algum modo a diversidade da História e que possibilitem a reflexão sobre os seus critérios de legitimação, contribuem para estimular o raciocínio dos jovens (p. 39).

Nesse sentido, as diferentes TDIC potenciam, à priori, o desenvolvimento de uma consciência crítica, uma vez que através delas se pode fazer a ponte entre o passado e o presente. Quantas vezes os professores de História procuram que os seus alunos formulem raciocínios de causalidade complexa e consigam perceber os acontecimentos a nível não só conjuntural mas também estrutural? A possibilidade de desenvolver este raciocínio a um nível mais prático, que a tecnologia digital, normalmente, pode possibilitar (tal como a visualização de mapas interativos, a construção de bases de dados com informação variada ou até a participação num jogo de computador) contribuirá, de certo, para que com mais facilidade e maior correção os alunos apreendam os conteúdos que os professores pretenderem lecionar.

Assim, e cientes de que as novas gerações, habituadas a viver rodeadas de tecnologia digital, têm hoje outra forma de encarar o acesso à informação, reconhecemos que é necessário também adequar a maneira como se ensina, pois os alunos

preferem a imagem antes do texto em vez do contrário. Preferem o acesso aleatório (como o hipertexto). Funcionam melhor quando estão em rede. Adoram a recompensa instantânea e constante. Preferem jogos a "tabalho sério"2 (Prensky, 2001: 2).

É por esse motivo que se torna necessário repensar o modelo educativo a seguir, de forma a adequá-lo ao novo tipo de estudantes que passam hoje pelas salas de aula. De facto, o mundo educativo encontra-se frente a uma enorme transformação, resultado da revolução digital.

2 Tradução nossa. No original: prefer their graphics before their text rather than the opposite. They prefer random access (like hypertext). They function best when networked. They thrive on instant gratification and frequent rewards. They prefer games to "serious" work. 
Nesse sentido, Moura (2012) indica que a escolarização era, normalmente, associada à frequência da Escola, mas que, hoje em dia, essa associação vem diminuindo cada vez mais. Contudo, a autora reconhece também que, por enquanto, são maiores as modificações nos equipamentos do que nos procedimentos.

É importante que a Escola assuma o efetivo contributo que variados dispositivos informáticos uma vez que hoje, mais do que um simples laptop, existe toda uma panóplia de equipamentos móveis que se revelam extensões da nossa memória e tornam mais valiosa a capacidade de pesquisa e seleção da informação do que, propriamente, a sua memorização. Por esse motivo Prensky (2013) refere que a tecnologia digital

é uma extensão dos nossos cérebros; é uma nova forma de pensar. É a solução que nós humanos criámos para lidar com o nosso difícil novo contexto de mudança, incerteza, complexidade e ambiguidade ${ }^{3}$ (online).

Nesse sentido, há que reconhecer e aceitar a importância que hoje tem o acesso e a capacidade de utilizar da melhor maneira a tecnologia digital, pois

reconhecer as nossas limitações não faz de nós menos capazes, pelo contrário. Conhecê-las e assumi-las torna-nos mais inteligentes e conscientes da forma como podemos contornar essas limitações (Cruz, 2009: 3).

Assim, e tal como refere a Comissão Europeia (2013) na Iniciativa "Abrir a Educação",

a integração das tecnologias digitais e dos conteúdos digitais na educação e nos sistemas educativos não significa simplesmente mais aparelhos eletrónicos ou mais ligações de banda larga. Apoiar a aprendizagem com tecnologias permite a combinação de pedagogias inovadoras com um uso efetivo de ferramentas e conteúdos

3 Tradução nossa. No original: is an extension of our brains; it's a new way of thinking. It's the solution we humans have created to deal with our difficult new context of variability, uncertainty, complexity, and ambiguity. 
digitais que podem aumentar a qualidade do processo de ensino e de aprendizagem $^{4}$ (p. 5).

Enquanto educadores, há que aceitar as capacidades que nos são fornecidas nesta Era Digital e aproveitá-las, da melhor forma possível, de forma a proporcionar ambientes de aprendizagem profícuos. Para que tal aconteça, é necessário que a utilização das TDIC não se resuma à atividade desenvolvida apenas numa disciplina, criada especificamente para o efeito (como é o caso da disciplina TIC, que faz parte do currículo previsto para o Terceiro Ciclo do Ensino Básico), mas que seja disponibilizada em todas as vertentes do ensino, para que os alunos aprendam a lidar e usufruir em pleno das vantagens da sua utilização, bem como conheçam as desvantagens de não saber lidar com essa mesma tecnologia digital. Cruz (2009) refere, a propósito, que

a escola não pode deixar de incorporar as novas transformações, devendo caminhar no sentido de estimular a integração de todos os serviços e recursos pedagógicos 'retirando-lhes' o que de melhor possuem para ajudar o aluno no seu processo de construção de aprendizagens. A revolução digital é um facto consumado e a escola tem que assumir esta realidade como um dos seus desafios (p. 6).

Talvez de uma forma provocatória, Prensky (2013) questiona o que faríamos se tivéssemos de redesenhar o currículo dos nossos estudantes a partir do zero e preocupados apenas com as necessidades dos nossos estudantes para o futuro. Como faríamos? Será que ensinaríamos a ler e a escrever da forma como ainda hoje fazemos?

Claro que, por outro lado, não podemos pensar que a utilização das TDIC no ensino virá solucionar todos os problemas que nele existem, nem eliminar todos os métodos e utensílios tradicionais de ensino. Como Tavares (2009) refere, "a sociedade da informação não implica necessariamente a morte de

4 Tradução nossa. No original: integration of digital technologies and digital content in education and training systems does not simply mean more electronic devices or more broadband connections. Supporting learning with technologies allows for the combination of innovative pedagogies with an effective use of digital tools and content which in turn can boost the quality of teaching and learning processes. 
Gutenberg. Permite é o acesso rápido, cómodo e económico ao conhecimento" (online).

Importante é reconhecer que a combinação das TDIC com estratégias de ensino inovadoras poderá proporcionar ambientes de aprendizagem mais ricos e apropriados às necessidades dos nossos alunos. Contudo, Moura \& Carvalho (2013) recordam que

para aumentar a experiência de aprendizagem: temos de organizar cuidadosamente os conteúdos, temos de apresentar os objetivos de forma clara, ajudando o aprendente a sentir-se motivado [...]; temos de usar os resultados e o feedback para medir os objetivos de aprendizagem e motivar os aprendentes [...]; experiências adequadas e relevantes podem ser um aspeto importante no desenvolvimento de novas ou melhoradas competências 5 (p. 63).

Assim e conscientes da importância que as tecnologias digitais, em particular as tecnologias digitais móveis, têm vindo a ter no desenvolvimento de ambientes de aprendizagem motivadores e na promoção de ambientes de ensino eficazes, definimos como problema principal a verificação da relevância que pode ter o uso de tecnologias digitais móveis na sala de aula, como forma de potenciar ambientes de ensino mais enriquecedores e aumentar, assim, a qualidade da educação.

Com esta obra pretendemos responder à seguinte questão: que impacto têm os dispositivos móveis como os tablets, e os ambientes tecnológicos que lhes estão associados, no envolvimento e na aprendizagem dos alunos nas aulas de História?

Esta investigação torna-se particularmente importante no caso da História, enquanto disciplina que tem um carácter complexo, cujo estudo envolve, frequentemente, a abordagem de diferentes perspetivas e que se encontra sempre em evolução, resultante do facto de o conhecimento histórico

5 Tradução nossa. No original: to enhance the learning experience: we must carefully organize contents, we must present goals and objectives clearly, which helps the learner to engage [...]; we must use outcomes and feedback to measure learning goals and objectives and motivate learners [...]; adequate and relevant learning experiences can be an important aspect in developing new or improved skills (p. 63). 
estar sempre em contínuo desenvolvimento (assumindo assim um carácter provisório - as verdades de hoje podem sempre sofrer alterações mediante as descobertas de amanhã).

Para além disso, a revisão de literatura efetuada acerca da utilização de tecnologias digitais móveis no ensino, revela, sobretudo, um maior envolvimento dos alunos durante as aulas e, consequentemente, uma maior apropriação dos conteúdos lecionados, para além de também identificar algumas vantagens no que diz respeito à disponibilização de um tipo de aprendizagem just-for-me, ou seja, mais individualizada e, sobretudo, construtivista.

Neste novo ecossistema digital emergente elegemos o iPad e a plataforma iTunes $U$ como paradigma de ambientes onde se combinam dispositivos móveis, repositórios de recursos educacionais e software de consumo e criação de conteúdos.

Para o nosso estudo de caso desenhámos um modelo de trabalho que abrange conteúdos abordados no 9. ${ }^{\circ}$ ano de escolaridade, ano terminal do Terceiro Ciclo do Ensino Básico: o período revolucionário português de 1974-76. A temática escolhida exemplifica as especificidades relativas ao ensino da História, uma vez que é um acontecimento cujo estudo mobiliza diferentes conceitos históricos de segunda ordem, para além de ser um processo bastante complexo, que envolveu diferentes forças e intervenientes, cada um com a sua perspetiva, mostrando assim a complexidade associada ao processo de construção do conhecimento histórico. 


\title{
PA RTE I
}

\section{H ISTÓRIA，TECNOLOGIAS DIGITA IS E MOBILE LEARNING}

\begin{abstract}
A professora olhava para o entusiasmo com que os seus alunos ligavam os tablets e se posicionavam nos grupos para trabalharem nas tarefas que ela tinha pedido. Pensava ela consigo mesma a diferença que uma máquinas faziam... Como aqueles jovens de repente tinham começado a participar ativamente na aula, a querer fazer mais. Ainda bem que o Diretor a tinha convencido a abraçar aquele projeto. Aulas diferentes... Aulas com tecnologias... "Primeiro estranba-se, depois entranha-se", não é o que costumam dizer? Agora ela percebia que não precisava abandonar as suas metodologias. Tinha bastado acrescentar novas, diferentes, mas que ajudavam a desenvolver tantas outras competências nos seus estudantes. E tudo por causa de uma candidatura a um projeto europeu!
\end{abstract}


(Página deixada propositadamente em branco) 


\section{AS TECNOLOGIAS DIGITAIS NA EDUCAÇÃO}

No século XVII um grande estudioso da educação e das estratégias que deveriam ser desenvolvidas para uma correta e eficaz educação, Comenius, tornou-se no primeiro a incluir imagens nos livros, defendendo que a junção das duas coisas melhorava a capacidade de aprender. Hoje partilhamos também a opinião de Guay (2007) que refere que se este pedagogo vivesse no século XXI seria, de certeza, um adepto da utilização das TDIC no ensino. De facto, Comenius entendia que os alunos aprendiam melhor se pudessem ter imagens que os auxiliassem a melhor visualizar os conceitos que lhes estavam a ser ensinados.

Para além disso, se observarmos a lista dos princípios de Comenius para uma boa educação, sintetizada por Guay (2007), verificamos quão bem se podem adaptar esses mesmos princípios ao uso das TDIC no ensino:

Aprende-se a forjar enquanto se forja, assim como se aprende a escrever enquanto se escreve.

Aprende-se ao fazer.

Deve-se usar o conhecimento anterior antes de se iniciar novas aprendizagens. Aprende-se melhor quando se tenta encontrar as causas das suas dificuldades. Aprende-se quando as coisas a serem aprendidas são interessantes e parecem úteis. Encher o crânio é uma atividade fútil e estéril.

Aprendemos quando conseguimos estabelecer ligações entre o conhecimento.

Aprende-se melhor quando são usados objetos concretos de treino (ensinar as palavras com objetos, ilustrações).

É mais valioso quando mais de um sentido é utilizado. 
Aprendemos quando temos prazer em fazê-lo.

Para aprender, não se deve apenas ser um observador'6 (pp. 1-2).

É sobretudo desde os anos 90 que vem crescendo a importância atribuída à aplicação das TDIC no ensino, assinalando-se essa valorização no relatório Educação - um tesouro a descobrir, coordenado por Delors, em 1996, onde é referido que "bem utilizadas, as tecnologias da comunicação podem tornar mais eficaz a aprendizagem e oferecer ao aluno uma via aliciante de acesso a conhecimentos e competências, por vezes difíceis de encontrar no meio local" (p. 139).

A informática foi sendo cada vez mais considerada um auxiliar importantíssimo na educação, uma vez que através da sua utilização "vem preencher a impossibilidade que o cérebro humano tem não só de reter um elevado número de informações como a impossibilidade de as combinar" (Rodrigues, 1981: 7). Assume-se assim que, em qualquer disciplina as TDIC poderão ajudar a procurar a informação pretendida, relacionar dados, e ajudar os alunos a produzir o seu próprio conhecimento.

$\mathrm{Na}$ educação, a capacidade de aproveitar os recursos disponibilizados pela informática foi-se tornando cada vez mais importante, na medida em que se entende que vivemos numa era em que o acesso à informação se torna imprescindível para a construção do conhecimento e para evitar aquilo a que alguns autores apelidam de infoexcluídos.

Em relatórios como o da UNESCO, ou outros emitidos pela União Europeia, é indicado que as estruturas educativas deverão ser responsáveis por fornecer à sua comunidade os instrumentos necessários para a correta utilização das TDIC e para o seu máximo aproveitamento em benefício da educação de todos, relacionando-se isto com a democratização do ensino, de que já falámos, e também com a heterogeneidade que cada vez mais se vai encon-

6 Tradução nossa. No original: One learns how to forge while forging just as one learns how to write while writing. One learns while doing. One should use his former knowledge before launching out in new apprenticeships. One learns better when trying to find the causes of his difficulties. One learns when the things to be learned are interesting and seem useful. Cranium stuffing is a futile and sterile activity. We learn when we succeed in establishing links between knowledge. One learns better when concrete objects of training are used (to teach the words with objects, illustrations). It is more valuable when more than one sense is utilised. We learn when one has pleasure in doing so. To learn, one should not only be an observer. 
trando entre discentes, uma vez que "o recurso ao computador e aos sistemas multimédia permite traçar percursos individualizados em que cada aluno pode progredir de acordo com o seu ritmo" (Delors, 1996: 164) e também aos docentes a organização de atividades diferentes, consoante as turmas que irão lecionar. Reforçando esta ideia, Mendelsohn (responsável pela unidade de TDIC, na Faculdade de Psicologia e Ciências da Educação da Universidade de Genebra), dizia que:

as crianças nascem envoltas numa cultura em que a informação está à distância de um click e os seus professores têm que inevitavelmente acompanhar essa evolução, porque se a escola não seguir esse rumo corre o risco de se desqualificar e ver instalar-se a desmotivação (apud Ribeiro-Geraldes \& Morais, 2007: 265)7.

A Sociedade do Conhecimento, cada vez mais, constrói-se a partir da escola e por isso esta tem de estar preparada para assumir essa função. Aliás, como cada vez mais se caminha para um mundo em que quem sabe usar eficazmente a informação a que pode aceder transformando-a em conhecimento tem maiores probabilidades de sucesso, a correta utilização das ferramentas digitais poder-se-á tornar, cada vez mais, num fator de diferenciação.

A utilidade de que as TDIC se revestem é imensa. Por exemplo, Bento Silva refere que se juntarmos o hipertexto com a Internet e o correio eletrónico desenvolvemos uma "comutação generalizada, constituindo uma rede universal de comunicação entre textos, autores e leitores" (Silva, 2001: 73). Silva acrescenta ainda que, em termos sociais, isto representa um sistema onde tudo se encontra ligado e onde o valor do conhecimento está na capacidade de estabelecer uma conexão. Para além disso, as TDIC permitem agora que se apresente a informação de uma forma mais dinâmica e, consequentemente, mais atrativa e, eventualmente, mais compreensível para o aluno. Nesse sentido refere Matta (2001) que

as novas tecnologias permitem que a imagem digitalizada seja decomposta, recomposta e indexada, trabalhada de várias formas e em alta velocidade, da mesma

\footnotetext{
7 Sem referência sobre a proveniência da declaração.
} 
forma o som, assim como a capacidade de ligar certos aspectos e conotações a outros blocos de informação. Estas possibilidades criaram uma nova escrita hipertextual que está mais próxima do espetáculo e dramatização de uma sociedade oral, que do texto escrito (p. 19).

Enciclopédias, jogos educativos, possibilidade de comunicar de forma síncrona e assíncrona, programas de treino, tudo isto e muito mais se pode utilizar através da tecnologia digital, possibilitando o acesso a redes complexas mundiais, coisa que há uns anos atrás nem se pensava ser possível mas que, para os jovens de hoje, é dado como natural. Estes abraçam imediatamente todas as novidades tecnológicas, facto relevante que pode, e deve, ser aproveitado até como fator motivador para o ensino.

Importantes neste contexto são também as palavras de Lencastre e Araújo (2007):

quem lida normalmente com jovens ou está atento aos seus interesses, sabe o quanto os telemóveis, computadores, $i P o d$, consolas, etc., são do seu agrado. A facilidade com que aderem e lidam com estes objectos é um campo de possibilidades tão rico e cheio de potencialidades para aprendizagens várias que é totalmente absurdo que a escola não o utilize para atingir os seus objectivos pedagógicos (p. 625).

Cabe à escola dotar os alunos de capacidades para utilizar todas essas ferramentas de forma correta por forma a transformar a informação em conhecimento.

Voltando atrás, e aos princípios educativos de Comenius, encontramos entre eles, como referimos, as ideias do construtivismo, que podem também ser devidamente colocadas em prática recorrendo às tecnologias digitais. De facto, "a informática e os jogos podem permitir ao estudante experimentar formas de aprender que se focam na imersão e na prática, suportadas por estruturas que levam à especialização, a competências profissionais e a um pensamento inovador"8 (Huizenga et al., 2007: 1). Não só a utilização do com-

8 Tradução nossa. No original: computer and games can let student experience ways of learning that stress immersion in a practice, supported by structures that lead to expertise, professional-like skills, and innovative thinking. 
putador nas aulas mas, sobretudo, a possibilidade de os alunos utilizarem a tecnologia digital para aprender gera, tendencialmente, mais motivação, como também leva a que a aprendizagem se centre muito mais no aluno e possibilite que seja este a construir os seus conhecimentos. Essa capacidade que têm as diferentes ferramentas tecnológicas de facilitar uma atitude construtivista face à educação e, sobretudo, desenvolver competências ao nível do pensamento crítico (Jonassen, 2000).

Desta forma,

o recurso à Internet e a sua integração nas práticas pedagógicas, permite desenvolver o espírito crítico, praticar o raciocínio, assimilar melhor o conhecimento levando a uma maior colaboração e interacção no processo de ensino-aprendizagem. Se a educação até aqui estava assente num paradigma de transmissão de saberes, hoje o paradigma emergente leva a que alunos e professores colaborem na construção do conhecimento (Santos, 2006: 35-36).

Contudo, um dos problemas em relação à utilização das TDIC em ambiente de ensino prende-se com a desconfiança que muitas vezes os professores apresentavam (e ainda hoje alguns apresentam) em relação a isso. Outro problema, que na verdade acaba por se relacionar ou mesmo depender do primeiro, é aquilo que diferentes autores apelidam de tecnofobia dos professores (Lencastre \& Araújo, 2007; Silva, 1999).

O que acontece é que as novidades tecnológicas são colocadas à disposição de alunos e professores ao mesmo tempo e normalmente as reações são diferentes: os primeiros aceitam naturalmente, os segundos receiam. Muitas vezes ainda se ouve nas salas de professores que as TDIC só servem para os alunos ouvirem música, verem filmes ou jogarem. Poucos também são aqueles que utilizam as TDIC nas suas aulas, sobretudo para mais do que utilizar um PowerPoint da mesma maneira que utilizariam um acetato. Um estudo de Paiva, realizado em 2003, indicava que apesar de $81 \%$ dos professores inquiridos dizer que utilizava o computador para a preparação de aulas, apenas 20\% destes o usavam para fazer apresentações. No mesmo inquérito apenas $26 \%$ dos docentes usavam o computador com os seus alunos no contexto da sua disciplina (Paiva, 2003: 9). 
Silva (2001) referia que os professores precisam compreender que a introdução das TDIC no ensino permite que se evolua do sistema de transmissão de saber simples

para um modelo cujo funcionamento se baseia na construção colaborativa de saberes, na abertura aos contextos sociais e culturais, à diversidade dos alunos, aos seus conhecimentos, experimentações, interesses (p. 81).

Acrescenta ainda este autor que a Sociedade da Informação valoriza o papel que o professor continua a ter como intermediário entre o conhecimento e os seus alunos mas, ao mesmo tempo, lança um enorme desafio ao tentar levá-lo a "mudar de paradigma pedagógico" (Silva, 2001: 83). Contudo, o corpo docente só muito recentemente começou a poder aceder a um muito mais diversificado número de ações de formação em TDIC mas ainda mantém alguma relutância sobre a capacidade de aprender a lidar corretamente com as TDIC. Novamente, nas palavras de Lencastre e Araújo (2007), "esta espécie de tecnofobia relativamente a uma área onde a sua identidade e autoridade é muitas vezes posta em causa, tem reduzido a possibilidade de se interessarem pelo uso da informática, e de se familiarizarem com as culturas juvenis" (p. 3).

No Livro Branco da Comissão Europeia, publicado em 1995, referia-se a necessidade de dar a hipótese aos professores de se adaptarem às TDIC, numa era em que os próprios materiais multimédia ainda não eram considerados de grande qualidade para além de que as infraestruturas escolares ainda não estavam preparadas para o uso desse mesmo material (1995a). Já mais recentemente a Comissão Europeia (2013) retoma a questão das TDIC no ensino, invocando que a sua utilização deve ter um efeito transformativo na forma de encarar o ensino e a aprendizagem.

Em Portugal, e apesar de nos anos 90 se terem desenvolvido alguns projetos no âmbito da formação contínua de professores, em 2006, a formação em TDIC não era considerada ainda uma prioridade na formação contínua dos docentes pois estes continuavam a não usar os conhecimentos e as competências já adquiridas para trabalhar na sala de aula (Lencastre \& Araújo, 2007). Os professores argumentavam, sobretudo, a necessidade de cumprimento do programa, os comportamentos dos alunos e as burocracias envolvidas com a 
utilização dos equipamentos, situação que apenas ficou ultrapassada, alguns anos mais tarde, quando o Ministério da Educação colocou em prática projetos de dotação de todas as salas de aulas com os equipamentos informáticos necessários. Já em 2009, e no seguimento da interação com as políticas europeias e do Plano Tecnológico da Educação, o Ministério da Educação estabeleceu um "plano de formação e de certificação de competências TIC para docentes" com o objetivo de reforçar as qualificações e valorizar as competências, "ultrapassando os principais factores inibidores da modernização tecnológica do sistema educativo, promovendo a integração das TIC nos processos de ensino e aprendizagem e na gestão escolar" (M. Educação, 2009: 4340). Desta forma, procurava-se dotar os docentes de maiores competências digitais, para que estes pudessem adotar práticas educativas mais inovadoras que, consequentemente, contribuíssem para a melhoria das aprendizagens, numa clara assunção de que o (correto) uso das tecnologias digitais muito pode beneficiar o ensino.

Portugal tem procurado acompanhar a caminhada europeia em direção a uma sociedade digital, incorporando as tecnologias digitais a vários níveis e não só na educação. Desta forma, são vários os projetos que os Governos portugueses vão definindo e colocando em prática para cumprir os objetivos definidos a nível internacional. Desde meados dos anos 80 multiplicaram-se as iniciativas de integração das TDIC no ensino de que falaremos em seguida, resultando na existência de um cada vez maior número de escolas "digitais", ou seja, cujas infraestruturas incluem equipamentos informáticos, acesso à Internet de banda larga e com disciplinas, no currículo, dedicadas ao ensino das TDIC, aos quais se acrescenta a melhoria das competências informáticas do corpo docente.

\subsection{Projetos portugueses e da União Europeia para integração das TDIC na Educação}

Em Portugal e na Europa podemos encontrar, a partir dos anos 90 do século $\mathrm{XX}$, inúmeras iniciativas de integração das TDIC no ensino e de preparação da população europeia para uma Era onde a literacia informática se 
veio a tornar fundamental, tendo por objetivo manter esta população competitiva nos mercados de trabalho mundiais. A consciência de que o acesso à informação digital se tornou um fator decisivo para o sucesso não só no trabalho como na vida em geral, despoletou toda uma série de documentos e projetos para tornar a Europa competitiva a nível global. Em Portugal, como país membro da União Europeia, havia, obviamente, a necessidade de colocar em prática esses projetos europeus mas, ao mesmo tempo, outras iniciativas foram sendo organizadas, para que o nosso país efetivamente acompanhasse a revolução tecnológica internacional.

Contudo, no âmbito deste trabalho, não nos interessa aqui expor todas essas iniciativas mas apenas elencar aquelas que, desenhadas quer na União Europeia (e com aplicação no nosso território) quer em Portugal, se adequam, de uma forma mais ou menos direta, a sua utilização no contexto do Secondary School System (em particular no que diz respeito ao ISCED ${ }^{9} 2$ ).

\subsubsection{Projetos da União Europeia}

Com a chegada dos anos 90, a Europa viu surgir também uma nova sociedade, cada vez mais tecnológica e onde o acesso à informação se tornava cada vez mais rápido e eficaz. Com esta nova era tornava-se fundamental dotar todos os países europeus (não só a nível estrutural como humano) dessas ferramentas, para que estes territórios se mantivessem competitivos no mercado mundial. Nesse sentido, defendem as instituições europeias que "para ser capaz de competir mundialmente, a indústria Europeia tem de explorar todas as possibilidades de melhorar a sua competitividade fazendo uso efetivo das TDIC"10 (Comissão Europeia, 1993: 93). Essas melhorias, para efetivamente terem resultados, precisam começar ao nível do próprio ensino, para que se possa diminuir o mais possível a "infoexclusão" de que falámos já.

\footnotetext{
9 International Standard Classification of Education.
}

10 Tradução nossa. No original: to be able to compete worldwide, European industry must exploit all possible ways of improving its competitiveness by making growing and effective use of ICTs. 
Na verdade, existiu desde cedo, ao nível das instituições governativas, uma certa preocupação com a integração das tecnologias digitais no ensino, conscientes de que isso iria propiciar uma revolução na relação entre o professor e o aluno. Contudo, crescia com isto a preocupação com a criação de software educativo adequado e que proporcionasse conteúdos educativos ricos, uma vez que de nada adiantaria modificar o processo educativo se os materiais não fossem adequados (Comissão Europeia, 1995a).

Acompanhando estas ideias, várias iniciativas foram sendo produzidas e taskforces organizadas, com vista a configurar e a promover a Sociedade da Informação na Europa. O objetivo principal dizia respeito, sobretudo, à criação de emprego e à promoção da competitividade das empresas europeias reconhecendo-se, contudo, com frequência a importância do ensino nesta equação. No Livro Verde Viver e trabalhar na sociedade da informação refere-se que

especial atenção deve ser dada a professores e formadores e assegurada a qualidade da sua formação inicial e do seu desenvolvimento profissional contínuo de modo a serem capazes de explorar as novas TIC. [...] Os Estados-membros, que têm uma responsabilidade inequívoca na organização e conteúdo do ensino escolar, devem continuar a conceber programas adequados orientados para a SI. [...] Além do mais, o Conselho Europeu de Florença solicitou à Comissão que elaborasse rapidamente um plano de acção subordinado ao tema "Aprender na Sociedade da Informação", que incluirá a interconexão de redes de escolas a nível europeu, a promoção de conteúdos curriculares multimédia e o estímulo à sensibilização e formação de professores e formadores para a utilização das novas ferramentas da Sociedade da Informação (Comissão Europeia, 1996a: 20).

A Comissão Europeia refere que existem grandes vantagens na utilização das TDIC no ensino, uma vez que estas "facilitam a aquisição de novos conhecimentos e suscitam o desenvolvimento de novos métodos de aprendizagem, flexíveis, personalizados e interactivos" (Comissão Europeia, 1996b: 6). Esta ideia é reforçada ainda pelo interesse em que todos os jovens tenham igual acesso à sociedade da informação, para que não sejam apenas as classes mais elevadas a beneficiar dos contributos dos conteúdos multimédia existentes 
no mercado. Assim, foi delineado pela Comissão Europeia um plano de ação concreto para uma iniciativa europeia cujos objetivos gerais eram

acelerar a entrada das escolas na sociedade da informação, dando-lhes novas possibilidades de abertura para o mundo; favorecer a generalização das práticas pedagógicas multimédia e a criação de uma massa crítica de utilizadores, de produtos e de serviços multimédia educativos (Comissão Europeia, 1996b: 7).

Para que estes objetivos fossem cumpridos, a Comissão determinou o desenvolvimento de algumas linhas de ação complementares, relacionadas com o aumento dos conteúdos multimédia produzidos e de formação de professores, fazendo crescer ambientes pedagógicos experimentais, grupos de trabalho e plataformas de interação comunitária onde "boas práticas pedagógicas multimédia" fossem difundidas e contribuíssem para criar uma rede comunitária e que, no início do ano 2000, "todas as escolas, universidades e bibliotecas estejam ligadas às redes do saber [...] a fim de que o conjunto dos jovens Europeus possa tirar o melhor partido da revolução multimédia” (Comissão Europeia, 1996b: 18). Para que isto se pudesse concretizar, convidou os Estados-membros a colaborarem nesta iniciativa, colocando em prática as ações atrás mencionadas (JO C195/8 de 6/7/1996 e C303/7 de 4/10/1997), mostrando assim que o impacto das TDIC se fazia sentir de forma crescente na sociedade europeia.

À porta do novo milénio, e antecedendo o primeiro grande projeto de integração das TDIC na educação europeia de que em seguida falaremos, foi produzido mais um relatório (por parte da Comissão Europeia e para o Conselho e Parlamento Europeus) que procurava fazer um balanço dos progressos realizados entre 1996 e 1999 ao nível da introdução das TDIC na educação europeia, para além de procurar identificar os principais desafios para os anos seguintes e as ações que deveriam ser realizadas com maior brevidade pois,

sem constituir uma panaceia, as TIC podem favorecer a aplicação de pedagogias ativas, contribuir para um ensino de melhor qualidade e desempenhar um papel de catalisador da mudança. No entanto, a realidade dos usos continua a não ser conforme às oportunidades oferecidas. Tal como foi salientado por um estudo rea- 
lizado no terreno, os usos multimédia educativos continuam a basear-se essencialmente no vídeo, nos programas televisivos e no software. A utilização da Internet, do correio electrónico e da videoconferência está ainda muito distante (Comissão Europeia, 2000a: 7).

A utilização das TDIC é valorizada no ensino por se entender que pode contribuir para o melhorar pois modifica o papel do aluno aumentando a sua curiosidade e a aprendizagem pela descoberta e experimentação, reconhecendo-se que altera também o papel do professor que terá de se manter atualizado não só na sua disciplina mas também numa área que, à partida, pode considerar que não é a sua.

Passemos então a descrever os objetivos e principais ações desenvolvidas ao nível comunitário para o novo milénio.

\subsubsection{A iniciativa eEurope2002}

Em dezembro de 1999, a União Europeia lançou a iniciativa eEurope - an information society for all, aprovada durante o Conselho Europeu em Lisboa, em março de 2000, com o desejo de que, em 2010, as tecnologias digitais estivessem em toda a Europa e que todos os cidadãos europeus tivessem competências para as usar. Os principais objetivos desta iniciativa eram:

- Colocar todos os cidadãos, todas as famílias e escolas, todas as empresas e todos os órgãos da administração pública na era digital e em linha.

- Criar uma Europa digitalmente instruída, apoiada por uma cultura empresarial pronta a financiar e a desenvolver novas ideias (Comissão Europeia, 1999: 2).

Entre as várias ações a desenvolver, constava a "entrada da juventude europeia na era digital”, em linha com as ideias desenvolvidas nos documentos anteriores, desejando que todos os jovens pudessem ter o mesmo acesso à tecnologia digital, fator crucial para o desenvolvimento individual, nacional e comunitário. 
Sendo necessário que a adaptação dos jovens à Era Digital fosse feita nas escolas, uma das metas que havia sido estabelecida anteriormente era que a rede escolar europeia se encontrasse totalmente ligada à Internet até 2002. Com a iniciativa eEurope pretendia-se então que todos os jovens europeus fossem proficientes na cultura digital: dominassem a Internet e os recursos multimédia, utilizassem esses mesmos recursos para aumentar os seus conhecimentos e adquirissem competências essenciais como a criatividade, o trabalho colaborativo ou a pluridisciplinaridade, entre outras (Comissão Europeia, 1999).

As ações a desenvolver no âmbito da cultura e educação deveriam assegurar que, até ao final de 2001, todas as escolas tivessem acesso à Internet e a recursos multimédia e que em locais públicos estes mesmos recursos estivessem também disponíveis para todos os jovens, para além de que deveria estar disponível para professores e alunos um conjunto de serviços de apoio. Até ao final de 2002 todos os professores deveriam possuir equipamento e competências para utilizar os recursos disponibilizados e todos os alunos deveriam ter acesso a recursos multimédia e Internet rápida em todas as salas de aula. Por último, até ao final de 2003 todos os jovens deveriam ter "cultura digital" aquando da sua saída do sistema de ensino (Comissão Europeia, 1999: 7).

Como parte da estratégia eEurope e para a ajudar a atingir os seus objetivos desenvolveu-se, em 2000, a iniciativa eLearning que se pretendia constituir como "um elemento importante na reflexão geral preconizada pelo Conselho no tocante à plena integração das novas tecnologias da informação nos domínios da educação e da formação (Comissão Europeia, 2000b: 4).

As ações promovidas pela iniciativa eLearning seriam ao nível concreto da educação e da formação, procurando integrar as decisões tomadas no Conselho Europeu de Lisboa, de março de 2000, com a política de emprego europeia, com todo o plano de ação da iniciativa eEurope e ainda com as resoluções tomadas, em 1996, no que toca ao desenvolvimento de software educativo e multimédia, explorando assim o que as TDIC tinham para oferecer ao setor educativo.

Em maio de 2000, foi elaborado e discutido pelos Estados-Membros um Plano de Ação para o projeto, que foi posteriormente aprovado no Conselho Europeu de Santa Maria da Feira que decorreu entre 19 e 20 de junho do mesmo ano. Esse plano tinha por principal objetivo garantir as metas fixa- 
das no texto que atrás referimos, definindo as medidas a adotar para a sua concretização.

Para este efeito, foram discriminados três objetivos principais ("uma Internet barata e segura; investir nas pessoas e nas qualificações; estimular a utilização da Internet" [Conselho Europeu e Comissão Europeia, 2000: 1-2]), cada um deles com várias áreas de ação. Para além disso, foram também definidos os três principais mecanismos a adotar para que as metas fossem alcançadas: “acelerar a criação de um ambiente jurídico adequado [...]; apoiar as novas infra-estruturas e serviços por toda a Europa [...]; aplicar um método aberto de coordenação e avaliação do desempenho [...]" (Conselho Europeu e Comissão Europeia, 2000: 2).

Realizado o balanço, no início de 2003, verificou-se que não só no geral a iniciativa tinha sido um sucesso, como também no que dizia respeito ao sector da educação: 93\% das escolas passaram a estar ligadas à Internet, o número de alunos por computador baixou, aumentou o acesso por banda larga e mais de metade dos professores tiveram formação relativa ao uso de computadores e da Internet no ensino. Nesse momento, o passo seguinte estava em tornar mais eficaz o uso dos computadores. Refere o relatório final que

nas escolas, está a ser dada maior importância à qualidade dos produtos e serviços de ensino electrónico e ao contexto pedagógico da sua utilização. Está-se a passar das questões ligadas à conectividade e à infra-estrutura para as questões associadas aos conteúdos, formação dos professores e implicações organizativas, incluindo novas interacções sociais dentro e fora das escolas (Comissão Europeia 2003b: 13).

Contudo, percebendo que o uso efetivo das TDIC não avançara tão rápido quanto a conectividade, as atenções voltavam-se agora para um plano que contribuísse para um melhor e mais eficaz uso dessas mesmas tecnologias digitais.

\subsubsection{A iniciativa eEurope2005}

Continuando a linha de ação iniciada com a iniciativa eEurope2002, este novo projeto europeu, iniciado em 2002, vinha reforçar e $e$-inclusão de todos 
os cidadãos europeus, procurando, por um lado, "estimular serviços, aplicações e conteúdos, abrangendo serviços públicos em linha e negócios electrónicos; por outro, aborda[r] as questões subjacentes da infraestrutura de banda larga e da segurança” (Comissão Europeia, 2002: 3). Se com a estratégia eEurope2002 se tinha conseguido assegurar um franco crescimento da conectividade europeia, com a eEurope2005 esperava-se aumentar a produtividade e melhorar a qualidade e acessibilidade dos serviços, não descurando a necessidade de criar um sistema digital seguro e acessível ao maior número possível de cidadãos.

No campo da educação, o principal objetivo era o desenvolvimento de uma estrutura digital adequada, bem como de estratégias de aprendizagem eletrónicas. Mais concretamente, as ações a desenvolver visavam: o acesso de todas as escolas e universidades à Internet através de uma ligação de rede de banda larga; a criação de um programa específico de ensino em linha; campus virtuais para todos os estudantes de modo a elevar ao máximo a qualidade e a eficácia dos processos e das atividades de ensino; um sistema de cooperação universidades-investigação assistido por computador; requalificação dos adultos para a sociedade do conhecimento (Comissão Europeia, 2002).

Quando em 2004 a Comissão produziu um relatório intercalar, o plano de ação era avaliado de forma muito positiva, atribuindo-se-lhe a responsabilidade por ter estimulado muitos esforços nacionais e regionais (referia, por exemplo, que se verificava o constante crescimento do número de escolas em linha). Contudo,

o relatório também concluía que os esforços não tinham sido adequados às necessidades, concentrando-se em tecnologia, aplicações e iniciativas, ao passo que eram necessários mais esforços para compartilhar experiências e adequar os serviços às necessidades dos utilizadores ${ }^{11}$ (European Commission, 2007: 13).

Assim, o plano foi revisto e pequenas atualizações foram feitas. Quando chegou a hora de proceder à sua avaliação final, o relatório refere que o

11 Tradução nossa. No original: the review also concluded that efforts were not enough demand driven, concentrating on technology, applications and initiatives, whereas more effort was needed to share experience and to tailor services to user needs 
plano de ação eEurope2005 foi muito importante para que países com diferentes contextos institucionais e culturais, prioridades e agendas relativas à sociedade da informação dialogassem entre si e verificassem ser necessária a existência de um elemento unificador e coordenador nestas matérias. Para além disso, o plano foi também importante para manter as TDIC na agenda dos debates europeus.

\subsubsection{A iniciativa i2010}

A Comissão Europeia lançou, em junho de 2005, a i2010 - a European Information Society for 2010 que surge ainda na reta final do plano de ação eEurope2005 para aproveitar o momento político, onde o debate sobre as TDIC estava em pleno, mas também para ajudar ao crescimento económico e do emprego na sociedade da informação e nas indústrias a ela associadas. Assim, as prioridades para este novo programa eram:

- Completar o Espaço Único Europeu da Informação, que promove um mercado interno aberto e competitivo para a sociedade da informação e os meios de comunicação social;

- Fortalecer a inovação e o investimento em pesquisa em TIC para promover o crescimento e mais e melhores empregos;

- Conseguir uma sociedade da informação europeia inclusiva que promova o crescimento e o emprego de uma forma coerente com o desenvolvimento sustentável e que dê prioridade a melhores serviços públicos e qualidade de vida ${ }^{12}$ (European Commission, 2007: 16).

Esta nova iniciativa surgiu devido ao reconhecimento de que um quarto do crescimento do PIB da União Europeia e 40\% da produtividade se devem

12 Tradução nossa. No original: - To complete the Single European Information Space which promotes an open and competitive internal market for information society and media;

- To strengthen innovation and investment in ICT research to promote growth and more and better jobs;

- To achieve an inclusive European Information Society that promotes growth and jobs in a manner that is consistent with sustainable development and that prioritizes better public services and quality of life 
às TDIC e que quanto mais investimento nesse sector faz um país, maior o seu nível de competitividade, promovendo "uma economia digital aberta e concorrencial e coloca[ndo] a tónica nas TIC enquanto factor de inclusão e de qualidade de vida" (Comissão Europeia, 2005a: 3). Contudo, este projeto já não refere, especificamente, qualquer ação relativa às TDIC na educação. Se nos anteriores planos de ação se pretendia dotar as escolas de equipamentos informáticos para que todos os jovens aprendessem a trabalhar com eles e beneficiassem com essa aprendizagem, nesta iniciativa a tónica da eInclusão é colocada nos mais velhos, que estão já fora da escola e que, por isso, necessitam de outro tipo de mecanismo para se integrarem na Sociedade da Informação.

Vale também a pena destacar que foi a partir da iniciativa $i 2010$ que se deu início à famosa base Europeana (simultaneamente um museu, uma biblioteca e um arquivo multimédia europeus em linha).

Considerada a $i 2010$ um sucesso e também responsável pelo lançamento dos "alicerces de uma sociedade moderna assente nas TIC" (Comissão Europeia, 2009a: 13), entende a Comissão Europeia que não se pode ficar por aqui, pelo que uma nova agenda política para o digital deveria começar a ser preparada com o contributo de todos os Estados Membros.

Nesse sentido, a Comissão lançou, em março de 2010, a estratégia Europa 2020 , ainda em curso, criada dentro do contexto da crise económica que a Europa vive e preparando-a para novos desafios. Essa estratégia é composta por 7 iniciativas, sendo uma delas a Agenda Digital para a Europa, que "visa definir o importante papel que a utilização das tecnologias da informação e das comunicações (TIC) terá de desempenhar se a Europa quiser ver as suas ambições para 2020 coroadas de sucesso" (Comissão Europeia, 2010c: 54).

\subsubsection{Agenda Digital Europeia}

A Agenda Digital Europeia é uma das sete iniciativas constantes da estratégia Europa $2020^{13}$, e tem por objetivo

13 Veja-se a esse respeito a Comunicação da Comissão Europeia Europa 2020 in http:// eur-lex.europa.eu/LexUriServ/LexUriServ.do?uri=COM:2010:2020:FIN:PT:PDF (acessível em 15/04/2014). 
definir o importante papel que a utilização das tecnologias da informação e das comunicações (TIC) terá de desempenhar se a Europa quiser ver as suas ambições para 2020 coroadas de sucesso (Comissão Europeia, 2012a: 3).

Esta Agenda procura, uma vez mais, rentabilizar o potencial dos recursos digitais ao serviço da economia e da sociedade europeias, desenvolvendo ações em torno de sete domínios que considera problemáticos e que incluem a falta de literacia e de qualificações em matéria digital.

Neste campo, prevê que todos os cidadãos europeus saibam utilizar tecnologias digitais e meios de comunicação digitais, prevendo por isso duas ações-chave:

Acção-chave 10: Propor a literacia e as competências em matéria digital como prioridade para o regulamento relativo ao Fundo Social Europeu (2014-2020);

Acção-chave 11: Até 2012, desenvolver ferramentas que permitam identificar e reconhecer as competências dos profissionais e dos utilizadores das TIC, em articulação com o Quadro Europeu das Qualificações e o EUROPASS, e desenvolver um quadro europeu do profissionalismo no domínio das TIC tendo em vista melhorar as competências e aumentar a mobilidade destes profissionais em toda a Europa (Comissão Europeia, 2012a: 30).

É no campo da educação que a Comissão Europeia vê a concretização destas ações, formando os jovens europeus e dando as ferramentas necessárias também aos educadores para que todos possam tirar o máximo proveito daquilo que as tecnologias digitais podem oferecer (Comissão Europeia, 2012b).

Contudo, para se conseguir perceber em que ponto se encontra cada país, a Comissão decidiu organizar o Survey of Schools: ICT in Education, para se perceber também os progressos realizados em cada território no que diz respeito à acessibilidade e ao uso das TDIC, incluindo competências em e atitudes para com as TDIC. Os resultados gerais indicam que

quanto mais velhos forem os alunos, mais confiantes estarão no uso das TIC. Isso aplica-se a uma variedade de habilidades, incluindo Web 2.0 e competências tec- 
nológicas. Enquanto isso, apenas um em cada três alunos de todos os níveis é ensinado por professores para os quais a participação em formação em TIC é obrigatória. No entanto, é encorajador que $70 \%$ dos alunos de todos os níveis sejam ensinados por professores que se envolveram em aprendizagens pessoais sobre TIC no seu próprio tempo ${ }^{14}$ (Comissão Europeia, 2012b: 40).

Os resultados do estudo para o caso português, apesar de nos parecerem um pouco elevados, revelam que:

os estudantes das escolas portuguesas desfrutam de níveis de equipamento relativamente elevados, com velocidades de banda larga rápidas, acima da média da UE, de computadores desktop ligados à Internet e "conectividade" quase universal. Os níveis de confiança de uso e de TIC em todos os níveis são consistentemente altos, tanto para professores quanto para alunos. Os professores tiveram níveis relativamente altos de formação em TIC e tendem a frequentar escolas com coordenadores de TIC, mas a sua participação em medidas inovadoras de formação e apoio, como as comunidades online, é inferior à média da UE15 (Comissão Europeia, 2012a: 28).

\subsubsection{Iniciativa Abrir a Educação (2013)}

Em setembro de 2013 a Comissão Europeia apresentou uma comunicação intitulada Abrir a Educação: Ensino e aprendizagem para todos de maneira inovadora graças às TIC e aos Recursos Educativos Abertos, com o objetivo

14 Tradução nossa. No original: the older the students are, the more confident they are in their use of ICT. This applies to a variety of skills including web 2.0 and technological skills. Meanwhile, only one in three students at all grades are taught by teachers for whom participation in ICT training is compulsory. However, it is encouraging that $70 \%$ of students at all grades are taught by teachers who have engaged in personal learning about ICT in their own time.

15 Tradução nossa. No original: students in Portuguese schools enjoy relatively high equipment levels, with fast broadband speeds, above EU average provision of desktop computers connected to the Internet, and almost universal 'connectedness'. Use and ICT confidence levels at all grades are consistently high, both for teachers and students. Teachers have had relatively high levels of ICT training and tend to be in schools with ICT coordinators, but their participation in innovative training and support measures such as online communities is lower than the EU mean. 
de "fomentar formas inovadoras de aprendizagem e ensino, de elevada qualidade, através do recurso às novas tecnologias e aos novos conteúdos digitais" (Comissão Europeia, 2013: 2).

Esta iniciativa visa a promoção de ações nacionais e internacionais para:

- Ajudar os estabelecimentos de ensino, professores e alunos a adquirir competências informáticas e métodos de aprendizagem;

- Apoiar o desenvolvimento e a disponibilidade de recursos educativos abertos;

- Interligar as salas de aula e instalar equipamento e conteúdos informáticos;

- Mobilizar todas as partes interessadas (professores, estudantes, famílias, parceiros económicos e sociais) para alterar o papel das tecnologias informáticas nos estabelecimentos de ensino (Comissão Europeia, 2013: 2).

Destaca a Comissão Europeia que os alunos de hoje esperam que haja uma maior personalização, colaboração e ligação entre mecanismos de aprendizagem formais e informais, assentes sobretudo na utilização de mecanismos digitais.

Nesse sentido, reconhecem como fundamental a exploração das potencialidades do uso da informática, através dos conteúdos abertos, da partilha de informações, do acesso a novas fontes de informação e a um vasto leque de recursos educativos, para além das vantagens de um acesso à educação que não fica confinado ao espaço de uma sala de aula.

Para colocar em prática os objetivos desta iniciativa, a Comissão Europeia pretende promover:

- o desenvolvimento de enquadramentos e normas abertos para a interoperabilidade e a mobilidade dos conteúdos, das aplicações e dos serviços educativos digitais, incluindo os REA, em cooperação com as organizações e os programas europeus de normalização, e desenvolverá componentes para um mercado eficiente das tecnologias educativas, incluindo a coordenação de cadernos de encargos conjuntos para concursos públicos no domínio das soluções inovadoras, de modo a ajudar a multiplicação de equipamento, software e conteúdos económicos; 
- a investigação e a inovação de tecnologias, análise pedagógica e jogos digitais para a aprendizagem adaptativa, em ligação com os industriais inovadores (Comissão Europeia, 2013: 13).

Em dezembro de 2013, a Comissão da Cultura e da Comunicação do Parlamento Europeu emitiu um projeto de relatório sobre esta iniciativa, no qual considera que deve a União Europeia ajudar os docentes a integrar as tecnologias digitais nas suas práticas pedagógicas e também a promover a utilização de Recursos Educativos Abertos (Comissão da Cultura e da Educação, 2013), relatório esse que foi aprovado em março de 2014. Desde então, este projeto já deu origem a um site de recursos digitais abertos, o portal OpenEducationEuropa, cujo objetivo é reunir ideias inovadoras e que partem do potencial das tecnologias digitais, para que possam ser usadas, discutidas e disseminadas de forma a desenvolver práticas educativas cada vez melhores ${ }^{16}$.

Concluindo, na União Europeia, desde os anos 90 do século passado, tiveram lugar várias ações com vista a uma utilização alargada das TDIC, nas quais foi sendo integrada a necessidade de que também os jovens aprendessem a utilizá-las, ainda enquanto estudantes, para que no futuro pudessem usufruir em pleno dos seus benefícios. Foi, sobretudo, com a primeira iniciativa, eEurope2002, e mais concretamente com a ação eLearning, que se verificou um empenho na criação de situações de aprendizagem digitais, recorrendo à criação de software adequado e formação do pessoal docente, para além das ações focadas na integração dos alunos e das escolas na Sociedade da Informação. Estas ações provocaram dinâmicas de modernização tecnológica nos países membros, como é o caso de Portugal onde, também desde o final do século passado se começou a apostar na integração das TDIC na sociedade em geral e no ensino em particular.

$16 \mathrm{O}$ projeto encontra-se em https://www.openeducationeuropa.eu/en 


\subsubsection{Projetos em Portugal}

Em consonância com discursos internacionais, também em Portugal, desde meados dos anos 80, se foi tentando adequar o nosso sistema de ensino às mudanças culturais e tecnológicas da Sociedade da Informação, surgindo nessa década os primeiros projetos com vista ao alargamento das TDIC a todas as escolas. A nível governamental foi em 1995, com o programa do XIII. ${ }^{\circ}$ Governo Constitucional, encabeçado por António Guterres, que foi criada a Sociedade da Informação, na senda das iniciativas que se desenvolviam a nível europeu, e para acompanhar a revolução que se dava na sociedade com o desenvolvimento das TDIC. Neste programa ficava definido, para o campo da educação, que

em articulação com as alterações curriculares do sistema educativo e com a política de difusão do conhecimento científico e tecnológico será generalizada a formação na utilização das tecnologias de informação, facultando progressivamente os meios tecnológicos e pedagógicos adequados (Assembleia da República, 1996: 126).

A partir daqui os programas dos nossos representantes governativos incluem projetos variados que interligam as tecnologias digitais com diferentes vertentes da nossa sociedade, com exceção para o projeto apresentado pelo XIX. ${ }^{\circ}$ Governo, em 2011, que não faz referência à Sociedade da Informação nem a qualquer medida tecnológica no campo educativo.

Não nos interessa alongar muito este tema pois vários outros trabalhos já tiveram oportunidade de o fazer mas deixaremos aqui uma breve síntese dos mais relevantes, desenvolvidos no âmbito do ensino e com relevância sobretudo, e como referimos atrás, para o equivalente ao Secondary School System. Assim, da lista que em seguida apresentamos (Tabela 1.1), apenas daremos explicações um pouco mais pormenorizadas dos projetos/iniciativas que se encontram assinalados em negrito, os quais consideramos marcantes no que diz respeito à integração das tecnologias digitais nesse nível de ensino em Portugal: 
Tabela 1.1 - Principais projetos de introdução das tecnologias digitais no ensino na União Europeia e em Portugal

\begin{tabular}{|c|c|c|}
\hline & 1985 a 1994 & $\begin{array}{l}\text { Projeto Minerva (Meios Informáticos no Ensino: } \\
\text { racionalização/ valorização/ actualização) }\end{array}$ \\
\hline & 1989 a 1992 & Projeto IVA (Informática para a Vida Activa) ${ }^{17}$ \\
\hline & 1992 & $\begin{array}{l}\text { Projeto FOCO (inserido no PRODEP } 1990-94 \text { - medida } \\
1.3)^{18}\end{array}$ \\
\hline & 1993 & $\begin{array}{l}\text { Projeto FORJA (Fornecimento de Equipamentos, } \\
\text { suportes logísticos e acções de formação de } \\
\text { professores) } \\
\text { pr }^{19}\end{array}$ \\
\hline & 1995 & $\begin{array}{l}\text { EDUTIC (Educação para as Tecnologias da Informação e } \\
\text { Comunicação) }\end{array}$ \\
\hline \multirow[b]{2}{*}{$\begin{array}{l}1999 \text { a } 2002: \\
\text { eEurope } 2002\end{array}$} & 1996 & $\begin{array}{l}\text { Publicação do Livro Verde para a Sociedade da } \\
\text { Informação }\end{array}$ \\
\hline & 1996 a 2004 & $\begin{array}{l}\text { Programa NóNIO-Século XXI (deriva do projeto } \\
\text { EDUTIC) }\end{array}$ \\
\hline \multirow{3}{*}{$\begin{array}{l}2002 \text { a } 2005: \\
\text { eEurope } 2005\end{array}$} & 2005 & $\begin{array}{l}\text { Iniciativa Ligar Portugal (que interliga com o programa } \\
\text { i2010) }\end{array}$ \\
\hline & 2005 & Criação da Equipa Missão CRIE 21 \\
\hline & 2005 & eduTIC $^{22}$ \\
\hline \multirow{2}{*}{$\begin{array}{l}2005 \text { a } 2010: \\
\text { iniciativa } i 2010\end{array}$} & 2006 & Programa Educação e Formação 2010 \\
\hline & & \\
\hline $\begin{array}{l}\text { Agenda Digital } \\
\text { Europeia }\end{array}$ & 2007 a 2013 & $\begin{array}{l}\text { Plano Tecnológico da Educação (que substitui a } \\
\text { equipa CRIE pela ERTE) }\end{array}$ \\
\hline
\end{tabular}

17 Objetivos: "Proporcionar aos alunos do $12 .^{\circ}$ ano um laboratório de informática; formar professores na área das TIC na Educação, com base em utilitários MS.DOS e UNIX; desenvolver actividades com alunos do $12 .^{\circ}$ ano; promover a cooperação entre escolas e as autarquias para desenvolvimento de projectos de trabalho com computadores" (M. Educação, 1994: 25).

18 Objetivos: "apoio à formação contínua de professores, por forma a facilitar o acesso e a utilização das tecnologias de informação e a desenvolver as competências pedagógicas e culturais para um nível óptimo de desempenho do processo de ensino-aprendizagem" (M. Educação, 1992: 10630).

19 Surge no quadro do projeto FOCO e como uma melhoria ao projeto IVA mas acabou por ter uma ação muito limitada. Objetivos: "equipar as escolas com equipamentos homogéneos e de maior qualidade e garante uma formação de base mais completa aos professores que nele participam - privilegiando os aspectos acentuadamente técnicos" (Ponte, 1994: 15).

20 Não chegou a ser alvo de Despacho e foi transferido para o programa Nónio.

21 Objetivos: "destinada à coordenação, articulação, concepção, realização e avaliação das iniciativas relativas ao uso de computadores, redes e Internet nas escolas, equipa que 


\subsubsection{O Projecto MINERVA (1985)}

Com o crescimento da valorização da ação das TDIC no ensino foi publicado o Despacho n. ${ }^{\circ}$ 68/SEAM/84, em 19 de outubro de 1984, onde é nomeado um grupo de estudo que deveria preparar um conjunto de medidas para aproximar as tecnologias digitais do sistema educativo, uma vez que

a importância da tecnologia de informação criou exigências que se estendem às instituições escolares, apontando para modificações profundas nos sistemas educativos, como, aliás, vem acontecendo em vário países (GSEAME, 1984: 9547).

O trabalho deste grupo deu origem ao que ficou conhecido como Relatório Carmona, publicado em 1985, que acabou por preceder a introdução dos computadores nas escolas e o primeiro grande projeto tecnológico na educação. Nesse relatório reconhece-se a importância de uma reformulação do ensino para a introdução das TDIC, uma vez que

os sistemas educativos são actualmente objecto de pressão externa, consubstanciada pelos diversos fenómenos portadores de mudança, o êxito da ciência e da técnica, a institucionalização da investigação e do espírito inovador, a capitalização do saber, o rápido intervalo entre a descoberta científica e a sua aplicação, e ainda a necessidade de adaptação a novos quadros de vida com expressões de instabilidade individual e comunitária bem como as incidências da evolução dos sistemas sócio-económicos e políticos. [...] E a reforma actualmente mais propalada é a da

funcionará no âmbito do Ministério da Educação" (M. Educação, 2005a: 11099-11100). Promoveu, entre outras a iniciativa "Escolas, Professores e Computadores Portáteis".

22 Objetivos: "a) Coordenar a rede de centros de competência existente e promover o seu alargamento para apoio e cobertura nacional dos agrupamentos de escolas, com vista a uma efectiva integração das TIC nas práticas pedagógicas;

b) Dinamizar a rede de escolas ENIS (European Network of Innovative Schools) [...];

c) Promover a elaboração de estudos sobre as TIC na educação;

d) Promover a utilização de ambientes virtuais de aprendizagem nas escolas e a criação de conteúdos educacionais multimédia;

e) Desenvolver e implementar um portal de educação nacional, [...];

f) Participar nas estruturas de decisão da European Schoolnet, [...];

g) Promover o intercâmbio europeu e internacional no âmbito das TIC na educação [...]" (GIASE, 2005: 5463). 
via tecnológica, a segunda de maior impacto da Educação depois da imprensa, nos tempos modernos (Carmona et al., 1985: 10-11).

Foi neste contexto que surgiu o primeiro projeto tecnológico no campo da educação, cujo acrónimo remete para a deusa romana das artes e da sabedoria, intitulado Meios Informáticos No Ensino: Racionalização, Valorização, Actualização, e oficializado pelo Despacho n. ${ }^{\circ}$ 206/ME/85, de 31 de outubro. O programa funcionou entre 1985 e 1994 e teve como principais objetivos

- a inclusão do ensino das tecnologias de informação nos planos curriculares;

- o uso das tecnologias de informação como meios auxiliares do ensino das outras disciplinas escolares;

- a formação de orientadores, formadores e professores (Ponte, 1994: 11).

O projeto, dedicado a todos os ciclos de estudos não superiores, decorreu em três fases diferentes, uma primeira entre 1985 e 1988 (circunscrita a um reduzido número de escolas e designada de "fase-piloto"), a segunda até 1992 (caracterizada por um franco alargamento do número de escolas envolvidas) e a última fase, de encerramento, teve lugar entre esse ano e 1994.

Os programas FORJA e FOCO (que identificámos na Tabela 1.1) surgem com alguma interligação ao MINERVA, sendo os "recursos humanos garantidos em grande escala por professores que tinham feito a sua formação em tecnologias da informação nas equipas do Projecto MINERVA" (Ponte, 1994: 15).

No final do projeto, feito o balanço, identificou-se um alargamento na área de ação inicialmente prevista, uma vez que

o Projecto MINERVA proporcionou a afirmação de conceitos educativos importantes como a noção de utilização crítica da informação, o trabalho de projecto, a colaboração interdisciplinar, a integração das tecnologias de informação nas disciplinas existentes e o papel dos centros de recursos nas organizações escolares. Estes conceitos solidificaram-se através das abordagens gerais, concepções, vivências, práticas e soluções concretas vividas pelos diversos pólos (Ponte, 1994: 60). 


\subsubsection{Livro Verde para a Sociedade da Informação (1996)}

Como já referimos, foi no Programa do XIII. ${ }^{\circ}$ Governo Constitucional, chefiado por António Guterres e com Marçal Grilo à frente da pasta da Educação, que surgiu, pela primeira vez, uma referência à importância que têm, cada vez mais, as TDIC, uma vez que "transformam hoje em dia, consideravelmente, muitos aspectos da vida económica e social, tais como [...] a importância da educação e da formação e, ainda, a forma como as pessoas comunicam entre si" (Governo Português, 1995: 126).

Nesse sentido, ficou estabelecido, no mesmo documento, a criação da Sociedade da Informação:

d) Formação para a Sociedade de Informação: Em articulação com as alterações curriculares do sistema educativo e com a política de difusão do conhecimento científico e tecnológico será generalizada a formação na utilização das tecnologias de informação, facultando progressivamente os meios tecnológicos e pedagógicos adequados.

Serão lançados programas específicos de valorização e de reconversão profissionais, tendo em conta as novas exigências funcionais da era da informação (Governo Português, 1995: 126).

Resultado das preocupações relacionadas com a introdução das TDIC na sociedade portuguesa surgiu o Livro Verde para a Sociedade da Informação em Portugal, publicado após aprovação no Conselho de Ministros de 17 de abril de 1997. Este documento é da responsabilidade da Missão para a Sociedade da Informação, que entende que ainda havia muito a fazer no âmbito da integração das TDIC na sociedade, em particular, que "urge agora concretizar mais. Acelerar [...] a disponibilização de meios de base e de recursos às escolas" (MSI, 1997: 5).

Neste documento reconhece-se a importância dos meios tecnológicos, da Internet e do multimédia bem como a sua "omnipresença" na vida de todos. Baseado no Livro Branco Crescimento, competitividade, emprego - os desafios e as pistas para entrar no século XXI, publicado pela Comissão Europeia, no final de 1993 (durante a presidência de Jacques Delors), no qual se declarava 
que "a competitividade da economia Europeia vai depender em grande parte tanto nas condições de utilização como no desenvolvimento e na aplicação destas tecnologia"23 (Comissão Europeia, 1993: 92), reconhecia-se que se tornava incontornável o desenvolvimento de estruturas, em diferentes campos da nossa sociedade, que acompanhassem a revolução tecnológica e mantivessem todos os portugueses a par dos benefícios que esta podia trazer.

Para cumprir estes votos de que todos os cidadãos portugueses tenham igual acesso à Sociedade da Informação a escola teria um papel fundamental:

As escolas do ensino básico e secundário terão de desempenhar um papel fundamental na eliminação de assimetrias com origem em diferentes condições de acesso no lar, que são uma função do estrato económico da família. Se os alunos nesses graus de ensino estiverem excluídos do acesso aos meios de interacção com a sociedade da informação no interior dos seus estabelecimentos escolares, resultará irremediavelmente uma estratificação entre aqueles que têm acesso no lar e os que não têm esse benefício (MSI, 1997: 16).

Assim, no campo da educação, e de maneira a equipar as escolas e as salas de aula, ajudar na formação de professores e contribuir para o desenvolvimento de jovens informados e perfeitamente integrados numa sociedade tecnológica, este Livro Verde estabelecia as seguintes medidas:

MEDIDA 4.1 - Instalar em todas as Bibliotecas Escolares do $5 .^{\circ}$ ao $12 .^{\circ}$ anos um Computador Multimédia Ligado à Internet.

MEDIDA 4.2 - Criar Conteúdos e Serviços de Informação na Rede para Suporte à População Escolar

MEDIDA 4.3 - Desenvolver Projectos Escolares em Telemática Educativa MEDIDA 4.4 - Promover a Formação de Professores para a Sociedade da Informação MEDIDA 4.5 - Promover a Revisão dos Programas Escolares para Contemplar a Sociedade da Informação

23 Tradução nossa. No original: the competitiveness of the European economy will to a great extend depend both on the conditions of utilization and on the development and application of these technologies. 
MEDIDA 4.6 - Avaliar o Impacto dos Programas em Tecnologias da Informação [...] (MSI, 1997: 49-50).

Estas medidas, em conjunto com outras presentes neste Livro Verde, procuraram dar o impulso para aproximar Portugal dos níveis europeus, e estão na base de projetos que daí em diante foram organizados no nosso país.

Um desses projetos foi o Programa Internet na Escola, implementado em 1997, que visava a instalação nas escolas de um computador ligado à Internet. Desenvolvido pela Unidade de Apoio à Rede Telemática Educativa (UARTE), em colaboração com a Fundação para a Computação Científica Nacional (FCCN) e articulado com entidades regionais, começou pelas escolas entre o 2. ${ }^{\circ}$ Ciclo e o Secundário e, em 1999, alargou o seu âmbito às escolas do 1. ${ }^{\circ}$ Ciclo. Ao longo do programa alunos e professores foram sensibilizados para a utilidade que a Internet pode ter no ensino, como motor de busca e recolha de informação (Ministério da Ciência e da Tecnologia, 1999).

Outro projeto foi a iniciativa computador para todos, a qual, para incentivar o uso generalizado de computadores, permitiu a dedução à coleta de $20 \%$ dos valores gastos com a aquisição de computadores, modems, placas RDIS, aparelhos de terminal e ainda programas de computador (Ministério da Ciência e da Tecnologia, 2000).

\subsubsection{Programa NÓNIO-Século XXI (1996)}

Entre 1994 e 1996 realizaram-se outros projetos de aposta na introdução das TDIC no ensino mas foi o Programa NÓNIO-Século XXI (Programa de Tecnologias de Informação e Comunicação na Educação), lançado em outubro de 1996 pelo Ministério da Educação, que deu continuidade aos trabalhos desenvolvidos pelo MINERVA, agora focado nas novas exigências da Sociedade da Informação ao nível das infraestruturas, dos conhecimentos e das práticas:

tendo presente a importância dos mais recentes desenvolvimentos tecnológicos, nomeadamente a emergência e importância da sociedade de informação e o poten- 
cial renovado de comunicação do equipamento e material multimédia, procura-se encontrar respostas diversificadas, adequadas à nova fase da evolução científica e técnica que atravessamos com vista à criação de uma "escola informada" e aberta ao mundo (M. Educação, 1996: 15011).

Nesse sentido, pretendia-se que o Programa NÓNIO-Século XXI, dedicando "especial incidência no domínio das tecnologias multimédia e das redes de comunicação" (Silva \& Silva, 2002: 8), atuasse ao nível da formação contínua de professores (não pretendendo, de forma alguma, sobrepor-se ao programa FOCO), contribuísse para a modernização e melhoria do processo de ensino-aprendizagem, incentivasse o efeito de rede e a cooperação internacional e ainda desenvolvesse a produção de software educativo. Ao longo do projeto foram constituídos 27 Centros de Competência para apoiar as escolas que o integrassem.

No final do projeto, inicialmente previsto para 2002 mas depois adiado para 2005 (quando foi substituído pelo projeto eduTIC), cada escola participante fez a sua própria avaliação, com base na resposta a um questionário enviado pelo Ministério da Educação, demonstrando em geral as vantagens que o projeto tinha, mas reconhecendo que ainda alguns acertos precisavam ser feitos ${ }^{24}$.

${ }^{24}$ Bento Silva e Ana Silva, num relatório de avaliação do projeto (1999: 572) referem as seguintes conclusões: Em síntese, os resultados apontam para algumas decisões possíveis a considerar a nível micro (escola), meso (Centro de Competência) e macro (Ministério da Educação).

A nível micro, importa que os órgãos de gestão das Escolas considerem o enquadramento jurídico do novo modelo de gestão (Dec.-lei . $^{\circ} 115 \mathrm{~A}$, de 4 de maio de 1998 ) no sentido de assumirem um maior protagonismo na organização dos tempos escolares, assegurando maior disponibilidade no horário dos responsáveis e dinamizadores dos Projectos. Importa ainda que os orgãos de gestão e os responsáveis dos Projectos problematizem a melhor forma de acesso, actualização e manutenção dos equipamentos. [...]

A nível macro, importa que o Ministério da Educação, na qualidade de principal fonte financiadora dos Projectos, atente na celeridade da atribuição das verbas, se possível atribuídas numa única tranche anual. Considera-se ainda a pertinência em ser ponderado o reforço nos equipamentos, bem como o favorecimento de condições para a criação de sistemas eficientes de actualização e manutenção dos mesmos, prevendo já as situações problemáticas que possam surgir neste domínio após o término formal do Projecto, garantindo deste modo a continuidade dos seus efeitos. 


\subsubsection{Iniciativa Ligar Portugal (2005)}

Entre 1999 e 2005 os vários Governos portugueses foram dando destaque à Sociedade da Informação nos seus programas e, ao longo dos seus mandatos, interligando os projetos desenvolvidos no nosso país com os programas europeus.

A Iniciativa Ligar Portugal ${ }^{25}$ surgiu em 2005, como resposta aos desafios colocados pelo projeto europeu $i 2010$. No documento que define os objetivos e as estratégias para esta iniciativa refere-se a distância a que ainda se encontrava Portugal da União Europeia (então formada por 15 países) no que dizia respeito à utilização regular da Internet (25\% da população entre os 16 e os 74 anos, contra 41\% na União Europeia). Com estes dados presentes, o novo projeto visava aproximar ainda mais os portugueses das TDIC, "facilitando a sua familiarização com a utilização de computadores e a Internet, nomeadamente promovendo sempre que necessário agentes de intermediação para combater a info-exclusão" (MCTES, 2005: 9).

Entre as medidas definidas para esta iniciativa, são várias as que se relacionam com os espaços educativos:

facilitar a utilização de computadores em casa por estudantes, [...]; apoiar a massificação de ofertas integradas de computadores e ligação em banda larga à Internet, especialmente por estudantes; assegurar a ligação em banda larga de todas as escolas do país, até ao final de 2005 (MCTES, 2005: 5).

Pretendia-se que os estudantes pudessem usufruir de ambientes de trabalho virtuais, documentos de apoio em formato eletrónico, sistemas de acompanhamento e de trabalho em rede e até mesmo um portfólio digital do aluno que terminava a escolaridade obrigatória. Esperava-se também conseguir chegar a 2010 com um ratio de um computador por cada cinco estudantes. Com tudo isto se previa a melhoria da qualidade da educação e das competências tecnológicas digitais dos alunos em vias de entrar para o mercado de traba-

25 http://www.ligarportugal.pt/ 
lho, para além da modernização do país, através da qualificação de todos os portugueses.

\subsubsection{Plano Tecnológico da Educação (2007-2013)}

Em 18 de setembro de 2007 foi aprovado, pelo XVII. ${ }^{\circ}$ Governo Constitucional, o Plano Tecnológico da Educação (Conselho de Ministros n. ${ }^{\circ}$ 137/2007), considerado o maior projeto de modernização tecnológica das escolas portuguesas e tendo por base a Estratégia de Lisboa, a Estratégia Nacional de Desenvolvimento Sustentável, o Plano Tecnológico e o Quadro de Referência Estratégico Nacional 2007-2013.

Este plano foi estruturado tendo em conta que "é essencial [...] consolidar o papel das tecnologias da informação e da comunicação (TIC) enquanto ferramenta básica para aprender e ensinar nesta nova era" (Conselho de Ministros, 2007: 6563).

Para além disso, pretendia o Governo que este projeto contribuísse para que Portugal não só recuperasse os atrasos observados mas também passasse a estar entre os cinco países europeus mais avançados na modernização tecnológica do ensino até 2010, para que a escola passasse a ser "o centro de uma rede de projectos direccionados para o que realmente importa: aprender e ensinar mais e melhor, os professores e os alunos" (Conselho de Ministros n. ${ }^{\circ}$ 137/2007: 6564), preparando assim os alunos para os desafios da Sociedade da Informação e do Conhecimento.

Entre 2007 e 2010 dever-se-ia conseguir um ratio de 2 alunos por computador com ligação à Internet; garantir que todas as escolas tinham acesso de banda larga; assegurar que as TDIC seriam utilizadas, por docentes e discentes, pelo menos em $25 \%$ das aulas; assegurar que $100 \%$ de alunos e professores teriam endereços de correio eletrónico que permitam a massificação do uso de meios de comunicação eletrónicos; ter $90 \%$ dos docentes com as suas competências TIC certificadas e certificar 50\% dos alunos em TIC (Conselho de Ministros n. ${ }^{\circ}$ 137/2007: 6567).

Para que estes objetivos fossem alcançados determinaram-se os problemas que ainda impediam o avanço tecnológico nas escolas e todo o programa 
foi desenhado com vários projetos que visavam precisamente ultrapassar ou eliminar esses obstáculos e organizado em quatro eixos de atuação principais: Tecnologia, Conteúdos, Formação e Investimento e Financiamento. No primeiro eixo organizaram-se os seguintes projetos: Kit Tecnológico Escola, Internet em Banda Larga de Alta Velocidade, Internet nas Salas de Aula, Cartão Electrónico do Aluno, Videovigilância, Centro de Apoio Tecnológico às Escolas. No âmbito dos Conteúdos, os projetos foram: Mais-Escola.pt, Escola Simplex, Manuais Escolares Electrónicos, Plataforma de Comunicação Electrónica Integrada. Relativamente ao eixo Formação os projetos foram: Formação e certificação de Competências TIC - Formação Pro, Avaliação Electrónica, Integração das TIC nos métodos de ensino e aprendizagem, Literacia em Aplicações Open Source. No último eixo, os projetos foram: Financiamento Comunitário, Fundo para a Inclusão na Educação, Mecenato Tecnológico e parcerias com o setor privado.

Para gestão do programa criou-se uma equipa de coordenação, monitorização e avaliação do PTE, um Conselho Consultivo e em todas as escolas foram criadas equipas PTE que deveriam colocar em prática todos os projetos definidos no Plano Tecnológico.

Em 2010 fez-se uma análise do andamento do Plano verificando-se uma significativa melhoria na implementação das TDIC nas escolas, ainda que não se tivessem atingido em pleno os objetivos inicialmente delineados. Entre todas as indicações fornecidas pelos autores do relatório destaca-se que há uma positiva opinião sobre as tecnologias digitais na perspetiva da lecionação. Quase todos os alunos usaram estas tecnologias nas aulas mas nota-se que, apesar de se considerarem absolutamente proficientes, ainda as usam mais como ferramenta social. Do lado dos professores também cresceu a confiança no uso de tecnologias digitais nas aulas e a maioria destes profissionais reconhece, em geral, a sua utilidade e o seu benefício para o reforço dos conhecimentos dos alunos. Contudo, ainda entendem que devem continuar a ter formação em TDIC (Carneiro et al., 2010).

No início de 2011 o XVIII. ${ }^{\circ}$ Governo Constitucional aprovou o programa e.escola 2.0, indo ao encontro dos objetivos da Agenda Digital Europeia, pois "vem dar continuidade ao programa de infoinclusão e modernidade no actual 
quadro orçamental e dar um impulso determinante aos conteúdos educativos e à utilização de redes de nova geração" (Conselho de Ministros, 2011: 700).

O antecessor deste programa (o e.escola, lançado em 2009) havia já sido um sucesso, tendo equipado com um computador portátil 1.700 .000 alunos e professores e permitido o acesso à Internet de banda larga a cerca de 1.000 .000 destes. O e.escola 2.0 procura garantir a continuidade desse projeto e, uma vez que as estatísticas oficiais indicavam, na época, que $96 \%$ e $91 \%$ dos jovens entre os 10 e os 15 anos de idade utilizavam o computador e acediam à Internet, respetivamente, era necessário dar-lhe respostas educativas inovadoras. Por esse motivo deveria

continuar a promover a infoinclusão, [...] fomentar a criação de recursos educativos; incrementar a utilização das redes de nova geração; [...] continuar a massificar a utilização do computador portátil e de banda larga [...] (Conselho de Ministros, 2011: 700-701).

Em jeito de conclusão, resta-nos dizer que muito se evoluiu em Portugal, ao longo dos últimos 25 anos, em matéria de tecnologia digital no ensino. Atualmente, as escolas encontram-se, em geral, equipadas com Internet de alta velocidade, mesmo nas salas de aula, os professores e os alunos têm aumentado as suas competências em TDIC e cada vez mais os recursos tecnológicos e multimédia são uma realidade no ensino português, aproximando-nos cada vez mais das taxas europeias.

Se na Lei de Bases do Sistema Educativo de 1986 nada aparece ainda sobre a utilização das TDIC na escola, aquando da reorganização curricular o mesmo já não acontece. De facto, quando se operacionalizou a reforma curricular do final dos anos 90 do século XX, o Decreto-lei 6/2001, regulamentador da reforma do ensino básico

consagra [...] a utilização das tecnologias de informação e comunicação como formações transdisciplinares, no âmbito do ensino básico, abordando de forma integrada a diversificação das ofertas educativas, tomando em consideração as necessidades dos alunos (M. Educação, 2001: 259). 
Esta legislação decreta o caráter transdisciplinar que devem ter as TDIC e o desejo de que os alunos saiam deste nível de escolaridade com as competências básicas adquiridas e deseja também que as atividades de aprendizagem possam recorrer, entre outros recursos, às TDIC.

Em consonância com a legislação aprovada, no documento referente às competências essenciais previstas para o ensino básico, a utilização das TDIC surge entre as competências genéricas a desenvolver pelo aluno, sobretudo como forma de acesso à informação, pelo que são referidas diversas ações a desenvolver pelos professores nas suas aulas e que envolvam a utilização destas tecnologias digitais para que os alunos saibam, de uma forma transversal, utilizar as suas potencialidades em benefício da sua própria aprendizagem (M. Educação, 2001).

As medidas implementadas iam no sentido de aproximar toda a comunidade educativa dessas mesmas tecnologias digitais de maneira a criar uma economia cada vez mais baseada no conhecimento e na sociedade da comunicação. A utilização das TDIC é "fortemente recomendada", pelo Governo, nos novos programas como um "recurso a privilegiar" (EURYDICE, 2007b: 31). É ainda defendido que o recurso às TDIC contribui também para desenvolver competências de pesquisa e de gestão e seleção da informação, competências essas de desenvolvimento fundamental ao longo de todo o ensino básico e secundário.

Resumindo, Portugal foi empreendendo um grande esforço para ultrapassar o atraso significativo em que o país se encontrava face à União Europeia. De uma situação, nos finais dos anos 80, em que a existência de computadores, quer nas escolas, quer nas casas, quase não passava de uma miragem, privilégio apenas de alguns, passou-se para um momento em que praticamente todas as salas de aula têm equipamentos informáticos e Internet de banda larga e em que a posse de computadores portáteis é uma realidade para muitos professores e alunos. É, de facto, louvável que nos últimos 30 anos o país tenha conseguido desenvolver tantos projetos (muitos para além daqueles que aqui apresentámos) que procuraram dotar crianças, jovens e adultos de conhecimentos e utensílios que lhes permitam usufruir dos benefícios que as tecnologias digitais podem trazer ao ensino. Contudo, parecem-nos parcas as referências à utilização das TDIC nos documentos oficiais que regulamentam 
o ensino básico e secundário, sobretudo quando observamos a quantidade de projetos integrados na Sociedade da Informação e do Conhecimento que têm vindo a ser desenvolvidos, não refletindo uma verdadeira integração das TDIC nos currículos oficiais. Concordamos com Pedró (1998) que refere, nesse sentido, que a nível europeu a reorganização dos currículos para enfrentar as mudanças operadas por essas tecnologias digitais se limitou sobretudo à introdução da informática como mais uma disciplina, para além de que as indicações nos parecem resumir-se também ao desejo de que as TDIC sejam transversais aos currículos e que os alunos aprendam a lidar com elas.

Contudo, e face à Era Digital em que nos encontramos, não podemos deixar de concordar com as afirmações de Carvalho e Pessoa (2012) quando indicam que

acreditamos que é hora de dar acesso nas salas de aula aos dispositivos móveis que os alunos carregam nos seus bolsos, rentabilizando-os. É uma oportunidade de promover a aprendizagem móvel 26 (p. 104).

\subsection{Novas abordagens educacionais para a Era Digital}

\subsubsection{Conectivismo}

Com os avanços tecnológicos ocorridos sobretudo desde os anos 90, alguns autores consideram que as teorias de aprendizagem mais frequentemente seguidas já não são suficientes face ao impacto que a tecnologia digital proporcionou no campo do ensino. George Siemens (2004) indica que

Behaviorismo, cognitivismo e construtivismo são as três teorias de aprendizagem mais utilizadas na criação de ambientes instrucionais. Essas teorias, no entanto, foram desenvolvidas num momento em que a aprendizagem não foi afetada pela

26 Tradução nossa. No original: creemos que es el momento de dar acceso en las aulas a los dispositivos móviles que los estudiantes llevan en el bolsillo, rentabilizándolos así. Es una oportunidad para impulsar el móvel-learning. 
tecnologia. Nos últimos vinte anos, a tecnologia reorganizou a maneira como vivemos, como comunicamos e como aprendemos. As necessidades de aprendizagem e as teorias que descrevem princípios e processos de aprendizagem devem refletir os ambientes sociais subjacentes 27 (parag. 1).

Nesse sentido, e para justificar estas afirmações, refere o autor que a maioria destas teorias defende que a aprendizagem ocorre "dentro" de uma pessoa, mesmo no que diz respeito ao construtivismo, não contemplando a possibilidade de a aprendizagem ser guardada ou manipulada pela tecnologia digital nem o facto de que a aprendizagem ocorre dentro de organizações (Siemens, 2004). De facto, sendo a aquisição do conhecimento encarada como um processo contínuo, que assenta no individual mas que reside no coletivo (Siemens, 2006a: 14), Siemens (2004) começa a formular um novo modelo de aprendizagem, afirmando que

incluir tecnologias e conexões como atividades de aprendizagem começa a mover teorias de aprendizagem numa era digital. Não podemos mais experimentar pessoalmente e adquirir as aprendizagens que precisamos para agir. Nós derivamos a nossa competência da capacidade de formar conexões ${ }^{28}$ (parag. 15).

É deste modo que se desenvolve o conectivismo, como uma assunção de que o conhecimento é um ato coletivo, assente num processo de formação de redes, isto é, procurando contemplar aquilo que podemos aprender com base nas ligações que temos, nas conexões que fazemos, nas "redes" que criamos. Stephen Downes, outro grande defensor deste conceito, apelida-o de network-based pedagogy (Downes, 2011), baseando-o na ideia de que o

27 Tradução nossa. No original: Behaviourism, cognitivism, and constructivism are the three broad learning theories most often utilized in the creation of instructional environments. These theories, however, were developed in a time when learning was not impacted through technology. Over the last twenty years, technology has reorganized how we live, how we communicate, and how we learn. Learning needs and theories that describe learning principles and processes, should be reflective of underlying social environments.

28 Tradução nossa. No original: including technology and connection making as learning activities begins to move learning theories into a digital age. We can no longer personally experience and acquire learning that we need to act. We derive our competence from forming connections. 
conhecimento se encontra distribuído através de redes de relações e que a aprendizagem consiste na capacidade de construir e cruzar essas mesmas redes (Downes, 2010).

Karen Stephenson refere que, apesar de a experiência ser considerada a melhor professora que podemos ter, "uma vez que não conseguimos experimentar tudo, as experiências das outras pessoas, e portanto as outras pessoas, tornam-se os substitutos para o conhecimento"29 (Stephenson, 1998: online). Desta forma torna-se extremamente importante alargar a experiência da aprendizagem não só ao que o indivíduo pode aprender mas também ao que as pessoas em seu redor sabem (Siemens refere em Knowing Knowledge, 2006b, que "dançamos e cortejamos o conhecimento dos outros", p. 7), ou ao que a tecnologia digital permite aceder, passando a ser mais importante ainda a capacidade de filtrar o conhecimento e saber utilizá-lo corretamente.

Para Siemens, o conectivismo apresenta-se assim como uma teoria inovadora que procura integrar princípios como o caos, as redes, a complexidade e a auto-organização, assente na ideia de que as decisões têm de ser tomadas com base em situações que estão em constante movimento e que, consequentemente, estamos sempre a adquirir mais conhecimentos. Por isso, torna-se quase vital saber distinguir o que é importante do que é muito importante. É neste contexto que as relações que estabelecemos se tornam tão importantes e que se torna também fundamental a capacidade de utilizarmos a tecnologia digital para ampliar os conhecimentos que detemos. A própria tomada de decisões, neste contexto, torna-se um importante passo no processo de aprendizagem.

Para além disso, consideramos também importante deixar aqui aqueles que são considerados por Siemens como os princípios base do conectivismo:

A aprendizagem e o conhecimento repousam na diversidade de opiniões.

A aprendizagem é um processo de conexão de nódulos especializados ou de fontes de informação.

A aprendizagem pode residir em aparelhos não humanos.

29 Tradução nossa. No original: since we cannot experience everything, other people's experiences, and hence other people, become the surrogate for knowledge. 
A capacidade de saber mais é mais crítica do que se sabe atualmente.

Nutrir e manter conexões é necessário para facilitar a aprendizagem contínua.

A capacidade de ver conexões entre campos, ideias e conceitos é uma habilidade essencial.

Conhecimento preciso e atualizado é o objetivo de todas as atividades de aprendizagem conectivistas.

A tomada de decisão é em si um processo de aprendizagem. Escolher o que aprender e o significado da informação recebida é visto através das lentes de uma realidade em mudança. Embora haja uma resposta correta agora, pode ser errada amanhã devido a alterações no fluxo de informações que afetam a decisão ${ }^{30}$ (Siemens, 2004: parag. 25).

Esta abordagem surge assim para fazer face a uma época de abundante fluxo de informação que se encontra ao alcance de todos, que por vezes se torna complexa e que muda constantemente.

Deste modo, e como estamos constantemente a adquirir mais informação e a aumentar os nossos conhecimentos, é também importante sabermos criar conexões que nos permitam estar sempre a aumentar esses mesmos conhecimentos, bem como a saber fazê-lo da forma correta. Surge assim, intimamente associada à ideia do conectivismo, a noção de rede (network), pressupondo-se então que a aprendizagem seja um processo de formação de conexões/ redes. De acordo com Siemens (2006b)

a aprendizagem é o processo de criação de redes. Os nódulos são entidades externas que podemos usar para formar uma rede. Ou podem ser pessoas, organizações, bibliotecas, sites, livros, periódicos, bancos de dados ou qualquer outra fonte de

30 Tradução nossa. No original: Learning and knowledge rests in diversity of opinions. Learning is a process of connecting specialized nodes or information sources. Learning may reside in non-human appliances. Capacity to know more is more critical than what is currently known. Nurturing and maintaining connections is needed to facilitate continual learning. Ability to see connections between fields, ideas, and concepts is a core skill. Currency (accurate, up-to-date knowledge) is the intent of all connectivist learning activities. Decision-making is itself a learning process. Choosing what to learn and the meaning of incoming information is seen through the lens of a shifting reality. While there is a right answer now, it may be wrong tomorrow due to alterations in the information climate affecting the decision. 
informação. $\mathrm{O}$ ato de aprender (as coisas tornam-se um pouco complicadas aqui) é criar uma rede externa de nódulos - onde nos conectamos e formamos fontes de informação e conhecimento. A aprendizagem que acontece nas nossas cabeças é uma rede interna (neural). As redes de aprendizagem podem então ser percebidas como estruturas que criamos para permanecermos atuais e continuamente adquirirmos, experimentarmos, criarmos e conectarmos novos conhecimentos (externos). $\mathrm{E}$ as redes de aprendizagem podem ser percebidas como estruturas que existem dentro das nossas mentes (internas) na conexão e criação de padrões de compreensão ${ }^{31}$ (p. 29).

A rede torna-se assim fundamental no processo de aprendizagem, uma vez que permite manter os nossos conhecimentos atualizados e pode processar, filtrar, avaliar e validar nova informação (Mota, 2009: 108).

É neste contexto que Siemens aborda o conceito de network learning como um subsistema do conectivismo, uma vez que um dos seus princípios é o da formação de networks. Refere Siemens (2005c) que

A rede é a aprendizagem. A agregação dos nódulos da rede é a estrutura de aprendizagem. Se algum nódulo crítico for removido de uma rede de aprendizagem, todo o organismo perde efetividade. A aprendizagem é evolutiva. A aprendizagem não é um evento ou objetivo final. A aprendizagem é um processo. A nossa rede pessoal vai sendo aumentada e aprimorada continuamente por novos nódulos e conexões ${ }^{32}$ (parag. 2).

31 Tradução nossa. No original: learning is the process of creating networks. Nodes are external entities which we can use to form a network. Or nodes may be people, organizations, libraries, web sites, books, journals, database, or any other source of information. The act of learning (things become a bit tricky here) is one of creating an external network of nodes-where we connect and form information and knowledge sources. The learning that happens in our heads is an internal network (neural). Learning networks can then be perceived as structures that we create in order to stay current and continually acquire, experience, create, and connect new knowledge (external). And learning networks can be perceived as structures that exist within our minds (internal) in connecting and creating patterns of understanding.

32 Tradução nossa. No original: The network is the learning. The aggregation of network nodes is the learning structure. If any critical nodes are removed from a learning network, the entire organism loses effectiveness. Learning is evolutionary. Learning is not an event or end goal. Learning is a process. Our personal network is continually being augmented and enhanced by new nodes and connections. 
Contribuindo também para o desenvolvimento das ideias do conectivismo, Stephen Downes aborda o conceito de connective knowledge, definindo-o como um terceiro grande tipo de conhecimento, a acrescentar ao conhecimento qualitativo e ao quantitativo. Connective knowledge é todo o conhecimento que pode ser descrito como "distribuído", uma vez que se encontra espalhado por mais do que um indivíduo, ou seja, "a propriedade de uma entidade deve conduzir ou tornar-se propriedade de outra entidade para que sejam consideradas conectadas"33 (Downes, 2007: online).

Para além dos conceitos de conectivismo e de conhecimento conectivo, interessa também perceber que todo o ambiente de aprendizagem pode ser organizado em torno de uma ecologia que promove e suporta a criação de comunidades de aprendizagem. Alargando esta ideia ao ambiente de aprendizagem, uma ecologia permite a formação de comunidades de interesses que se podem sobrepor e partilhar conhecimento de forma organizada, evoluindo constantemente e permitindo a interação entre os seus participantes.

Siemens vai desenvolver também um pouco mais este conceito de learning ecology, defendendo que as suas características podem ser ampliadas, nomeadamente quando falamos de ambientes formais de aprendizagem, onde o conceito de auto-organizado dá lugar a um processo mais estruturado de transmissão de conhecimentos sendo que o professor terá o papel do "jardineiro" (Siemens, 2003). Concluindo esta definição, Siemens defende que, uma learning ecology, deverá ser baseada nas seguintes componentes: informal, rica em ferramentas, consistente, confiável, simples, descentralizada e conectada, com grande tolerância para a experimentação e para o erro (parag. 18).

Em suma, o conectivismo procura fazer face uma época dominada pela tecnologia digital em rede e estar preparado para novas gerações que crescem ao lado dessa mesma tecnologia digital e que levam tantos autores a utilizar, para as caraterizar, a expressão "growing up digital". Nesse sentido, tanto

33 Tradução nossa. No original: a property of one entity must lead to or become a property of another entity in order for them to be considered connected. 
mais valioso é o nosso conhecimento quanto as relações que conseguimos estabelecer, para além de que, sendo a aprendizagem contínua, deverá ser possível integrar mais do que o que pode caber na sala de aula ou na estrutura curricular de um curso. Para que nos possamos manter atualizados temos de fazer parte de uma comunidade, de uma ecologia, enfim, de uma network. Assim, quando um estudante aprende estando ligado a uma comunidade, através da qual dá e recebe informação, estaremos perante aprendizagem conectivista.

Contudo, rapidamente se apresentaram críticas ao conectivismo, sobretudo por Pløn Verhagen, Bill Kerr, Ana Amélia Carvalho, Rita Kop e Adrian Hill e também Curtis Bonk. O primeiro (Verhagen, 2006), de uma forma bastante direta, afirmou que o conectivismo não pode ser considerado uma teoria de aprendizagem mas apenas uma visão pedagógica da educação, uma vez que tem que ver apenas com o que é aprendido e porquê e não com como a aprendizagem tem lugar. Para além disso, Verhagen ainda defendeu não existir qualquer novidade na teoria de Siemens e que o uso de conhecimentos guardados em "aplicações não-humanas" tem vindo a ser feito ao longo dos tempos dado que "as limitações da memória foram compensadas escrevendo as coisas, imprimindo livros e criando bancos de dados. As ferramentas cognitivas modernas nada mais são do que uma extensão do kit de ferramentas"34. Kerr (2007), por seu lado, recupera noções de Vygotsky, de Papert (ambos pré-Internet) e de Clark, indicando que "o andaime fornecido pela linguagem e pelos objetos para pensar estende a nossa mente do cérebro para o meio ambiente"35 (Kerr, 2007: online), ou seja, o conectivismo não vinha fornecer nada de novo aos estudos sobre o desenvolvimento do conhecimento. Carvalho (2007) reconhece "a importância que a conectividade tem na era digital" (p. 29), embora entenda que caracterizá-la de "teoria da aprendizagem" seja "infundado". Kop e Hill (2008) acrescentam, aos estudiosos referidos por

34 Tradução nossa. No original: memory limitations have been compensated by writing things down, printing books and creating databases. Modern cognitive tools are nothing but an extension of the toolkit.

35 Tradução nossa. No original: the scaffolding provided by language and objects to think with extends our mind from the brain into the environment. 
Kerr, os nomes de Lave e Wenger que se dedicavam, antes de Siemens ou de Downes, ao estudo das chamadas "comunidades de prática", reconhecendo, contudo, que estamos perante uma "mudança de paradigma" e pode estar a surgir uma nova epistemologia, mas que essa mudança não se pode propriamente configurar como uma teoria de aprendizagem independente (Kop e Hill, 2008).

Finalmente, através de um texto de Siemens temos também acesso à crítica de Bonk, o qual questiona também se podemos ou não ver o conectivismo como uma teoria de aprendizagem, no sentido clássico, ou se apenas pode ser incluída numa concepção sociológica ou antropológica da aprendizagem (Siemens, 2009).

Na generalidade, aceita-se que o conectivismo possa ter importância na era digital que vivemos e que de facto são importantes as conexões na aprendizagem, mas surgem algumas reservas no que toca a apelidar este conceito de teoria de aprendizagem (Carvalho, 2007: 29).

Em resposta, principalmente às críticas apontadas por Verhagen, Siemens enfatiza a necessidade de uma nova teoria que reflita as mudanças ocorridas na sociedade atual e nas implicações que isso tem na forma como devemos encarar os espaços e as estruturas do ensino nos dias de hoje (Siemens, 2006a) e que esta mudança de paradigma na aprendizagem permite aos estudantes muito maior controlo sobre a criação de conteúdo e a interação com outros (Siemens, 2008a).

\subsubsection{Educação Rizomática}

Se pela mão de George Siemens se começaram a delinear, por volta de 2004, as características do conectivismo, foi pouco tempo depois, em 2008, que surgiram os primeiros tópicos relativos ao modelo rizomático, num artigo de Dave Cormier, intitulado Rhizomatic education: Community as curriculum.

Cormier entende que

O modelo educacional existente, com seu ciclo de planeamento e publicação pedagógica centrado em especialistas, é muito estático e prescrito para acomodar o tipo 
de concepção fluida e transitória de conhecimento que é necessário para entender o mais simples dos conceitos baseados na Internet ${ }^{36}$ (2008: 1).

Apesar de sabermos que o conectivismo reconhece a necessidade de um modelo educativo que possa/saiba fazer face à evolução, quase vertiginosa, que a aquisição de conhecimento foi sofrendo com o avanço das tecnologias digitais, Cormier considera-o insuficiente para representar a natureza da aprendizagem no mundo digital, juntamente com a pedagogia social construtivista, uma vez que ambas assumem, no seu entender, que o conhecimento ou o que se aprende é algo independente daquilo que pode ser definido pelo currículo (Cormier, 2008).

Desta forma, este autor utiliza uma metáfora botânica, de Deleuze e Guat$\operatorname{tari}^{37}$, para explicar de que forma se deve procurar conceber o conhecimento na era digital: o rizoma. Esta planta é "um emaranhado de tubérculos sem início ou fim aparente. Em constante mudança de forma, e cada ponto parece estar conectado com todos os outros pontos"38 (Driscoll, 2004: 389). Nos tempos que correm (e aqui utilizamos literalmente esta palavra), com a evolução constante da informação e do conhecimento, surge a necessidade de conceber a aprendizagem como uma negociação que não necessite de uma aprovação prévia de peritos:

36 Tradução nossa. No original: The existing educational model with its expert-centered pedagogical planning and publishing cycle is too static and prescribed to accommodate the kind of fluid, transitory conception of knowledge that is necessary to understand the simplest of Web-based concepts.

37 Na sua obra, Mil Planaltos, (2007: 25-28) os autores referem: "subtrair o único da multiplicidade a constituir; escrever a n-1. Um tal sistema podia ser chamado rizoma. [...] Sentimos bem que não convenceremos ninguém se não enumerarmos algumas características aproximativas do rizoma. $1 .^{\circ}$ e $2 .^{\circ}$ Princípios de conexão e de heterogeneidade: qualquer ponto de um rizoma pode ser conectado com qualquer outro, e tem de sê-lo. [...] 3. ${ }^{\circ}$ Princípio de multiplicidade: é apenas quando o múltiplo é efectivamente tratado como substantivo, como multiplicidade, que já não tem nenhuma relação com o Um como sujeito ou como objecto, como realidade natural ou espiritual, como imagem e mundo. [...] $4 .^{\circ}$ Princípio de ruptura assignificante: contra os cortes demasiado significantes que separa as estruturas ou atravessam alguma. Um rizoma pode ser interrompido, quebrado num sítio qualquer, retoma segundo esta ou aquela das suas linhas e segundo outras linhas [...]".

38 Tradução nossa. No original: a tangle of tubers with no apparent beginning or end. In constantly changes shape, and every point in it appears to be connected with every other point. 
no modelo rizomático da aprendizagem, o currículo não é impulsionado por contribuições predefinidas de especialistas; é construído e negociado em tempo real pelas contribuições daqueles envolvidos no processo de aprendizagem. Essa comunidade atua como o currículo, modelando, construindo e reconstruindo espontaneamente a si mesmo e ao tema da sua aprendizagem, da mesma forma que o rizoma responde às mudanças nas condições ambientais [... $]^{39}$ (Cormier, 2008: 3).

Cormier defende que a validação tradicional do conhecimento, através de aprovação e de peer review, demora demasiado tempo, tempo esse que hoje em dia, perante a constante mutação da informação, pode representar que, quando for validado esse conhecimento já estará ultrapassado. Thomas e Brown referem mesmo que "tornar o conhecimento estável num mundo em mudança é um jogo que nunca se conseguirá ganhar” (2011: 46). Assim, Cormier sugere que o conhecimento pode ser validado, em tempo real, pela própria comunidade que o está a usar e desenvolver, desde que a informação seja reconhecida como útil para essa mesma comunidade ou porque esta se mostra capaz de fazer algo com ela (Cormier, 2008).

De acordo com o modelo rizomático de educação, o currículo não será então definido previamente pelos peritos da área, mas passará a ser construído em tempo real pelos que dele estão a beneficiar. Cormier refere que a comunidade não é o caminho para o conhecimento mas que a comunidade na verdade é o próprio conhecimento (Cormier, 2008). Mary Ann Rilley segue as mesmas ideias de Cormier e defende que

ao conceber a aprendizagem rizomática, ajuda pensar em alunos que se assemelham a um mar de "intermediários", que são continuamente formados e reformados com base em alianças determinadas por necessidades, interesses, orientações, perguntas, redirecionamentos, avaliações e compromissos ${ }^{40}$ (2011, online).

39 Tradução nossa. No original: In the rhizomatic model of learning, curriculum is not driven by predefined inputs from experts; it is constructed and negotiated in real time by the contributions of those engaged in the learning process. This community acts as the curriculum, spontaneously shaping, constructing, and reconstructing itself and the subject of its learning in the same way that the rhizome responds to changing environmental conditions.

40 Tradução nossa. No original: in conceiving of rhizomatic learning, it helps to think of learners resembling a sea of "middles," who are continuously formed and reformed based 
Se Siemens e Downes entendem que no mundo em que vivemos se tornam cada vez mais importantes as ligações que estabelecemos e que o conhecimento assenta no todo e não no individual, Cormier acrescenta que o conhecimento tem de ser negociável socialmente, e que a comunidade não é apenas o caminho para a compreensão do conhecimento/currículo mas que ela própria pode ser esse conhecimento/currículo.

on alliances determined by needs, interests, directions, questions, redirections, assessments, and commitments. 


\title{
AS TECNOLOGIAS DIGITAIS NA ERA MOBILE
}

Uma vez que a sociedade atual se encontra absolutamente imersa na tecnologia digital,

\begin{abstract}
indivíduos e alunos precisam saber como aprender num ambiente de rede e gerir processos educacionais em rede, como existir em uma sociedade em rede e como usar as ferramentas pertencentes à sociedade em rede ${ }^{41}$ (Ozan \& Kesim, 2013: 174).
\end{abstract}

Por isso, as escolas do novo milénio têm de se preparar para os novos estudantes, profundamente habituados a viver rodeados de tecnologia digital, e que vários autores vieram apelidar de Generation Digital (Montgomery, 2007) ou iGeneration (Rosen, 2010). Nesse sentido, Rosen explicava que

com o "i" representando os tipos de tecnologias móveis que são usados por crianças e adolescentes (iPhone, iPod, Wii, iTunes), para além do facto de que essas tecnologias são em grande parte "individualizadas" na forma como são usadas. Os meus colegas e eu sentimos que esta nova geração engloba as crianças e adolescentes nascidos no novo milénio e são definidos pela sua tecnologia e pelo uso dos media, pelo seu amor pela comunicação eletrónica e pela sua necessidade de realizar múltiplas tarefas ao mesmo tempo ${ }^{42}$ (Rosen, 2010: 8).

41 Tradução nossa. No original: individuals and learners need to know how to learn in a networked environment and manage networked educational processes, how to exist in a networked society and how to use the tools belonging to the networked society.

42 Tradução nossa. No original: with the "i" representing both the types of mobile technologies being heralded by children and adolescents (iPhone, iPod, Wii, iTunes) plus the fact that these technologies are mostly "individualized" in the way they are used. My colleagues and I feel that this new generation encompasses those children and teens born 
Para além disso, o autor explica a dimensão do "i" que se inclui na expressão, como algo que não só remete para toda a panóplia de equipamentos digitais, como também para as tarefas individualizadas que a tecnologia digital permite realizar.

De facto, não podemos esquecer que estes jovens têm hoje toda uma nova forma de encarar o conhecimento. Prensky (2010) refere, a propósito, que

uma das maiores ironias na era digital é que a geração anterior, pré-digital (que inclui muitos dos professores de hoje) foi criada para não partilhar - o seu lema era "conhecimento é poder: mantenha-o perto do peito" - enquanto que a geração de nativos digitais (que inclui a maioria dos nossos alunos) cresceu pensando que a partilha de informações (postando, blogando, enviando mensagens de texto, tuitando etc.) é exatamente como se obtém reconhecimento e poder. O lema da geração mais jovem, se tivesse um, seria - "no partilhar está o poder"43 (p. 279-280).

Prensky distingue até esta nova geração de nativos digitais, que nasceram completamente imersos nas possibilidades criadas pela tecnologia digital, dos imigrantes digitais, que são todas as gerações anteriores, que tiveram de aprender a trabalhar neste novo mundo digitalmente ligado.

Moura (2009) refere-se a esta nova geração como geração bit, nascida em pleno mundo digital e para quem a tecnologia digital é tão normal como o ar, indicando que para estes jovens,

os computadores, a internet, os jogos de vídeo e os telemóveis são comuns. Expressar-se através destas ferramentas é a norma. [...] Dada a forma como estas tecno-

in the new millennium and are defined by their technology and media use, their love of electronic communication, and their need to multitask.

43 Tradução nossa. No original: one of the biggest ironies in the digital age is that the older, predigital generation (which includes many of today's teachers) was raised not to share - their motto was "knowledge is power: keep it close to the vest" - while the generation of digital natives (which includes most of our students) have grown up thinking that sharing information (by posting, blogging, texting, tweeting, etc.) is precisely how you get recognition and power. The motto of the younger generation, if they had one, would be - "sharing is power". 
logias estão presentes nas suas vidas, os jovens actuam, pensam e aprendem de forma diferente (Moura, 2009: 60).

Para além disso, a capacidade que a maioria dos alunos tem hoje para, através dos seus dispositivos, aceder à informação,

remove o terreno sólido da aprendizagem em sala de aula e da educação como a transmissão ou a construção do conhecimento dentro dos limites estabelecidos por um currículo, e substitui-a por um processo cibernético de aprendizagem através da negociação e exploração contínuas ${ }^{44}$ (Sharples, 2005: 6).

Ao seu alcance estão leitores de $M p 3$ ou de $M p 4$, Smartphones das mais variadas marcas, computadores tanto de secretária como portáteis, tablets, consolas de jogos e tantos outros equipamentos que permitem que estes se mantenham em contacto uns com os outros e mesmo com o mundo inteiro. Por isso se torna hoje muito importante que os professores sejam capazes de comunicar com os jovens na sua linguagem e foi com estas ideias em mente que muitas escolas, em diferentes países, começaram a apostar na introdução de tecnologias digitais móveis nos seus estabelecimentos:

foi essa crença de que os alunos de hoje são versados digitalmente, bem como digitalmente imersivos, que levou algumas escolas a considerar a integração de dispositivos móveis através de programas de implementação escolar ou do BYOD (bring-your-own-device) ${ }^{45}$ (Grant \& Barbour, 2013: 286).

Hoje em dia, a capacidade que os alunos têm de aceder à informação com a rapidez de um clique ou do deslizar de um dedo, torna o uso de tecnologias

44 Tradução nossa. No original: removes the solid ground of classroom instruction, and of education as the transmission or construction of knowledge within the constraints set by a curriculum, and replaces it with a cybernetic process of learning through continual negotiation and exploration.

45 Tradução nossa. No original: It is this belief that today's students are digitally savvy, as well as digitally immersive, that has prompted some schools to consider integrating mobile computing devices through school implementation or bring-your-own-device (BYOD) programs. 
digitais móveis na escola cada vez mais uma realidade. Os estudantes do novo milénio estão de tal forma habituados a esta corrente constante de informação que estão formatados para pensar, também na escola, de uma forma diferente da de gerações anteriores. Para além disso, a proliferação dos equipamentos móveis também contribui para esta nova mentalidade. A propósito, Moura (2008) refere que

falar em tecnologias móveis não é só falar em telemóveis mas também em mentes móveis. Não se sabe ainda como os alunos que aprendem através destas tecnologias irão actuar na sociedade futuramente. No entanto, os dispositivos móveis levam os alunos a envolver-se na aprendizagem como nunca foi visto antes o que certamente terá consequências nos seus desempenhos (p. 126).

Para além disso, a impossibilidade de usar, quando estão na escola, os dispositivos móveis habituais (ipod, smartphone, tablets ou tantos outros) que são para estes estudantes tão importantes quanto a roupa que vestem, e que os faz trazer o mundo no bolso, torna-se por vezes um fator desmotivador. De facto, ouvir o professor falar durante uma hora parece-lhes muito menos interessante do que todos os links, posts ou sons consultados durante o intervalo das aulas. Apesar disso, como Moura (2010) refere,

muitos pais e professores não veem com bons olhos o facto dos jovens estudarem a ouvir música, preferirem uma pesquisa rápida na Internet a uma na biblioteca, não estarem motivados por palestras, não gostarem de ler em papel e realizarem muitas tarefas ao mesmo tempo (p. 12).

Contudo, é necessário compreender que hoje em dia é incontornável a forma como os jovens preferem organizar o seu dia-a-dia e, em particular, como preferem encarar o acesso à sua própria formação.

A esta questão se associa o facto de que, com tantos recursos digitais e tecnológicos ao nosso dispor, é hoje quase impossível guardar nos nossos cérebros toda a informação a que podemos ter acesso em curtos espaços de tempo. É assim cada vez mais importante sabermos filtrar e selecionar essa informação do que guardá-la nos nossos cérebros. 
Assim, se, por um lado, cabe à escola e aos educadores criar um ambiente de aprendizagem estimulante, é também seu dever adaptar-se a uma nova era educacional e desenvolver as competências digitais necessárias para preparar os alunos para este "novo" mundo digital:

à saída da escola os alunos devem saber utilizar a tecnologia digital, as ferramentas de comunicação, as redes sociais, bem como gerir, integrar, avaliar e criar informação que lhes permita viver numa sociedade altamente informatizada e conectada (Moura, 2012: 127).

Para além disso, entendemos que é deveras importante o aproveitamento de todas as vantagens de utilização das tecnologias digitais para o ensino de uma disciplina como a História que é considerada habitualmente complexa e não linear. O pensamento bistórico requer capacidade de análise e de interpretação e,

para saber 'ler' a informação, debater e seleccionar mensagens, fundamentadamente, é preciso saber interpretar fontes, analisar e seleccionar pontos de vista, comunicar sob diversas formas, apostar em metodologias que envolvam os alunos no acto de pensar historicamente (Barca, 2007: 6).

Desta forma, consideramos que o caráter multimédia que a tecnologia digital hoje em dia assume pode permitir ao estudante de História o desenvolvimento de aptidões, sobretudo, ao nível do raciocínio crítico e auxiliar no desenvolvimento da capacidade de perceber a complexidade associada ao conhecimento histórico.

\subsection{Mobile Learning}

Se diferentes estudos têm vindo a público referindo que o uso de computadores portáteis nunca chegou a ser verdadeiramente adotado pelos alunos na escola, os aparelhos móveis que os alunos trazem para as salas de aula, entre cadernos e manuais, e que são cada vez "mais pequenos, mais leves, com 
maior capacidade de armazenamento, com funcionalidades diversificadas, e com acesso à Internet" (Carvalho, 2012: p. 7), tornaram-se uma ferramenta de eleição para uso constante por qualquer aluno.

Será por isso que as edições de 2012 e 2013 do Horizon Report K-12 ${ }^{46}$ referem que os mobile devices \& apps e o tablet computing aparecem como as tecnologias digitais que iriam ter maior impacto educativo nos 12 meses seguintes. Mesmo em relatórios mais recentes surge o BYOD (2014 e 2015), a realidade virtual (2016 e 2017) ou as aprendizagens online (2016), mostrando a importância e o impacto de aprendizagens assentes não só em tecnologias digitais móveis mas também na "nuvem".

No que diz respeito aos dispositivos móveis este Relatório referia que:

as possívei aplicações dos smartphones são vastas e variam de gráficos de equações matemáticas complexas até ao armazenamento e partilha de anotações. Os aplicativos, em particular, são a dimensão que mais cresce no setor móvel nos níveis de ensino do pré-escolar ao $12 .^{\circ}$ ano, com impactos em praticamente todos os aspectos da vida informal e, cada vez mais, potencial em quase todas as disciplinas académicas ${ }^{47}$ (Johnson et al., 2012: 4).

Desta forma, a educação não se pode mais manter afastada das potencialidades que as tecnologias digitais (e sobretudo as móveis) promovem, uma vez que

incluir a tecnologia e fazer conexões como atividades de aprendizagem começa a mover teorias de aprendizagem numa era digital. Não podemos mais experimentar

46 Este relatório, destinado ao ensino não superior, é internacionalmente reconhecido pela sua pesquisa anual relativamente às seis tecnologias emergentes ou práticas que maior impacto terão na educação em todo o mundo nos cinco anos que se seguem à sua edição.

47 Tradução nossa. No original: the potential applications of mobiles are vast, and range from graphing complex mathematical equations to storing and sharing notes and e-book annotations. Apps in particular are the fastest growing dimension of the mobile space in the K-12 sector right now, with impacts on virtually every aspect of informal life, and increasingly, potential in almost every academic discipline. 
pessoalmente e aprender tudo o que precisamos para agir. Derivamos a nossa competência da capacidade de formar conexões ${ }^{48}$ (Siemens, 2004: online).

Assim, entendemos que a utilização das tecnologias digitais no ensino pode contribuir para o desenvolvimento, nas salas de aula, de um modelo construtivista de ensino. A esse propósito Nastu (2011) refere que

quando as escolas puderem fornecer um dispositivo para cada um dos alunos, a pedagogia e o currículo podem mudar. Os professores param de "contar" e os alunos começam a "encontrar", o que move o ensino de uma experiência centrada no professor para uma experiência centrada no aluno ${ }^{49}$ (2011: parag. 18).

É, assim, importante, tal como já referimos, reconhecer o valor que hoje tem, e cada vez mais, a capacidade de acesso à informação. Como a busca do conhecimento se torna agora uma questão que já não está restrita ao espaço da sala de aula, comprometendo a manutenção de um espaço tradicional de aprendizagem e, aceitando-se as possibilidades educativas propiciadas pelas tecnologias digitais móveis, cabe agora encontrar tanto novas metodologias de aprendizagem como marcos conceptuais que as alberguem (Camacho, 2012).

\subsubsection{Mobile learning: conceito}

Consideramos, então, que é necessário usufruir destes novos dispositivos, tão apelativos para os jovens, e capitalizar o seu uso na educação. O conceito mobile learning tem, assim, vindo a tornar-se cada vez mais presente no ensino e, associado também ao termo BYOD (bring your own device), procura demonstrar, tanto a educadores como a aprendentes, que estas ferramentas,

48 Tradução nossa. No original: including technology and connection making as learning activities begins to move learning theories into a digital age. We can no longer personally experience and acquire learning that we need to act. We derive our competence from forming connections.

49 Tradução nossa. No original: when schools can supply a device for every student, the pedagogy and curriculum can change. Teachers stop "telling," and students start "finding," which moves teaching from a teacher-centric to a student-centric experience. 
antes consideradas puramente lúdicas, podem agora ter uma utilidade no contexto da educação.

De facto, Bring Your Own Device torna-se cada vez mais atrativo, uma vez que permite aos estudantes trazer para a sala de aula os seus próprios equipamentos tecnológicos e, ao mesmo tempo, contribui para o alcance do desejado nível de um dispositivo por aluno (Moura, 2012).

Em articulação com estas ideias, Ally refere que "educadores e estagiários aumentam o seu poder, pois podem usar a tecnologia móvel para comunicar com os alunos em qualquer lugar e a qualquer momento" 50 (2009: 1).

Por isso, e como já destacámos, a utilização das tecnologias digitais móveis no ensino pode contribuir para uma maior motivação dos alunos nativos digitais, promovendo também, e consequentemente, um maior sucesso destes mesmos alunos.

Contudo, há que procurar também perceber exatamente o significado de mobile learning, pois,

embora o termo learning não levante muitas dúvidas, o conceito mobile pode reportar-se tanto às tecnologias móveis, como à mobilidade do aprendente e também à mobilidade dos conteúdos. Neste sentido, a mobilidade não deve ser apenas entendida em termos do movimento espacial, mas também em termos de transformações temporais e derrube de fronteiras, alargando os horizontes da aprendizagem e do acesso à informação (Moura, 2010: 8).

Quinn foi um dos primeiros autores a procurar uma definição para esta expressão, começando por a associar a eLearning através de dispositivos eletrónicos (Quinn, 2000) mas, mais tarde, sentiu a necessidade de a desenvolver e atualizar, face à evolução tecnológica que vem decorrendo, descrevendo então m-learning como

qualquer atividade que permita aos indivíduos serem mais produtivos ao consumir, interagir ou criar informações, mediada por um dispositivo digital portátil com-

50 Tradução nossa. No original: educators and trainees are empowered since they can use the mobile technology to communicate with learners from anywhere and at anytime. 
pacto que o indivíduo carrega regularmente, que possui conectividade confiável e que cabe num bolso ou carteira ${ }^{51}$ (Quinn, 2011: 4).

Para além disso, este autor aborda ainda os 4 C's do mobile learning, como uma forma de explicar as suas potencialidades. São eles aceder a conteúdos (content), produzir informação (capture), produzir respostas (compute) e comunicar com outros (communicate) (Quinn, 2011), explicando o autor que content remete para a capacidade de aceder ou guardar conteúdos num equipamento, capture se refere à capacidade de produzir novos conteúdos (fotografias, sons, vídeos, texto, etc.) com esse mesmo equipamento, compute, está associado às aplicações existentes ou compradas para o equipamento e que permitem a produção de resultados que não um indivíduo não conseguiriam fazer de memória e, finalmente, communicate pois quando partilhamos dados, "comunicamos", algo que naturalmente fazemos através dos aparelhos móveis (Quinn, 2013).

Diferentes autores têm vindo a procurar estabelecer o significado de mobile learning, mas a tarefa acaba por se ver dificultada pela rapidez com que a tecnologia digital vem evoluindo. Para além disso, e como refere Camacho (2012), "estas definições foram obviamente influenciadas pelos avanços tecnológicos e representam um ecossistema de desenvolvimento de aprendizagem móvel"52 (p. 113).

Em 2005, Traxler reconhecia que apesar de se poder definir mobile learning como "qualquer estratégia educativa onde as únicas ou as tecnologias dominantes podem ser movidas apenas com uma mão” (p. 262), essa definição poderia ser demasiado tecnocêntrica e mesmo instável.

Crompton (2013a), refere que ao longo da última década as definições de mobile learning têm sido estabelecidas a partir de quatro ideias essenciais:

51 Tradução nossa. No original: any activity that allows individuals to be more productive when consuming, interacting with, or creating information, mediated through a compact digital portable device that the individual carries on a regular basis, has reliable connectivity, and fits in a pocket or purse.

52 Tradução nossa. No original: estas definiciones, evidentemente, han sido influenciadas por los avances tecnológicos y representan un ecosistema de desarrollo de aprendizaje móvil. 
"pedagogias de aprendizagem, aparelhos tecnológicos, contexto, e interações sociais" (p. 48). A partir destes conceitos, esta autora apresenta, em conjunto com Muilenburg e Berge, uma nova definição, onde

a redação foi escolhida para reduzir a ambiguidade, e a inclusão adicional também foi incluída para maior clareza. Portanto, a definição de Crompton, Muilenburg e Berge para m-learning é "aprendizagem em múltiplos contextos, através de interações sociais e de conteúdo, usando dispositivos eletrónicos pessoais"53 (Crompton, 2013b: 4).

É para nós a definição de mobile learning que melhor apresenta o significado deste tipo de aprendizagem, pelo que será neste conceito que nos basearemos na definição do nosso estudo.

Em Portugal, Moura (2012) faz também, no âmbito da sua tese de doutoramento sobre o uso de telemóveis no ensino, uma análise dos mais recentes trabalhos dedicados a este tema. É de destacar a descrição que esta autora faz sobre o modelo de apropriação de tecnologia digital, considerando "que a adopção (apropriação) de uma determinada tecnologia é influenciada tanto pelas limitações, como pelas possibilidades oferecidas aos utilizadores, combinadas com as suas necessidades" (Moura, 2012: 315). Refere a autora, a partir do estudo que realizou com a utilização do telemóvel na sala de aula, que

os alunos encaram o telemóvel como uma ferramenta de aprendizagem, porque sendo uma ferramenta pessoal têm total controlo sobre ela e podem controlar a sua aprendizagem. Por outro lado, trata-se de uma ferramenta conveniente por satisfazer as necessidades do aluno e ser livre de constrangimento de tempo e espaço. Como referido nas justificações, podem consultar os conteúdos e tirar dúvidas em qualquer momento, pois a ferramenta está sempre à mão, permitindo aprender sem estar na aula. É uma ferramenta com utilidade (familiaridade), podendo ser

53 Tradução nossa. No original: the wording has been chosen to reduce ambiguity, and additional ponctuation has also been included for clarity. Therefore, Crompton, Muilenburg and Berge's definition for m-learning is "learning across multiple contexts, through social and content interactions, using personal electronic devices". 
aproveitável como meio de aprendizagem, pois proporciona grande ajuda e permite ao aluno estudar e aprender mais (Moura, 2012: 329).

A tecnologia digital móvel e com acesso à rede permite múltiplas estratégias, que poderão reavivar o interesse dos alunos pelo que a escola lhes pode ensinar. Apesar dos debates sobre o uso de dispositivos móveis nas salas de aula, concordamos com Moura (2012) que refere que «esta metodologia é apropriada para aprender destrezas de resolução de problemas, facilitar a experimentação e a investigação» (p. 132).

Entre os dispositivos móveis que podem ser utilizados no ensino está então o telemóvel, que é considerada a tecnologia digital que teve a mais rápida expansão em toda a história da Humanidade, para além de ampla recetividade entre os jovens que, se inicialmente o usavam apenas para estar em contato com os seus amigos, acabaram por aprender a usá-lo também como uma ferramenta de aprendizagem (Moura, 2010).

Mas não só com o telemóvel como também com toda uma panóplia de outros dispositivos móveis, o aluno passa a aceder a quantidades imensuráveis de informação apenas com o toque de um dedo, quando quiser, sempre que quiser, onde quiser.

Tendo em conta, como já referimos, a relevância que estes dispositivos têm para os estudantes deste novo milénio, trata-se assim de capitalizar esse interesse em benefício da aprendizagem.

\subsubsection{Potencialidades do mobile learning}

Hoje em dia tem sido mais fácil a integração de diferentes tecnologias digitais móveis no ensino, uma vez que estes equipamentos se têm vindo a tornar, por um lado, mais leves e fáceis de transportar e, por outro, a sua tecnologia digital tem vindo a permitir atividades cada vez mais diversificadas. Para além disso,

hoje, as tecnologias móveis são comuns mesmo em áreas onde as escolas, os livros e os computadores são escassos. Como o preço da compra de smartphones con- 
tinua a diminuir, mais e mais pessoas, incluindo aquelas em áreas extremamente pobres, provavelmente possuem e sabem como usar um dispositivo móvel 54 (Vosloo, 2012: 3).

Com a proliferação destes dispositivos um pouco por todo o lado, verifica-se também que se tornaram hoje parte integrante da sociabilização dos jovens. Para além da necessidade de comunicarem uns com os outros através deles (sejam telemóveis, PDAs ou tablets),

o contágio tecnológico entre os adolescentes é quase inevitável. Se um jovem tem um determinado equipamento $\mathrm{Hi}$-Tec ou utiliza um determinado serviço na Internet, os outros jovens que com ele contactam sentem necessidade de ter ou fazer igual, tornando-se num consumismo espontâneo (Moura, 2009: 60).

Assim, e como refere Coutinho (2011), "mobilidade, portabilidade e omnipresença são as três principais características das tecnologias móveis que as tornam únicas para a promoção de uma aprendizagem eficaz e de qualidade" 55 (p. 181).

Para além desta quase omnipresença tecnológica, entre as vantagens associadas à utilização de tecnologias digitais móveis no ensino, encontramos, sobretudo, a opinião de que a sua utilização contribui para aumentar a motivação dos alunos (Garcia, Friedmann, 2011; Hutchinson et al., 2012; Sheppard, 2011).

Devaney reforça que é muito importante que a tecnologia digital, quando utilizada, tenha um impacto positivo pois se isso acontecer, muitos podem ser os benefícios alcançados:

- Melhorias na assiduidade e na disciplina;

- Ampla gama de recursos e experiências de aprendizagem;

54 Tradução nossa. No original: today mobile technologies are common even in areas where schools, books, and computers are scarce. As the price of mobile phone ownership continues to decline, more and more people, including those in extremely impoverished areas, are likely to own and know how to use a mobile device.

55 Tradução nossa. No original: mobility, portability and ubiquitousness are the three main features of mobile technologies that make them unique for the promotion of effective and quality learning. 
- Maior frequência e qualidade de interações individuais e coletivas de apoio;

- Melhorias nas atitudes dos alunos e dos pais em relação à escola;

- Aumento no desempenho dos alunos ${ }^{56}$ (2011: parag. 5).

Rosen (2011) referia também que a tecnologia também tem a ver com a motivação. A forma como vemos os jovens enquanto utilizadores quer dos equipamentos quer dos programas informáticos mais variados (como o Skype, o Facebook ou o Youtube), acessíveis 24 horas por dia, 7 dias por semana, profundamente motivados por todas as suas possibilidades, tem de ser colocada ao serviço da educação.

Importante, também, é a sua ligação com as ideias construtivistas e de fomento da aprendizagem pela descoberta o que se revela também uma motivação para o seu uso na aprendizagem:

Aprendizagem que costumava ser entregue "just-in-case", agora pode ser entregue "just-in-time, just enough and just-for-me". Encontrar informações em vez de possuí-las ou conhecê-las torna-se a característica definidora da aprendizagem em geral e da aprendizagem móvel, em particular, e isso pode levar a aprendizagem de volta à comunidade 57 (Traxler, 2009: 14).

Através do uso de tecnologias digitais móveis, os aprendentes já não precisam de esperar pelo momento em que a informação lhes é veiculada, eles poderão por si próprios procurar essa informação e decidir quando a querem receber e onde lhe querem aceder, assumindo desta forma muito maior controlo sobre aquilo que vão aprender (Camacho, 2012). Para além disso, podem aceder a materiais adicionais ou personalizados ou a partir da Internet ou dos professores ou mesmo da sua instituição (Ally, 2009).

56 Tradução nossa. No original: Improvements in attendance and discipline; Broader array of learning resources and experiences; Increased frequency and quality of supportive individual and group interactions; Improvements in student and parent attitudes toward the school; Increases in student achievement.

57 Tradução nossa. No original: Learning that used to be delivered "just-in-case," can now be delivered "just-in-time, just enough, and just-for-me". Finding information rather than possessing it or knowing it becomes the defining characteristic of learning generally and of mobile learning especially, and this may take learning back into the community. 
A utilização de dispositivos móveis na aprendizagem pode potenciar muito a aprendizagem, uma vez que estes equipamentos permitem aumentar a cognição humana e se

tais dispositivos servem para aumentar a aprendizagem humana (uma forma de atividade sócio-cognitiva), então a psicologia da história de informar como aprendemos e promover uma compreensão dos fatores que auxiliam as nossas interações com a tecnologia pode ser a chave para desvendar algumas das desafios mais importantes. Estes desafios surgirão da interação do ser humano com o meio ambiente, a tecnologia e as outras pessoas ${ }^{58}$ (Terras \& Ramsay, 2012: 823).

De facto, a utilização dos dispositivos móveis permite que o aluno encontre mais informação do que aquela que à partida o professor poderia fornecer, fazendo com que

se um aluno tiver uma pergunta, em vez de levantar a mão para perguntar ao professor, ele pode pesquisar no Google e encontrar a resposta por conta própria. Além disso, ele pode descobrir algo que o professor não sabia e levantar a mão e compartilhar esse novo conhecimento com o professor e o resto da turma ${ }^{59}$ (Nastu, 2011: parag. 60).

O facto de este tipo de dispositivos possibilitarem então uma aprendizagem ubíqua e extremamente pessoal (just-for-me) fomenta não só a aprendizagem pela descoberta, eventualmente até colaborativa, mas também facilita a sincronização entre o desenvolvimento individual e o contexto, promovendo

58 Tradução nossa. No original: such devices are to augment human learning (a form of socio-cognitive activity), then psychology with its established history of informing how we learn and promoting an understanding of the factors that assist our interactions with technology may hold the key to unlocking some of the most important challenges. These challenges will emerge from the interaction of the human with their environment, technology and other people.

59 Tradução nossa. No original: if a student has a question, instead of raising his hand to ask the teacher, he might Google it and find the answer on his own. What's more, he might find out something the teacher didn't know, and raise his hand and share this newfound knowledge with the teacher and the rest of the class. 
maior motivação, mais diálogo, interação e comunicação (Grant \& Barbour, 2013; Moura \& Carvalho, 2013).

Ozan e Kesim (2013) referem também a importância da utilização das tecnologias digitais móveis no ensino, associando-as a uma nova estrutura social, uma vez que proporcionam a interligação entre ambientes formais e informais de aprendizagem, e também entre plataformas individuais e sociais. Referem estes autores que "os media sociais criam uma atmosfera na qual os indivíduos podem aprender com seus colegas sobre normas e culturas de comunicação"60 (p. 174), contribuindo também para o desenvolvimento dos princípios conectivistas. Nesse sentido, apresentam uma representação que procura demonstrar como se pode criar um ambiente conectivista de aprendizagem móvel.

É ainda natural que, sendo as políticas e os regulamentos internos existentes, documentos preparados numa era pré-tecnologias digitais móveis, seja difícil sustentar, em cada escola, as potencialidades destas mesmas tecnologias digitais, sem embater nas restrições habituais, que previnem o seu uso em sala de aula.

Contudo, é muito importante, tal como quando falamos de qualquer outra tecnologia digital aplicada ao ensino, que seja uma estratégia pensada e criteriosamente organizada para que, de uma forma efetiva, contribua para uma aprendizagem eficaz. Como refere Moura (2012),

devemos evitar a tentação de usar a tecnologia pela tecnologia, porque saciado o momento de curiosidade e descoberta da ferramenta, se o conteúdo, a metodologia e a pedagogia não tornarem a atividade interessante e significativa para o aluno, de pouco adiantam os efeitos especiais. O essencial é que a tecnologia escolhida seja adequada aos conteúdos, ao público-alvo e às competências a serem trabalhadas (p. 145).

Nesse sentido, Moura e Carvalho (2013) referem que, para promover um correto enquadramento das tecnologias digitais nas experiências pedagógi-

60 Tradução nossa. No original: social media create an atmosphere in which individuals can learn from their peers about communication norms and cultures. 
cas, se pode recorrer à articulação de estratégias construtivistas e da Teoria da Atividade ${ }^{61}$, colocando o mobile learning no centro de um processo de articulação entre

o sujeito (o aluno) usando um artefacto móvel (ferramenta móvel), que juntos medeiam a ação de aprendizagem (atividade) e passam a mudar interativamente o objeto/motivo (integração de tecnologias móveis no processo de aprendizagem). A combinação pode facilitar o aprimoramento de habilidades anteriores integrando-os nos novos conhecimentos (aprendizagem). As estratégias de ensino (pedagogia) realizadas através de dispositivos móveis (mediação) facilitam a partilha de conhecimentos e envolvem os alunos na sua própria aprendizagem e melhoram o seu desempenho académico (aprendizagem) ${ }^{62}$ (p. 60-61).

Apesar de todas as vantagens reconhecidas, alguns autores apresentam ainda algumas preocupações no que toca à aplicação de atividades pedagógicas assentes em tecnologias digitais móveis. A primeira prende-se com o facto de que estes equipamentos não são, ainda, baratos, pelo que nem todos os alunos lhes poderão ter acesso (Devaney, 2011), a não ser que providenciados pelos próprios estabelecimentos de ensino (a maioria dos quais, provavelmente, dependerá de patrocínios para poder fazer um investimento tão avultado).

É também fundamental perceber que não se pode fazer o investimento sem primeiro formar os próprios educadores (Carvalho, 2011; Vosloo, 2012). Como já referimos, o uso das TDIC por si só não pode ter resultados verdadeiramente positivos, deve ser devidamente preparado tendo em conta diversos aspetos, para que se consiga retirar dela os melhores resultados.

${ }^{61} \mathrm{Na}$ sua tese de Doutoramento, Adelina Moura (2010) apresenta a evolução da Teoria da Aprendizagem, que caracteriza como um "quadro conceptual para estudar diferentes práticas humanas e desenhar ambientes de aprendizagem construtivistas" (p. 85).

62 Tradução nossa. No original: the subject (the student) using a mobile artefact (mobile tool), which together mediate the learning action (activity) and go on to interactively change the object/motive (integration of mobile technologies in the learning process). The combination can facilitate de improvement of previous skills on the internalization of new knowledge (learning). Teaching strategies (pedagogy) conducted through mobile devices (mediation) facilitate the sharing of knowledge and engage students in their own learning and improve their academic achievement (learning). 
Nesse sentido, a UNESCO apresentou algumas recomendações, visando o apoio ao trabalho desenvolvido pelos professores, para que não se caia no erro de usar a tecnologia digital para continuar a fazer as mesmas coisas:

- Priorizar o desenvolvimento profissional dos professores. O sucesso da aprendizagem móvel depende fundamentalmente da capacidade dos professores de maximizar as vantagens educacionais dos dispositivos móveis, minimizando suas desvantagens.

- Incentivar os centros de formação de professores a incorporar a aprendizagem móvel nos seus programas e currículos.

- Proporcionar oportunidades para os professores compartilharem estratégias para integrar efetivamente a tecnologia nas escolas com necessidades e populações estudantis similares ${ }^{63}$ (Vosloo, 2012: 8).

Há também ainda a preocupação com a falta de controlo que os professores poderão ter quando os estudantes podem trazer os seus equipamentos pessoais para o espaço da sala de aula. Traxler evidencia que um dos problemas se prende com o facto de que

esses dispositivos permitem que os alunos acedam e armazenem imagens e informações de sua própria escolha e, talvez, criem e distribuam novas imagens e informações independentemente dos palestrantes e da universidade ${ }^{64}$ (2010: 156).

Assim, se alguns autores veem a liberdade de escolha na aprendizagem, possibilitada pelo uso de uma dada tecnologia digital móvel, outros destacam

63 Tradução nossa. No original: Prioritise the professional development of teachers. The success of mobile learning hinges fundamentally on the ability of teachers to maximize the educational advantages of mobile devices, while minimizing their drawbacks. Encourage teacher training institutes to incorporate mobile learning into their programs and curriculum. Provide opportunities for teachers to share strategies for effectively integrating technology in schools with similar needs and student populations.

64 Tradução nossa. No original: these devices allow students to access and store images and information of their own choosing and perhaps create and distribute new images and information independently of the lecturers and of the university. 
a falta de controlo que poderá daí decorrer por parte dos professores e da própria instituição escolar.

Contudo, as potencialidades das tecnologias digitais móveis, parecem ultrapassar, em larga escala, os receios relativos à utilização das mesmas, os quais, na maioria, podem ser devidamente tratados e ultrapassados, como por exemplo através da negociação de responsabilidade com os alunos na utilização de dispositivos móveis na sala de aula. Terminamos, por isso, com uma frase de Naismith et al. (2004), que, em parte, sintetiza as potencialidades da aprendizagem através do mobile learning:

o desafio será descobrir como usar tecnologias móveis para transformar a aprendizagem numa parte contínua da vida quotidiana, a ponto de não ser reconhecido como aprendizagem ${ }^{65}$ (p. 5).

\subsection{Tablets na Educação}

A introdução de tablets no mercado veio provocar uma pequena revolução na forma como as pessoas em geral interagem com a tecnologia digital e, em particular, como esta pode ser aproveitada na educação.

De acordo com um estudo realizado nos Estados Unidos da América, em 2012, o número de estudantes com um tablet mais do que triplicou no espaço de um ano. Além disso, revelou que tanto estudantes como professores entendem que estes equipamentos são tão válidos tanto para o entretenimento como para a educação e que os alunos acreditam que este equipamento irá transformar a forma como aprendem (Pearson Foundation, 2012).

Com a velocidade de um deslizar de dedo, a interatividade proporcionada pelos tablets permite aos alunos encontrar um laboratório de ciências, uma recreação histórica, um estúdio de música, ou transportar-se virtualmente para uma biblioteca, um museu ou para qualquer canto do mundo.

65 Tradução nossa. No original: The challenge will be to discover how to use mobile technologies to transform learning into a seamless part of daily life to the point where it is not recognized as learning at all. 
Não nos surpreende, por isso, que cada vez mais estudos estejam a ser realizados, com o objetivo de identificar, claramente, de que forma podem estes equipamentos contribuir para melhorar a educação, e que sejam também cada vez mais as escolas que procuram integrá-los, em pleno, no seu quotidiano educativo.

Em Portugal, e integrado no projeto internacional Creative Classroom Labs, coordenado pela European Schoolnet e também através de outros projetos nacionais, várias escolas têm vindo a integrar este tipo de tecnologia digital móvel nas atividades letivas e não letivas. Neste espaço, vamos analisar as características que podem tornar estes equipamentos tão eficazes, enquanto hardware ao dispor das escolas, vantagens e aspetos a ter em conta para que o seu contributo possa ser, efetivamente, positivo, e vamos também dar conta dos projetos mais relevantes que têm vindo a ser colocados em prática no nosso país.

\subsubsection{Características e acessibilidade dos tablets}

Como refere Moura (2012), a entrada dos tablets no mercado veio preencher um espaço vazio existente entre os smartphones e os laptops, uma vez que "é possível levar um tablet para todo o lado como o telemóvel e realizar trabalho útil como num computador portátil" (p. 134), para além de que, "na educação, são encarados como adequados para fornecer informação na sala de aula e fáceis de usar, com uma curta curva de aprendizagem” (p. 134).

Entre as ferramentas móveis com uma crescente utilização no ensino encontram-se os iPads. Este equipamento, desde o seu lançamento em 2010, veio a reunir cada vez mais adeptos, sobretudo no setor educacional. Para além disso, a sua bateria é mais potente do que a da maioria dos laptops, muitas das suas aplicações estão preparadas para a visualização de diferentes tipos de conteúdos (como música, vídeos, revistas, jogos, e-books, entre tantos outros) e oferecem não só consumo mas interação e possibilidade de exploração, para não falar das suas caraterísticas físicas que possibilitam enorme portabilidade (EDUCAUSE, 2011). 
Algumas das características que consideramos mais importantes no uso das tecnologias digitais móveis em geral, e dos tablets em particular, são a possibilidade de intercalar entre texto, vídeo e som, que podem ser preparados tendo em conta diferentes níveis de aprendizagem. Facilita o acesso a toda uma panóplia de novos conteúdos educativos que estão a começar a aparecer cada vez mais e de forma gratuita na Internet.

A versatilidade destes equipamentos permite uma certa personalização da educação, o que cada vez mais se começa a ver acontecer entre os estudantes que, como referimos já no subcapítulo anterior, querem os conteúdos just-in-time e just-for-me. As experiências que agora têm estes estudantes, ao buscarem exatamente os conteúdos de que necessitam,

mudou as suas expectativas gerais para a sua educação, e não apenas para o uso da tecnologia. Dois terços dos alunos disseram-nos nas pesquisas Speak Up deste ano que definem o sucesso escolar pela realização dos seus próprios objetivos pessoais de aprendizagem, superando as marcas tradicionais de sucesso, como honras escolares ou prémios (45\%) ou até o orgulho dos pais (55\%) ${ }^{66}$ (Project Tomorrow, 2012: parag. 2).

Num dos diversos estudos que desde 2010 têm vindo a ser realizados sobre o impacto dos iPad na educação (Ireland \& Woollerton, 2010: 38), são apresentados cinco motivos para se considerar que este equipamento poderá revolucionar a sala de aula de uma forma distinta dos outros laptops:

1 - preço;

2 - portabilidade e peso;

3 - uso mais intuitivo;

4 - aplicações variadas, muitas delas gratuitas e de aprendizagem bastante simples;

5 - touch screen que permite uma melhor manipulação do equipamento.

66 Tradução nossa. No original: has changed their overall expectations for their education, and not just for the use of technology. Two-thirds of students told us in this year's Speak Up surveys that they define school success by the achievement of their own personal learning goals, far exceeding traditional marks of success such as school honors or awards (45\%) or even parent pride (55\%). 
Conjugam-se então algumas das melhores características de um equipamento tecnológico potenciando, cada vez mais, a sua utilização no ensino: por um lado, a sua portabilidade e acessibilidade fazem com que o ensino móvel seja possível em qualquer local, dependendo apenas de uma bateria e do acesso à internet (Melhuish \& Falloon, 2010) e, por outro lado, oferecem uma nova forma de interagir com os conteúdos, pois estes equipamentos levam-nos e desenvolver toda uma nova forma de pensar (Alberta Education, 2011).

\subsubsection{Vantagens e recomendações na utilização de tablets no ensino}

Instrumentos absolutamente atrativos para os alunos de hoje, tudo o que se relaciona com tecnologias digitais, móveis ou não, suscita, à partida, curiosidade e maior motivação quando apresentado em contexto de sala de aula.

Apesar de estes equipamentos estarem no mercado e, sobretudo, a preços mais acessíveis, há menos de 10 anos, já são vários os estudos sobre escolas que optaram pela sua utilização. São projetos desenvolvidos em diferentes países (com preponderância para os realizados nos Estados Unidos, mas também Reino Unido, Alemanha e Austrália, entre outros), normalmente através de projetos de financiamento, que permitem equipar escolas com vários tablets ou mesmo possibilitando que cada aluno tenha o seu próprio dispositivo móvel (como foi o caso da Longfield Academy, em Kent, Reino Unido ${ }^{67}$ ).

Em Portugal, a partir de diferentes projetos da Fundação Calouste Gulbenkian, de apoio a Bibliotecas Escolares/Centros de Recursos de agrupamentos de escolas, e às próprias escolas, desenvolvidos desde 2012, várias escolas introduziram estes equipamentos nas suas bibliotecas, sendo os mesmos utilizados também em salas de aula, sobretudo no apoio ao desenvolvimento da leitura e da escrita. São disso exemplo o Agrupamento de Escolas de Campo Maior, o Agrupamento de Escolas Padre Benjamim Salgado (Vila nova de Famalicão) e a Escola Secundária José Régio (Vila do Conde).

67 http://www.e-learningfoundation.com/Websites/elearningfoundation/images/PDF\%20 Documents/Longfield-The_iPad_as_a_Tool_for_Education.pdf (acessível em 03/03/2014) 
No blog da escola de Campo Maior ${ }^{68}$ referem-se as vantagens reconhecidas com a utilização de iPads nas aulas de português (mas também há referências de que são utilizados noutras disciplinas), indicando-se que "o iPad já traz a mistura preparada. Doseia o texto escrito com sons e imagens, tornando a experiência de ler mais apelativa”.

No blog da Biblioteca do Agrupamento de Escolas Padre Benjamim Salgado $^{69}$ relatam-se as explorações efetuadas no âmbito do projeto Ciência em Linha, apoiado pela Rede de Bibliotecas Escolares e da candidatura Ideias com mérito 2012, não só na biblioteca como também nas aulas de Geografia, de Filosofia e de Português. As responsáveis pela Biblioteca Escolar indicam que

o objetivo fundamental deste projeto é a promoção da leitura e das literacias de informação, apoiada na utilização de dispositivos digitais. Pretendemos provocar não só uma mudança tecnológica, mas também metodológica, nas práticas de leitura e no trabalho de sala de aula, partindo da incorporação de um novo dispositivo digital - o $i \mathrm{Pad}^{70}$.

A biblioteca da Escola José Régio ${ }^{71}$ tem também vindo a dinamizar diversas iniciativas, sobretudo no campo da leitura, nomeadamente, levando os alunos a ler diferentes histórias em formato ebook, e também a construir novas histórias a partir dessas leituras ${ }^{72}$. As Bibliotecas Escolares dos Concelhos de Sintra, Cascais, Oeiras e Amadora também já adquiriram vários iPads que, referem no seu blog ${ }^{73}$, rivaliza com os e-readers já existentes no

68 http://biblioteca-escm.blogspot.pt e também http://bemaior.files.wordpress. com/2011/09/resumo_leituras-luminosas.pdf (acessível em 03/03/2014).

$69 \mathrm{http}: / /$ w.espbs.net/index.php?option=com_content\&view=category\&id=36 (acessível em 03/03/2014).

70 http://cienciaemlinha.blogspot.pt/ (acessível em 03/03/2014).

$71 \mathrm{http}$ ///biblioteca.esc-joseregio.pt/?tag=ipad (acessível em 03/03/2014).

72 É reportado, no blog da biblioteca, que uma turma do ensino secundário trabalhou em ambiente aula a versão de Paul Robinson, da tradicional história do Capuchinho Vermelho, a partir do ebook Akaneiro e que os alunos terão criado uma nova versão, também em ebook (http://biblioteca.esc-joseregio.pt/?p=1569, acessível em 14/06/2014).

73 http://linhadeleitura.wordpress.com/2010/12/17/o-triunfo-do-ipad-na-biblioteca/ (acessível em 03/03/2014). 
espaço. As Bibliotecas dos Agrupamentos de Escolas Galopim de Carvalho e Padre Alberto Neto juntaram-se num projeto inovador que procura que alunos e professores trabalhem conteúdos curriculares e produzam novos recursos digitais com o apoio de $i P a d s$, de forma a "promover não só a leitura e a utilização da informação mas também a produção de recursos de disseminação" (Mendinhos, 2012: 1).

O projeto internacional que identificámos no início deste Capítulo, Creative Classroom $\operatorname{Labs}^{74}$, teve início no final de 2013, sob coordenação da European Schoolnet, e conta com a participação de Ministérios da Educação de nove países diferentes (Áustria, Bélgica - comunidades francesa e flamenga -, Eslováquia, Itália, Lituânia, Portugal, Reino Unido e República Checa), para além de parceiros associados que são cinco grandes fornecedores de material informático (Acer, Microsoft, Texas Instruments, Samsung e SMART).

Este projeto pretende

proporcionar um conjunto de experiências a nível pan-europeu envolvendo 45 turmas em nove países sobre o uso de tablets em ambiente escolar com o objetivo de informar e ajudar a orientar o desenvolvimento de políticas relacionadas com a implementação de abordagens pedagógicas 1:1 [e] permitirá aos Ministérios da Educação enfrentar de forma comum desafios relacionados com a rápida introdução de tecnologias tablet $^{75}$.

Em 2014 o projeto entrou na fase 2, etapa em que foram testados cenários pedagógicos nas escolas que foram associadas ao projeto. No caso português integram o projeto o Agrupamento de Escolas de Freixo, o Colégio Monte Flor (Carnaxide), a Escola Secundária Quinta do Marquês (Oeiras) e o Agrupamento de Escolas Monte da Lua (Sintra).

Para além disso, encontra-se também em desenvolvimento um Projeto-piloto da autoria da Direção Geral de Estabelecimentos Escolares - Direção de Serviços Região Alentejo, iniciado em setembro de 2013, em prática no Agrupamento de Escolas de Cuba com alunos de uma turma do 7..$^{\circ}$ ano, que

\footnotetext{
74 Veja-se o site do projeto em http://creative.dge.mec.pt/ (acessível em 20/03/2014).

75 http://creative.dge.mec.pt/apresentacao/breve-resumo/ (acessível em 22/03/2014).
} 
passaram a ter os manuais escolares em versão para tablets. Este projeto conta com o apoio da "Porto Editora com os livros digitais, [d]a Fujitsu com os aparelhos e [d]a Universidade Católica como instituição que vai monitorizar e avaliar a experiência [e que] permitiram dar gás ao projecto"76 que tem como objetivos:

1. Adaptar o processo ensino-aprendizagem às características individuais de cada aluno;

2. Utilizar tecnologias e metodologias avançadas de ensino, visando proporcionar aos alunos uma maior e melhor aprendizagem;

3. Tornar o processo de ensino/aprendizagem mais interativo e dinâmico;

4. Formar alunos mais competentes, técnica e cientificamente;

5. Introduzir uma dimensão dinâmica e interativa no manual;

6. Contribuir para um repensar do mercado das Editoras em Portugal numa dimensão mais competitiva e fértil em conteúdos;

7. Perspetivar uma redução de custos dos encarregados de educação com os manuais escolares;

8. Melhorar a interação professor/aluno;

9. Desmaterializar dimensões do processo ensino-aprendizagem;

10. Reduzir o peso a transportar pelo aluno para a escola;

11. Não depender de uma ligação à internet;

12. Tornar o manual escolar facilmente atualizável e corrigível.

Cada vez mais as editoras escolares têm apostado na dinamização de plataformas de apresentação de manuais digitais e de recursos variados, tal como o projeto 20AulaDigital, que

é uma plataforma desenhada para as necessidades pedagógicas específicas de cada escola, na qual é possível partilhar conteúdos pedagógicos e promover a comunicação entre professores, alunos e pais. O 20AulaDigital permite experiências de aprendizagem únicas, com vídeos, animações, gráficos, testes interativos, jogos,..${ }^{77}$.

76 http://www.ionline.pt/artigos/portugal/revolucao-cuba-escola-alentejo-trocou-livrostablets (acessível em 20/06/2014).

77 http://www.cjp.com.pt/projetos/20-escola-digital (acessível em 20/06/2014). 
Uma das grandes vantagens que é várias vezes referida quando falamos da utilização de equipamentos móveis como os tablets no ensino, é a personalização da aprendizagem que estes aparelhos oferecem aos seus utilizadores (Alberta Education, 2011; Ireland \& Woollerton, 2010; Melhuish \& Falloon, 2010; Moura, 2012), uma vez que "um indivíduo pode adaptar os seus aplicativos de acordo com as suas metas e propósitos específicos, da mesma forma que um professor pode fazer para atender às necessidades de aprendizagem de um aluno"78 (Melhuish \& Falloon, 2010: 11), mas permite que cada aluno esteja a desenvolver as tarefas que lhe interessam naquele momento, em sala de aula, transformando o professor apenas num "facilitador" do conhecimento, alguém que gere todas as atividades que toda uma turma poderá estar a desenvolver ao mesmo tempo.

A este propósito foi já referida a relevância dos conceitos just-in-time e just-for-me, possíveis com este tipo de aparelhos, os quais fomentam "um modelo educativo que promove a mudança de uma aula centrada no docente para uma aprendizagem centrada no aluno, mais prática, ativa e personalizada" (Moura, 2012: 132). Moura acrescenta, sobre os tablets em particular, que "quando usado em todo o seu potencial educativo pode ser considerado um estúdio pessoal de aprendizagem" (Personal Learning Studio, 2012: 133).

De acordo com um estudo realizado pelo Departamento de Educação de Alberta (Austrália) em escolas onde se utilizam já iPads, as vantagens identificadas acompanham as ideias que atrás reproduzimos:

- O acesso contínuo ao trabalho dos alunos e de outros, melhorando a escolha do aluno de onde e quando trabalhar;

- Estudante na posse da sua aprendizagem;

- Envolvimento do aluno na seleção de aplicativos ${ }^{79}$ (Alberta Education, 2011: 17)

78 Tradução nossa. No original: an individual can tailor their applications to suit their specific goals and purposes, in the same way that a teacher could do to meet the learning needs of a student.

79 Tradução nossa. No original: - Continual access to students work and that of others, enhancing student choice of where and when to work; Student ownership of their learning; Student involvement in selection of apps. 
Mas há ainda um outro pormenor que, julgamos, torna ainda mais relevante este caráter individualizador de como e quando se aprende: é o facto de que cada aluno pode controlar todo o processo de aprendizagem sem o estigma das dificuldades que pode ter nesse processo, ou seja,

Se os alunos não entenderem a matéria pela primeira vez, eles poderão assistir repetidamente até que a aprendam, disse John Sipe, gerente nacional de vendas de varejo da Houghton Mifflin Harcourt, em San Diego. "Eles podem assistir ao vídeo 15 vezes, e ninguém precisa saber, e isso tira o estigma de não conseguir", disse ele. "Este é um movimento em direção a uma instrução personalizada e individualizada para que os alunos tenham mais domínio sobre a sua aprendizagem"80 (eSchool News, 2011: online $\left.^{81}\right)$.

Vários autores referiram já que o efeito de novidade das TDIC, que tendencialmente propicia maior entusiasmo por parte dos alunos, e que quando esmorece perde os seus efeitos positivos. A esse propósito refere Harmon que a sensação de controlo da aprendizagem que este equipamento propicia o torna verdadeiramente especial (2011).

A interatividade proporcionada pelo uso do tablet terá também um impacto no aumento do envolvimento dos alunos no ensino pois

um fator importante que influencia o engajamento fornecido pela tecnologia móvel é que o feedback é dado em tempo real. O feedback direto em tempo real para as ações de um aluno reduz o nível de distração, pois permite que ele flua facilmente para a próxima tarefa, em vez de ficar ocioso na aula, aguardando feedback antes de prosseguir82 (Henderson \& Yeow, 2012: 79).

80 Tradução nossa. No original: If students don't understand the lesson the first time, they can watch it repeatedly until they've learned it, said John Sipe, national retail sales manager for Houghton Mifflin Harcourt in San Diego.

"They could watch the video 15 times, and no one has to know, and it takes away the stigma of not getting it," he said. "This is a move toward personalized and individualized instruction so the students take more of a role in their learning".

81 http://www.eschoolnews.com/2011/05/09/schools-see-rising-scores-with-ipads/3/ (acessível em 03/04/2014).

82 Tradução nossa. No original: an important factor which influences engagement that is provided by mobile technology is that feedback is given in real time. Direct real-time 
Em geral, os tablets parecem ser considerados, tanto por alunos como por educadores, aparelhos confiáveis e funcionais e que permitem o desenvolvimento de ambientes de aprendizagem atrativos e contribuem para a aprendizagem pela descoberta:

tais dispositivos não podem ser descartados como meros brinquedos ou distrações e, embora tragam questões técnicas e administrativas, são superados em muito pelo aumento da motivação, do progresso e da colaboração entre os alunos. Os estudantes que os usam regularmente indicam que os seus iPads se tornaram uma ferramenta indispensável, facilitando a pesquisa, a comunicação com os professores e, como na arte, economizando um tempo considerável, permitindo uma maior realização ${ }^{83}$ (NAACE, 2012: 50).

Este aumento do engajamento (ou do engagement) é estimulado pela capacidade que a maior parte das aplicações do iPad têm de interagir e interligar-se umas com as outras. Por exemplo,

alguns aplicativos, como o History: Maps of the World, exploram os recursos do iPad para suportar vários estilos de aprendizagem, convidando os utilizadores a combinar música e arte no touchscreen com a hora e a localização geográfica apropriadas, apresentando dados visuais, auditivos e cinestésicos. Ao mesmo tempo, o interface tátil do iPad e a abordagem amigável aos media introduzem um elemento de diversão na experiência de aprendizagem ${ }^{84}$ (EDUCAUSE, 2011: 2).

feedback to a student's actions reduces the level of distraction, since it allows them to seamlessly flow on to the next task at hand, rather than idling in class, waiting for feedback before moving on.

83 Tradução nossa. No original: such devices cannot be dismissed as mere toys or distractions and while they bring with them technical and management issues, these are far outweighed by increased student motivation, progress and collaboration. Students using them regularly indicate that their iPads have become an indispensible tool, facilitating research, communication with teachers and, as in art, saving considerable time so enabling greater achievement.

84 Tradução nossa. No original: some applications, like History: Maps of the World, exploit the iPad's capabilities to support multiple learning styles, inviting users to match music and artwork on the touchscreen with the appropriate time and geographic location, thus presenting data that is visual, auditory, and kinaesthetic. At the same time, the iPad's tactile interface and media-friendly approach introduce an element of fun into the learning experience. 
Também numa iniciativa desenvolvida no Reino Unido, Tablets for Schools, e que procura equipar as escolas com tablets, criando novas dinâmicas de ensino e aprendizagem, os primeiros resultados refletem já algumas vantagens, nomeadamente ao nível do engagement. Neste ponto, referem que os alunos apreciam a variedade de metodologias de aprendizagem e, sobretudo, na produção dos seus próprios trabalhos:

os alunos que anteriormente se esforçavam para se expressar por escrito gostam de ter métodos alternativos de articular sua aprendizagem, como filmar, produzir uma apresentação, uma animação ou um mapa mental ${ }^{85}$ (Clarke, Svanaes \& Zimmermann, 2013: 48).

Esta relação que os alunos podem estabelecer com os seus tablets, e em particular com as variadas aplicações do $i P a d$, fomenta uma maior motivação para o estudo porque, como referimos, torna a aprendizagem mais pessoal e interativa, mas também propicia essa motivação porque promove o desenvolvimento da criatividade e torna os alunos ativos participantes no processo de aprendizagem. Assim, na utilização de dispositivos móveis como estratégias educativas, é importante que os alunos sejam colocados frente a desafios e obstáculos que eles possam ultrapassar através do uso da sua criatividade e de diferentes domínios cognitivos, para que se encoraje a aprendizagem através da descoberta e da construção individual do seu conhecimento (Bottentuit Junior, 2012).

Promovendo o trabalho individual do aluno na busca do conhecimento, este equipamento poderá contribuir para o desenvolvimento do espírito crítico, da capacidade de resolver problemas e de reagir perante diferentes situações, para além de aumentar (neste caso tal como qualquer outro equipamento com ligação wifi) o acesso ao conhecimento.

Articulam-se estas questões com a corrente pedagógica construtivista, onde os alunos conduzem a aprendizagem e, como referimos atrás, os professores

85 Tradução nossa. No original: pupils who have previously struggled to express themselves in writing enjoy having alternative methods of articulating their learning, such as filming themselves, producing a presentation, an animation or a mind map. 
procuram ajudá-los a caminhar na direção certa. Desta questão dão também conta Melhuish \& Falloon (2010), referindo que

enquanto o iPad oferece aplicativos de utilidade e produtividade (por exemplo, verificação de tempo ou $i$ Works), os desenvolvedores de aplicativos do iPad que trabalham em áreas educacionais têm maior probabilidade de aproveitar aplicativos mais imersivos. [...] Isso poderia proporcionar aplicações de resolução de problemas mais autênticas e complexas, idealmente adequadas para experiências de aprendizagem de tipo construtivista 86 (p. 7-8).

De facto, muitas das aplicações do iPad transformam-no num equipamento que serve não apenas para consumo mas também para produção de novos conteúdos, num processo construtivo de aplicação dos conhecimentos que vão sendo recolhidos (Ireland \& Woollerton, 2010). Moura (2012) refere, a propósito, que

as aplicações que podem ser descarregadas para os dispositivos móveis estão a expandir a experiência de aprendizagem tanto dentro, como fora da sala de aula. Desde aulas interativas e materiais de estudo, até ferramentas de produtividade, as aplicações apresentam grandes potencialidades (p. 135).

Com tão variado acesso e possibilidade de trabalho, torna-se óbvio o aumento na produtividade tanto dentro como fora da sala de aula. Norris e Soloway (2013) explicam que mesmo parecendo só uma quantidade de gadgets, a boa tecnologia acaba por ser uma excelente oportunidade para colocar as pessoas a fazer coisas que antigamente nunca seriam concretizáveis. Por isso, mesmo que não existam ainda muitos estudos que comprovem que a utilização de iPads está diretamente relacionada com a melhoria dos resultados

86 Tradução nossa. No original: while the iPad offers both utility and productivity applications (for example, weather checking and iWorks), iPad apps developers working in educational fields are most likely to leverage more immersive applications. [...] This could lend itself to more authentic and complex problem solving applications, ideally suited to constructivist-referred learning experiences. 
obtidos pelos alunos em avaliações ${ }^{87}$, é possível determinar que o iPad é visto como uma ferramenta para aumentar a produtividade, tornando as coisas mais acessíveis e simples (Henderson \& Yeow, 2012).

Harmon (2011) elaborou um estudo onde comparou os resultados obtidos em exames por alunos da Euclid City School (Estado do Ohio), que tiveram acesso a iPads durante o ano letivo que antecede a realização desses exames, com os resultados de alunos da mesma escola que não tiveram acesso a este equipamento e verificou que o grupo dos alunos com acesso a iPads obteve uma taxa de aprovação mais elevada.

Aplicações variadas, usabilidade, acessibilidade e portabilidade são algumas características que tornam agradável a utilização de iPads nas salas de aula e produzem um reflexo positivo tanto na aprendizagem como no ensino. O Relatório do projeto que atrás referimos, Tablets for Schools, apelida os tablets de "caixas de ferramentas pedagógicas portátil" (Clarke, Svanaes \& Zimmermann, 2013: 43).

Também assim se justifica que tenhamos encontrado, num relatório sobre a utilização de iPads no Trinity's College, um comentário de um aluno que entendemos ser digno de aqui ser referido:

Sinto-me muito sortudo por ter uma oportunidade tão rara de estudar de uma forma totalmente nova com o iPad e sinto-me comovido com esta surpreendente peça de alta tecnologia. Se for possível, eu gostaria de mantê-lo comigo e gostaria também de o recomendar à minha mãe porque o iPad também é muito útil na nossa vida diária. Por último, estou ansioso para que este projeto seja bem desenvolvido no futuro 88 (Jennings et al., 2011: 4).

87 Pode consultar-se, a propósito, o estudo "Unlocking litteracy with iPad", realizado por Harmon em 2011.

(http://www.throughstudentseyes.org/ipads/unlocking_literacy_with_ipad/ipads_files/ unlocking_literacy_ipad.pdf), onde o autor compara os resultados obtidos em exames por alunos que tiveram ou não acesso a iPads.

88 Tradução nossa. No original: I feel very lucky to have such a rare chance studying in a brand new way with the iPad and I'm moved by this surprising piece of new hightech. If it is possible I really want to keep it with me and I would like to recommend to my mum cause iPad is also very helpful in our daily life. Finally, I'm looking forward that this project will be well developed in the future. 
Contudo, se as correntes favoráveis às vantagens da introdução de tablets no ensino parecem estar em franca maioria, há também aqueles que colocam algumas reservas. De acordo com o Observatório de Recursos Educativos,

a vaga de otimismo algo incontrolado que até agora girava em torno destes recursos educativos começa, efetivamente, a conhecer as primeiras reservas - as quais, acrescente-se, em nada sugerem que se descure a sua mobilização em contexto de sala de aula mas que precisamente se ponderem, com racionalidade e prudência, os modos da sua utilização (2014: 5).

Neste mesmo trabalho destacam-se diferentes estudos cujos resultados apontam para a redução de rendimento em termos cognitivos, a diminuição da concentração e, consequentemente, a compreensão do que está a ser exposto na sala de aula e que quando se leem textos no computador se consegue perceber menos o seu significado do que quando estamos a ler um documento em papel (Observatório de Recursos Educativos, 2014).

Mesmo assim, é importante não esquecer algo que atrás já referimos: quando ao aluno é dada liberdade para traçar a forma como vai desenvolver a sua aprendizagem, o professor deve sempre procurar ser um guia nesse processo.

Outra questão a ter também em conta diz respeito à apresentação da informação, que agora pode chegar de forma absolutamente truncada às "mãos" dos nossos estudantes. Traxler (2010) refere a esse propósito que

nas suas formas mais antigas, o conhecimento e a aprendizagem vinham de palestras, um formato linear de um autoritário "sábio-no-palco" sem pausas, avanços rápidos ou retrocessos, e de livros, substanciais e lineares, mas segmentados e acedidos aleatoriamente. A entrega de conhecimento e aprendizagem por computadores em rede significou uma quebra da linearidade com a introdução de hiperlinks e de novas heurísticas de usabilidade que prescreviam como o conhecimento e a aprendizagem deveriam ser fragmentados e $\operatorname{apresentados}^{89}$ (p. 8).

89 Tradução nossa. No original: in its earliest forms, knowledge and learning came from lectures, a linear format from an authoritative 'sage-on-the-stage' with no pause, fast 
Contudo, se se procurar, enquanto educador, aferir se cada aluno traça o melhor percurso para a sua aprendizagem, as vantagens superam, de certo, as reservas que podem ser apontadas e que, na verdade, podem existir em qualquer processo de aprendizagem.

Um dos participantes do estudo realizado pela Alberta Education referia que os iPads não são nem computadores portáteis nem de secretária e que nos levam a adotar novas formas de pensamento (2011: 4). É este, no nosso entender, um dos importantes pontos a reter: a dinâmica das aplicações destes equipamentos é diferente e extremamente adaptável aos interesses do seu utilizador, porque está preparado para ser, como referimos já, just-for-me.

Infelizmente, não existem ainda muitos estudos realizados com base em trabalhos com iPad na área das ciências sociais. Um dos poucos exemplos encontrados, efetuado numa escola secundária nos EUA, vem reforçar as vantagens do iPad no desenvolvimento de trabalho colaborativo e interativo, sobretudo devido à possibilidade de usar fontes primárias nas aulas (Garcia, Friedmann, 2011).

Também estes autores reforçam a utilidade da utilização de $i P a d s$ nas aulas de História, que consideram não só benéfico para o desenvolvimento do espírito crítico e da capacidade de resolução de problemas, mas também ajuda a incorporar na educação o desenvolvimento das competências para o século 21 (Garcia, Friedmann, 2011).

O estudo realizado abrangeu conteúdos relacionados com os acontecimentos de 11 de setembro de 2001 e dois grupos de alunos: um grupo de 49 alunos que trabalhou com iPads e outro grupo composto por 25 estudantes que estudaram a mesma matéria através dos métodos tradicionais. Nos testes realizados com os dois grupos os melhores resultados foram os dos que utilizaram tecnologia digital, para além de que os textos produzidos por este grupo eram um pouco mais detalhados. Por isso, e de acordo com os autores, um dos outcomes mais importantes que extraíram dos resultados dos testes finais foi que

forward, or rewind, and from books, substantial and linear, but segmented and randomly accessed. The delivery of knowledge and learning by networked computers meant a break from linearity with the introduction of hyperlinks and new heuristics of usability that prescribed how knowledge and learning should be chunked and presented. 
a capacidade de análise da documentação apresentada aos alunos, contribuiu para a produção de textos de maior qualidade (Garcia, Friedmann, 2011).

Garcia e Friedmann reconhecem assim a importância que podem assumir nas aulas de História aplicações que agregam fontes primárias, algo importante para o trabalho nesta disciplina e que pode ver-se dificultado quando o acesso é feito diretamente através das inúmeras páginas da World Wide Web. Para além disso, apontam também o formato interativo dos iPads como uma vantagem na promoção da motivação entre os estudantes. Assim, defendem que o seu trabalho, ainda que com algumas limitações, demonstrou que o sucesso dos alunos foi bastante potenciado pela presença, durante estas aulas, de uma aplicação interativa (Explore 9/11) como a usada no iPad. 
(Página deixada propositadamente em branco) 


\section{COMPLEXIDADE EM HISTÓRIA}

Muitos autores têm procurado explicar de que forma a especificidade desta disciplina justifica maior dificuldade na sua compreensão por parte dos alunos e também têm realizado diversos estudos com vista a aferir se existe ou não uma idade ideal para a compreensão de determinados conceitos históricos, como pretendemos descrever em seguida.

É por isso que pretendemos perceber porque será a História uma disciplina complexa. Quais as suas especificidades e o que é que a torna diferente de outras como a Matemática, a Física ou a Biologia? Conscientes de que não existe uma única explicação, é nosso desejo deixar os fatores que achamos fundamentais para percebermos a especificidade da História como ciência e as suas consequências para a História didática.

Quantas vezes ouvimos e lemos a pergunta "o que é a História?". Será que alguma vez sentimos verdadeiramente ter encontrado a resposta a esta questão? Como Griffin cita no seu artigo na World Book Encyclopedia (1963), todos pensamos saber exatamente o que é a História mas quando a tentamos definir apercebemo-nos da dificuldade que há em o fazer.

Se pensarmos apenas no vocábulo, numa qualquer língua românica, encontramos um problema que, a priori, parece apenas linguístico, mas que outras dificuldades poderá acarretar. Como refere o historiador Jacques le Goff (1982), nas línguas latinas a palavra "História" exprime conceitos diferentes:

significa: 1) a pesquisa das "acções realizadas pelos homens" (Heródoto), que se esforçou por se constituir em ciência, a ciência histórica; 2) o objecto da pesquisa, aquilo que os homens realizaram. [...] Mas a história pode ainda ter um terceiro sentido, o de narração (p. 20-21). 
Muitas vezes é esta mesma falta de distinção entre o que é a História-ciência e o que é a História-ação que torna mais difícil definir com exatidão aquilo que propomos tratar, uma vez que sobrepõe os sentidos objetivo e subjetivo da História (Limón, 2002). Pode parecer uma questão menor mas, na verdade, pensando nós como professores, de que forma levamos os nossos alunos a perceber corretamente a importância e o valor daquilo que aprendem nas aulas de História? É importante que eles entendam a diferença entre um facto ou o que, em português, podemos referir como uma "estória" ou ainda, como referia Marc Bloch, percebam, verdadeiramente, que é "a ciência que estuda os homens no tempo".

Dado que a análise sobre o significado da História foi sendo alvo de diversos estudos ao longo de muitos séculos, destacamos aqui os trabalhos de Olga Magalhães ${ }^{90}$, onde é abordada a evolução da ideia de História a partir do século XIX (como refere a autora, "considerou-se, de acordo com a generalidade da literatura, que foi no século XIX que a disciplina se autonomizou enquanto conhecimento específico e se afirmou enquanto disciplina universitária”, p. 221), desde as ideias de Von Ranke, Comte, Marx, Weber, passando pela Escola dos Annales e terminando com uma reflexão sobre as abordagens mais recentes de Popper, Foulcault, White e Dray. Também sobre o tema se debruçou Fernando Catroga, parecendo-nos pertinente destacar aqui um dos seus trabalhos mais recentes, Os passos do homem como restolbo do tempo: memória e fim do fim da história (2009), onde o autor descreve algumas das formas como se tem vindo a representar o passado, a memória, a narrativa histórica, no fundo, de que forma a filosofia da História foi definindo a maneira como o Homem, "compensando a incapacidade de saber o que é o tempo, [...] enreda o seu fio invisível para, debalde, o apanhar" (Catroga, 2009: 7). Explorando as diferentes perspetivas face à construção do conhecimento histórico, Catroga indica que

a joeira do sujeito, com todas as suas pré-ocupações (epistemológicas, culturais, sociais, psicanalíticas, linguísticas), faz com que a historiografia seja um trabalho sempre em aberto, tanto mais que a sua capacidade de dar translucidez ao pas-

90 Concepções de História e de Ensino de História. Um estudo no Alentejo, 2002. 
sado a partir de traços - que se revelam, também se escondem - nunca conseguirá captar aquilo que, no outro e no diferente, sempre escapará à perscrutação do presente-futuro (Catroga, 2009: 131).

Apesar das divergências sobre qual será a melhor definição de História optamos por transmitir aqui as palavras de um dos mais relevantes historiadores que conhecemos. Bloch, ainda que consciente da dificuldade de o fazer da forma menos redutora, apresentava a definição de História, que já referimos, ou seja, a "ciência dos homens no tempo" (1993 [1949]: 29), demonstrando a importância de se abarcar a diversidade humana, do coletivo e, é claro, da duração.

Uma das primeiras coisas que se deve ter em conta quando se aprende História é que é necessário desenvolver a capacidade de "compreender o presente através do passado" e de "compreender o passado através do presente" (como referia Bloch), uma vez que tudo está interrelacionado. Contudo, é importante também não perder a objetividade quando se procura essa relação entre o passado e o presente. Por outras palavras, e retomando o que atrás referíamos, ao estudar História temos de formular questões que vão, precisamente, levar-nos à compreensão tanto do nosso passado como do nosso presente. Essa objetividade torna-se fundamental sobretudo por essa interação passado/presente, tendo em conta que estamos no presente e, logicamente, somos (ou fomos) afetados pelo nosso passado.

Ao aluno cabe assim entender que quando foca o seu estudo na disciplina "História", ele estará a fazer mais do que a fixar datas e batalhas infindas mas terá que ser capaz de perceber a ligação que existe entre o "seu" mundo presente e um passado longínquo que, a priori, parece nada lhe dizer. Quando este objetivo é plenamente atingido, normalmente, o mistério da História tem tendência a tornar-se mais claro.

Para além do que já referimos, outra problemática relacionada com a aprendizagem da História remete, como lembra Magalhães (2002), para a necessidade de os alunos dominarem

diferentes níveis de conhecimento, que, sendo específicos da História, utilizam frequentemente palavras do dia a dia, constitui também um desafio que tem de ser 
vencido para que a aprendizagem ultrapasse o domínio do senso comum e possa constituir, de facto, aquisição de novos conhecimentos e competências históricas (p. 74).

Cabe aos alunos perceber os vários sentidos que uma dada expressão pode ter e, mais ainda, que pode ter tido no passado, para além de serem capazes de identificar em algum desse vocabulário eventuais juízos de valor ou significados alternativos que possa ter.

Magalhães continua referindo que outro problema se pode encontrar na questão do tempo: os alunos irão receber uma quantidade de informação que se encontra balizada no tempo mas não podem deixar de lado a explicação de cada um desses mesmos acontecimentos. Para cada uma das informações que lhes forem sendo dadas têm de saber fazer um exame crítico e procurar a sua devida explicação.

O que pretendemos aqui argumentar é que, ao contrário do que pode acontecer na Matemática ou na Física, quando se pretende ensinar História está-se a tentar ensinar sobre uma matéria sobre a qual nem sequer é consensual exatamente o que é que se está a ensinar. É cronologia? São factos?

Desta forma, apesar de o programa da disciplina (para o Terceiro Ciclo do Ensino Básico) referir que uma das finalidades do ensino de História é

proporcionar o alargamento do horizonte cultural e a compreensão do mundo contemporâneo e da realidade portuguesa, através do desenvolvimento de noções operatórias e da aquisição de conhecimentos sobre a estrutura e evolução das sociedades (DGEBS, 1991: 125),

entendemos também que a História é a capacidade das crianças de terem uma compreensão do passado em toda a sua complexidade.

Em suma, a História, apesar de todas estas dificuldades, ao tratar do passado e dos seres humanos desse mesmo passado, apresenta uma série de características especiais enquanto disciplina: tem a questão da temporalidade, tem a questão da multiperspetiva, tem também a questão da complexidade e tem ainda uma série de conceitos estruturais que são determinantes na capa- 
cidade de verdadeiramente compreender o que é ensinado em qualquer aula de História.

\subsection{Especificidades da História}

\subsubsection{Complexidade e emergência em História}

Tal como todos os trabalhos desenvolvidos na área da pedagogia, e que têm vindo a demonstrar que a construção do pensamento histórico dos jovens depende de vários fatores e que há um conjunto de questões cognitivas que têm de ser tidas em conta, muitos outros autores de diferentes áreas têm vindo a trabalhar sobre a questão da complexidade em História.

Pretendemos aqui demonstrar como as teorias da complexidade e de emergência que têm vindo a ser desenvolvidas no âmbito de diferentes trabalhos, não podem de forma alguma ser ignoradas quando tratamos o ato de desenvolvimento do conhecimento histórico em jovens, uma vez que, como temos vindo a defender ao longo do nosso trabalho, é reconhecido que este conhecimento é muito mais do que a mera recoleção de datas e de acontecimentos, assentando no desenvolvimento de complexos conceitos de segunda ordem e em estruturas que são, também elas, complexas e não lineares.

Antes de mais, devemos explicar a noção de complexidade, termo que utilizámos já por diversas vezes para caracterizar a matéria que se estuda em História, ou seja, o conhecimento do Homem e das Civilizações e da forma como ambos foram evoluindo ao longo dos tempos:

complexidade distingue-se de regularidade. [...] A complexidade é algo que ocorre quando existe um padrão que não é demasiado regular nem demasiado aleatório, na zona entre uma entropia baixa e uma entropia alta (Carvalho, 1999: 637).

Sobre o significado de complexidade, algo que se encontra a meio caminho entre a simplicidade e o caos, escreveu também Edgar Morin (1995) referindo que este termo define um conjunto de situações que constituem a nossa existência, apresentando-se "com os traços inquietantes da confusão, 
do inextrincável, da desordem, da ambiguidade, da incerteza" (p. 20). Ora, um sistema complexo é, normalmente, bastante difícil de ser explicado, contudo não é de tal forma caótico que a sua compreensão seja impossível de atingir (Batty, 2005). Ou seja, um sistema complexo compõe-se de tantos elementos e de tamanha variedade de interações que se torna necessário aprender a observá-lo e estudá-lo através da análise do todo e não apenas de cada uma das partes que o compõem.

Nas ciências sociais, a análise de sistemas complexos assume-se com frequência como uma realidade, sendo que as mudanças nestes sistemas nunca ocorrem de forma linear. É o caso dos acontecimentos que são estudados em História. David Byrne refere que

na realidade, ao contrário dos modelos matemáticos, onde a dimensão crucial e as mudanças ocorrem é no tempo. Em sistemas não lineares, pequenas mudanças nos elementos causais ao longo do tempo não produzem necessariamente pequenas mudanças em outros aspectos particulares do sistema, ou nas características do sistema como um todo. Qualquer um ou ambos podem mudar muito, de facto, e, além disso, podem mudar de maneiras que não envolvem apenas um resultado possível91 (1998: 14).

Pelo contrário, Jacobson e Spiro referem que "existem muitos domínios que podem ser caracterizados como sendo essencialmente complexos, mas bem estruturados por natureza (por exemplo, matemática avançada, física, fisiologia)"92 (1994: 7).

Assim, verificamos a necessidade de explicarmos aos alunos que estudam História que, para perceberem um dado acontecimento, não podem olhar

91 Tradução nossa. No original: in reality, as opposed to mathematical models, the crucial dimension along with changes occur is time. In nonlinear systems small changes in causal elements over time do not necessarily produce small changes in other particular aspects of the system, or in the characteristics of the system as a whole. Either or both may change very much indeed, and, moreover, they may change in ways which do not involve just one possible outcome.

92 Tradução nossa. No original: there are many domains that may be characterized as being primarily complex but well-structured in nature (e.g., advanced mathematics, physics, physiology). 
para ele de forma isolada mas sim como parte de um todo maior e mais complexo, sendo que as ações individuais e o próprio tempo podem contribuir para que se produzam resultados diferentes.

É por isso necessário compreender que a complexidade se relaciona também com emergência, uma vez que "encontramos a noção de emergência quando observamos que um conjunto de princípios simples produzem fenómenos complexos" (Carvalho, 1999: 639). É por esse motivo que o estudo da sociedade, o estudo do Homem no tempo, como logo no início deste capítulo definimos História, se reveste de uma complexidade emergente: a sociedade é mais do que a soma das partes, ela é o resultado da interação da soma dessas partes e é essa interação que nos leva à complexidade. Sawyer (2005) refere, a propósito, que "ambos os factos sociais e as representações coletivas são fenómenos sociais emergentes. Ambos são propriedades sui generis de um sistema social, emergindo de uma associação de indivíduos"93 (p. 105). Ou seja, os mesmos elementos podem produzir resultados diferentes. Sobre esta questão refere Sawyer (2005) que

quando as leis que regem um sistema são relativamente simples, o comportamento do sistema é fácil de entender, explicar e prever. No outro extremo, alguns sistemas parecem comportar-se de forma aleatória. Pode haver leis que governam o comportamento de um sistema desse tipo, mas o sistema é altamente não-linear - pequenas variações no estado do sistema num momento podem resultar em mudanças muito grandes nos estados posteriores do sistema. Esses sistemas costumam ser considerados caóticos. Sistemas complexos estão nalgum lugar entre esses dois extremos. Um sistema complexo não é fácil de explicar, mas não é tão caótico que a compreensão seja completamente impossível ${ }^{94}$ (p. 14).

93 Tradução nossa. No original: both social facts and collective representations are emergent social phenomena. Both are sui generis properties of a social system, emerging from the association of individuals.

94 Tradução nossa. No original: when the laws governing a system are relatively simple, the system's behaviour is easy to understand, explain, and predict. At the other extreme, some systems seem to behave randomly. There may be laws governing the behaviour of a system of this type, but the system is highly nonlinear - small variations in the state of the system at one time could result in very large changes to later states of the system. Such systems are often said to be chaotic. Complex systems are somewhere in between 
Battram (2004) também discute esta questão, alertando para o facto de que, quando as partes que compõem um sistema adaptativo complexo interagem, "podem causar alterações significativas na natureza dos próprios componentes e terem importantes consequências para o sistema como um todo" (p. 56). Ou seja, uma vez mais se explica a particularidade do ensino da História, uma ciência onde a soma dos fatores pode determinar resultados diferentes ou, mais ainda, onde "o efeito combinado não é necessariamente a soma de efeitos separados. Pode ser maior ou menor, porque os fatores podem reforçar ou anular-se um ao outro de formas não lineares"95 (Byrne, 1998: 20).

É por isso que é necessário, no estudo de uma ciência como a História, adquirir a consciência de que temos de ser capazes de lidar com as incertezas e com fenómenos aleatórios. Morin (1995) refere a propósito que "a complexidade num sentido tem sempre contacto com o acaso" (p. 52). É por isso que temos de ser conscientes de que iremos sempre ter uma noção dos acontecimentos históricos próxima da totalidade mas nunca poderemos ter a certeza de um saber total. No fundo, ganham em História novos contornos as teorias relativistas que defendem que é impossível obtermos um conhecimento absoluto.

Contudo, e como atrás já referíamos, não é tarefa impossível sermos capazes de compreender a complexidade, uma vez que ao olharmos para os acontecimentos históricos, que à primeira vista se apresentam como caóticos, não lineares ou até mesmo contraditórios, poderemos ser capazes de vislumbrar "a emergência da ordem no meio da desordem" e compreender "que dentro da Natureza existem fenómenos que demonstram uma tendência da matéria para a organização em circunstâncias que, apesar de particulares, são frequentes" (Carvalho, 1999: 625).

Assim, para conseguir vislumbrar esta situação, é importante abordar a complexidade tendo sempre em conta que ela se compõe de diferentes perspetivas, todas elas importantes para a compreensão não só das partes como

these two extremes. A complex system is not easy to explain, but it is not so chaotic that understanding is completely impossible.

95 Tradução nossa. No original: the combined effect is not necessarily the sum of separate effects. It may be greater or less, because factors can reinforce or cancel out each other in non-linear ways. 
do todo mas, sobretudo, de como as partes interagem (Battram, 2004; Carvalho, 2007; Morin, 1995).

Não podemos terminar este assunto sem deixar uma palavra sobre a ação que a tecnologia digital pode desenvolver como auxílio na aprendizagem de sistemas complexos. Como Batty (2005) refere, devido à imprevisibilidade dos resultados do funcionamento de um sistema complexo,

essa imprevisibilidade, é claro, é apenas com relação à sua especificação formal, ou seja, não há como os métodos tradicionais de análise serem usados para permitir a previsão do seu comportamento. A simulação é o único recurso. [...] É impossível adivinhar os seus resultados sem simulação ${ }^{96}$ (p. 64).

Para auxiliar na compreensão de sistemas complexos Spiro desenvolveu, nos anos 80, a Teoria de Flexibilidade Cognitiva, com o objetivo de preparar "as pessoas para selecionar, adaptar e combinar conhecimento e experiência de novas maneiras, para lidar com situações que são diferentes daquelas que encontraram antes"97 (Spiro, 2002). Refere ainda o autor que, no caso da História, "onde múltiplas perspectivas e até mesmo contextos e factos concorrentes estão frequentemente presentes, a flexibilidade cognitiva pode permitir que os estudantes obtenham uma compreensão mais profunda"98.

Aplicamos, por isso, a Teoria da Flexibilidade Cognitiva a ambientes complexos, na medida em que se relaciona com a aprendizagem para lidar com diferentes perspetivas. Nesse sentido, Carvalho e Moreira (2005) explicam que

os fundamentos dessa teoria baseiam-se basicamente na transferência de conhecimento adquirido nos estágios iniciais de aprendizagem para os mais avançados e

96 Tradução nossa. No original: this unpredictability of course is only with respect to their formal specification, that is, there is no way in which traditional methods of analysis can be used to enable the prediction of their behaviour. Simulation is the only resort. [...] It is impossible to guess their outcomes without simulation.

97 Tradução nossa. No original: people to select, adapt, and combine knowledge and experience in new ways to deal with situations that are different than the ones they have encountered before.

98 Tradução nossa. No original: where multiple perspectives and even competing contexts and facts are often present, cognitive flexibility can allow students to gain a deeper understanding. 
é por isso que, para que isso aconteça, a informação deve ser apresentada a partir de múltiplas perspectivas intelectuais que derivam de estudos de caso que atuam como instâncias diversas de conhecimento produzido em contexto ${ }^{99}$ (p. 2).

Desde os primeiros trabalhos de Spiro, ainda nos anos 80, vários têm vindo a ser os autores que se têm debruçado sobre o assunto, em articulação com este autor, tais como Feltovich, Jacobson e Coulson ${ }^{100}$, a nível internacional, e, no nosso país, sobretudo, os trabalhos de Ana Amélia Carvalho ${ }^{101}$.

Assim, é necessário percebermos que a sociedade é complexa porque resulta do somatório de uma infinita quantidade de partes diferentes umas das outras e, por isso, para entendermos essa complexidade precisamos de, por um lado, saber observar o funcionamento do todo e conseguir aí visualizar o singular e, por outro, perceber que não raras vezes a interação dos mesmos elementos, ao contrário de uma qualquer ciência exata, pode produzir um resultado diferente.

Em resumo, História tem a ver com a maneira como os sistemas complexos evoluem. Assim sendo, estas teorias da complexidade acabam por fazer a ponte entre a História e todas as outras ciências.

Por esse motivo, se de facto existe algo que, disciplinarmente, chamamos História, este é um conceito que ao longo do tempo teve várias interpretações e que, para além de ter a ver com a vida dos Homens ao longo do tempo, tem também uma série de características específicas, de multitemporalidade, multiperspetiva, complexidade e imprevisibilidade.

99 Tradução nossa. No original: the foundations of this theory lie basically on transfer of knowledge acquired at initial stages of learning to more advanced ones and that is why it purports that, for this to happen, information should be presented from multiple intellectual perspectives that stem from case studies that act as diverse instantiations of knowledge in context.

100 Vejam-se, a propósito, os trabalhos de Paul Feltovich, Rand Spiro \& Richard Coulson (1989); Michael Jacobson (1990); Rand Spiro, Richard Coulson, Paul Feltovich \& Daniel Anderson (1988 e 1989); Rand Spiro \& Jihn-Chang Jehng (1990); Rand Spiro, Paul Feltovich, Michael Jacobson \& Richard Coulson (1991a e 1991b).

101 A autora tem desenvolvido variados trabalhos nesta área, também em conjunto com outros autores, recomendando-se a leitura do trabalho Criss-crossing Cognitive Flexibility Theory based research in Portugal: an overview (2005), que relata os diferentes trabalhos produzidos em Portugal na área da Flexibilidade Cognitiva. 
Estamos numa área que tem uma especificidade própria em relação a outras disciplinas curriculares sem por isso deixar de ser uma área em que os processos cognitivos que são invocados sejam úteis noutros contextos, como por exemplo arqueologia, redes sociais, evolução de sistemas biológicos, colocando desta forma uma série de desafios que consistem nos conceitos estruturais do conhecimento histórico.

Assim, para perceber História e o que se procura ensinar nas escolas, é necessário começar por identificar as multiplicidades conceptuais que envolvem esta disciplina, nomeadamente no que diz respeito ao seu próprio significado, que na verdade pode incluir muitos sentidos diferentes, bem como quando pensamos no tempo histórico e em tudo o que ele pode efetivamente incluir.

Finalmente, não podemos deixar de perceber que quando se ensina História nas escolas, os conteúdos que compõem os seus programas foram selecionados previamente, mediante uma perspetiva, baseada também ela no caminho percorrido por vários historiadores. Assumimos que esse percurso foi feito de forma adequada, mas temos de ser capazes de, quer enquanto alunos, quer enquanto professores, adotar uma postura crítica face ao que nos é apresentado e procurar desenvolver capacidades relacionadas com "pensar histórico", para podermos, recolher essas informações, analisá-las e organizá-las da melhor forma possível.

\subsubsection{A importância do estudo da História}

Em qualquer dos textos oficiais com o programa da disciplina, a importância da História para a formação dos jovens estudantes que frequentam o ensino secundário é defendida com base na necessidade que estes têm de obter "referentes seguros que lhes permitam interpretar as realidades sociais que com eles interagem”, para além de lhes darem uma base de conhecimentos que os auxiliem na compreensão do presente e sua relação com o passado, na interpretação de problemas nacionais e internacionais e mesmo que contribua para os apoiar nas escolhas que poderão ter de realizar (Mendes, 2001: 4). Como afirma Marília Gago, “aprender história será aprender-se a si 
próprio, isto é, ao acentuar-se a dimensão temporal da identidade pessoal há uma tomada de consciência de si e do seu tempo" (2008: 57).

Para além disto, os nossos Governantes têm sempre defendido a necessidade de manter bem presente uma dimensão europeia e internacional do nosso país, dimensão essa que, ao nível do Ensino Secundário, poderá ser devidamente tratada em algumas disciplinas em concreto, nomeadamente, na Língua Portuguesa, na História, nas Línguas Estrangeiras, na Geografia, na Economia e na Filosofia. No caso da História,

a articulação da História de Portugal/ História da Europa/ História Mundial expressa, pela sua própria natureza, uma dimensão europeia e internacional. Por outro lado, o programa apresenta como finalidades, entre outras, a promoção da capacidade de interpretação crítica e fundamentada do mundo actual e o desenvolvimento da consciência da cidadania, na sua dimensão, quer nacional, quer universal (Comissão Europeia, 2007a: 272).

Reforçando a ideia de que a presença da História no currículo se justifica também pela sua utilidade na vida social e ativa de cada jovem, Chatelet afirma que

a base última sobre a qual esta compreensão - mesmo fragmentária - da historicidade pode ser desenvolvida e a decisão cultural de "fazer história" é a tomada pelo Homem da dimensão política do seu destino, a consciência de que tem que ser um sujeito agindo neste mundo sensível-profano dentro de uma comunidade da qual depende, isto é, o conhecimento do que é a verdadeira liberdade ${ }^{102}$ (Chatelet, $1962: 10)$.

Articulando estas afirmações com a própria Lei de Bases do Sistema Educativo, não podemos deixar de citar alguns dos seus artigos, ligados à preocu-

102 Tradução nossa. No original: l'assise ultime sur laquelle peuvent se développer cette compréhension - même fragmentaire - de l'historicité et la décision culturelle de "faire de l'histoire» est la saisie par l'homme de la dimension politique de son destin, la conscience qu'il a d'être un sujet agissant en ce monde sensible-profane au sein d'une communauté dont il dépend, c'est-à-dire la connaissance de ce qu'est la liberté réelle. 
pação com uma participação ativa no desenvolvimento integral dos alunos, os quais se enquadram perfeitamente no que referimos nos parágrafos anteriores:

[...] 5 - A educação promove o desenvolvimento do espírito democrático e pluralista, respeitador dos outros e das suas ideias, aberto ao diálogo e à livre troca de opiniões, formando cidadãos capazes de julgarem com espírito crítico e criativo o meio social em que se integram e de se empenharem na sua transformação progressiva. $[\ldots]^{103}$

O sistema educativo organiza-se de forma a:

a) Contribuir para a defesa da identidade nacional e para o reforço da fidelidade à matriz histórica de Portugal, através da consciencialização relativamente ao património cultural do povo português, no quadro da tradição universalista europeia e da crescente interdependência e necessária solidariedade entre todos os povos do mundo; [...].104

\section{Objectivos $^{105}$}

[...] c) Fomentar a aquisição e aplicação de um saber cada vez mais aprofundado assente no estudo, na reflexão crítica, na observação e na experimentação;

d) Formar, a partir da realidade concreta da vida regional e nacional, e no apreço pelos valores permanentes da sociedade, em geral, e da cultura portuguesa, em particular, jovens interessados na resolução dos problemas do País e sensibilizados para os problemas da comunidade internacional (M. Educação, 1986: 5125-5127).

Em total harmonia com estas ideias, José Mattoso (1999) defendia que

A História oferece, quando abre os seus horizontes às dimensões do mundo e da Humanidade, uma visão ampla e diversificada da sociedade, não tanto de um

\footnotetext{
103 Artigo 2. ${ }^{\circ}$.

104 Artigo $3 .^{\circ}$.

105 Subsecção II, Ensino Secundário, Artigo 9. .
} 
ponto de vista estático, mas sobretudo, como é evidente, do ponto de vista temporal e dinâmico. Habitua a olhar para todos os acontecimentos como resultantes das causas e de condições muito variadas e que se conjugam, a uma certa escala, de maneira aleatória, mas que também se organizam, a outra escala (digamos, a uma escala superior), segundo linhas de força suficientemente visíveis e racionais para que a sua descoberta seja parte essencial da sua explicação ou da descoberta do seu sentido global. Habitua a descobrir a relatividade das coisas, das ideias, das crenças e das doutrinas, e a detectar por que razão, sob aparências diferentes, se voltam a repetir situações análogas, se reproduz a busca de soluções parecidas ou se verificam evoluções paralelas (p. 17).

Apesar de cada vez mais se defender e praticar a interdisciplinaridade, é à História que tem cabido o principal papel na formação de uma consciência histórica, na construção de valores culturais e sociais e na integração destes conhecimentos na vida de cada um dos jovens que passam pela escola.

Roldão (1995) destaca que já Platão falava no valor educativo da História,

insistindo no poderoso fascínio que exerce sobre a mente, sobretudo das crianças, mas não só, tornando fácil de memorizar e interiorizar o significado que lhes está associado. Para o grande filósofo grego tal potencial deveria ser utilizado para veicular as "boas» mensagens e os exemplos desejáveis, dentro da utopia moralista e fortemente normativa que concebeu na República (p. 25).

Como é uma disciplina que pode contribuir verdadeiramente para um melhor conhecimento da sociedade, para um melhor entendimento do mundo e porque de facto pode ensinar a construir um espírito crítico e consciente face ao passado e ao presente, voltamos às palavras de Roldão (2002a) que menciona que

aquilo que a História traz ao currículo do aluno é o constituir-se num dos saberes de referência, enquadradores fundamentais para que o indivíduo saiba mover-se no mundo de informações de todo o tipo a que cada vez mais terá acesso (p. 138).

Não interessa tanto a descrição cronológica de acontecimentos mas sim a criação de mecanismos que permitam ao aluno usar esses dados para com- 
preender melhor o mundo que o rodeia, interpretando o passado por forma a poder adotar uma postura interventiva no seu próprio presente. Mattoso (1999) dizia mesmo que "o que interessa não é "gostar de História», mas estar convencido que sem ela não se pode compreender o mundo em que vivemos” (pp. 13-14). Essa é uma das mais valias da História, com a qual não temos sequer que concordar mas devemos compreender, por forma a podermos olhar com outros olhos para o presente em que vivemos. É, por isso, importante que os alunos compreendam a importância das competências que podem adquirir com o estudo desta disciplina, algo que por vezes não é facilmente percecionado por eles. Se, por um lado, aceitam a importância do passado, por outro não dão grande relevância às matérias escolares, aos manuais ou aos professores. Luís Marques Alves apontava para a necessidade de refletir mais e melhor sobre o espaço que tem sido reservado à disciplina, pois tem havido algum desencontro entre "potencialidades da História, função social a desempenhar e disciplina leccionada" (2009: 20). Este autor referia ainda que

a História é uma forma de estar na vida, na sociedade, no exercício da cidadania. A sua utilidade vê-se na falta que faz àqueles que não entenderam que até o útil tem que ser belo e a beleza do presente tem os parâmetros da compreensão do passado (Alves, 2009: 20).

Hoje em dia, o papel das aulas de História assume ainda maior importância quando os alunos são confrontados, diariamente, com uma sociedade totalmente mediatizada, movimentada, pluralista e complexa. Os jovens têm cada vez mais acesso aos mass media, que inundam as suas vidas de informações que precisam ser descortinadas e contextualizadas. Sendo agora outros os desafios, a História tem de assumir o seu papel na formação para a cidadania, numa sociedade mais dinâmica e também criar as devidas motivações para uma abordagem do presente em conjunto com toda a informação (ou desinformação) que também rodeia cada um dos jovens estudantes (Barca, Bastos \& Carvalho, 1998). É por isso papel fulcral da Escola mas também da História no que toca a capacitar os seus alunos de competências de pesquisa, compreensão, interpretação e contextualização da informação recolhida, para que estes se tornem cidadãos informados, críticos e ativos (Costa, Sobral \& 
Alves, 2009; Barca, 1995). José Pais, de forma algo poética, mencionava também que "só voltando para trás o filme da História é que se torna compreensível o último fotograma: o presente" (1999: 26).

Numa sociedade pluralista, é necessário e desejável a capacidade de julgamento crítico que, não existindo, poderá dar azo a manipulação da identidade histórica. É por isso importante a apresentação de diferentes perspetivas, mesmo contraditórias, para dar ao aluno a possibilidade de desenvolver a sua opinião, que será sempre útil na sua formação não só educativa como também, e sobretudo, pessoal e social.

Concluindo, a disciplina de História deve então constar dos currículos, não só no Ensino Básico mas também no Ensino Secundário, não só porque se trata de um saber específico mas, sobretudo, porque em si mesma procura formar os alunos através do desenvolvimento de variadas capacidades (Proença, 1989: 85). Mais ainda, e como já foi referido, nos tempos atuais em que a informação está ao alcance de todos, é fundamental que cada um aprenda a saber interpretar e usar corretamente essa mesma informação. Palmira Alves (2004) refere, nesse sentido, que

na perspectiva da "mudança cultural acelerada", [...] necessitamos de formas de aprendizagem complexas, isto é, totalizadoras, integradoras e orientadas para os processos. Essas formas de trabalho permitirão aos alunos a aquisição de determinados conhecimentos (por exemplo, a dinâmica social das sociedades industrializadas, a mudança das estruturas familiares e das relações sociais), não só ao «nível cognitivo" enquanto "saber histórico", mas também em situações concretas e este saber deve ser útil como competência social na sua vida quotidiana (p. 116).

\subsection{Ensino da História e as TDIC}

No capítulo 1 foram descritos os principais projetos de integração das TDIC para modernização da sociedade, preparados pela União Europeia e por diferentes Governos e também, em concreto, para a sua introdução no ensino, nomeadamente no que dizia respeito à preparação das escolas (ao nível das infraestruturas) e de professores e alunos, com vista a dotar todos de conhecimentos que os possam tornar mais competitivos, os primeiros por melhor 
poderem vir a ensinar e preparar os seus discentes, os segundos porque no futuro poderão ser melhores profissionais. Desta forma, ao longo dos últimos 25/30 anos tornou-se cada vez mais clara a importância da utilização de variados instrumentos tecnológicos para melhor descortinar diferentes conteúdos e permitir, não apenas a alguns mas a todos os alunos, um melhor desempenho no seu percurso académico.

Entre projetos de massificação de acesso a computadores e a uma Internet altamente veloz (não só na escola mas também em casa) e outros visando a produção de software adequado, deseja a União Europeia tornar os seus jovens cidadãos competitivos em relação ao resto do mundo, votos também partilhados em Portugal, sobretudo tendo em conta o atraso tecnológico em que o país se encontrava.

Em Portugal, no programa de História para o Terceiro Ciclo do Ensino Básico de 1991 surge uma breve referência ao uso das TDIC. Em primeiro lugar, refere este programa que o aluno se deve familiarizar com a utilização das TDIC e que os professores devem utilizar, entre a variedade de recursos didáticos, aqueles que sejam oferecidos pelas TDIC.

Depois da reforma de 2001 o documento com as competências essenciais dedica também algumas palavras a esta questão, desejando que todos os alunos aprendam a utilizar as TDIC ao serviço a aprendizagem em História e que utilizem programas adequado à disciplina, sobretudo "no tratamento de informação (mapas e gráficos), no processamento de informação e comunicação de ideias e consulta, interpretação, organização e avaliação da informação" (M. Educação, 2001).

Na verdade, esta opção por uma referência, que consideramos demasiado breve, à importância do uso das TDIC como uma competência ou uma sugestão metodológica para os professores, vem na linha do observado por Cruz (2009):

quando procedemos à análise do conteúdo deste documento, ao nível das competências específicas, encontramos algumas referências ao termo "tecnologias de informação e comunicação", indicadas mais no sentido de rentabilizar as potencialidades das mesmas na construção do conhecimento mas sem uma clarificação quanto ao modo como podem ser utilizadas em cada área do saber (p. 17). 
Depois das referências que fomos encontrando, relativas aos benefícios que as TDIC podem trazer para o ensino, e dos esforços realizados a nível institucional, não só no sentido de criar as condições para que as escolas estejam devidamente equipadas mas também de contribuir para que todos os estudantes tenham acesso aos equipamentos e estruturas também em suas casas, tratamos agora de procurar as evidências de que as TDIC são, efetivamente, úteis para o ensino e para a aprendizagem da História.

Até aqui, verificámos também que, de acordo com as diretrizes governamentais não só em Portugal mas também em todos os países analisados no nosso estudo, os programas curriculares relativos à História fazem menção, de uma forma mais ou menos específica, à utilização das TDIC nessa disciplina.

Contudo, pretendemos ainda perceber quais são os motivos que justificam o interesse do uso destas tecnologias digitais no ensino da História. É certo que a maioria dos autores que tivemos oportunidade de estudar tem defendido a importância destas ferramentas tecnológicas e digitais, que contribuem para uma melhor organização do trabalho didático, maior acesso à informação e mesmo o facto de que um ensino que recorre às TDIC será, se corretamente aplicado, um ensino tipicamente construtivista.

Nesse sentido, não podemos deixar de referir aqui a interação entre as ideias construtivistas e o ensino da História através das TDIC, com o objetivo de desenvolver o raciocínio crítico e a capacidade de tomar decisões. De acordo com White (1999),

a fusão da tecnologia com o construtivismo oferece muita esperança para o futuro da educação em Ciências Sociais. Uma orientação construtivista para a formação de professores é importante se quisermos incentivar os alunos nas escolas a desenvolver habilidades de resolução de problemas e pensamento crítico, e aplicar, analisar, sintetizar e avaliar conhecimentos, habilidades e atitudes ${ }^{106}$ (p. 8).

106 Tradução nossa. No original: the merging of technology and constructivism offers much hope for the future of social studies education. A constructivist orientation to teacher education is important if we are to encourage students in schools to develop problem solving and critical thinking skills, and to apply, analyze, synthesize, and evaluate knowledge, skills, and attitudes. 
Para além disto, consideramos que, de facto, o simples facto de termos acesso a toda uma nova forma de apresentação da informação histórica constitui, per se, um benefício incontornável. Na verdade, sendo a própria História uma disciplina multimédia, uma vez que, como referem Wiley \& Ash (2005), "o historiador compara e contrasta informações entre múltiplas fontes, mesmo quando todas as fontes podem ser do mesmo meio"107 (p. 376), a utilização de ferramentas multimédia nas aulas de História acaba por nos parecer imprescindível.

Analisando as competências que se pretende que os alunos desenvolvam, encontramos entre as mais relevantes o desenvolvimento de espírito crítico e de um pensamento histórico. Nesse sentido, julgamos que, uma vez mais, a ação das TDIC nas aulas de História pode contribuir para o desenvolvimento destas mesmas competências. Nesse sentido, Matta (2001) indica que

a educação na sociedade informatizada tem caminhado para a aprendizagem coletiva, colaborativa, crítica e construtiva, que possibilita o desenvolvimento da autonomia nos alunos e que tem conteúdo dinâmico, baseado no ambiente experimentado e questionamentos autênticos. Esta constatação, conduz à suposição de que o uso das novas tecnologias da comunicação e informática, para organizar ambientes mediadores da aprendizagem em História, pode produzir o desenvolvimento do pensar histórico nos alunos (pp. 31-32).

De facto, verificamos que, uma vez que cada vez mais instituições detentoras de inúmeros documentos históricos, importantes para o ensino da disciplina, têm vindo a disponibilizá-los online, permitem aos alunos trabalhar diretamente sobre as fontes, analisá-las, selecioná-las e estruturar a partir delas o seu pensamento (Cohen \& Rosenzwieg, 2006), aprendendo, com a ajuda do professor, a realizar a própria tarefa de um historiador, ou seja, desenvolvendo o seu espírito crítico e o pensamento histórico. São vários os professores que têm divulgado estudos sobre o que têm feito nas suas aulas, onde desenvolvem projetos informáticos, sejam eles a utilização de um jogo

107 Tradução nossa. No original: the historian compares and contrasts information across multiple sources, even when all sources might be of the same medium. 
de computador (veja-se o exemplo de Cuenca Lopez [2004] que utilizou nas suas aulas o jogo Iter Itineris ou de Guay que colocou os seus alunos a fazer jornalismo de investigação [2007], entre muitos outros), ou, como Cruz (2009) que integrou variadas ferramentas da Web (Podcasts, Caça ao Tesouro, Bubbleshare, Wiki, Movie Maker, YouTube, WebQuest, CMaptools, Google Page Creator, HotPotatoes, Fórum, Dandelife e variadas ferramentas de comunicação como chat, email e videoconferência).

Assim sendo, a tecnologia digital revela-se importante para o estudo das ciências sociais em geral pois tem o potencial para facilitar o desenvolvimento do pensamento de ordem superior para além de competências ao nível da resolução de problemas mas, como refere Zhao (2004), muitos dos estudiosos deste tema referem, sobretudo, a primeira destas duas características. Nesse sentido, também Jonassen, Peck e Wilson (1999) referem que os dois aspetos referidos não devem parecer surpreendentes, se as TDIC forem corretamente aplicadas, ou seja, "envolver os alunos em trabalhos importantes e desafiadores e levá-los a discutir esse trabalho com os outros e a pensar profundamente sobre isso eles mesmos"108 (p. 47).

Para além disso, a possibilidade de lidar, de uma forma um pouco mais direta, com a documentação relativa aos conteúdos que estão a aprender, torna os alunos um pouco mais próximos desse passado que, por vezes, se revela distante demais. Habitualmente, o ensino da História traduzia-se numa metodologia centrada no professor, que privilegiava apenas a memorização e a repetição de conteúdos, levando à "predominância do intelectualismo e enciclopedismo, que impedem os problemas de serem sentidos como realidade vivida pelos alunos e pela sociedade, ou de serem vistos como historicamente constituídos" (Matta, 2001: 28).

Tantas e tantas vezes se queixavam alunos e professores de História, os primeiros porque não encontravam a relevância da disciplina para a sua vida, os segundos porque não sentiam que os seus discentes aprendessem verdadeiramente. Mas no que toca à aprendizagem da História, mais do que em qualquer outra disciplina, é deveras importante que os alunos sintam empatia

108 Tradução nossa. No original: to engage students in important, challenging work, and to cause them to discuss this work with others and to think deeply about it themselves. 
com o que o professor ensina, que se sintam relacionados com o seu passado e entendam de que forma pode ele ser relevante para o seu presente. A empatia, ou seja a capacidade de se colocarem na perspetiva dos antepassados, é mesmo um dos principais conceitos estruturais das aulas de História, juntamente com evidência, causa ou mudança (Blow, 1990). Neste sentido, o uso das TDIC na aula de História pode contribuir para tornar o passado mais próximo dos alunos e, consequentemente, fazer com que estes se consigam motivar para a sua aprendizagem e até mesmo desenvolver a curiosidade de procurar mais informação fora da sala de aula.

Dentro das várias TDIC, algumas podem ser mais adequadas do que outras para cumprir este objetivo mas consideramos que uma das melhores será a Internet, sobretudo porque é nela que conseguimos cada vez mais encontrar um manancial de dados, fontes primárias, recursos mais ou menos interativos mas que se torna incontornável porque pode "tornar o passado mais ricamente documentado, mais acessível, mais diversificado, mais responsivo a futuros investigadores e, acima de tudo, mais democrático"109 (Cohen \& Rosenzweig, 2006). A História ensinada com recurso a programas tecnológicos que permitem, de alguma forma, trazer o passado até ao presente, torna-se mais real, mais viva, e, consequentemente, mais atrativa para qualquer aluno (Haydn, 2000; Hillis, 2001). Para além disso, foram já feitos estudos que indicam que os alunos tendem a gostar mais de História quando se utilizam as TDIC para a ensinar (DenBeste, 2003).

$\mathrm{Na}$ verdade, a maior parte dos estudos que tivemos oportunidade de analisar referiam-se à utilização da Internet. É através deste portal virtual para o mundo que se pode aproximar os alunos do seu passado, enriquecendo as aulas e tornando a aprendizagem da História mais atrativa. Contudo, no que toca a esta interação entre a Internet e as aulas de História, reconhecemos que há vantagens e desvantagens, explicadas de uma forma bastante sucinta por Cohen e Rosenzweig ${ }^{110}$ (2006):

109 Tradução nossa. No original: make the past more richly documented, more accessible, more diverse, more responsive to future researchers, and above all more democratic.

110 http://chnm.gmu.edu/digitalhistory/introduction/ (acessível em 21/06/2014). 
esta introdução esboça brevemente sete qualidades dos media digitais e das redes que potencialmente nos permitem fazer melhor as coisas: capacidade, acessibilidade, flexibilidade, diversidade, manipulabilidade, interatividade e hipertextualidade (ou não-linearidade). Também falamos sobre os cinco perigos na superestrada da informação: qualidade, durabilidade, legibilidade, passividade e inacessibilidade. Este scorecard de possibilidades e problemas parece, no balanço, sugerir um futuro digital que vale a pena ${ }^{111}$ (online, parag. 9).

Mas também outros recursos tecnológicos servem para a construção do pensamento histórico nas aulas. Seja para apresentação de conteúdos, tratamento de dados, elaboração de trabalhos escritos, hoje em dia existe cada vez mais software genérico que pode ser aplicado na disciplina em questão, mas também começam a aumentar os recursos preparados especificamente para as aulas de História, apesar de julgarmos que, pelo menos em Portugal, a maioria desse software se reporta mais ao ensino da História até ao $9 .^{\circ}$ ano de escolaridade.

A possibilidade de apresentar diferentes documentos através de um computador pode até parecer, à primeira vista, que complica a aprendizagem mas, na verdade, se bem organizado pelo professor, vem sim facilitar pois os alunos, enquanto ouvem o professor apresentar os conteúdos, podem estar a observar essa mesma informação. Ou seja,

quando a informação é apresentada de forma sequenciada, incorporando de forma dinâmica, passo a passo, cada um dos elementos que a constituem ou que queremos destacar, a compreensão melhora e a aprendizagem é facilitada porque cada elemento é isolado, a reflexão é facilitada e explicação do mesmo e, consequentemente, a sua compreensão e a sua retenção, se houver o tempo necessário para isso ${ }^{112}$ (Rivero Garcia, 2011: 170).

111 Tradução nossa. No original: this introduction briefly sketches seven qualities of digital media and networks that potentially allow us to do things better: capacity, accessibility, flexibility, diversity, manipulability, interactivity, and hypertextuality (or nonlinearity). We also talk about five dangers or hazards on the information superhighway: quality, durability, readability, passivity, and inaccessibility. This scorecard of possibilities and problems seems, on balance, to suggest a digital future worth pursuing.

112 Tradução nossa. No original: cuando la información se presenta de manera secuenciada, incorporando de manera dinámica, paso a paso, cada uno de los elementos que la 
A possibilidade de recorrer a tecnologias digitais que permitem a visualização dos acontecimentos não serve apenas por uma questão de decoração, ou como elemento atrativo mas sim porque servem, de facto, para melhorar a forma como se comunica com os alunos e como se transmite a informação relativa ao passado (Staley, 2003).

A riqueza de informação e a diversidade com que ela pode ser apresentada permite a criação de tarefas bastante atrativas e úteis para a compreensão e interpretação do passado, apesar de ser necessário estar atento a alguns problemas. Em primeiro lugar, e apesar de reconhecermos que a Internet é um manancial de recursos, temos de estar atentos em relação às informações que dela recolhemos ou deixamos os alunos recolher, uma vez que

se a diversidade temática disponível não deixa de ser algo fascinante, deixa-nos apreensivos a diversidade da qualidade da informação. É imprescindível saber avaliar a qualidade da informação. Para além deste requisito, também é importante saber pesquisar a informação (Carvalho, 2004: 234).

É por esse motivo que se foram desenvolvendo, ao longo dos anos, sistemas de avaliação da informação existente online, de uma forma mais ou menos precisa, para tentar fazer a verificação dos dados apresentados. Peter Sterns criou o Cliolator, Dan Cohen e Roy Rosenzweig desenvolveram o $H$-Bot, apenas para citar alguns exemplos de mecanismos criados para tentar reduzir a possibilidade de apresentação de informação errada a todos aqueles que fazem pesquisa histórica online.

Retomando a última afirmação de Carvalho (2004), esta leva-nos, de novo, à interação entre a História e as TDIC: se por um lado estas nos podem ajudar no ensino da História, a capacidade de tratamento de informação que um historiador deve ter e que também um aluno deve ser capaz de fazer, também pode, e deve, ser aplicada na seleção da informação que encontramos disponível online. Assim, os alunos podem desenvolver as suas capacidades

constituyen o que se quieren destacar, la comprensión mejora y se facilita el aprendizaje porque se aísla cada elemento, se facilita la reflexión y explicación del mismo y, en consecuencia su comprensión y su retención, si se proporciona el tiempo necesario para ello. 
tecnológicas, também através do uso da História. Recuperando algumas das ideias sobre a educação conectiva e a educação rizomática, sobre as quais foi já referida a necessidade de saber escolher e analisar a informação que nos é dada ser muito mais importante do que o armazenamento da informação no nosso cérebro, a interação das duas disciplinas é incontornável. Nesse sentido refere Meyniac (2005) que,

parece que a História ensinada, nos seus objetos e métodos, pode desempenhar um papel real numa melhor apropriação das TICs e, mais particularmente, da Internet, desde que se priviligie menos o conhecimento e o mapa da análise crítica seja minuciosamente trabalhado ${ }^{113}$ (p. 10).

Importa ainda destacar que os alunos nunca devem fazer atividades nas aulas sem que estas tenham objetivos por trás. O mesmo se deve passar quando se utiliza uma determinada tecnologia digital. Haydn (2000) destaca dois princípios a ter em conta sempre que se pretende utilizar a tecnologia digital para desenvolver o pensamento histórico dos jovens:

a primeira é que os alunos devem ser solicitados a fazer algo com as informações apresentadas, em vez de simplesmente receberem acesso a um volume maior de informações históricas. A segunda é que deve haver algum propósito histórico válido para as atividades que os alunos estão envolvidos, em vez de apenas compreensão, correspondência e exercícios de representação ${ }^{114}$ (Haydn, 2000: 105).

Assim, ao realizar uma tarefa específica, com recurso a uma determinada tecnologia digital pré-estabelecida pelo professor, os alunos aprendem de

113 Tradução nossa. No original: il semble que l'histoire enseignée, dans ses objets et méthodes, peut jouer un vrai rôle dans une meilleure appropriation des TIC et plus particulièrement d'Internet à condition de moins privilégier le savoir et de jouer à fond la carte de l'analyse critique.

114 Tradução nossa. No original: the first is that pupils must be asked to do something with the information they are presented with, rather than simply being provided with access to an increased volume of historical information. The second is that there should be some valid historical purpose to the activities that pupils are engaged in, rather than meretricious comprehension, matching and representation exercises. 
forma construtiva, para além de desenvolverem competências na disciplina. Neste caso, como a História procura desenvolver, como já referimos, competências no campo da análise de dados e tomada de decisões, isto confere também um aumento das aptidões dos alunos quando envolvidos em tarefas que utilizam a tecnologia digital.

Em suma, a interação com as TDIC pode operar-se em diferentes níveis. A forma, mais atrativa e também mais variada, com que os conteúdos históricos podem ser apresentados aos alunos e trabalhados por eles facilita $o$ processo de aprendizagem, para além de poder ajudar a aproximar os alunos do seu passado e até mesmo a perceber como é difícil, mas ao mesmo tempo atrativo, o trabalho do historiador. Por outro lado, sendo fundamental que os alunos aprendam a interpretar, analisar e selecionar a informação a que acedem através das TDIC, levam também um pouco do próprio trabalho do historiador para o domínio das competências em TDIC.

Contudo, praticamente tudo o que aqui acabámos de referir relativamente à utilidade que as tecnologias digitais podem ter para o ensino e a aprendizagem de História acaba por ser relevante também para o ensino de qualquer outra disciplina. Apesar disso, há um outro aspeto que, curiosamente, poucos dos autores estudados referiram mas que, para nós, se revela o mais importante de todos e, por isso mesmo, alvo principal do nosso estudo.

Esse aspeto refere-se à complexidade e não linearidade da História, conceitos que também podemos aplicar às tecnologias digitais, em particular à Internet e, em parte, ao hipertexto. Ou seja, reconhecemos, tal como a maioria dos autores, que as TDIC podem ser extremamente úteis no ensino, não só da História mas de todas as disciplinas, porque ajudam a visualizar a informação, a apresentá-la de uma forma mais atrativa, a disponibilizar mais informação desenvolvendo nos alunos a capacidade de a selecionar e também de a avaliar, entre muitos outros aspetos positivos.

Mas, no caso da História, há um fator que torna a utilização das tecnologias digitais extremamente úteis, e que não existe em qualquer outra disciplina: a História é uma disciplina complexa e não linear. As tecnologias digitais, ao permitirem a apresentação da informação de uma forma também não linear, podem contribuir para auxiliar os alunos na compreensão dos conteúdos históricos que lhes são ensinados. 
(Página deixada propositadamente em branco) 


\section{PA R T E I I}

\section{ENSINAR HISTÓRIA NA ERA DIGITAL}

O João estava todo contente com o seu novo smartphone. Dizia a toda a gente que tinha no bolso um computador mais potente do que aquele que tinha ajudado a colocar o primeiro bomem na lua!

Sempre que alguém tinha uma dúvida, lá puxava o João do telemóvel para encontrar a resposta! O seu telemóvel tinha jogos, uma enciclopédia, vários websites gravados, música, até livros de história!! Enfim, o João guardava com orgulho o mundo no bolso. Mas na escola o João não era feliz, não tinha sequer boas notas, não gostava das aulas. O João sofria porque ficava o dia inteiro sem poder observar o mundo... 
(Página deixada propositadamente em branco) 


\section{O ESTUDO DE CASO: METODOLOGIA}

\section{a) Questão de investigação e objetivos}

A utilização de aplicações móveis no ensino é hoje praticamente incontornável, em particular no que se refere à utilização de tablets no ensino e das vantagens inerentes às suas aplicações. Por esse motivo, cada vez são mais as ações promovidas pela União Europeia tal como a iniciativa da Comissão Europeia Abrir a Educação, aprovada em 2014, e que demonstra o interesse desta organização na promoção de ambientes educativos digitais abertos que permitam o alargamento das aprendizagens para fora do espaço de sala de aula uma vez que, como refere a resolução do Parlamento Europeu (2014), "as novas tecnologias e os REA [Recursos Educativos Abertos] possibilitam uma experiência de aprendizagem mais interativa e são instrumentos de grande valor, colocando o estudante no centro do processo de ensino" (online).

Acompanhando o interesse manifestado em Portugal (a par de todos os desenvolvimentos relativos a tecnologia digital na educação, a partir de diretrizes europeias) pela importância de desenvolver condições estruturais, humanas e mesmo sociais que beneficiem das vantagens de uma vivência plena numa era digital, o setor educativo português tem vindo a conhecer cada vez mais projetos associados à integração das TDIC nas escolas. Por outro lado, no caso específico da História, verifica-se que não só esta disciplina pode beneficiar da utilização das TDIC, como as suas próprias dinâmicas justificam, em pleno, uma interação entre História e TDIC.

Por isso, e tendo presente o acesso fácil à informação online através de dispositivos móveis e as facilidades para neles disponibilizar documentos em diferentes formatos, pretende-se com este estudo aquilatar o impacto desses 
dispositivos no desenvolvimento dos alunos na aprendizagem quer na consulta das fontes quer na produção das atividades solicitadas.

Para isso procuraremos identificar se a utilização deste tipo de equipamentos os ajuda na aquisição de competências para a construção do conhecimento histórico, tal como está previsto nos programas desta disciplina no Terceiro Ciclo do Ensino Básico. De facto, verificamos que muitas vezes os alunos deste nível de ensino têm muita dificuldade em analisar documentação e extrair da mesma a informação necessária para a compreensão histórica. Por esse motivo, procuramos também com este estudo que os alunos tomem um maior contacto com diferentes fontes e procurem interagir com elas para que, individualmente ou em grupo, consigam desenvolver as competências previamente definidas.

Para muitos professores, um dos problemas apontados para as falhas nesta disciplina relaciona-se com a falta de empatia para com ela. Desta forma, interessa-nos verificar se estes alunos conseguem desenvolver, de uma forma positiva, as tarefas que lhes são propostas, se sentem que isto contribui para melhorar os seus conhecimentos e se é eficaz o trabalho colaborativo e construtivista.

O estudo que realizámos procura responder, por isso, à seguinte questão de investigação:

- Que impacto têm os novos dispositivos móveis como os tablets e os ambientes tecnológicos que lhe estão associados no envolvimento e na aprendizagem dos alunos nas aulas de História?

Para responder a esta questão, e tal como já enunciámos na introdução do nosso trabalho, entendemos que o iPad e a plataforma iTunes $U$ podem funcionar como o eixo de um ecossistema tecnológico onde podemos combinar dispositivos móveis, recursos educacionais e software para consumo e criação de conteúdos.

Assim, os nossos objetivos são:

- identificar as implicações da utilização de um recurso tecnológico como o iPad e da plataforma iTunes $U$, nas aulas de História no Terceiro Ciclo do Ensino Básico; 
- perceber se, a partir do uso do iPad e da plataforma iTunes $U$, os alunos revelam competências ao nível da comunicação em História e do tratamento de fontes;

- verificar se, através da utilização do iPad e da plataforma iTunes $U$, os alunos se apropriaram de conceitos estruturais para a construção do conhecimento histórico.

\section{b) Opções metodológicas}

Partindo das possibilidades que se nos ofereciam, optámos por fazer um estudo descritivo com caráter exploratório (Yin, 2003), colocando a ênfase do estudo "nas qualidades das entidades e nos processos e significados que não são examinados experimentalmente ou medidos [...] em termos de quantidade, quantidade, intensidade ou frequência"115 (Denzin \& Lincoln, 2005: 10).

Tomámos esta opção uma vez que nos interessamos por "compreender" como poderemos usufruir das valências das tecnologias digitais por forma a aumentar a qualidade da educação. Assim, e como refere Coutinho (2006b),

se o meu objectivo é compreender os fenómenos educativos pela busca de significações pessoais e interacções entre pessoas e contextos, então devo optar por uma abordagem qualitativa ao problema em questão (p. 3).

Conscientes da importância de que se reveste a escolha concreta do fenómeno a estudar, definimos que o nosso objetivo seria fazer uma análise das potencialidades da utilização de iPads nas aulas de História, realizando-se um estudo de caso, uma vez que "o método de estudo de caso permite aos investigadores manter as características holísticas e significativas dos eventos da vida real"116 (Yin, 2003: 2), para além de que esta escolha não é uma

115 Tradução nossa. No original: on the qualities of entities and on processes and meanings that are not experimentally examined or measured [...] in terms of quantity, amount, intensity, or frequency.

116 Tradução nossa. No original: the case study method allows investigators to retain the holistic and meaningful characteristics of real-life events. 
opção metodológica mas sim uma escolha do objeto a ser estudado, uma vez que "escolhemos estudar o caso" (Stake, 1994: 236) e, como refere Yin, é ”o método de escolha quando o fenómeno em estudo não é facilmente distinguível de seu contexto"117 (1993: 3).

A utilização do termo bolístico, na citação de Yin, remete para o facto de que temos de ter em conta tanto o comportamento das pessoas como os fenómenos sociais que são, normalmente, determinados por diferentes causas. Swanborn (2010) refere, a esse respeito, que "como consequência, modelos causais simples, como aqueles usados na maioria das pesquisas, não são adequados”118 (p. 18). Para além disso, este autor ainda reforça essa necessidade de que os estudos de caso devam ser holísticos uma vez que "um estudo de caso é realizado porque não é (ainda) possível isolar o fenómeno em estudo do seu ambiente"119 (2010: 20).

Desta forma, como em qualquer estudo de caso, escolhemos um conjunto de acontecimentos de um determinado fenómeno que analisamos, ao longo de um determinado espaço de tempo e onde a informação sobre cada momento foi extraída através de diferentes formas (inquérito, observação direta, análise de documentos, etc.). Por isso,

não há apenas muitas variáveis separadas para medir, mas o fenómeno também é seguido ao longo do tempo, medindo repetidamente algumas dessas variáveis. Isso explica o rótulo "intensivo". O monitoramento ajuda-nos a descrever e explicar a história, as mudanças durante o período estudado e a estrutura complexa do fenómeno. Cada instância, ou exemplo, é geralmente chamado de caso. Portanto, uma abordagem intensiva é geralmente chamada de "estudo de caso" ou um estudo de casos múltiplos se mais de uma instância do fenómeno for estudada120 (Swanborn, 2010: 2).

117 Tradução nossa. No original: the method of choice when the phenomenon under study is not readily distinguishable from its context.

118 Tradução nossa. No original: as a consequence, simple causal models, such as those used in most survey analysis, are not adequate.

119 Tradução nossa. No original: a case study is undertaken because it is not (yet) possible to isolate the phenomenon under study from its environment.

120 Tradução nossa. No original: there are not only many separate variables to measure, but a phenomenon is also followed over time by repeatedly measuring some of these 


\section{Para além disso, Swanborn (2010) explica ainda que}

o rótulo 'estudo de caso' atualmente não é usado apenas em conexão com o estudo de um caso, mas inclui o estudo de um pequeno número de casos também. "Pequeno" significa que normalmente não mais do que quatro ou cinco casos são incluídos num estudo. [...] Na literatura mais antiga, uma distinção nítida costumava ser mantida entre 'estudos não comparativos' ou 'estudos de caso' $(\mathrm{N}=1)$ e o 'método comparativo', no qual mais de um caso é incluído' ${ }^{121}$ (p. 14).

\section{c) Seleção dos participantes}

\section{i) As instituições}

Depois de estruturado o trabalho que pretendíamos desenvolver contactámos uma instituição, para o colocar em prática. Esta é uma escola urbana, com uma oferta formativa ao nível do Ensino Básico e também do Secundário, tanto com cursos científico-humanísticos como profissionais e que conta com um corpo discente de cerca de 700 alunos e docente de cerca de 60 professores, na sua maioria do quadro, entre os quais dois são docentes de História.

É uma instituição bem equipada a nível informático, existindo em quase todas as suas salas um computador e um projetor, para além de salas destinadas especificamente ao trabalho com as tecnologias digitais. Associado a isto, disponibiliza ainda, através de rede wifi, o acesso à Internet e à Intranet de acesso a documentação específica da instituição (como por exemplo pla-

variables. This explains the label 'intensive'. Monitoring helps us to describe and explain the history, the changes during the period under study and the complex structure of the phenomenon. Each instance, or example, is usually called a case. Therefore, an intensive approach is generally called a 'case study', or a multiple-case study if more than one instance of the phenomenon is studied.

121 Tradução nossa. No original: the label 'case study' nowadays is not only used in connection with the study of one case, but includes the study of a small number of cases as well. 'Small' means that normally not more than four or five cases are included in a study. [...] In the older literature, a sharp distinction used to be maintained between 'noncomparative' or 'case studies' $(\mathrm{N}=1)$ and the 'comparative method', in which more than one case is included. 
nificações, projeto educativo da escola, entre outros), restrita a funcionários docentes e não docentes. Queremos com isto mostrar que é uma escola onde o recurso à tecnologia digital estará, de alguma forma, presente no quotidiano tanto de professores como de alunos. Contudo, ainda nenhuma delas tem entre os seus equipamentos tecnológicos os tablets, que permitissem no seu quotidiano a aprendizagem just-in-time e just-for-me.

\section{ii) Os participantes}

Os alunos selecionados frequentavam o $9 .^{\circ}$ ano de escolaridade e o grupo incluiu 20 rapazes e 27 raparigas (Tabela 4.1).

Tabela 4.1 - Género dos alunos participantes

\begin{tabular}{|l|c|c|}
\hline \multirow{2}{*}{ Caso } & \multicolumn{2}{c|}{$\begin{array}{c}\text { Participantes } \\
(\mathbf{n = 4 7 )}\end{array}$} \\
\cline { 2 - 3 } Género & $\mathrm{f}$ & $\%$ \\
\hline Masculino & 20 & 42,6 \\
\hline Feminino & 27 & 57,4 \\
\hline
\end{tabular}

Este grupo é composto por elementos com idades compreendidas entre os 14 e os 16 anos, havendo uma maior preponderância entre os alunos mais novos, encontrando-se, por esse motivo, a média global de idades deste grupo de alunos em 14,5 anos (Tabela 4.2).

Tabela 4.2 - Idade dos alunos participantes

\begin{tabular}{|l|c|c|}
\hline \multicolumn{1}{|c|}{ Caso } & \multicolumn{2}{c|}{$\begin{array}{c}\text { Participantes } \\
\text { (n=47) }\end{array}$} \\
\cline { 2 - 3 } Idade & $\mathrm{f}$ & $\%$ \\
\hline 14 anos & 26 & 55,3 \\
\hline 15 anos & 18 & 38,3 \\
\hline 16 anos & 3 & 6,4 \\
\hline
\end{tabular}


São também alunos, na generalidade, bons ou muito bons, uma vez que a maioria (66\%) obteve, no ano letivo anterior, uma classificação de níveis 4 ou 5, conforme se pode observar em pormenor na Tabela 4.3.

Tabela 4.3 - Classificações obtidas na disciplina de História no ano letivo anterior

\begin{tabular}{|l|c|c|}
\hline \multicolumn{1}{|c|}{ Caso } & \multicolumn{2}{c|}{$\begin{array}{c}\text { Particiantes } \\
\text { (n=47) }\end{array}$} \\
\cline { 2 - 3 } $\begin{array}{l}\text { Classificação em } \\
\text { História no ano transato }\end{array}$ & $\mathrm{f}$ & $\%$ \\
\hline inferior a nível 2 & 2 & 4,3 \\
\hline nível 3 & 14 & 29,8 \\
\hline nível 4 & 13 & 27,7 \\
\hline nível 5 & 18 & 38,3 \\
\hline
\end{tabular}

\section{d) Seleção das técnicas de recolha de dados}

Neste estudo, e como forma de procurar aumentar a validade dos nossos resultados (Yin, 2003; Cohen \& Manion, 1990), optámos pelas seguintes técnicas de recolha de dados: o inquérito através de questionários, observação de aulas, registo no diário de bordo e análise documental. Desta forma, ao longo das sessões, a nossa escolha incidiu sobre a realização de questionários escritos e de pequenas tarefas avaliadoras dos conhecimentos desenvolvidos pelos alunos.

Os registos no diário de bordo privilegiaram a anotação dos acontecimentos no decorrer das sessões com os alunos, nomeadamente ao nível dos comportamentos dos alunos, as suas interações com a tecnologia digital e conversas, entre outros, uma vez que "a sua realização possibilita ao investigador uma melhor compreensão do caso uma vez que não é possível o controlo nas diferentes situações que se foram sucedendo" (Cruz, 2009: 231). Yin (2003) refere também que, quando o estudo é sobre o currículo ou uma nova tecnologia digital, "observações do currículo no trabalho são auxílios inesti- 
máveis para a compreensão dos usos reais da tecnologia ou do currículo ou de quaisquer possíveis problemas encontrados"122 (p. 110).

\section{e) Elaboração dos instrumentos de recolha de dados}

Cabe agora a descrição de todos os instrumentos de recolha de dados que realizámos, a qual será feita seguindo a ordem pela qual os mesmos foram apresentados aos alunos, nomeadamente questionário sobre Literacia Digital, teste de conhecimentos, as tarefas de avaliação intercalar e final e o questionário de opinião sobre o estudo.

\section{i) Questionário de literacia digital}

Este questionário pretendeu caracterizar a literacia digital dos participantes e também algumas informações específicas da disciplina de História, caracterizando os sujeitos ao nível da faixa etária e do género.

A primeira dimensão incide sobre literacia digital e integra um conjunto de questões destinadas a identificar os conhecimentos dos sujeitos ao nível da informática na ótica do utilizador, frequência de uso e motivos para a sua utilização (itens 1 a 6). Com estas questões, procurámos percecionar a afinidade dos sujeitos com as tecnologias digitais, questionando sobre a frequência de uso do computador e o acesso à Internet.

A segunda dimensão incide sobre os métodos de trabalho e de estudo dos sujeitos e a sua motivação para o uso de tecnologia digital no ensino e na aprendizagem (itens 7 a 10).

A terceira dimensão incide sobre a motivação dos sujeitos para a aprendizagem da História, preferências ao nível dos conteúdos e dos métodos de trabalho e classificação nessa disciplina no ano anterior (itens 11 a 16).

122 Tradução nossa. No original: observations of the curriculum at work are invaluable aids for understanding the actual uses of the technology or curriculum or any potential problems being encountered. 
A última questão (item 17) é de resposta aberta, onde solicitamos a opinião dos alunos sobre a importância da temática que iríamos abordar no nosso estudo.

À exceção deste último item, os restantes são todos de escolha múltipla, sendo possível assinalar mais do que uma opção nos itens 6, 8, 10, 11, 13 e 14 e podendo assinalar até três opções no item 16.

\section{ii) Teste de conhecimentos}

No início do estudo realizou-se um teste diagnóstico para caracterizar os participantes e um teste final. Os testes de conhecimentos foram estruturados de forma a permitir que os alunos demonstrassem os conhecimentos adquiridos.

O teste era constituído por itens de análise de documentos com identificação de dados constantes nesses mesmos documentos e por itens de identificação e explicação de acontecimentos relativos ao período revolucionário de 1974-76. O teste era composto por questões de preenchimento de espaços (item 1), identificação de informação nos documentos (itens 2 e 3) e explicação de conteúdos (itens 4 e 5) (Tabela 4.4).

Tabela 4.4 - Classificações dos testes de conhecimentos

\begin{tabular}{|c|c|c|}
\hline \multicolumn{3}{|c|}{ TESTE (9. $^{\circ}$ ANO) } \\
\hline Item & Tipologia de questões & Cotação \\
\hline 1 & preenchimento de espaços & $26 \%$ \\
\hline 2 & identificação de informação nos documentos & $14 \%$ \\
\hline 3 & identificação de informação nos documentos & $10 \%$ \\
\hline 4 & Explicação & $20 \%$ \\
\hline 5 & Explicação & $30 \%$ \\
\hline & & $100 \%$ \\
\hline
\end{tabular}

Neste estudo os alunos realizaram o teste de conhecimentos na sessão que antecedeu o início do estudo e na sessão seguinte ao seu término, tendo os testes sido concebidos para serem realizados em 30 a 45 minutos. 
Uma vez que o trabalho projetado se iria dividir por várias sessões e subtemas diferentes, optámos por introduzir no final de cada um desses temas uma tarefa para avaliação dos alunos. Essas tarefas incidiram sobre os mesmos temas no Terceiro Ciclo e no Ensino Secundário. Procurámos também que estas tarefas fossem diferentes entre si, de forma a contribuir para um processo avaliativo diversificado, para estimular diferentes competências ${ }^{123}$ dos alunos (Tabela 4.5) e também propiciar momentos de trabalho individual e em grupo (Tabela 4.6).

Tabela 4.5 - Competências a desenvolver em História distribuídas pelas tarefas

\begin{tabular}{|c|c|c|}
\hline Tarefas & \multirow{5}{*}{$\begin{array}{l}\text { Tratamento de } \\
\text { informação/ } \\
\text { utilização de fontes: } \\
\text { - Utiliza da } \\
\text { metodologia } \\
\text { específica da } \\
\text { história: participar } \\
\text { na seleção de } \\
\text { informação } \\
\text { adequada aos } \\
\text { temas em estudo; } \\
\text { - Interpreta } \\
\text { documentos } \\
\text { com mensagens } \\
\text { diversificadas; } \\
\text { - Infere conceitos } \\
\text { históricos a partir } \\
\text { da interpretação } \\
\text { e análise cruzada } \\
\text { de fontes com } \\
\text { linguagens e } \\
\text { mensagens } \\
\text { variadas. }\end{array}$} & \multirow[b]{2}{*}{$\begin{array}{l}\text { 3. }{ }^{\circ} \text { Ciclo do Ensino Básico } \\
\text { Compreensão histórica (temporalidade:) } \\
\text { - reconhece a simultaneidade de diferentes } \\
\text { valores e culturas e o carácter relativo dos } \\
\text { valores culturais em diferentes espaços e tempos } \\
\text { históricos }\end{array}$} \\
\hline Subtema 1 & & \\
\hline Subtema 2 & & $\begin{array}{l}\text { Compreensão histórica (temporalidade:) } \\
\text { - Identifica e caracteriza fases principais da } \\
\text { evolução histórica e grandes momentos de } \\
\text { ruptura }\end{array}$ \\
\hline Subtema 3 & & $\begin{array}{l}\text { Tratamento de informação/utilização de fontes: } \\
\text { - Utiliza metodologia específica da disciplina; } \\
\text { Compreensão bistórica (contextualização:) } \\
\text { - Interpreta o papel dos indivíduos e dos grupos } \\
\text { na dinâmica social; } \\
\text { Comunicação em história: } \\
\text { - Utiliza diferentes formas de comunicação escrita } \\
\text { na produção de narrativas, sínteses, relatórios } \\
\text { e pequenos trabalhos temáticos, aplicando o } \\
\text { vocabulário específico da História na descrição }\end{array}$ \\
\hline Subtema 4 & & $\begin{array}{l}\text { Compreensão histórica (temporalidade:) } \\
\text { - Identifica e caracteriza fases principais da } \\
\text { evolução histórica e grandes momentos de } \\
\text { ruptura }\end{array}$ \\
\hline
\end{tabular}

123 As competências referidas são as constantes dos programas das disciplinas para o 3. ${ }^{\circ}$ CEB (M. Educação, 2002). 


\begin{tabular}{|c|l|}
\hline Tarefas & \multicolumn{1}{c|}{$3 .^{\circ}$ Ciclo do Ensino Básico } \\
\hline \multirow{3}{*}{ Tarefa } & Comunicação em história: \\
Final & Enriquece a comunicação através da análise e produção de materiais \\
& - Recria situações históricas e expressão de ideias e situações, sob a forma \\
& plástica, dramática ou outra. \\
\hline
\end{tabular}

Tabela 4.6 - Tarefas de avaliação

\begin{tabular}{|c|l|}
\hline Subtemas & \multicolumn{1}{c|}{ Tarefas } \\
\hline 1 & Individual - responder a um questionário online (questões de associação) \\
\hline 2 & Em grupo - escrever uma cronologia \\
\hline 3 & Em grupo - escrever uma notícia \\
\hline 4 & Individual - responder a um questionário online (questões de escolha múltipla) \\
\hline No final & Em grupo - Elaboração de uma história de ficção sobre o tema estudado \\
\hline
\end{tabular}

As tarefas relativas aos subtemas 2 e 3 foram acompanhadas de um documento com os respetivos critérios de avaliação, para que os alunos pudessem também autoavaliar-se. No caso das tarefas dos subtemas 1 e 4 as respostas corretas eram apresentadas após a submissão do questionário.

A última tarefa, aglutinadora de todo o estudo, consistia na elaboração de uma pequena história sobre o período estudado, que incorporasse tanto factos históricos como elementos criados pelos alunos. Para a concretização desta tarefa os alunos tinham acesso a um guião com todas as indicações necessárias para a sua execução e que pretendia fomentar o desenvolvimento das competências relacionadas com a comunicação em história, tal como referimos já na Tabela 4.5, mas também se deseja que a realização desta tarefa contribua para que os alunos aprendam a utilizar as fontes na construção do conhecimento histórico, selecionando a informação relevante e adequada para o trabalho em causa e aprendam a construir documentos através dos quais possam reconstruir o passado.

\section{iv) Questionário de opinião sobre o estudo}

Foi preparado um questionário de opinião sobre o estudo, dividido em duas partes, para avaliação do trabalho desenvolvido ao longo das sessões. 
A primeira parte diz respeito à opinião dos alunos sobre as sessões e a forma de aprendizagem através do iPad e do programa iTunes $U$ e a segunda parte é dedicada à opinião dos alunos sobre a concretização da história, tarefa final do nosso estudo, que já referimos, e que inclui a utilização de diferentes programas do iPad para a sua concretização.

Na Parte I, a primeira dimensão refere-se aos recursos e tarefas realizadas, e é composta por seis itens, de escolha múltipla, sendo possível apenas no item 4 assinalar mais do que uma opção. Pretende-se nesta dimensão aferir as opiniões dos alunos sobre a utilização do iPad nas aulas de História (itens 1 e 2), sobre se essa utilização contribuiu para aprenderem melhor ou pior do que nas aulas tradicionais (item 3), sobre como caracterizavam a experiência (item 4), se as atividades propostas contribuíram para aumentar o interesse pela matéria lecionada (item 5) e se ver os conteúdos no manual digital tinha sido mais esclarecedor do que no manual em papel (item 6).

A segunda dimensão incide na comparação entre o manual digital e a aprendizagem dita "clássica", e contém oito afirmações que os alunos deveriam responder de acordo com a escala de tipo Likert (item 7). As afirmações apresentadas procuram aferir as vantagens do manual digital e o seu papel na sala de aula.

A terceira dimensão refere-se às competências trabalhadas, apresentando-se um item (8) de escolha múltipla e com possibilidade de assinalar mais do que uma opção. As competências referidas eram relativas à análise e seleção de informação, capacidade de produção de textos, capacidade de síntese e de trabalho em grupo, sendo ainda possível os alunos identificarem outras competências para além das apresentadas. Esta dimensão contempla também um item (9) de resposta aberta, pretendendo-se que os alunos escrevessem a sua opinião geral sobre o estudo.

Na Parte II do questionário apresenta-se a quarta dimensão, que diz respeito à construção da história final. Aqui apresentam-se, em primeiro lugar, seis afirmações sobre a elaboração da história, que deveriam ser respondidas de acordo com a escala de tipo Likert (item 1). Em seguida, os alunos têm três itens ( 2 a 4) de escolha múltipla (sendo possível assinalar apenas uma opção) relativos à sua opinião sobre as história realizadas pelos outros participantes 
e, finalmente, um item (5) de resposta aberta para que pudessem deixar a sua opinião sobre a realização da história.

\section{f) Recolha de dados}

A recolha dos dados foi efetuada sempre através de documentos escritos, pelos investigadores de acordo com a calendarização que apresentamos na Tabela 4.7 e foi realizada, entre os meses de maio e junho.

Tabela 4.7 - Sessões para recolha de dados

\begin{tabular}{|l|c|}
\hline Dados recolhidos (março a junho) & Sessões \\
\hline Resolução do teste diagnóstico de conhecimentos (inicial) & 1 \\
\hline Questionário sobre literacia digital & 1 \\
\hline Observação & Todas \\
\hline Tarefa do subtema 1 & 2 \\
\hline Tarefa do subtema 2 & 3 \\
\hline Tarefa do subtema 3 & 5 \\
\hline Tarefa do subtema 4 & 5 \\
\hline Observação da realização da história & 6 a 8 \\
\hline Resposta ao questionário de opinião sobre o estudo & 9 \\
\hline Resolução do teste de conhecimentos (final) & 9 \\
\hline
\end{tabular}

\section{g) Tratamento de dados}

No que diz respeito ao tratamento dos dados, pretendemos recorrer a várias análises de conteúdo, a partir da interpretação de diferentes questionários escritos, como forma de "sintetizar e reduzir a quantidade de informação disponível, para [chegar] a uma interpretação das principais tendências e padrões presentes nos seus dados" (Lima, 2013: 7).

Ao longo do estudo realizado utilizámos diferentes instrumentos, cujos dados foram submetidos a tratamento estatístico com recurso ao Microsoft 
Excel 2010, para Macintosh, e ao programa SPSS Statistics, versão 22.0, da IBM para Macintosh.

Realizámos um teste diagnóstico de conhecimentos, no início e um teste no final do estudo. Tendo presente as condições do estudo e o número diminuto de sujeitos, realizou-se o teste não paramétrico e, para se comparar dois testes num mesmo grupo, utilizou-se o de Wilcoxon Signed Rank. O nível de significância estatística adotado é de $\mathrm{p}=0,05$.

As tarefas intermédias foram cotadas em conformidade com os critérios de correção indicados no manual digital.

Relativamente aos itens cuja resposta implicava uma escala de tipo Likert de cinco pontos, sendo a classificação mais próxima de 1 a mais negativa e a classificação mais próxima de 5 a mais positiva, considerou-se que os participantes revelavam uma atitude negativa, tal como no trabalho de Carvalho (1998), quando a média dos resultados fosse entre 1,0 e 2,5; teriam atitude indefinida se a média fosse igual ou maior que 2,5 e menor que 3,5 e, finalmente, positiva se igual a 3,5 e até 5,0.

As duas questões de resposta aberta serviam para dar oportunidade aos participantes de destacar alguma questão que julgassem ser pertinente e que não estivesse contemplada nas restantes perguntas do questionário. Para análise destas duas questões identificaram-se as categorias à posteriori, apresentando-se as frequências e percentagem.

\section{h) Tema e recursos}

\section{i) Escolha do tema e definição dos objetivos de aprendizagem}

Decidimos recorrer a um tema que, como referimos no início do capítulo, é tratado no 9. ${ }^{\circ}$ e que ilustra essas imensas especificidades pedagógicas da História: a revolução democrática de abril de 1974.

O manual digital que organizámos apresenta-se então composto pela definição das competências previstas para esse tema, organizadas de acordo com os programas do Ministério da Educação para esta disciplina e assenta no pressuposto da preparação do aluno para o desenvolvimento de competên- 
cias ao nível do trabalho autónomo e colaborativo bem como do raciocínio crítico.

Com este novo recurso e a utilização de uma tecnologia digital móvel, esperamos que os alunos sejam colocados frente a desafios e obstáculos que possam ultrapassar através do uso da sua criatividade e de diferentes domínios cognitivos.

No programa de História do Terceiro Ciclo, datado de 1991, este tema insere-se no capítulo 11.3.2, Portugal do autoritarismo à democracia - Portugal democrático, e tem como aprendizagens relevantes previstas, que os alunos:

- conheçam as razões que levaram sectores importantes das Forças Armadas a revoltarem-se contra o regime, em 25 de Abril de 1974, explicando o apoio popular a esse movimento e caracterizando o processo revolucionário que então se desencadeia;

- compreendam o significado da democratização tornada possível com o 25 de Abril, identificando as principais instituições democráticas e sublinhando a importância para as populações da dinamização do poder autárquico e da criação das regiões autónomas;

- conheçam as circunstâncias em que se processou a descolonização e algumas das suas consequências, nomeadamente a necessidade de integração em Portugal de centenas de milhares de nacionais regressados ao país num curto espaço de tempo (M. Educação, 1991: 77).

Trata-se de um assunto relativamente complexo, dado que, com a existência de tantas forças, exige a identificação de diferentes perspetivas e mudanças sérias de comportamentos num curto espaço de tempo (1973-1975) e que combina uma série de circunstâncias que levaram à própria Revolução, aos seus resultados diretos e ao que em seguida teve lugar (o período do "Verão Quente"), mas que também se torna propício pela variedade de fontes de que dispomos, ao contrário do que pode acontecer com tantos outros acontecimentos.

Nesta temática, como em tantas outras no que toca aos conteúdos que são normalmente ensinados em História, é necessário explicar aos alunos que 
houve uma conjuntura muito específica que deu azo à concretização de uma revolução e que um conjunto de ações específico acabou por determinar o resultado ocorrido.

Neste exemplo, torna-se, por vezes, difícil auxiliar os alunos na compreensão de que um determinado conjunto de acontecimentos não dará sempre origem aos mesmos resultados. Aqui se verifica a enorme diferença entre a aprendizagem da História e a de uma qualquer ciência exata onde os fatores determinam sempre o mesmo resultado.

Para o efeito, estruturámos a temática em estudo em quatro subtemas, cada um articulado com o Programa de 1991 e com as Metas Curriculares que devem ser atingidas pelos alunos, de acordo com o que especificamos na Tabela 4.8.

Tabela 4.8 - Articulação entre as aprendizagens relevantes definidas ministerialmente e os subtemas definidos no manual digital do iTunes $U$

\begin{tabular}{|c|c|c|}
\hline Subtema & Metas Curriculares & $\begin{array}{c}\text { Aprendizagens } \\
\text { programáticas relevantes }\end{array}$ \\
\hline $\begin{array}{l}\text { 1. O Movimento } \\
\text { das Forças } \\
\text { Armadas e a } \\
\text { revolução }\end{array}$ & $\begin{array}{l}\text { 1. Explicar as motivações do } \\
\text { Golpe Militar do } 25 \text { de Abril } \\
\text { de } 1974 \text {. } \\
\text { 2. Mencionar os principais } \\
\text { acontecimentos do } 25 \text { de } \\
\text { Abril de } 1974 \text {. }\end{array}$ & \multirow[t]{2}{*}{$\begin{array}{l}\text { Conhecer as razões que levaram secto- } \\
\text { res importantes das Forças Armadas a } \\
\text { revoltarem-se contra o regime, em } 25 \\
\text { de Abril de } 1974 \text {, explicando o apoio } \\
\text { popular a esse movimento e caracteri- } \\
\text { zando o processo revolucionário que } \\
\text { então se desencadeia; }\end{array}$} \\
\hline $\begin{array}{l}\text { 2. Evolução } \\
\text { política e } \\
\text { ideológica } \\
\text { da sociedade } \\
\text { portuguesa } \\
\end{array}$ & $\begin{array}{l}\text { 3. Descrever sucintamente } \\
\text { o processo revolucionário, } \\
\text { salientando as divergências } \\
\text { dos projetos políticos em } \\
\text { confronto. }\end{array}$ & \\
\hline $\begin{array}{l}3 . \\
\text { Descolonização } \\
\text { portuguesa }\end{array}$ & $\begin{array}{l}\text { 4. Identificar as consequên- } \\
\text { cias do processo de desco- } \\
\text { lonização dos antigos terri- } \\
\text { tórios não autónomos. }\end{array}$ & \\
\hline $\begin{array}{l}\text { 4. A } \\
\text { Constituição } \\
\text { de } 1976 \text { e a } \\
\text { primeira revisão } \\
\text { constitucional } \\
\text { (1982) }\end{array}$ & $\begin{array}{l}\text { 5. Caracterizar a } \\
\text { organização da sociedade } \\
\text { democrática a partir da } \\
\text { Constituição de } \\
1976 .\end{array}$ & $\begin{array}{l}\text { Compreender o significado da demo- } \\
\text { cratização tornada possível com o } 25 \\
\text { de Abril, identificando as principais } \\
\text { instituições democráticas e sublinhan- } \\
\text { do a importância para as populações } \\
\text { da dinamização do poder autárquico e } \\
\text { da criação das regiões autónomas. }\end{array}$ \\
\hline
\end{tabular}


Por isso, definimos que os alunos teriam de responder a questionários online $^{124}$, acessíveis a partir do iTunes $U$, nomeadamente para avaliação dos subtemas 1 e 4, sendo que no primeiro subtema o que lhes foi pedido foi que soubessem associar determinadas afirmações com os respetivos autores e, no subtema 4 o questionário online incluía um conjunto de questões com respostas de escolha múltipla.

Já o subtema 2 levaria os alunos à execução de uma cronologia sobre os acontecimentos aí relatados, tendo por objetivo a construção de uma perspetiva diacrónica desses mesmos acontecimentos. Seguem também a mesma linha de trabalho o subtema 3 contendo tarefas que procuram que os alunos sejam capazes de sintetizar ideias, através da redação de uma pequena notícia. Neste caso pretende-se que os alunos se apropriem dos conteúdos e sejam capazes de sintetizar ideias, promovendo assim, sobretudo, o raciocínio escrito.

Todo o trabalho dos alunos pode ser realizado no $i P a d$, quer no próprio iTunes $U$, através da área de "notas", quer através da aplicação "Bloco de Notas" existente de origem em qualquer iPad. Uma vez que os critérios de correção se encontravam junto do guião de cada tarefa, era possível ao alunos procederem à sua própria avaliação. Esta possibilidade teve como objetivo dar aos alunos a hipótese de aplicarem os conhecimentos adquiridos e de verificarem e corrigirem os seus próprios erros, numa perspetiva construtivista da sua aprendizagem. Para o professor corrigir os trabalhos realizados os alunos teriam de lhos fazer chegar via email.

As atualizações que tem vindo a sofrer o iTunes $U$ permitem agora que os trabalhos sejam submetidos diretamente a partir da aplicação, sendo possível ao professor proceder à avaliação dos mesmos também a partir da plataforma. Para além disso, o iTunes $U$ permite agora também a criação de fóruns de discussão, criados pelos docentes e que podem contar com a participação de todos os inscritos no curso.

124 Estes questionários foram preparados através da ferramenta Google Forms que permite a disponibilização de questionários online. Os seus resultados podem ser consultados através de uma folha de cálculo no Google Docs. 


\section{ii) Escolha da tecnologia}

Partindo das ideias de Barca (2007), Ally (2009) e Prensky (2010), mas sobretudo de Siemens (2004), propusemos um estudo que rentabilizasse o iTunes, para a aprendizagem de um subcapítulo do programa de História para o 9..$^{\circ}$ ano de escolaridade, que permitisse aprender de forma autónoma em espaço de aula.

Escolhemos o iPad para o nosso trabalho pois, apesar de ser uma plataforma proprietária, pode mostrar como os grandes ecossistemas de distribuição e de divulgação de conteúdos online estão a integrar uma forte componente educativa.

A Apple, que tem uma longa história de aposta no mercado da educação (onde até teve sempre mais quota do que no mercado empresarial), tem vindo a desenvolver cada vez mais estratégias canalizadas para esse sector. No lançamento do iBooks 2 para $i P a d$, Philip Schiller (vice-presidente sénior da Apple para o Marketing Mundial) referia-se à veia educativa da Apple nos seguintes termos:

a educação está entranhada no DNA da Apple e o iPad pode ser o nosso produto educacional mais empolgante até agora. Com 1,5 milhão de iPads já em uso em instituições educacionais, incluindo mais de mil implantações individuais, o iPad está sendo adotado rapidamente por escolas nos EUA e em todo o mundo ${ }^{125}$.

Uma dessas estratégias foi a disponibilização no iTunes, loja online da Apple para distribuição de música e de outros conteúdos de lazer, de uma nova secção exclusivamente constituída por conteúdos educacionais preparados para dispositivos Apple. Essa nova secção, o iTunes $U$, começou por disponibilizar os seus conteúdos através de podcasts com PDFs de apoio, que

125 Tradução nossa. No original: Education is deep in Apple's DNA and iPad may be our most exciting education product yet. With 1.5 million iPads already in use in education institutions, including over 1,000 one-to-one deployments, iPad is rapidly being adopted by schools across the US and around the world. Veja-se a notícia completa em http://www. apple.com/pr/library/2012/01/19Apple-Reinvents-Textbooks-with-iBooks-2-for-iPad.html (acessível em 21/04/2014). 
correspondiam a uma determinada disciplina ou tema. Em maio de 2007, a Apple lançava o iTunes $U$ como

uma área específica dentro da iTunes Store [...] com conteúdos gratuitos, como palestras de cursos, aulas de línguas, demonstrações laboratoriais, destaques desportivos e visitas a campus fornecidas pelas melhores universidades dos EUA [...]. Criado em colaboração com universidades, o iTunes $U$ torna mais fácil do que nunca estender a aprendizagem, explorar interesses, aprender mais sobre uma escola e manter contacto com uma alma mater. O conteúdo do iTunes pode ser carregado num $i P o d{ }^{\circledR}$ com apenas um clique e experimentado a qualquer momento, tornando a aprendizagem a partir de uma palestra tão simples quanto apreciar a música ${ }^{126}$.

Já em 2010, e com o lançamento do iPad, a Apple pôde ampliar este formato criando algo mais parecido com um sistema de apoio ao ensino, com toda uma estrutura, diversificadas atividades e comunicação. Recorrendo a uma intensa estratégia de marketing, o investimento feito pela marca procurou demonstrar que o iPad poderia ser uma eficaz ferramenta de aprendizagem $^{127}$. Para além de servir como base a partir da qual se pode aceder a uma

126 Tradução nossa. No original: a dedicated area within the iTunes Store [...] featuring free content such as course lectures, language lessons, lab demonstrations, sports highlights and campus tours provided by top US colleges and universities [...]. Created in collaboration with colleges and universities, iTunes $U$ makes it easier than ever to extend learning, explore interests, learn more about a school and stay connected with an alma mater. Content from iTunes can be loaded onto an iPod® ${ }^{\circledR}$ with just one click and experienced on-the-go, anytime, making learning from a lecture just as simple as enjoying music. Veja-se a notícia completa em https://www.apple.com/pr/library/2007/05/30Apple-Announces-iTunes-U-onthe-iTunes-Store.html (acessível em 21/04/2014).

127 Em fevereiro de 2013 uma notícia da Apple (http://www.apple.com/pr/library/ 2013/02/28iTunes-U-Content-Tops-One-Billion-Downloads.html - acessível em 21/04/2014) anunciava a realização de mais de um bilião de downloads na plataforma iTunes U considerando-a "the world's largest online catalog of free educational content from top schools and prominent libraries, museums and organizations helping educators create courses including lectures, assignments, books, quizzes and more for iOs users around the world". Para além disso, esta notícia ainda reporta que "Educators can create iTunes U courses in 30 countries [...]. These courses, and other education content, can be accessed via the iTunes $\mathrm{U}$ app in 155 countries. In addition to thousands of individual iTunes U learning materials, over 75,000 educational apps are now available for iOS devices on the App Store ${ }^{\text {SM }}$. Additionally, with the free iBooks ${ }^{\circledR}$ Author app on the Mac® App Store, writers and publishers continue to bring ideas and stories to life sharing more than 10,000 original Multi-Touch ${ }^{\mathrm{TM}}$ books with the world". 
enorme quantidade e variedade de conteúdos, o iPad permite ainda, através de outras aplicações, nomeadamente o iBooks Author ${ }^{128}$, que sejam os próprios utilizadores a criar novos conteúdos como ebooks também eles de teor educativo e cujo resultado pode também ser integrado no iTunes $U$.

Assim, e apesar de o iTunes $U$ ser uma plataforma proprietária (ainda que de acesso gratuito), mostra como a atividade de ensino e de aprendizagem se pode desenrolar num ambiente criado para os nativos digitais, com música ou vídeos online, aplicativos para telemóveis, jogos, e, sobretudo, no mundo dos conteúdos just-for-me.

Assim, no nosso estudo recorremos a programas desenvolvidos para iPad, nomeadamente a plataforma iTunes $U$, uma vez que através dela,

os alunos podem reproduzir palestras em vídeo ou áudio e fazer anotações sincronizadas com a palestra. Podem ler livros e ver apresentações. Ver uma lista de todas as tarefas do curso e marcá-las quando estiverem concluídas'29 (Apple, 2013: sp).

De facto, esta plataforma permite uma estreita articulação entre a produção de conteúdos educativos, canais de distribuição, aplicações que se destinam à produção de materiais e ainda uma aplicação para consumo através de dispositivos móveis (iPad ou iPhone).

Assim, o iPad pode funcionar como o eixo de um ecossistema no qual se encontram todos os componentes necessários para que uma funcional experiência de aprendizagem possa ser desenvolvida: nele encontramos um canal de distribuição da informação (o iTunes), uma ferramenta de autoria de cursos ou módulos digitais de aprendizagem (o iTunes U Course Manager), diferen-

128 A aplicação iBooks Author permite ao utilizador, de uma forma bastante intuitiva, a criação de livros interativos, que podem integrar texto, vídeo, objetos 3D, diagramas interativos, gráficos, entre muitas outras coisas. O objetivo desta aplicação centra-se no aumento da motivação e da produtividade dos alunos: "With its fast, fluid navigation, easy highlighting and note-taking, searching and definitions, plus lesson reviews and study cards, the new iBooks 2 app lets students study and learn in more efficient and effective ways than ever before" (http://www.apple.com/pr/library/2012/01/19Apple-Reinvents-Textbookswith-iBooks-2-for-iPad.html - acessível em 21/04/2014).

129 Tradução nossa. No original: students can play video or audio lectures and take notes that are synchronized with the lecture. They can read books and view presentations. See a list of all the assignments for the course and check them off as they're completed. 
tes ferramentas de autoria de manuais ou de trabalhos complexos a realizar pelos alunos (como o Book Creator) e finalmente o software para consumo de informação e interação com a disciplina (o iTunes $U$ ). Todas estas componentes permitem uma variedade de atividades como seguir determinadas tarefas, fazer notas enquanto visualizam vídeos ou aceder a mais informação online, entre outras possibilidades, tornando a experiência de aprendizagem não só mais motivante mas, sobretudo, mais eficaz (Figura 4.1).

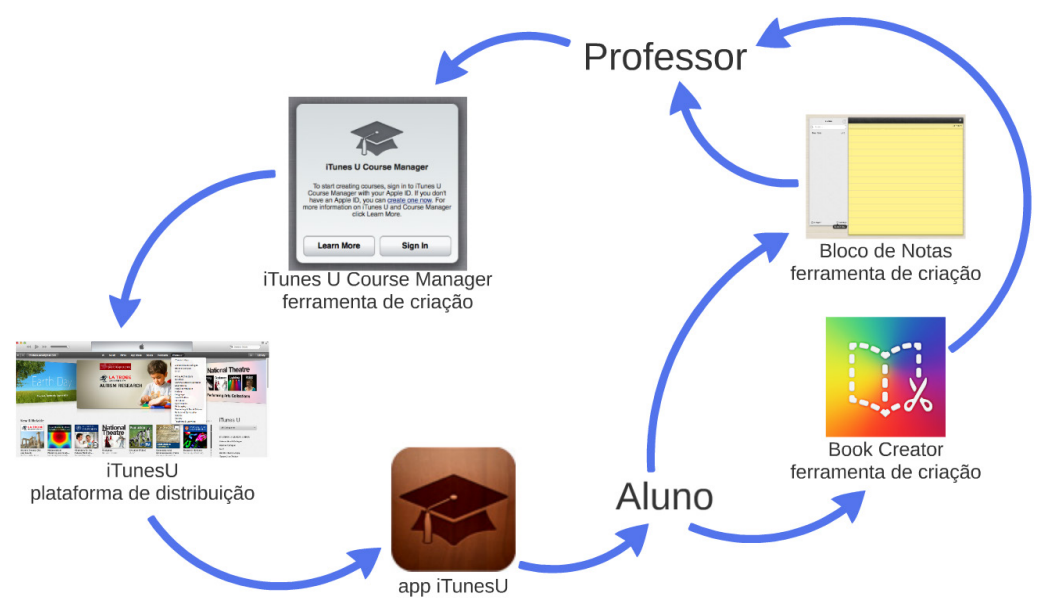

Figura 4.1 - Descrição da interação entre os componentes necessários ao desenvolvimento da experiência de aprendizagem assente no iPad

Entendemos também que esta plataforma, ainda que proprietária, nos poderá mostrar o contexto futuro. Apesar desse caráter assumido ainda pela Apple, esperamos que soluções deste género possam vir a ser implementadas de forma aberta e partilhável, tal como aconteceu já com no passado com outras plataformas (como, por exemplo, a Moodle).

\section{Utilização do iTunes para criar o manual digital}

Para a montagem do estudo foi necessário utilizar o iTunes $U$ Course Manager, que "é uma ferramenta baseada na Web destinada a formadores afi- 
liados ou não afiliados a instituições de educação que pretendam criar, editar, conceber, distribuir e leccionar cursos de forma totalmente digital"130.

Esta ferramenta permite reunir no mesmo espaço, conteúdos, questionários e materiais diversificados como

áudio, vídeo, livros e outros materiais educativos, juntamente com resumos, folhas informativas e questionários, e disponibilizar rápida e facilmente o curso e os materiais aos alunos sob a forma de um curso do iTunes $U$ para o aplicativo iTunes $U^{131}$.

Permite também criar, de uma forma muito prática e intuitiva, um curso em formato digital, onde podemos inserir informação sobre os docentes, páginas de informação, materiais audiovisuais, posts e checklists $^{132}$ para os utilizadores (Figura 4.2).

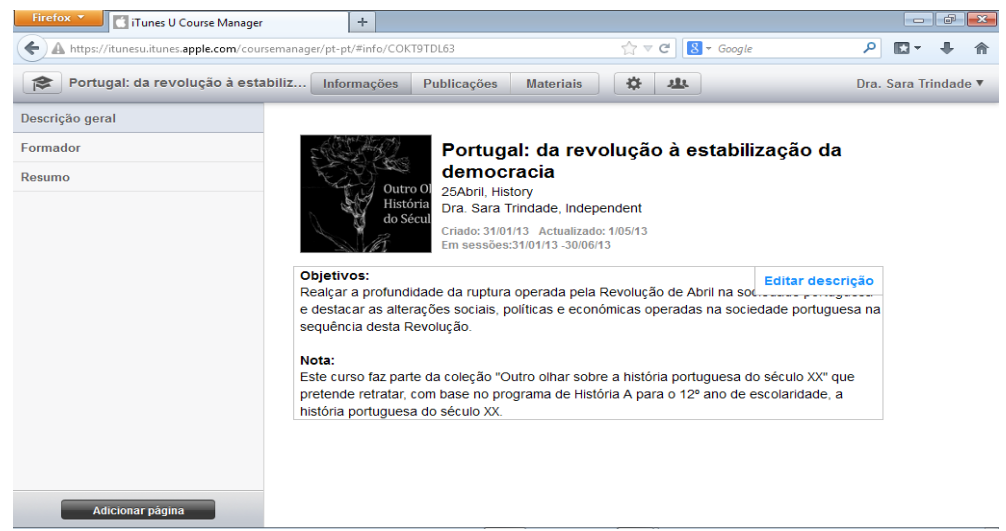

Figura 4.2 - Descrição geral do Curso na plataforma iTunes U Course Manager

A inserção da documentação e a descrição do trabalho a desenvolver é feita nesta ferramenta de produção, criando publicações consoante os nossos objetivos de trabalho (Figura 4.3).

130 https://iTunes U.itunes.apple.com/ (acessível em 21/04/2014).

131 https://iTunes U.itunes.apple.com/ (acessível em 21/04/2014).

132 Estas checklists servem apenas como possível guia de trabalho do aluno uma vez que o professor só verificando o iPad consegue saber que itens foram já visualizados. 


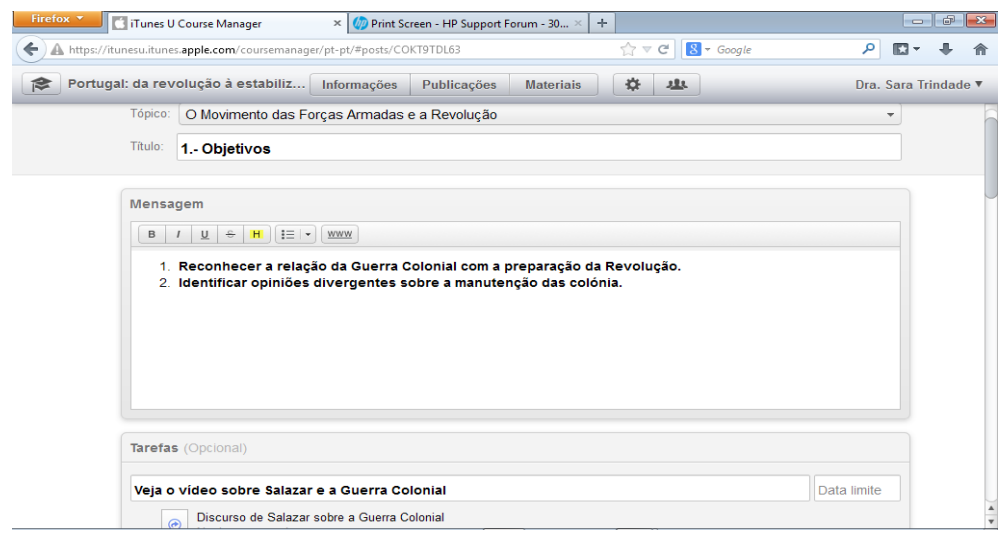

Figura 4.3 - iTunes $U$ Course Manager: introdução de publicações e de materiais

No nosso estudo entendemos ser importante a estruturação dos conteúdos em 4 subtemas, cada um com os seus objetivos, documentação variada para analisar e uma tarefa de avaliação (Figura 4.4).

Procurámos também que a documentação fornecida fosse variada, para que os alunos pudessem tomar contacto com diversas fontes, de uma forma progressiva, podendo assim ir testando os seus conhecimentos através da concretização das tarefas intermédias.

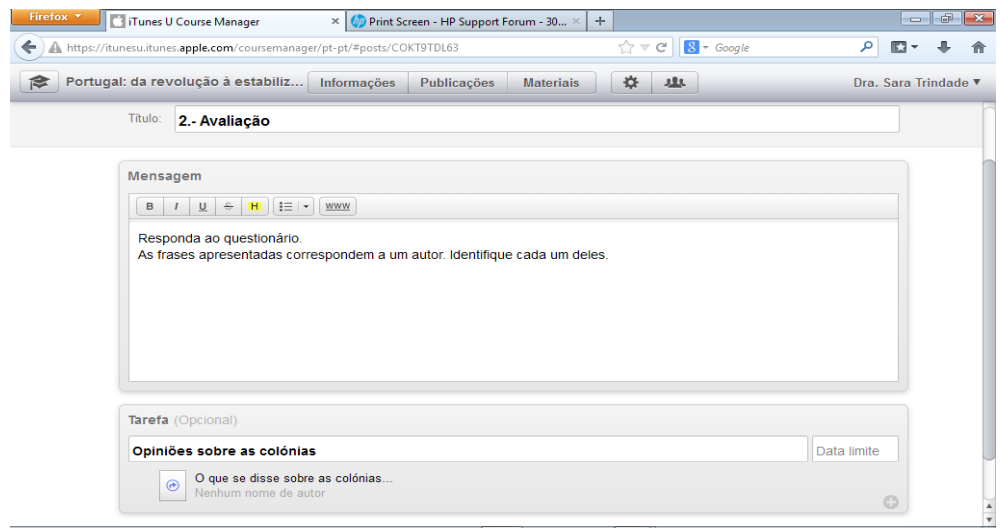

Figura 4.4 - iTunes $U$ Course Manager:

introdução de materiais para a indicação das tarefas de avaliação 
Para este manual digital decidimos também que seria importante os alunos visualizarem uma pequena cronologia sobre o século XX, pelo que foi produzido um vídeo para o efeito e introduzido nesta ferramenta, para visualização antes dos subtemas (Figura 4.5).

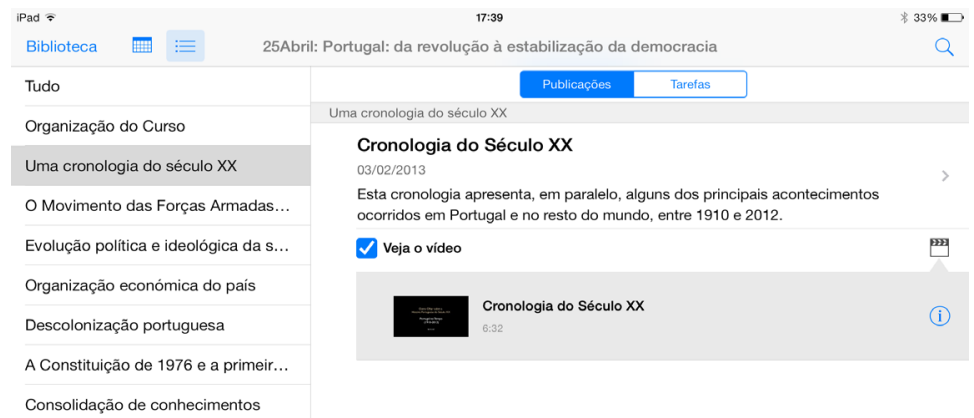

Figura 4.5 - iTunes $U$ : apresentação do vídeo com uma cronologia sobre o século XX

Os diferentes materiais podem ser carregados na aplicação quer através de upload feito a partir do computador, a partir da Web ou da plataforma iTunes ou ainda do interface "Materiais" (para onde podem ter sido já descarregados documentos) (Figura 4.6).

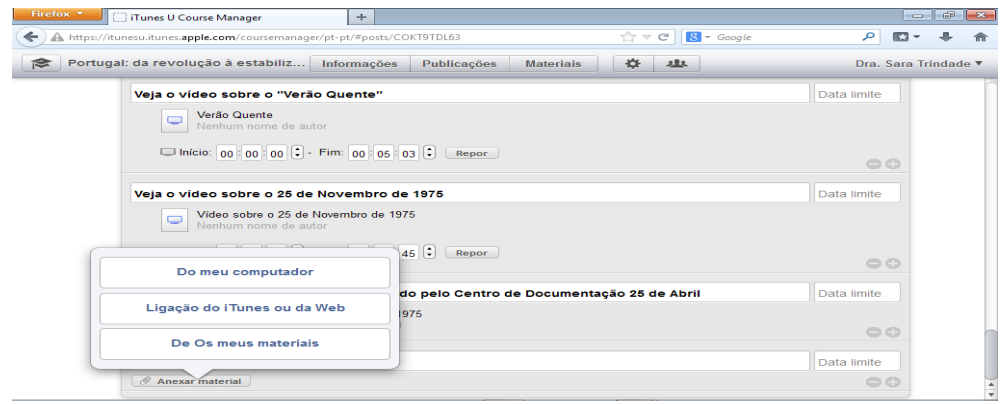

Figura 4.6 - iTunes U Course Manager: upload de documentos 
No caso dos vídeos é também possível especificar se queremos que visionem o recurso todo ou apenas uma parte do mesmo. Todos os materiais inseridos através de qualquer destas possibilidades ficam arquivados no interface "Materiais", distribuídos pelas diferentes tipologias de recursos (Figura 4.7).

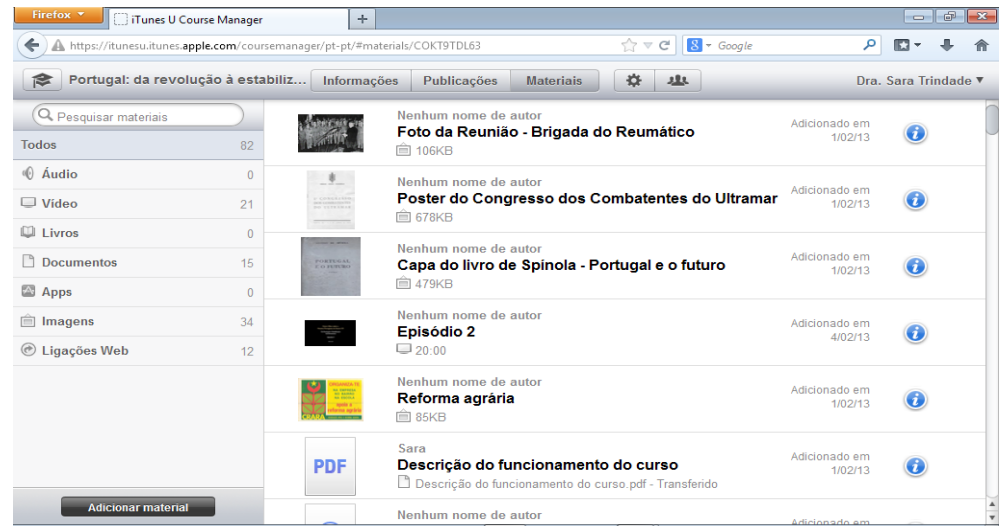

Figura 4.7 - iTunes U Course Manager: interface "Materiais"

Acesso ao curso online

Uma vez introduzidos todos os elementos, o que pode ser feito antes de iniciarmos o curso online ou durante o mesmo (uma vez que é sempre possível fazer alterações e atualizações), é possível inserir este curso na plataforma iTunes $U$, se pudermos integrar o nosso curso num determinado estabelecimento de ensino que esteja inscrito no programa, ficando assim acessível a qualquer pessoa. Não estando associados a qualquer estabelecimento de ensino basta fornecer um código URL de acesso aos utilizadores (Figura 4.8), os quais que terão de aceder através dos seus iPad ou iPhone, quando online, e que, posteriormente, carece de confirmação do formador do curso para ativar a participação (Figura 4.9). 


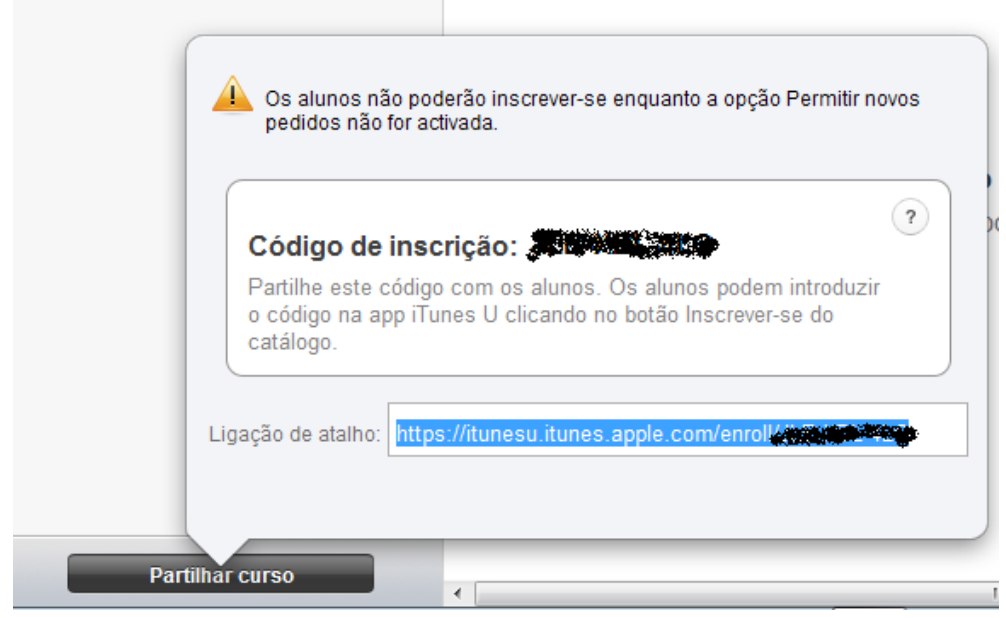

Figura 4.8 - iTunes U Course Manager: código URL de acesso

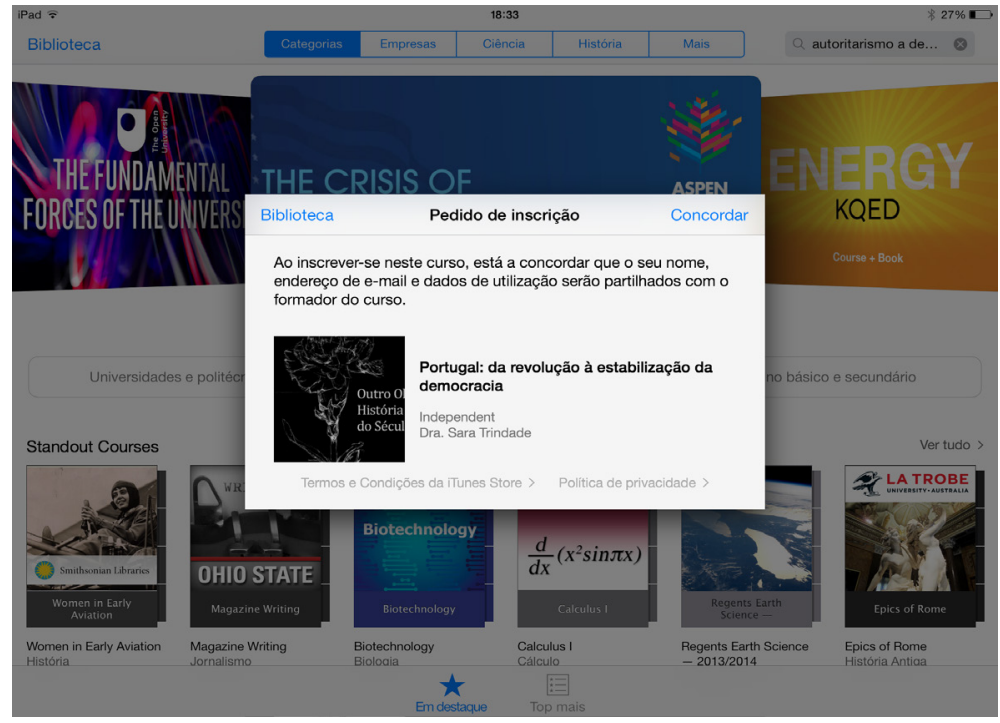

Figura 4.9 - iTunes $U$ : pedido de inscrição na plataforma

Obtido o acesso ao curso, os alunos acedem à plataforma iTunes $U$ em iPad ou iPhone, onde visualizam todos os conteúdos do curso e podem aceder a todos os documentos. Estes, com exceção das páginas web, podem ser descarregados para o iPad ou iPhone e visualizados mesmo não existindo uma ligação à Internet disponível. 
É importante destacar que nesta aplicação os alunos encontram não só a informação disponibilizada em diferentes materiais mas também todos os recursos relativos às tarefas de avaliação intercalar (o guião de trabalho e os respetivos parâmetros de correção), o acesso a páginas web onde podem aceder a mais informação e também o acesso a uma outra ferramenta de criação, o Book Creator, para concretização da tarefa final, de consolidação dos conhecimentos adquiridos (Figura 4.10).

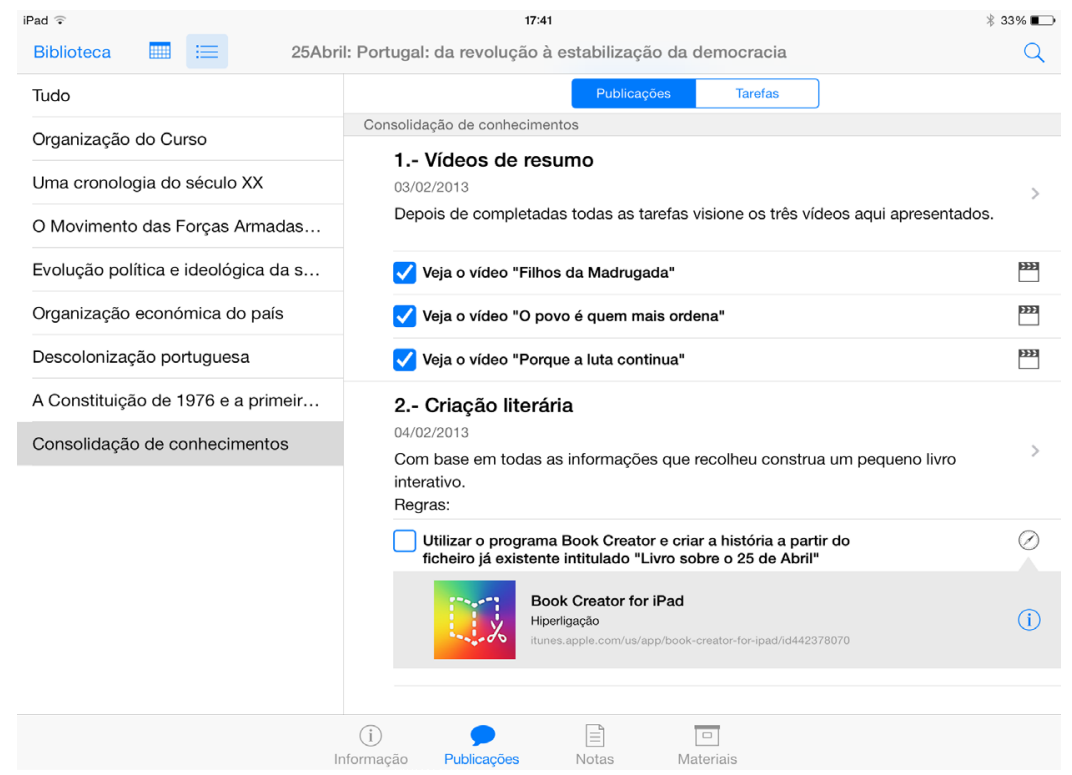

Figura 4.10 - iTunes $U$ : acesso através da aplicação ao Book Creator

\section{O Book Creator e o seu papel na estratégia educativa}

A partir do link apresentado, os alunos acedem à loja iTunes para descarregarem a aplicação Book Creator que é gratuita, intuitiva e permite a criação de livros que podem incluir não só texto (com uma oferta de formatação variada) mas também imagens ou vídeos (gravados no iPad ou criados pelos alunos), sons existentes também no iPad ou gravados no momento e até mesmo uma banda sonora (Figura 4.11). 


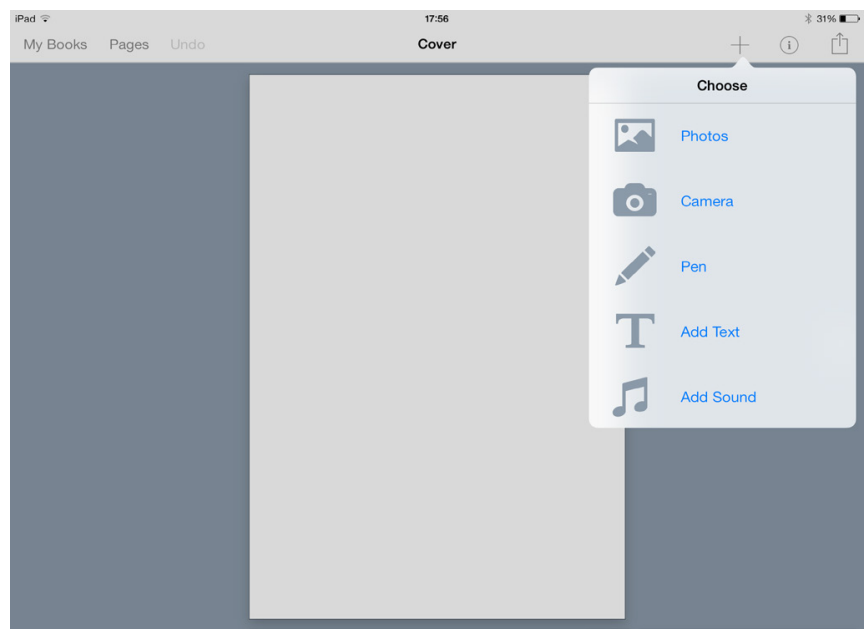

Figura 4.11 - Book Creator

Depois de os alunos trabalharem na criação da história, com o Book Creator, têm ainda a possibilidade de fazer upload da mesma para uma outra aplicação que existe de raiz nos iPads, o iBooks, e que serve para descarregar e ler livros ou conteúdos em PDF. Se o fizerem criam um recurso novo que pode estar ao mesmo nível dos recursos que antes visualizaram na plataforma iTunes $U$, e que é uma síntese que engloba informação multimédia, nova e já existente, acerca dos conhecimentos adquiridos (Figuras 4.12 e 4.13).

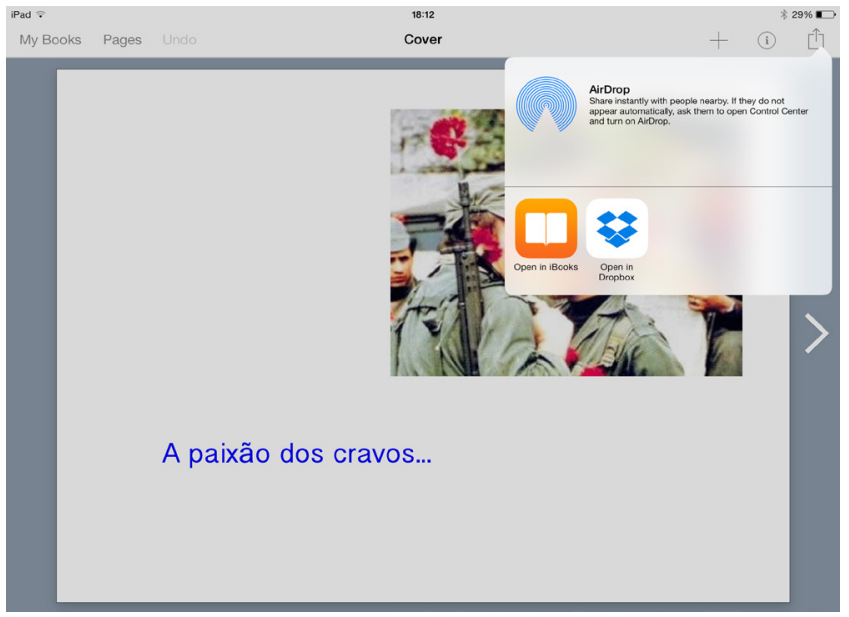

Figura 4.12 - Book Creator: possibilidade de upload ou partilha da história criada 


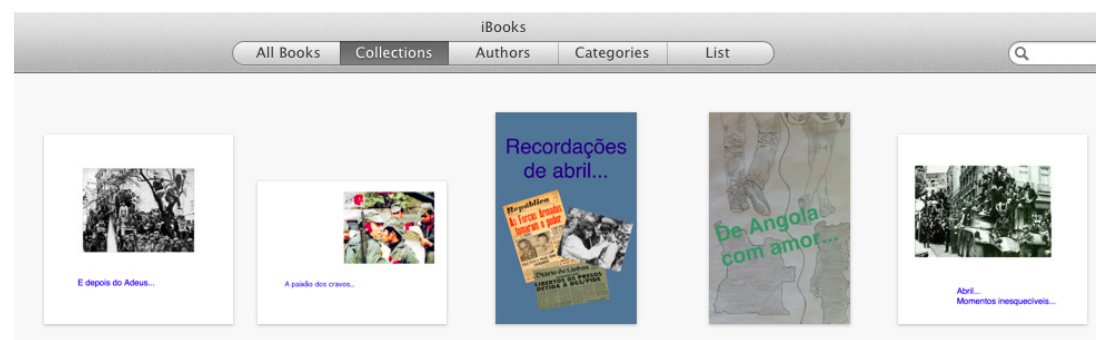

Figura 4.13 - iBooks: livros com histórias criadas por alunos

Do lado do professor é importante saber trabalhar com programas para produção de documentos, elaboração ou preparação de vídeos ou imagem mas, sobretudo, é necessária a criação de uma conta iTunes (para a qual serve qualquer endereço de email) e alguma preparação para a introdução de todos os elementos desejados no iTunes U Course Manager, bem como para trabalhar com o Book Creator e mesmo com o iBooks. Contudo, todas estas ferramentas são de fácil utilização e estão acompanhadas de tutoriais que fornecem toda a informação sobre cada uma delas e como trabalhar com as mesmas.

No caso dos alunos, é necessário, para aqueles que nunca trabalharam com tablets, dar-lhes algumas explicações sobre o seu funcionamento geral e pedir-lhes também a criação de uma conta iTunes para poderem aceder ao iTunes $U$. Todo o trabalho a realizar nesta aplicação é de fácil explicação aos utilizadores, sendo necessário que eles aprendam, sobretudo, como podem tirar partido das diferentes possibilidades desta aplicação, como poderem tirar notas durante a visualização de um vídeo (ficando o registo na própria aplicação do momento do vídeo a que diz respeito cada nota), fazer anotações genéricas sobre os conteúdos a visualizar, assinalar todos os documentos observados ou tarefas concretizadas.

A partir do manual digital no iTunes $U$, como atrás explicámos, é-lhes dado também o acesso a outras páginas web com mais informação e a questionários online, cujos links encontram na aplicação, e que, no caso destes questionários, apresentam também um guião do trabalho a desenvolver e, finalmente, 
às aplicações que atrás referimos para elaboração da história final e para a sua apresentação formal após concluída.

Cremos que estas ferramentas, em especial a plataforma iTunes $U$ em conjunto com a aplicação Book Creator, permitem aos alunos a passagem

por diferentes fases de trabalho e uma progressiva apropriação das fontes, lidando com diferentes recursos e ainda absorverem e consolidarem a informação recebida através da realização de diversas tarefas intermédias, até ao momento de colocação em prática das competências adquiridas através da realização da história final, que será o momento em que se apropriam da informação para poderem construir uma narrativa explicativa dos acontecimentos estudados, onde deverão ser capazes de utilizar de forma adequada diferentes conceitos estruturais do conhecimento histórico.

\section{iii) Estrutura do trabalho a desenvolver em aula}

\section{Organização do trabalbo}

O trabalho foi preparado, como já referimos, através do recurso ao $i T u$ nes $U$, criando um manual digital que congrega uma variedade de recursos e disponibiliza aos alunos o acesso a mais informação de forma a atingirem os objetivos que lhes são apresentados ao longo dos subtemas, e que também lhes confere a possibilidade de colocarem em prática os conhecimentos aí adquiridos, através de um conjunto de atividades diversificadas.

Procurámos, ao construir o nosso estudo, levar os alunos a conseguir visualizar a evolução dos acontecimentos enquanto procuravam resolver pequenas tarefas que os obrigavam a, permanentemente, ter de colocar em prática as suas capacidades ao nível da análise e sistematização da informação recebida.

Nesse sentido, e como referimos no subcapítulo anterior, cada um dos subtemas apresenta no início algumas questões que se pretende ver respondidas com a análise dos diferentes documentos apresentados, e que correspondem às aprendizagens previstas pelo Ministério da Educação. Cada subtema tinha também uma tarefa que os alunos deveriam realizar como forma de autoavaliação das competências adquiridas (Tabela 4.9). Algumas destas tarefas deve- 
riam ser realizadas de forma individual e outras em grupo. Pretendia-se, desta forma, que os alunos desenvolvessem competências tanto ao nível da seleção de informação como ao nível do trabalho individual e de grupo.

Tabela 4.9 - Recursos e tarefas por subtema, disponibilizados no iTunes $U$

\begin{tabular}{|c|c|c|c|c|c|}
\hline \multirow{2}{*}{ Subtemas } & \multicolumn{4}{|c|}{ Recursos } & \multirow{2}{*}{ Tarefas } \\
\hline & Vídeos & Fotografias & Textos & Websites & \\
\hline 1 & 8 & 4 & 2 & 2 & $\begin{array}{l}\text { Individual - responder a } \\
\text { um questionário de escolha } \\
\text { múltipla online (Figura 4.16) }\end{array}$ \\
\hline 2 & 8 & 5 & 4 & 3 & $\begin{array}{l}\text { Em grupo - escrever uma } \\
\text { cronologia (Figura 4.17) }\end{array}$ \\
\hline 3 & 1 & 8 & 2 & 1 & $\begin{array}{l}\text { Em grupo - escrever uma } \\
\text { notícia (Figura 4.18) }\end{array}$ \\
\hline 4 & 0 & 3 & 2 & 1 & $\begin{array}{l}\text { Individual - responder a } \\
\text { um questionário de escolha } \\
\text { múltipla online (Figura } 4.19 \text { ) }\end{array}$ \\
\hline
\end{tabular}

Tarefa final: elaboração, em grupo, de uma história passada no período cronológico estudado utilizando factos reais e elementos ficcionados bem como recursos reais e recursos criados pelos alunos (Figura 4.20)

Os materiais constantes de cada subtema permitiam aos alunos a observação de diferentes fontes da época (vídeos, sons, documentos, fotos, entre outros - Figura 4.14) e apresentavam também a possibilidade de consultarem mais informação acessível online, procurando, por um lado, que os estudantes pudessem percorrer a matéria consoante as suas necessidades e, por outro, estimular os alunos a buscar mais informação.

Veja-se através do exemplo da Figura 4.15 a possibilidade de tomar notas, que também referimos atrás, enquanto se visualiza um vídeo, o que contribui para alguma sistematização da informação que está a ser recolhida.

Para além disso, só abordando diferentes perspetivas é possível compreender assuntos complexos, o que é amplamente possibilitado com o recurso às tecnologias digitais. 


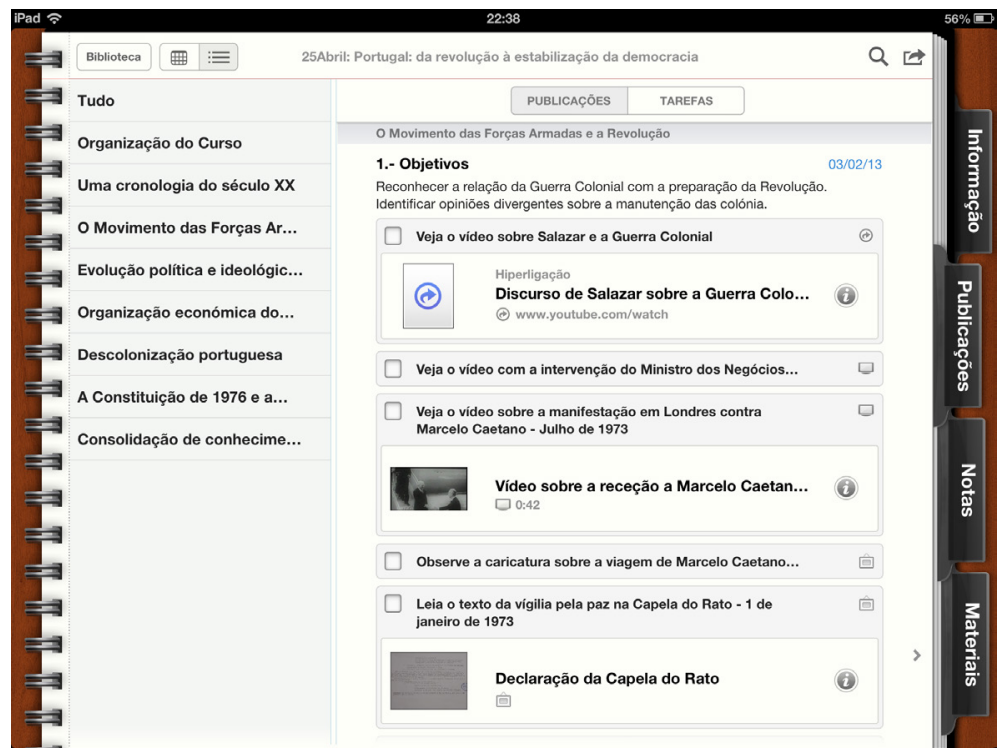

Figura 4.14 - Exemplo de materiais existentes no manual

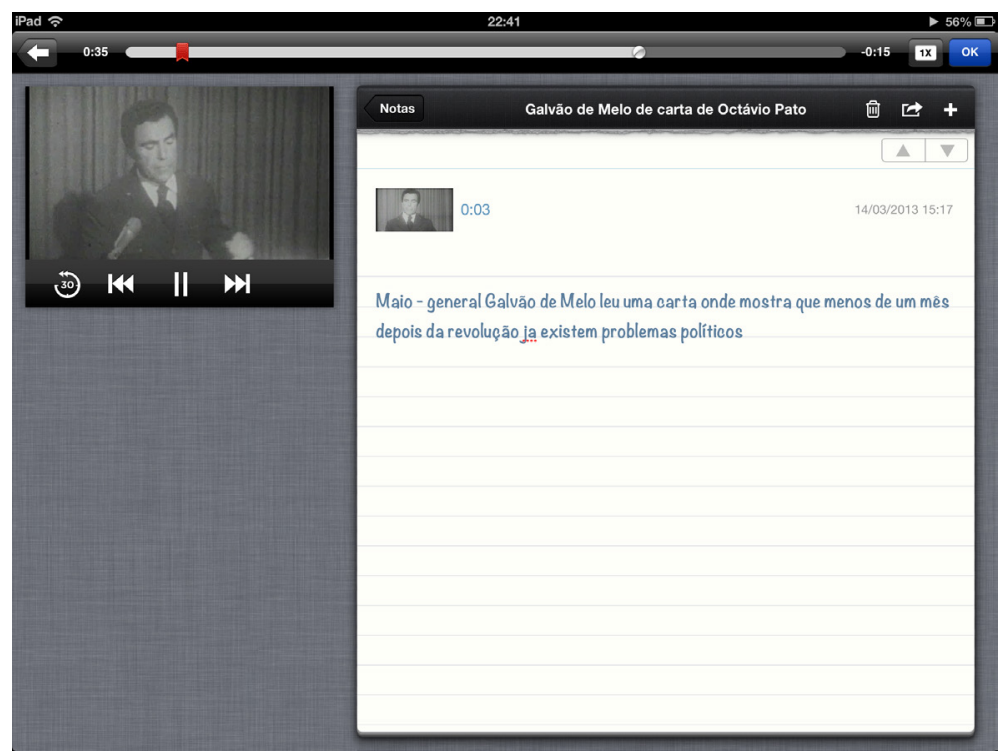

Figura 4.15 - Anotação de ideias durante a visualização de um vídeo 
Neste contexto, não apenas a utilização de um iPad mas de determinadas aplicações que este equipamento permite, contribui para a construção de um modelo educativo que não só procura ajudar os alunos a processar a informação de uma maneira mais eficaz e também promove maior motivação dos alunos, para além de os colocar perante tarefas que obrigam a um desenvolvimento de competências ao nível do pensamento crítico e complexo.

\section{Tarefas intermédias}

No que diz respeito às tarefas de aplicação de conhecimentos, foi proposto aos alunos que trabalhassem individual e colaborativamente. Já atrás demos a indicação de que, para que pudessem autoavaliar-se, a descrição das tarefas a realizar em grupo inclui orientações com a descrição do trabalho esperado, possibilitando aos alunos uma avaliação entre pares. Desta forma, os alunos iam construindo os seus textos à medida que iam observando toda a documentação, utilizando para o efeito, e como atrás referimos, a aplicação "Bloco de Notas" existente no iPad e também a aplicação de notas existente no próprio iTunes $U$ durante a visualização dos vídeos (reveja-se a Figura 4.15). Quando terminassem poderiam avaliar-se, verificando para isso as grelhas classificativas respetivas que constavam do Manual.

Procurando então a diversificação de atividades, a tarefa relativa ao subtema 1 (O Movimento das Forças Armadas e a Revolução) é um questionário de escolha múltipla a realizar online. A tarefa consiste na leitura de 5 frases de reconhecidos indivíduos/grupos, importantes para demonstrar a existência de diferentes opiniões sobre as colónias portuguesas, tendo os alunos que identificar os autores dessas mesmas frases (Figura 4.16). Serve esta tarefa para ajudar os alunos na aquisição de competências de análise de informação e sobretudo para aprenderem a distinguir diferentes perspetivas sobre um mesmo assunto.

A tarefa do subtema 2 (Evolução política e ideológica da sociedade portuguesa) procura o desenvolvimento das capacidades de análise crítica e temporal, levando os alunos a elaborar uma cronologia com os acontecimentos que para si eram mais importantes no período revolucionário entre 1974 e 1976 (Figura 4.17). 


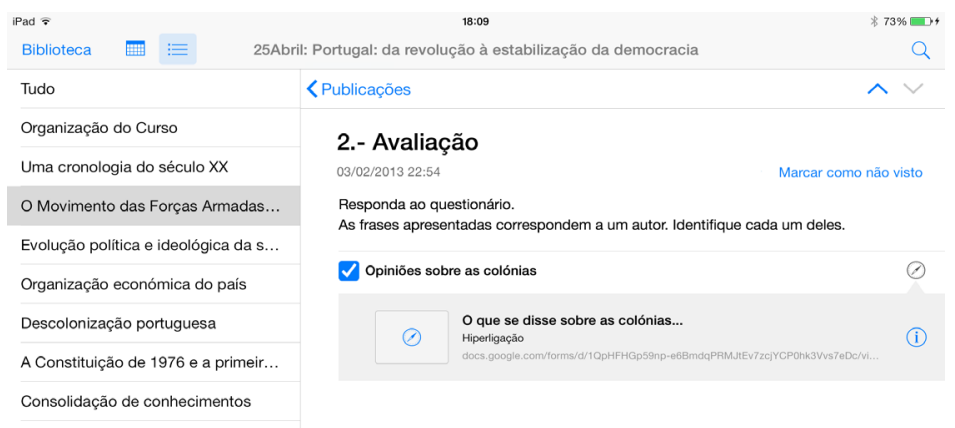

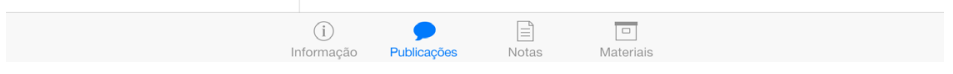

Figura 4.16 - Tarefa do subtema 1 - resposta a um questionário online

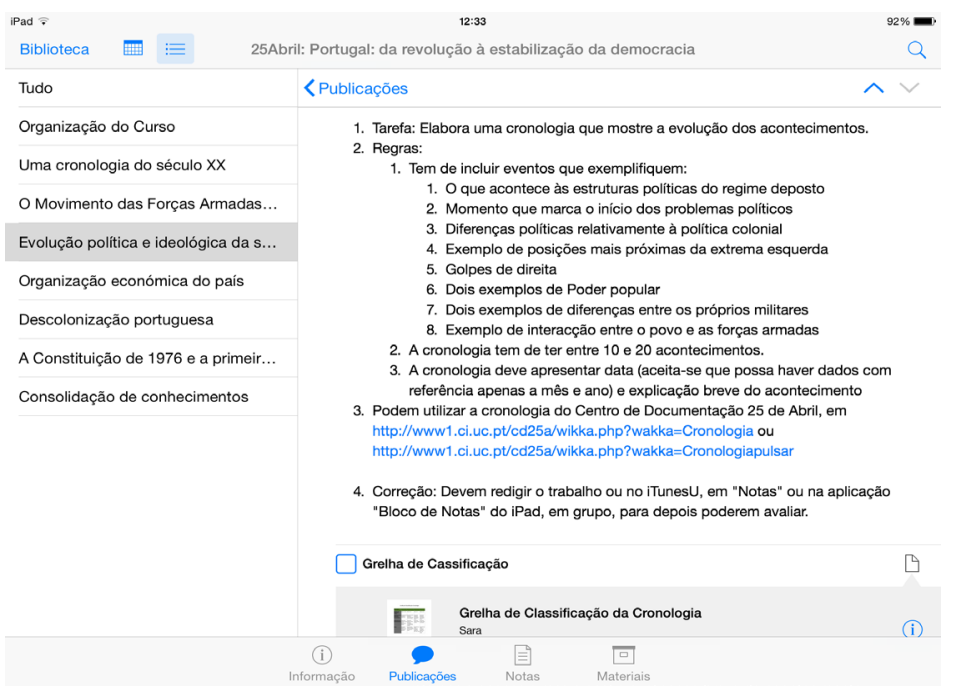

Figura 4.17 - Tarefa do subtema 2 - elaboração de uma cronologia

O subtema 3 (Descolonização portuguesa) tem também uma tarefa de síntese de ideias, neste caso para redação de uma pequena notícia que versasse o tema da descolonização portuguesa. Uma vez mais também aqui se pretende aferir as capacidades dos alunos ao nível da seleção de informação e capacidade de comunicação histórica (Figura 4.18). 


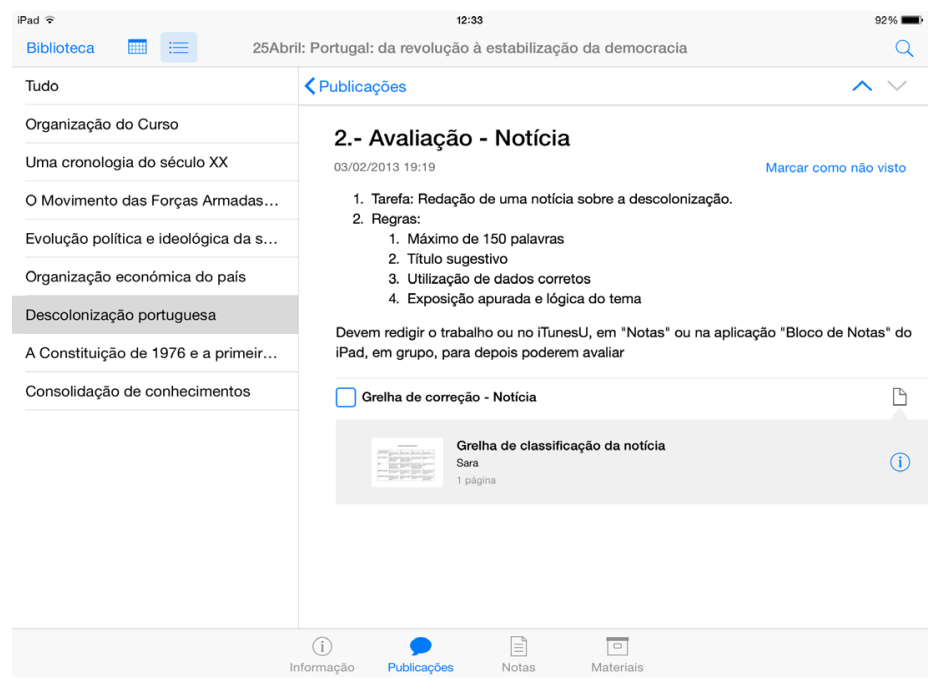

Figura 4.18 - Tarefa do subtema 3 - elaboração de uma notícia

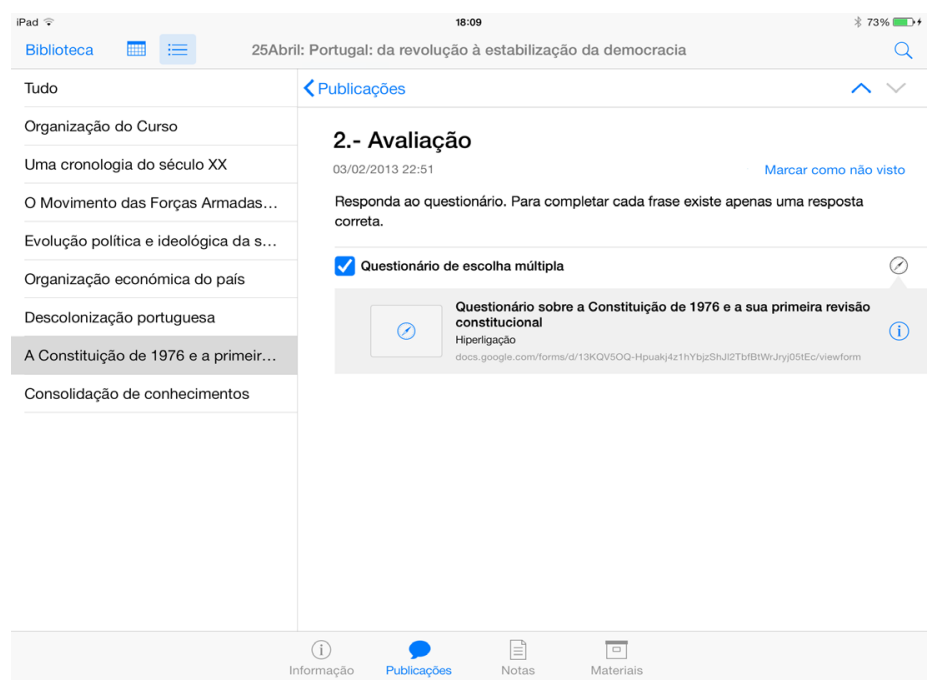

Figura 4.19 - Tarefa do subtema 4 - resposta a um questionário online

O subtema 4 (A Constituição de 1976 e a primeira revisão constitucional - 1982) tem de novo como tarefa a resposta a um questionário de escolha múltipla online. Este último subtema diz respeito a um assunto mais técnico, a Constituição Portuguesa e a sua primeira revisão constitucional, pelo que este questionário contém 12 itens sobre diferentes artigos destes documen- 
tos legais para que os alunos procurem perceber as principais mudanças daí decorrentes tanto na sociedade como na política portuguesa (Figura 4.19).

Realização da tarefa final: criação de uma história

Após a concretização de todas as tarefas intermédias, os alunos passam para a realização da tarefa final.

Esta tarefa consistia na criação de uma história ficcionada passada no período revolucionário de 1974-75, mas onde deveriam ser relatados acontecimentos reais. $\mathrm{O}$ manual digital incluía um documento com todas as regras para a concretização do trabalho, que obrigavam os participantes do estudo a fazer uma seleção de acontecimentos verídicos de forma a construir uma história cujo final lhes era previamente fornecido (Figura 4.20). Desta forma, os participantes deveriam selecionar recursos históricos que ilustrassem a história, para além de criarem os seus próprios recursos. Trabalhando em grupo, seriam levados a colocar em prática as competências adquiridas com o trabalho efetuado com o manual e teriam oportunidade de colocar em prática, de uma forma inovadora, essas mesmas competências.

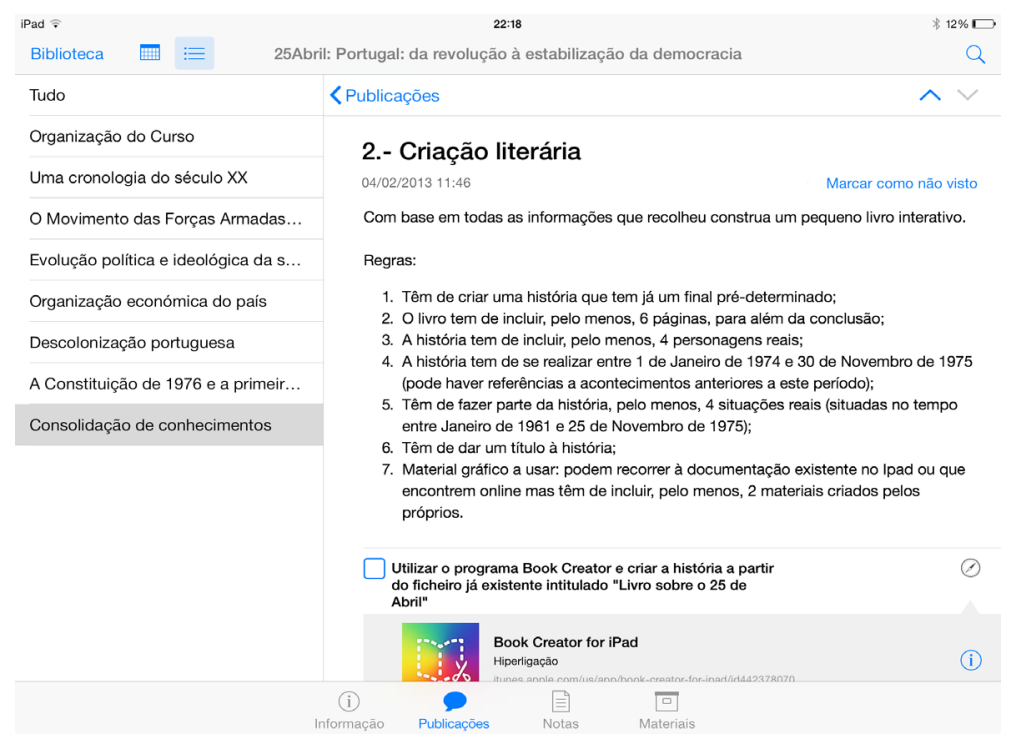

Figura 4.20 - Tarefa final: criação da história, síntese dos conteúdos estudados 
Como atrás tivemos já oportunidade de referir, o programa utilizado para a realização desta tarefa foi a aplicação Book Creator que permite, quando concluído o trabalho, a sua importação para a aplicação $i B o o k s$ que mostra o produto final em formato de livro. Para além disso foi necessário a utilização de outras aplicações do iPad, como a câmara fotográfica e de vídeo.

\section{Cronologia da recolha de dados}

A concretização do nosso estudo foi organizada de forma a realizarem-se os questionários de literacia digital e o primeiro teste de conhecimentos numa primeira sessão, podendo nessa mesma sessão serem explicados os objetivos do trabalho e, na sessão final, ser realizado o segundo teste de conhecimentos.

No total os participantes trabalharam connosco durante 11 horas e 15 minutos (Tabela 4.10).

Tabela 4.10 - Cronologia da recolha de dados

\begin{tabular}{|c|c|l|}
\hline Sessão & $\begin{array}{c}\text { Duração da } \\
\text { recolha }\end{array}$ & \multicolumn{1}{|c|}{ Dados Recolhidos } \\
\hline 1 & $\begin{array}{c}30^{\prime} \\
30^{\prime} \\
30^{\prime}\end{array}$ & $\begin{array}{l}\text { A - Resposta ao questionário sobre literacia digital } \\
\text { B - Resolução do teste diagnóstico de conhecimentos (inicial) } \\
\text { C - Explicação do trabalho a desenvolver }\end{array}$ \\
\hline 2 & $45^{\prime}$ & Subtema 1 e tarefa 1 \\
\hline 3 & $45^{\prime}+45^{\prime}$ & Subtema 2 e tarefa 2 \\
\hline 4 & $45^{\prime}$ & Subtema 3 \\
\hline 5 & $45^{\prime}$ & A - Subtema 3 e tarefa 3 \\
\hline 6 a 8 & $45^{\prime}+90^{\prime}+90^{\prime}$ & Preparação da história final \\
\hline & $30^{\prime}$ & A - Leitura das histórias \\
B - Resolução do teste de conhecimentos (final) \\
\hline
\end{tabular}

Assim, o nosso estudo foi delineado para que, numa primeira fase, os alunos adquirissem, através da plataforma, os conhecimentos previstos para este tema, observando toda a documentação apresentada; numa segunda fase, através das tarefas intermédias, colocassem em prática esses mesmos conheci- 
mentos e, numa terceira fase, e partindo uma vez mais do manual digital, utilizassem de forma crítica a informação aprendida, através da realização de um trabalho que exigia algum tratamento da informação estudada e sua aplicação na criação de uma história baseada nesses mesmos factos, e até mesmo uma certa apropriação dos factos por forma a reconstruírem não apenas "uma" história mas mesmo "a" própria história.

Conscientes de que utilizamos uma plataforma proprietária, reforçamos as palavras que escrevemos já neste capítulo referentes ao nosso desejo de que este tipo de soluções se mostre de tal forma eficaz que possa vir a ser implementada, num futuro próximo, de forma completamente livre. 
5

O ESTUDO DE CASO

\subsection{Caracterização dos participantes}

\subsubsection{Utilização de equipamentos tecnológicos}

Todos os participantes têm computador em casa e 66,0\% usam-no todos os dias, enquanto $25,6 \%$ o utiliza quase todos os dias. Aqui surgem participantes que indicam que utilizam apenas o computador semanalmente ou de vez em quando (4,2\% cada) (Tabela 8.44). O acesso à Internet é menos regular neste grupo, uma vez que somente $57,4 \%$ utilizam a Internet todos os dias, $27,6 \%$ acede-lhe quase todos os dias, existindo $12,8 \%$ de respostas que referem que o acesso à Web se faz apenas semanalmente e 2,2\% ainda indicam que apenas o fazem "de vez em quando" (Tabela 5.1).

Quase todos os participantes referem estar habituados a trabalhar com um PC (93,6\%), surgindo em seguida as consolas de jogos $(55,3 \%)$ e os leitores de Mp3 (48,9\%) e de $M p 4$ (46,8\%). No que diz respeito a ferramentas tecnológicas da marca Apple, 17\% indicam saber trabalhar com iPod, 29,8\% com o iPad, 8,5\% com o iPhone e também 8,5\% com computadores Macintosh (Tabela 5.2). Como indicámos aos participantes que, se tivessem iPads que pudessem trazer para as sessões, os podiam utilizar, houve vários que logo a partir da segunda sessão os trouxeram. 
Tabela 5.1 - Frequência de utilização do computador e da Internet $(n=47)$

\begin{tabular}{|l|l|c|c|}
\hline \multicolumn{2}{|c|}{ Utilização de computador e da Internet } & \multicolumn{2}{c|}{ Participantes } \\
\cline { 2 - 4 } & Utilização do Computador & Diariamente & $\%$ \\
\cline { 2 - 4 } & Alguns dias da semana & 31 & 66,0 \\
\cline { 2 - 4 } & Semanalmente & 2 & 4,2 \\
\cline { 2 - 4 } & De vez em quando & 2 & 4,2 \\
\cline { 2 - 4 } & Nunca & 0 & 0,0 \\
\hline \multirow{3}{*}{ Utilização da Internet } & Diariamente & 27 & 57,4 \\
\cline { 2 - 4 } & Quase todos os dias & 13 & 27,6 \\
\cline { 2 - 4 } & Semanalmente & 6 & 12,8 \\
\cline { 2 - 4 } & Outra (de vez em quando) & 1 & 2,2 \\
\hline
\end{tabular}

Tabela 5.2 - Equipamentos tecnológicos que os alunos estão habituados a utilizar $(n=47)$

\begin{tabular}{|l|c|c|}
\hline \multirow{2}{*}{ Equipamentos tecnológicos } & \multicolumn{2}{c|}{ Participantes } \\
\cline { 2 - 3 } & $\mathrm{f}$ & $\%$ \\
\hline iPod & 8 & 17,0 \\
\hline Mp3 & 23 & 48,9 \\
\hline Mp4 & 22 & 46,8 \\
\hline iPad & 14 & 29,8 \\
\hline Outro Tablet & 10 & 21,3 \\
\hline iPhone & 4 & 8,5 \\
\hline Smartphone & 6 & 12,8 \\
\hline PC & 44 & 93,6 \\
\hline Mac & 4 & 8,5 \\
\hline Consolas de Jogos & 26 & 55,3 \\
\hline Outros (Mp5) & 1 & 2,1 \\
\hline Outros (telemóvel) & 2 & 4,3 \\
\hline
\end{tabular}

\subsubsection{Uso do computador}

A utilização do computador é, sobretudo, para estar em contacto com os amigos (82,8\%), mas também para fazer trabalhos escolares $(65,6 \%)$ e estudar (55,3\%) (Tabela 5.3). 
Tabela 5.3 - Funções de utilização dos computadores $(n=47)$

\begin{tabular}{|l|c|c|}
\hline \multicolumn{1}{|c|}{ Utilização do computador } & \multicolumn{2}{c|}{ Participantes } \\
\cline { 2 - 3 } & $\mathrm{f}$ & $\%$ \\
\hline Jogar & 24 & 51,1 \\
\hline Estar em contacto com amigos & 39 & 82,8 \\
\hline Estudar & 26 & 55,3 \\
\hline Fazer trabalhos escolares & 31 & 65,6 \\
\hline $\begin{array}{l}\text { Outras (lazer, informação, ler, ouvir música, utilizar redes sociais, } \\
\text { multimédia, navegar na Internet, ver email) }\end{array}$ & 13 & 27,7 \\
\hline
\end{tabular}

Quando questionados sobre o que mais gostam de utilizar/fazer para aprender, os participantes indicam mais vezes a utilização da Internet (76,6\%) enquanto que em segundo lugar ficam, com igual percentagem, a visualização de filmes ou de peças de teatro e as visitas de estudo - 61,7\% cada (Tabela 5.4).

Mostram-nos estas respostas que este grupo é bastante dinâmico e que prefere aprender de maneiras diversificadas e que fogem às habituais estratégias de aulas expositivas.

Tabela 5.4 - Estratégias de aprendizagem preferidas $(n=47)$

\begin{tabular}{|l|c|c|}
\hline \multicolumn{1}{|c|}{ Estratégias de aprendizagem } & \multicolumn{2}{c|}{ Participantes } \\
\cline { 2 - 3 } & $\mathrm{f}$ & $\%$ \\
\hline Manual escolar & 11 & 23,4 \\
\hline Internet & 36 & 76,6 \\
\hline Apresentações em PowerPoint ou Prezi & 21 & 44,7 \\
\hline Visitas de estudo & 29 & 61,7 \\
\hline Filmes/peças de teatro & 29 & 61,7 \\
\hline outro (pelo conhecimento de outros; resumos retirados da Internet) & 2 & 4,3 \\
\hline
\end{tabular}

Também todos se servem de ferramentas digitais para fazer trabalhos escolares, preferindo, sobretudo, a utilização do PowerPoint $(89,4 \%)$, do Word $(80,9 \%)$ e da Wikipedia (80,9\%) (Tabela 5.5). É de notar que há vários alunos que demonstram saber trabalhar com ferramentas diversificadas como os Pod- 
casts (4,3\%), o Keynote (4,3\%) ou o MovieMaker (34\%) e mesmo um aluno que reconhece estar familiarizado com a aplicação Toontastic, que é uma aplicação para $i P a d$ para construção de cartoons.

Tabela 5.5 - Aplicações para realização de trabalhos escolares $(n=47)$

\begin{tabular}{|l|c|c|}
\hline \multirow{2}{*}{ Aplicações usadas para realizar trabalhos escolares } & \multicolumn{2}{|c|}{ Participantes } \\
\cline { 2 - 3 } & $\mathrm{f}$ & $\%$ \\
\hline Word & 38 & 80,9 \\
\hline Blogues & 23 & 48,9 \\
\hline Podcasts & 2 & 4,3 \\
\hline Keynote & 2 & 4,3 \\
\hline PowerPoint & 42 & 89,4 \\
\hline Wikipedia & 38 & 80,9 \\
\hline MovieMaker & 16 & 34,0 \\
\hline Toontastic & 1 & 2,1 \\
\hline Prezi & 7 & 14,9 \\
\hline FrontPage & 1 & 2,1 \\
\hline iTunes U & 0 & 0,0 \\
\hline Chat & 7 & 14,9 \\
\hline Moodle & 12 & 25,5 \\
\hline Email & 28 & 59,8 \\
\hline Scribd & 0 & 0,0 \\
\hline SlideShare & & 0,0 \\
\hline
\end{tabular}

\subsubsection{Nas aulas de História: preferências}

No que diz respeito ao tipo de aulas de História que preferem, estes participantes indicam gostar mais de fazer trabalhos em grupo (78,7\%) ou de explorar recursos audiovisuais $(76,6 \%)$ e as aulas expositivas são as que recolhem menos preferências (17\%) (Tabela 5.6). Estes fatores contribuem de certo, para uma muito boa receptividade e execução do trabalho que irá ser por nós proposto. 
Tabela 5.6 - Tipologia das aulas que os alunos preferem $(n=47)$

\begin{tabular}{|l|c|c|}
\hline \multirow{2}{*}{\multicolumn{1}{|c|}{ Tipologia de aulas }} & \multicolumn{2}{c|}{ Participantes } \\
\cline { 2 - 3 } & $\mathrm{f}$ & $\%$ \\
\hline Aulas expositivas & 8 & 17,0 \\
\hline Realização de trabalhos de grupo & 37 & 78,7 \\
\hline Diálogo entre professor e alunos & 26 & 55,3 \\
\hline Exploração de recursos audiovisuais & 36 & 76,6 \\
\hline Outros (leitura do manual) & 1 & 2,1 \\
\hline
\end{tabular}

Ao nível da participação nas aulas, praticamente dois terços do grupo $(63,8 \%)$ indica que gosta de o fazer de uma forma ativa (Tabela 5.7). Entre estes, é referido que a participação ativa nas aulas é determinada pelo facto de gostar bastante do professor $(83,3 \%)$ e porque têm bastante interesse pela disciplina $(63,3 \%)$, deixando para último lugar o facto de simplesmente gostarem de ter uma participação ativa em qualquer aula (33,3\%) (Tabela 5.8).

Tabela 5.7 - Participação dos alunos nas aulas de História $(n=47)$

\begin{tabular}{|l|c|c|}
\hline \multirow{2}{*}{\multicolumn{1}{|c|}{ Participação nas aulas }} & \multicolumn{2}{c|}{ Participantes } \\
\cline { 2 - 3 } & $\mathrm{f}$ & $\%$ \\
\hline Participa ativamente nas aulas de História & 30 & 63,8 \\
\hline Não participa ativamente nas aulas & 17 & 36,2 \\
\hline
\end{tabular}

Tabela 5.8 - Motivo para participação ativa nas aulas de História (n=30)

\begin{tabular}{|l|c|c|}
\hline \multirow{2}{*}{ Justificação para participação nas aulas de História } & \multicolumn{2}{|c|}{ Participantes } \\
\cline { 2 - 3 } & $\mathrm{f}$ & $\%$ \\
\hline Tem bastante interesse pela disciplina & 19 & 63,3 \\
\hline Gosta do professor & 25 & 83,3 \\
\hline Gosta de ter um papel ativo nas aulas & 10 & 33,3 \\
\hline
\end{tabular}

Para estudar para esta disciplina, os participantes destacam a realização de resumos do manual $(68,1 \%)$, ao que se segue a tomada de apontamentos nas aulas $(55,3 \%)$ e a consulta de mais informações através da Internet $(51,1 \%)$ (Tabela 5.9). Uma vez mais, as respostas a esta questão assumem um caráter 
relevante para o nosso estudo, por nos darem a indicação de que este grupo de trabalho estará habituado a procurar a informação em mais espaços para além do que lhes é fornecido pelo manual escolar.

Tabela 5.9 - Estratégias utilizadas para estudar História $(n=47)$

\begin{tabular}{|l|c|c|}
\hline \multirow{2}{*}{ Estratégia de estudo na disciplina de História } & \multicolumn{2}{c|}{ Participantes } \\
\cline { 2 - 3 } & $\mathrm{f}$ & $\%$ \\
\hline Lê várias vezes o manual & 21 & 44,7 \\
\hline Tira apontamentos nas aulas & 26 & 55,3 \\
\hline Faz resumos do manual & 32 & 68,1 \\
\hline Resolve exercícios do caderno de atividades & 11 & 23,4 \\
\hline Consulta mais informações através da Internet & 24 & 51,1 \\
\hline Consulta mais informações através de livros/revistas & 7 & 14,9 \\
\hline Outros (ouvir a professora) & 1 & 2,1 \\
\hline
\end{tabular}

Entre as matérias estudadas no $9 .^{\circ}$ ano de escolaridade que preferem, os participantes destacam, nos dois primeiros lugares, as duas Guerras Mundiais (a Primeira Grande Guerra, 66\%, e a Segunda Guerra Mundial, 63,8\%). Em terceiro lugar surge a sociedade e a cultura dos anos $20(51,1 \%)$, aparecendo apenas como quarta opção $(27,7 \%)$ a temática da revolução de abril de 1974 (Tabela 5.10).

Tabela 5.10 - Matérias preferidas pelos alunos $(n=47)$

\begin{tabular}{|l|c|c|}
\hline \multirow{2}{*}{ Matérias preferidas } & \multicolumn{2}{c|}{ Participantes } \\
\cline { 2 - 3 } & f & $\%$ \\
\hline A implantação da República Portuguesa & 9 & 19,2 \\
\hline A Primeira Guerra Mundial & 31 & 66,0 \\
\hline A sociedade e a cultura dos anos 20 & 24 & 51,1 \\
\hline As ditaduras europeias & 9 & 19,2 \\
\hline O período do Estado Novo & 0 & 0,0 \\
\hline A Segunda Guerra Mundial & 30 & 63,8 \\
\hline A Revolução de abril de 1974 & 13 & 27,7 \\
\hline A Guerra Fria & 8 & 17,0 \\
\hline A história da União Europeia & 1 & 2,1 \\
\hline Os novos modelos económicos & 1 & 2,1 \\
\hline
\end{tabular}




\subsubsection{Importância da Revolução de 1974}

Estes alunos expõem maioritariamente a importância da revolução democrática enquanto movimento que veio proporcionar o retorno à liberdade $(38,3 \%)$ nos mais variados campos da vida dos portugueses, nomeadamente no campo da liberdade de expressão com o fim da censura (29,8\%) (Tabela 5.11). Sobre isto um aluno apresentou uma resposta muito interessante, ao referir que "a revolução portuguesa de 25 de abril de 1974 consistiu na libertação do estado português da ditadura, que era nessa época governado por Marcelo Caetano, por isso os militares organizaram-se e invadiram e tomaram posse de Lisboa quando a música "vila morena" começou a tocar. Logo, esta revolução permitiu-nos a liberdade de expressão, ou seja, a libertação do povo português".

Também houve quem referisse que a revolução de abril tinha ajudado a que o país tivesse mais oportunidades para proceder ao seu desenvolvimento económico (10,6\%). Neste campo um dos participantes elabora um pouco mais a sua resposta, referindo que a revolução acabou por contribuir para "a escolarização da população, para a entrada de novos produtos vindos do estrangeiro e para o desenvolvimento da economia portuguesa. Para além deste desenvolvimento, [...] permitiu a entrada de Portugal para a União Europeia juntamente com a Espanha”.

Ainda assim notamos neste conjunto de participantes alguns problemas ao nível da terminologia científica, uma vez que muitos referem que a revolução foi muito importante para fazer com que o país passasse "do regime ditatorial para o regime republicano" $(23,4 \%)$.

Houve também um aluno que mencionou que foi "importante a revolução dos cravos porque apesar de ser um regime rigoroso a sociedade não tinha liberdade para se exprimir apesar da situação económica e financeira. Apesar dos nossos avós, principalmente os meus, preferiam, viver no tempo de Salazar". 
Tabela 5.11 - Categorias de resposta à questão aberta sobre a opinião dos participantes acerca da importância da Revolução de 1974 (n=47)

\begin{tabular}{|l|c|c|}
\hline \multicolumn{1}{|c|}{ Categorias } & \multicolumn{2}{c|}{ Participantes } \\
\cline { 2 - 3 } & $\mathrm{f}$ & $\%$ \\
\hline Permitiu a liberdade & 18 & 38,3 \\
\hline Portugal passou do regime ditatorial para o regime republicano & 11 & 23,4 \\
\hline Foi bom & 2 & 4,3 \\
\hline Acabou com a censura/ passou a haver liberdade de expressão & 14 & 29,8 \\
\hline Portugal tornou-se um país independente & 2 & 4,3 \\
\hline Foi muito importante & 4 & 8,5 \\
\hline Graças à revolução passámos a viver melhor & 1 & 2,1 \\
\hline Passámos a exprimir os nossos direitos e deveres & 1 & 2,1 \\
\hline Foi uma fase bonita e de bastante coragem & 1 & 2,1 \\
\hline Não tínhamos direitos e passámos a ter & 2 & 4,3 \\
\hline $\begin{array}{l}\text { Povo português pôde participar mais ativamente na governação } \\
\text { do país }\end{array}$ & 1 & 2,1 \\
\hline Serviu para o desenvolvimento do país & 5 & 10,6 \\
\hline Serviu para que a sociedade se soltasse perante todo o mundo & 1 & 2,1 \\
\hline $\begin{array}{l}\text { Foi importante apesar de os nossos avós, principalmente os meus, } \\
\text { preferirem viver no tempo de Salazar }\end{array}$ & 1 & 2,1 \\
\hline Se a revolução não tivesse acontecido ainda hoje vivíamos em ditadura & 2 & 4,3 \\
\hline Revolucionou por completo o nosso país & 1 & 2,1 \\
\hline Passou a haver maior insegurança e instabilidade governamental & 1 & 2,1 \\
\hline Contribuiu para maior escolarização da população & 1 & 2,1 \\
\hline Permitiu a entrada de Portugal na União Europeia & 1 & 2,1 \\
\hline Libertou Portugal das prisões que torturavam muitos portugueses & 2,1 \\
\hline
\end{tabular}

\subsection{Descrição do estudo}

\section{Sessão 1}

Nesta primeira sessão começámos por pedir aos alunos que respondessem ao questionário sobre literacia digital e, logo de seguida, ao teste diagnóstico de conhecimentos (inicial).

$\mathrm{Na}$ última parte da sessão explicámos como pretendíamos desenvolver o trabalho, aproveitando logo para perguntar aos alunos se tinham iPad que pudessem trazer para a escola. Três alunos disseram que poderiam trazer os 
seus pelo que lhes demos logo o URL para procederem à inscrição no iTunes $U$ e descarregarem em casa os conteúdos dele constantes.

Como são muitos alunos, pedimos-lhes também que nas sessões seguintes trouxessem headphones para poderem ouvir todos os sons sem se perturbarem uns aos outros e arranjámos nós vários headphone jack splitters para que em cada iPad pudessem, se necessário, ser ligados 2 conjuntos de headphones.

Fizemos também uma explicação sobre o funcionamento do iTunes $U$ e indicámos que nas sessões seguintes os iríamos ajudar a perceber o que deveriam fazer em cada uma das partes do trabalho.

\section{Sessão 2}

Tendo três dos participantes trazido os seus próprios equipamentos, a distribuição em grupos foi a seguinte:

- 7 grupos com três elementos;

- 13 grupos de dois elementos.

Os alunos dividiram-se pelos grupos, sendo essa escolha feita por eles e sem qualquer intervenção da nossa parte.

Durante esta primeira sessão distribuímos os iPads, pedindo a cada grupo que identificasse o seu devidamente para que nas sessões seguintes trabalhassem sempre com os mesmos equipamentos e pedimos que nos enviassem sempre um email com os trabalhos que desenvolvessem ao longo das sessões pois dessa forma não só teríamos sempre acesso ao trabalho desenvolvido como tínhamos a garantia de que o material produzido não se perderia.

Explicámos então que deveriam analisar os documentos constantes do subtema 1 (O Movimento das Forças Armadas e a revolução) para no final responderem a um questionário de escolha múltipla, referindo desde logo que essa tarefa deveria ser feita de forma individual mas que poderiam sempre rever a documentação caso tivessem dúvidas nas respostas.

Os alunos passaram a trabalhar de forma autónoma e nesta sessão fomos apenas chamados a intervir em pequenos pormenores técnicos como o resta- 
belecimento da rede wifi $^{133}$ ou a explicação sobre o funcionamento da função de bloco de notas nos vídeos do iTunes $U$.

À medida que os grupos terminavam a visualização da documentação começavam a responder à perguntas do questionário respetivo, não nos tendo feito qualquer questão sobre este exercício. Nesta fase começámos a apercebermo-nos de que havia alguns alunos que respondiam mais rapidamente, o que pode justificar a existência de classificações negativas.

\section{Sessão 3}

Esta sessão foi totalmente dedicada à análise do subtema 2 (Evolução política e ideológica da sociedade portuguesa), tendo quase todos os alunos trabalhado de forma bastante aplicada. Como a tarefa correspondente a este tema era a realização de uma cronologia, pedimos que fossem organizando uma lista de acontecimentos na aplicação Bloco de Notas (existente nos iPads), à medida que fossem visualizando os documentos.

A nossa referência, no parágrafo anterior, a que quase todos os alunos trabalharam bem, prende-se com o facto de termos tido que passar esta sessão a verificar que todos se concentravam na matéria e no trabalho que tinham para fazer e não se distraíam a experimentar as variadas funcionalidades dos iPads.

Apesar disso, todos conseguiram produzir o trabalho que era pedido, ainda que com algumas falhas (como se poderá ver mais à frente na Tabela 5.14 com as classificações gerais obtidas).

\section{Sessão 4}

A sessão 4 foi dedicada à análise dos documentos relativos ao subtema 4 (Descolonização portuguesa). Esta sessão, com a duração de apenas 45 minutos, não se revelou muito produtiva, uma vez que os alunos demoraram algum tempo a entrar na sala, organizar-se nos grupos que tinham sido formados na segunda sessão e a distribuir os equipamentos respetivos.

133 A Escola permitia o acesso a duas redes wifi. Por vezes tornava-se necessário alternar entre as redes. 


\section{Sessão 5}

A primeira parte da sessão foi ainda dedicada ao subtema 4, tendo os alunos trabalhado na execução da tarefa correspondente (elaboração de uma notícia). A maior parte dos textos redigidos foram relativamente sumários (ressalve-se que apenas pedíamos um máximo de 150 palavras), uma vez que os alunos manifestaram não ter grande experiência na produção de textos de caráter noticioso. Mesmo assim, conseguiram cumprir a generalidade dos objetivos, apresentando textos sem erros históricos e que podem de alguma forma mostrar o que consideraram mais relevante na matéria estudada (Figura 5.1).

\section{Milhares de portugueses regressam a casa!}

O aeroporto de Lisboa parece um autêntico acampamento. Milhares de portugueses não olharam para trás quando nas nossas colónias o caos despoletado pela perspetiva de independência desses territórios se espalhou pelas cidades e aldeias onde viviam.

Rumando a um Portugal liberto, não encontram agora maneira de reorganizar as suas vidas.

Muitos trouxeram consigo apenas a roupa que tinham vestida e um sonho de um Portugal livre. Quem os ajudará agora?

Precisam de casa, trabalho, uma vida nova. Para aqueles que não têm família por cá, parece ser cada vez mais difícil retomar a normalidade.

Figura 5.1 - Notícia elaborada por um dos grupos

Ainda nesta sessão houve tempo para estudar o subtema 5, A Constituição de 1976 e a primeira revisão constitucional (1982), e ainda responder ao questionário de escolha múltipla que lhe estava associado. Nesta fase o trabalho decorreu de forma célere e sem qualquer necessidade de intervenção da nossa parte para além de, uma vez mais, algum controle para impedir distrações (era necessário estar sempre a circular entre os grupos enquanto trabalhavam, para confirmar que não estavam a fazer outras coisas).

\section{Sessão 6}

Como este grupo tinha muitos alunos, começámos a sessão pedindo-lhes que distribuíssem os grupos formados por três grandes grupos, para que se elaborassem três histórias. 
Feita essa distribuição (o que aconteceu de forma bastante rápida) pedimos que cada um desses três grupos se juntasse para pensarem na história que gostariam de escrever.

Fomos abordando cada um dos grupos para verificar como queriam organizar o trabalho, e todos decidiram que dentro de cada grupo cada um ficaria responsável por uma parte da história. Assim, trabalharam durante esta sessão na elaboração do guião da história, com base no documento de trabalho existente no manual digital, para que na sessão seguinte pudessem ter todas as tarefas atribuídas.

\section{Sessão 7}

Ao longo desta sessão todos os grupos trabalharam de forma muito autónoma e responsável (mais do que nas sessões anteriores). Alguns pormenores ainda sobre a estrutura da história foram terminados nos primeiros minutos da aula e pudemos verificar que se organizaram muito bem atribuindo entre si as tarefas que mais gostavam: uns ficaram com a parte da redação do texto, outros com a seleção de imagens e documentos.

Fomos chamados a um dos grupos que nos pediu para escrever um final diferente daquele que apresentámos no guião do manual digital. Explicaram que o elaborariam de forma a que as restrições que apresentámos inicialmente não sofressem alterações. Por esse motivo acedemos ao pedido deles.

Durante esta sessão verificámos que houve muita dificuldade para imaginar materiais a criar pelos próprios (tal como pedíamos no guião) e houve uma aluna que começou a fazer um desenho para incluir numa das histórias mas acabou por não o terminar.

Os alunos que tinham a tarefa de encontrar documentos adequados para inserir nas histórias utilizaram os seus iPads para arquivar todos os documentos selecionados.

\section{Sessão 8}

Esta última sessão de trabalho na história serviu para a montagem das histórias realizadas, tendo os alunos escolhido alguns dos elementos dos seus grupos para a tarefa de associação de todos os elementos das histórias numa só e verificação de que todas as partes bateriam certo. 
Por email, todos os elementos da história foram sendo agregados em três iPads tendo sido necessária a nossa ajuda para verificar que tudo estava no devido local. Pediram-nos, ainda no final da sessão, para lermos as histórias criadas e aferirmos se todas faziam sentido.

\section{Sessão 9}

Na primeira parte da sessão os alunos tiveram oportunidade de ler todas as histórias e também estes alunos não foram exceção no que diz respeito à preferência pelo trabalho que haviam realizado.

Em seguida, pedimos que respondessem ao teste de conhecimentos (final), ressalvando-se aqui o facto de este servir, posteriormente, como avaliação dos alunos para a disciplina, facto que foi devidamente indicado nesta sessão aos participantes.

Na parte final da sessão pedimos a todos que preenchessem o questionário de opinião sobre o estudo.

\subsection{Teste de conhecimentos}

O estudo teve início com a realização, pelos participantes, de um teste diagnóstico de conhecimentos (inicial), esperando-se que as respostas deste primeiro teste refletissem os conhecimentos que os participantes já teriam sobre o tema, estudado tanto durante o Primeiro Ciclo do Ensino Básico como no $6 .^{\circ}$ ano de escolaridade.

Pelos resultados apresentados na Tabela 5.12, demonstra-se que as classificações obtidas foram, em média, muito baixas. Este grupo mostrou uma grande evolução nos resultados, duplicando ou quase triplicando os valores no caso da média, da mediana e da moda. Apesar de o teste final ainda ter tido resultados negativos (sendo o mais baixo de 17\%), há outros valores que podemos observar na Tabela 5.12, nomeadamente, a média, a mediana e a moda, que se apresentam francamente positivos. 
Tabela 5.12 - Resultados obtidos nos testes de conhecimentos (escala de 100 pontos) $(n=47)$

\begin{tabular}{|l|c|c|}
\hline Resultados & $\begin{array}{c}\text { Teste diagnóstico de } \\
\text { conhecimentos (inicial) }\end{array}$ & $\begin{array}{c}\text { Teste de conhecimentos } \\
\text { (final) }\end{array}$ \\
\hline Classificação mínima & 0 & 17 \\
\hline Classificação máxima & 66 & 98 \\
\hline Média & 26,4 & 69,3 \\
\hline Mediana & 25 & 72 \\
\hline Moda & 33 & 81 \\
\hline Desvio-padrão & 17,3 & 16,9 \\
\hline
\end{tabular}

Através da realização do teste não paramétrico Wilcoxon Signed Rank verificamos que houve diferenças estatisticamente significativas $(p=0,000)$ devido à aprendizagem alcançada (Tabela 5.13).

Tabela 5.13 - Teste não paramétrico Wilcoxon Signed Rank $(\mathrm{n}=47)$

\begin{tabular}{|c|c|c|}
\hline Posição média & Z corrigido & Significância estatística \\
\hline 15,3 & $-5,847$ & $\mathrm{p}=0,000 \mathrm{~S}$. \\
\hline
\end{tabular}

\subsection{Avaliação intercalar}

A Tabela 5.14 mostra-nos os resultados obtidos nas tarefas intermédias concretizadas no final do tratamento de cada um dos restantes quatro subtemas. As classificações obtidas acompanham os resultados do teste final, contribuindo para reforçar esses mesmos resultados.

Tendo estes alunos tido uma classificação média no ano anterior de nível 4 (em 5), parece-nos, contudo, que os resultados poderiam ter sido melhores. Apesar disso, uma observação feita por um dos participantes poderá justificar estas classificações, uma vez que referiu que apesar de ter gostado muito de ter participado e da inovação que este estudo trazia para o espaço das aulas de História, achava que talvez fossem inexperientes demais para ter tanto controle sobre o que viam, reviam ou analisavam (não querendo ele incluir aqui a 
realização da história final). Por outras palavras, este aluno entendia que este tipo de trabalho seria mais apropriado para alunos já do Ensino Secundário, mais maduros e experientes, defendendo, apesar disso, que a realização da história se tinha revelado uma tarefa mais acessível para todos ${ }^{134}$.

Tabela 5.14 - Resultados dos trabalhos desenvolvidos pelos participantes $(n=47)$

\begin{tabular}{|l|c|c|c|c|}
\hline Subtema & Subtema 1 & Subtema 2 & Subtema 3 & Subtema 4 \\
\hline Trabalho & Individual & Em grupo & Em grupo & Individual \\
\hline Tarefa & $\begin{array}{c}\text { questionário de } \\
\text { escolha múltipla }\end{array}$ & $\begin{array}{c}\text { elaboração de } \\
\text { uma cronologia }\end{array}$ & $\begin{array}{c}\text { elaboração de } \\
\text { uma notícia }\end{array}$ & $\begin{array}{c}\text { questionário de } \\
\text { escolha múltipla }\end{array}$ \\
\hline Média & $70 \%$ & $80 \%$ & $80 \%$ & $67 \%$ \\
\hline Mínimo & $20 \%$ & $70 \%$ & $60 \%$ & $50 \%$ \\
\hline Máximo & $100 \%$ & $90 \%$ & $90 \%$ & $75 \%$ \\
\hline Moda & $60 \%$ & $75 \%$ & $70 \%$ & $50 \%$ \\
\hline Mediana & $60 \%$ & $66,5 \%$ & $80 \%$ & $58 \%$ \\
\hline Desvio padrão & $22 \%$ & $9,15 \%$ & $10 \%$ & $8,95 \%$ \\
\hline
\end{tabular}

\subsection{Escrever uma história}

A concretização do trabalho final foi o momento mais marcante do estudo para a maioria dos alunos. Os 20 grupos que trabalharam durante a primeira parte do estudo reorganizaram-se para a concretização de três histórias diferentes, cabendo a cada um desses grupos iniciais a definição e preparação de uma parte da história.

Havendo grande número de participantes, verificámos que alguns dos seus elementos se esforçaram menos na concretização da tarefa, sendo necessário estar sempre a controlar o trabalho desenvolvido ou ainda por desenvolver e, sobretudo, verificar que não havia distrações com as diversas funcionalidades dos iPads.

134 Não podemos deixar de referir que o aluno que apresentou esta opinião é um dos que melhor aproveitamento tem na disciplina pelo que tomámos o seu comentário como extremamente valioso para as conclusões do nosso estudo. 
Apesar disso, acabou por desenvolver-se um bom trabalho e os alunos conseguiram cumprir os objetivos, aliando a diversão da criação de novos conteúdos para ilustração da história com a ampliação dos conhecimentos recentemente adquiridos com mais algumas pesquisas (Figura 5.2). Pudemos acompanhar a sua preocupação em conjugar a história criada com factos verídicos, apesar de termos encontrado alguns pequenos erros históricos, num trabalho que foi de grande colaboração entre os diferentes grupos.

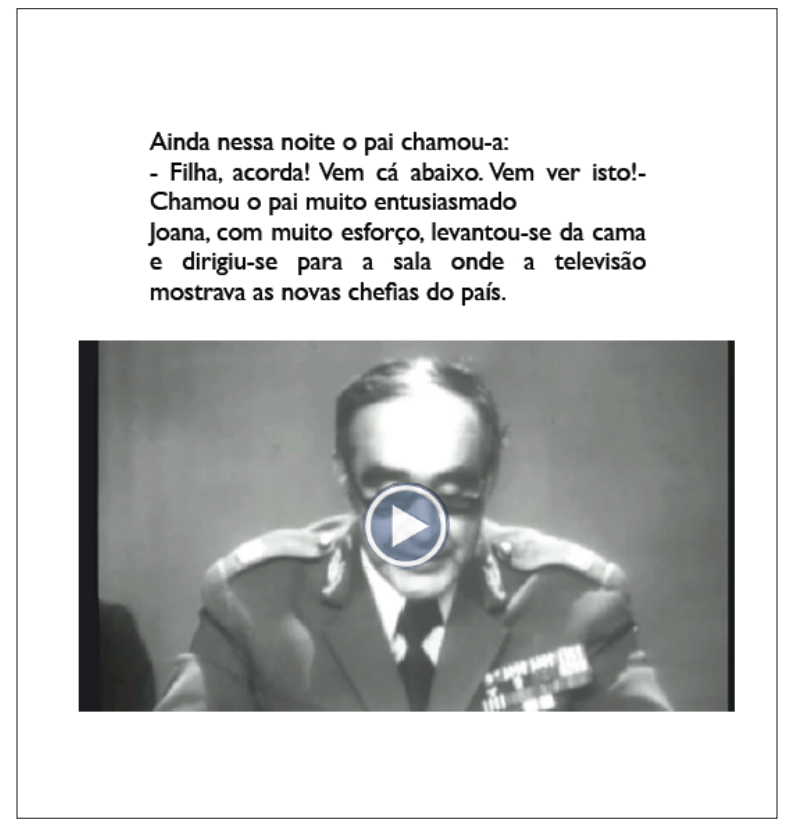

Figura 5.2 - Página de uma das histórias criadas

Em relação ao cumprimento do guião da história, o único aspeto que não foi cumprido na totalidade foi o da criação de materiais pelos alunos. Somente uma das histórias apresenta recursos criados pelos alunos para a história realizada (Tabela 5.15 e Figura 5.3). 
Tabela 5.15 - Cumprimento das regras apresentadas no Guião para a realização da história final

\begin{tabular}{|l|c|c|c|}
\hline Histórias & $\begin{array}{c}\text { A paixão } \\
\text { dos cravos }\end{array}$ & $\begin{array}{c}\text { Abril, momentos } \\
\text { inesquecíveis }\end{array}$ & $\begin{array}{c}\text { E depois } \\
\text { do adeus }\end{array}$ \\
\hline Título & $\checkmark$ & $\checkmark$ & $\checkmark$ \\
\hline Extensão (6 páginas + conclusão) & $\checkmark$ & $\checkmark$ & $\checkmark$ \\
\hline Respeito pela conclusão apresentada & $\checkmark$ & $\checkmark$ & $\checkmark$ \\
\hline 6 dados reais (acontecimentos, personagens...) & $\checkmark$ & $\checkmark$ & $\checkmark$ \\
\hline $\begin{array}{l}\text { Cronologia (história deve decorrer entre } \\
1 / 1 / 74 \text { e 30/11/75) }\end{array}$ & $\checkmark$ & $\checkmark$ & $\checkmark$ \\
\hline $\begin{array}{l}\text { Material gráfico (elaboração de, pelo menos, 2 } \\
\text { materiais novos) }\end{array}$ & $\begin{array}{c}\text { Não } \\
\text { realizado }\end{array}$ & $\checkmark$ & $\begin{array}{c}\text { Não } \\
\text { realizado }\end{array}$ \\
\hline
\end{tabular}

A hora aproximava-se e Rui ainda tinha que entregar à Joana a carta que lhe tinha escrito na noite anterior.

- Joana... tenho uma- Rui era para ter dito a Joana, mas foi interrompido por uma voz:

\section{$(4))$}

Figura 5.3 - Extrato da história "Abril, momentos inesquecíveis", onde foi inserido um som criado pelos alunos

Vejam-se as figuras 5.4 a 5.6 para exemplos de cada uma das histórias relativos à introdução de acontecimentos ou personagens reais no decorrer de cada um dos textos. 


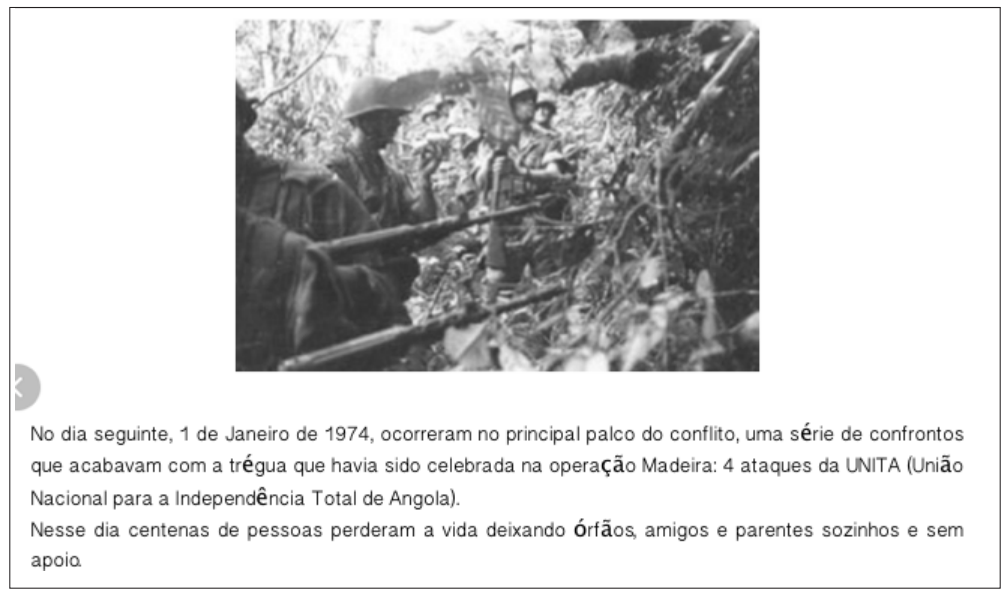

Figura 5.4 - Extrato da história "A paixão dos cravos", com referência a acontecimentos passados em Angola

Infelizmente, pouco tempo depois a alegria da revolução dava lugar aos desentendimentos entre portugueses anónimos...

Joana tinha acabado de sair de casa para ir ter com o seu pai mas quando passava pelas ruas observa a imensa violência nas ruas entre os partidos de esquerda e de direita. Joana estava chocada com os estragos causados ainda por cima tão pouco tempo depois do 25 de Abril. Surpreendida pensa para si mesma se o seu namorado em Angola passava pela mesma situação, preocupada com tudo o que se passava à sua volta.

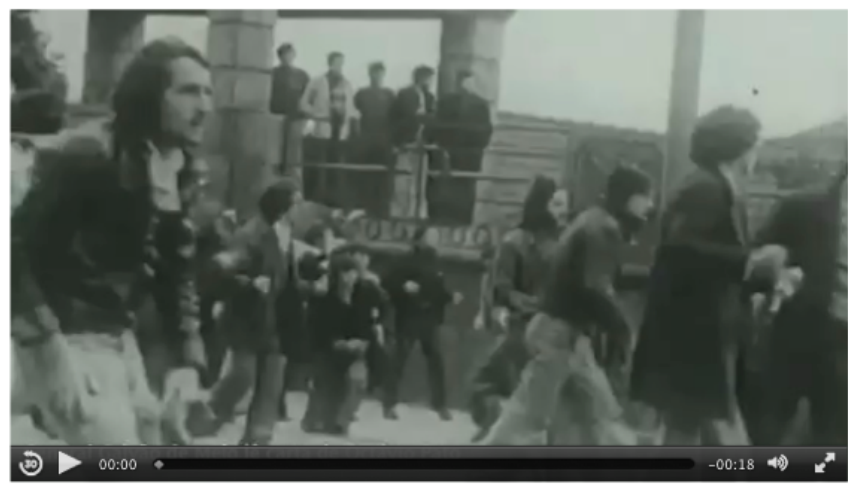

Figura 5.5 - Extrato da história "Abril, momentos inesquecíveis", com referência aos confrontos civis durante o Verão Quente 
Joana regressou com a família a Portugal no início de Abril de 1974.

Passado pouco tempo, Joana, no seu carocha de 69, atravessava a cidade de Lisboa, após um longo e atarefado dia de trabalho. Pouco passava da meia noite e, como era costume no regresso a casa, Joana ouvia a rádio Emissora Nacional. A música de Paulo de Carvalho "E depois do adeus", vencedora do festival da canção de Março, fazia-se ouvir nas colunas de som de alta qualidade do carocha. Mesmo com longas e duras horas de trabalho no corpo, Joana ainda conseguia "abanar o capacete". Aquele som fazia milagres...Chegou a casa e imediatamente se atirou para debaixo dos lençóis.

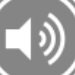

Figura 5.6 - Extrato da história " E depois do adeus", com referência a uma das senhas que marca o início da Revolução de 1974

No capítulo 4 reportámos as competências que pretendíamos ver desenvolvidas por estes alunos através da realização desta história, nomeadamente, procurando o enriquecimento da sua comunicação através da análise e produção de materiais variados. Se, por um lado, entendemos que os alunos foram capazes de analisar a variedade de documentos disponíveis (sons, vídeos, imagens) e selecioná-los de acordo com os seus interesses, sentimos que na história "Abril, momentos inesquecíveis" isso foi mais notório. Não privilegiando um momento específico do período revolucionário, os membros do grupo que escreveu esta história tentaram recriar todo um conjunto de momentos definidores do que para eles foram os anos de 1974 e 1975 em Portugal.

Outra competência, associada ainda à comunicação em História (recriação de situações históricas e expressão de ideias), mostra-se também adquirida por todos, uma vez mais sobretudo na história que atrás acabámos de referir.

Contudo, a história "E depois do Adeus" revela-se a menos conseguida, em termos de construção de conhecimento histórico, pois houve uma maior preocupação com o contexto ficcional do que propriamente com o histórico. Contudo, é de destacar que este grupo abordou o tema da "Maioria Silenciosa" e da demissão do General António de Spínola, deixando na história uma interrogação cuja resposta eles próprios confessaram ter tido mais dificuldade 
em perceber: porquê os desentendimentos entre os que no dia 25 de abril estavam lado a lado na luta pela liberdade.

\subsection{Questionário de opinião sobre o estudo}

\subsubsection{Recursos e tarefas realizadas}

O questionário de opinião reflete a elevada satisfação em relação ao trabalho desenvolvido. Apenas um participante referiu não ter gostado de trabalhar com o iPad (Tabela 5.16): prefere trabalhar com o manual e aulas expositivas. A grande maioria dos restantes participantes gostou muito $(80,9 \%)$.

Uma pequena minoria referiu ter tido alguma ou muita dificuldade no trabalho com o iPad (respetivamente 4,3\% e 2,1\%) e, mais de $75 \%$ da amostra considerou o trabalho fácil.

Para 66\% dos alunos a opinião é de que aprenderam melhor do que noutras aulas e apenas um aluno (o mesmo que não gostou de trabalhar com o $i P a d$ ) indica ter aprendido pior.

$\mathrm{Na}$ generalidade, a experiência foi considerada interessante $(72,3 \%) \mathrm{e}$ divertida $(55,3 \%)$, mas no que toca a ter aumentado o seu interesse pela matéria (recordamos que a temática do 25 de abril foi escolhida como um dos temas mais interessantes da matéria de História de 9. ano apenas por $27,7 \%$ dos inquiridos) a quase totalidade dos participantes respondeu "mais ou menos" (80,9\%) e ninguém respondeu afirmativamente.

Indo um pouco ao contrário do que a maioria respondeu na questão 3 (à qual a $66 \%$ responderam que tinham aprendido melhor), quando questionados sobre se ver os conteúdos no manual digital era mais esclarecedor do que no manual em papel, voltamos a encontrar alguma indecisão pois 59,6\% responderam "mais ou menos" e os restantes $40,4 \%$ escolheram uma resposta negativa.

Em resumo, as respostas às seis primeiras questões do questionário final apresentam algumas discordâncias que nos parecem acabar por refletir o comentário que referimos no ponto 5.3.4 sobre a falta de maturidade deste grupo de alunos (devido essencialmente à sua idade). Se claramente foi uma 
boa experiência, manifestam-se algumas dúvidas quanto a aumentar o interesse pela matéria.

Tabela 5.16 - Opiniões sobre os recursos e as tarefas realizadas $(n=47)$

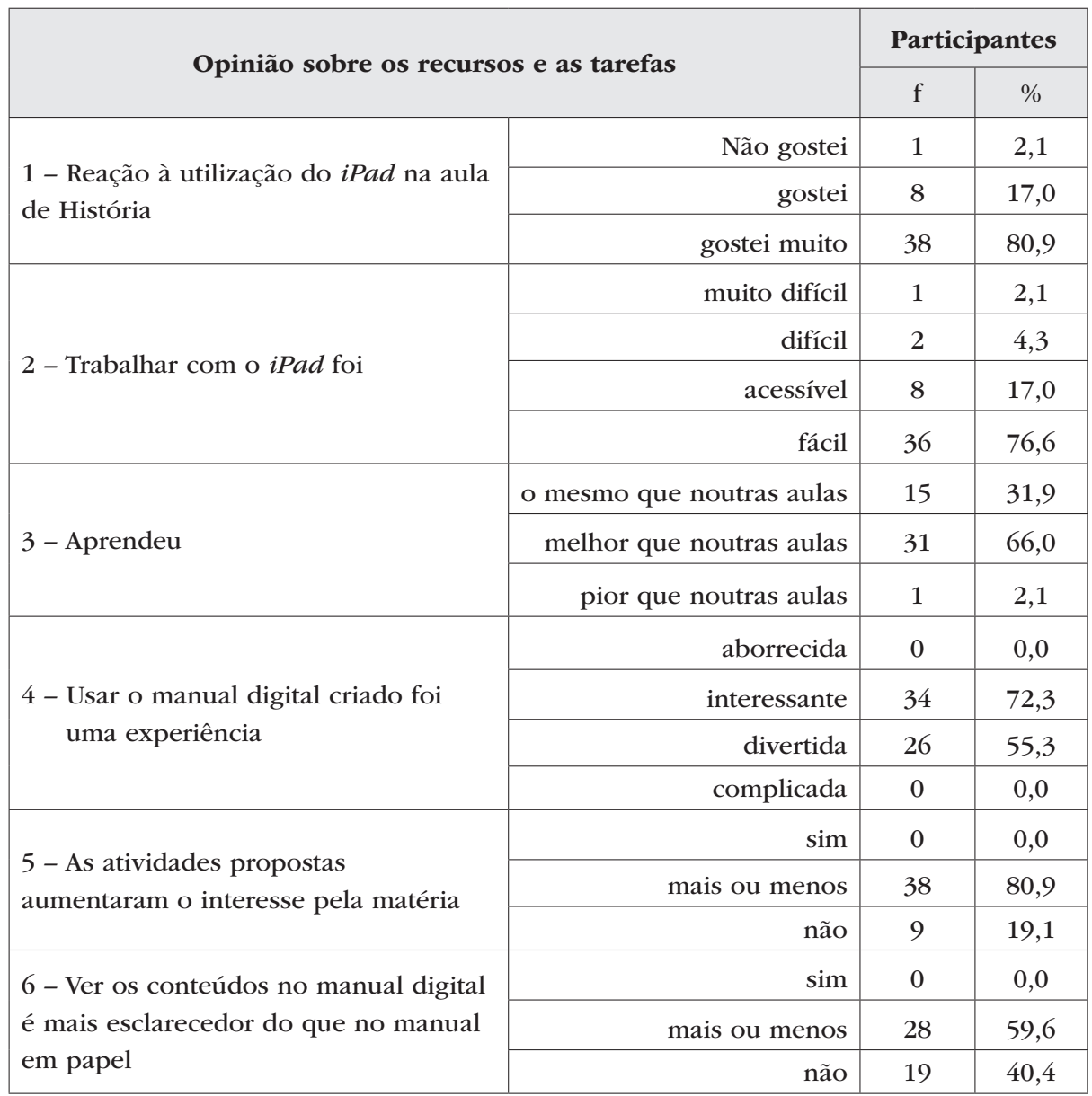

\subsubsection{Manual digital versus aprendizagem dita clássica}

Conforme podemos observar na Tabela 5.17, os participantes discordam que o manual digital substitua o professor, não têm opinião sobre se o manual digital pode substituir a presença nas aulas e concordam que o manual apre- 
senta a matéria de uma forma mais atrativa e a sua interatividade é também uma vantagem. Por outro lado, concordam que o manual digital poderá servir como complemento da aula apenas e não têm opinião definida sobre se preferem ouvir o professor explicar a matéria (itens 3 e 7).

Em suma, este quadro, apesar de à partida parecer algo confuso, acaba por nos dar a indicação de que este grupo de participantes vê no nosso estudo um trabalho estimulante e apelativo. Contudo, a necessidade de um professor que os guie, e o suporte seguro do manual em papel, onde a informação se encontra absolutamente explícita, afigura-se-lhes ainda demasiado importante para deixar que a interatividade do manual digital suplante algumas preferências em relação à tipologia clássica de ensino.

Tabela 5.17 - Comparação entre o manual digital e a aprendizagem dita "clássica" $(n=47)$

\begin{tabular}{|c|c|c|c|c|c|c|c|c|c|c|}
\hline \multirow{3}{*}{$\begin{array}{l}\text { Manual digital } \\
\text { versus aprendizagem } \\
\text { dita "clássica" }\end{array}$} & \multicolumn{10}{|c|}{ Participantes } \\
\hline & \multicolumn{2}{|c|}{1} & \multicolumn{2}{|c|}{2} & \multicolumn{2}{|c|}{3} & \multicolumn{2}{|c|}{4} & \multicolumn{2}{|c|}{5} \\
\hline & $\mathrm{f}$ & $\%$ & $\mathrm{f}$ & $\%$ & $\mathrm{f}$ & $\%$ & $\mathrm{f}$ & $\%$ & $\mathrm{f}$ & $\%$ \\
\hline $\begin{array}{l}1 \text { - Tendo um manual } \\
\text { digital não preciso de } \\
\text { assistir a aulas }\end{array}$ & 20 & 42,6 & 7 & 14,9 & 8 & 17 & 3 & 6,4 & 9 & 19,1 \\
\hline $\begin{array}{l}2 \text { - O manual digital } \\
\text { substitui o professor }\end{array}$ & 39 & 83 & 4 & 8,5 & 3 & 6,4 & 0 & 0 & 1 & 2,1 \\
\hline $\begin{array}{l}\text { 3- O manual digital } \\
\text { serve só como } \\
\text { complemento da aula }\end{array}$ & 2 & 4,3 & 6 & 12,8 & 11 & 23,4 & 12 & 25,5 & 18 & 38,3 \\
\hline $\begin{array}{l}\text { 4- O manual digital } \\
\text { apresenta a matéria de } \\
\text { uma forma mais atrativa } \\
\text { do que o manual em } \\
\text { papel }\end{array}$ & 0 & 0 & 2 & 4,3 & 3 & 6,4 & 9 & 19,1 & 33 & 70,2 \\
\hline $\begin{array}{l}5 \text { - O manual digital } \\
\text { apresenta melhor a } \\
\text { matéria porque a posso } \\
\text { organizar de acordo com } \\
\text { as minhas necessidades }\end{array}$ & 0 & 0 & 4 & 8,5 & 8 & 17 & 13 & 27,7 & 22 & 46,8 \\
\hline
\end{tabular}




\begin{tabular}{|c|c|c|c|c|c|c|c|c|c|c|}
\hline \multirow{3}{*}{$\begin{array}{l}\text { Manual digital } \\
\text { versus aprendizagem } \\
\text { dita "clássica" }\end{array}$} & \multicolumn{10}{|c|}{ Participantes } \\
\hline & \multicolumn{2}{|c|}{1} & \multicolumn{2}{|c|}{2} & \multicolumn{2}{|c|}{3} & \multicolumn{2}{|c|}{4} & \multicolumn{2}{|c|}{5} \\
\hline & $\mathrm{f}$ & $\%$ & $\mathrm{f}$ & $\%$ & $\mathrm{f}$ & $\%$ & $\mathrm{f}$ & $\%$ & $\mathrm{f}$ & $\%$ \\
\hline $\begin{array}{l}6 \text { - Gosto de poder } \\
\text { escolher como vejo os } \\
\text { conteúdos do manual } \\
\text { digital }\end{array}$ & 0 & 0 & 4 & 8,5 & 6 & 12,8 & 8 & 17 & 29 & 61,7 \\
\hline $\begin{array}{l}7 \text { - Prefiro ouvir a } \\
\text { professora explicar a } \\
\text { matéria }\end{array}$ & 3 & 6,4 & 5 & 10,6 & 20 & 42,6 & 11 & 23,4 & 8 & 17 \\
\hline $\begin{array}{l}8 \text { - Prefiro estudar pelo } \\
\text { manual em papel }\end{array}$ & 23 & 48,9 & 5 & 10,6 & 13 & 27,7 & 2 & 4,3 & 4 & 8,5 \\
\hline
\end{tabular}

\subsubsection{Competências trabalhadas}

Apesar de tudo, a experiência produziu um resultado positivo, sobretudo ao nível do desenvolvimento de competências de trabalho prático, um vez que este grupo evidenciou, sobretudo, as aprendizagens desenvolvidas ao nível da seleção da informação mais relevante e do trabalho em grupo (cada opção recolheu $73,3 \%$ das respostas) e da análise da informação apresentada $(68,1 \%)$ (Tabela 5.18).

Tabela 5.18 - Aprendizagens adquiridas através da utilização do manual digital $(n=47)$

\begin{tabular}{|l|c|c|}
\hline \multirow{2}{*}{\multicolumn{1}{c|}{ Aprendizagens adquiridas }} & \multicolumn{2}{c|}{ Participantes } \\
\cline { 2 - 3 } & $\mathrm{f}$ & $\%$ \\
\hline Analisar atentamente a informação mais relevante & 32 & 68,1 \\
\hline Selecionar a informação mais relevante & 34 & 73,3 \\
\hline Produzir textos com rigor e qualidade & 22 & 46,8 \\
\hline Sintetizar as informações principais & 30 & 63,8 \\
\hline Trabalhar em grupo na concretização das tarefas & 34 & 73,3 \\
\hline Outras & 0 & 0,0 \\
\hline
\end{tabular}

Sobre a sua experiência com o manual digital, 61,7\% dos participantes referem ter gostado muito (consideraram um trabalho "muito divertido", "fixe" e "interessante"), 23,4\% acham que foi uma atividade bastante motivadora e 
$14,9 \%$ acham que trabalharam mais nestas aulas (referindo, por exemplo, que aprenderam "mais do que com o manual em papel" e que ajudou a "analisar documentos e a selecionar expressões e material necessário para perceber a matéria") (Tabela 5.19).

Destacamos apenas algumas das outras afirmações deixadas nos questionários por estes alunos, como "adorei trabalhar com o manual digital, pois foi uma maneira de aprender a matéria de forma diferente. Trabalhámos mais do que em qualquer outra aula, para além de nos divertirmos bastante", ou "o manual digital foi uma ajuda preciosa nas aulas e levou-me a subir a minha nota". Houve apenas um aluno que referiu que "foi divertido, mas [prefere] estudar e aprender pelo livro" e ainda quatro alunos que não deram qualquer resposta.

Tabela 5.19 - Opinião geral sobre o estudo $(n=47)$

\begin{tabular}{|l|c|c|}
\hline \multirow{2}{*}{ Categorias } & \multicolumn{2}{c|}{ Participantes } \\
\cline { 2 - 3 } & $\mathrm{f}$ & $\%$ \\
\hline Gostei muito & 29 & 61,7 \\
\hline Aprendi a trabalhar com uma nova tecnologia & 3 & 6,4 \\
\hline Trabalha-se mais/ melhor & 7 & 14,9 \\
\hline Ajuda a trabalhar em grupo & 4 & 8,5 \\
\hline Forma diferente de aprender & 4 & 8,5 \\
\hline Experiência a repetir & 2 & 4,3 \\
\hline Ajuda a ter uma relação diferente com a História & 1 & 2,1 \\
\hline Motivador & 11 & 23,4 \\
\hline Prefiro estudar e aprender pelo livro & 1 & 2,1 \\
\hline Levou-me a subir a minha nota & 1 & 2,1 \\
\hline Não responde & 4 & 8,5 \\
\hline
\end{tabular}

\subsubsection{Construção da história}

De acordo com as respostas apresentadas, este grupo sente que a concretização desta tarefa os terá ajudado a melhorar os seus resultados. Concordam também que a realização deste trabalho os ajudou a aprender mais sobre o tema em estudo, discordando com a afirmação de que o trabalho teria sido 
apenas uma brincadeira. Por isso se explicará, então, que 95,7\% concordem que foi uma boa experiência, que $97,8 \%$ não achem que tenha sido uma perda de tempo, que concordem que tenha contribuído para melhorar os seus resultados (item 5) e que $83 \%$ entendam que deveria ser realizada mais vezes nas aulas, pois se aprende muito com ela (Tabela 5.20).

Tabela 5.20 - Opinião sobre a elaboração da história $(n=47)$

\begin{tabular}{|c|c|c|c|c|c|c|c|c|c|c|}
\hline \multirow{3}{*}{$\begin{array}{l}\text { Opinião sobre a } \\
\text { elaboração da história }\end{array}$} & \multicolumn{10}{|c|}{ Participantes } \\
\hline & \multicolumn{2}{|c|}{1} & \multicolumn{2}{|c|}{2} & \multicolumn{2}{|c|}{3} & \multicolumn{2}{|c|}{4} & \multicolumn{2}{|c|}{5} \\
\hline & $\mathrm{f}$ & $\%$ & f & $\%$ & $\mathrm{f}$ & $\%$ & $\mathrm{f}$ & $\%$ & $\mathrm{f}$ & $\%$ \\
\hline $\begin{array}{l}1 \text { - Ao ter de preparar } \\
\text { conteúdos para elaborar } \\
\text { a história aprendi mais } \\
\text { sobre o tema }\end{array}$ & 0 & 0 & 0 & 0 & 9 & 19,1 & 17 & 36,2 & 21 & 44,7 \\
\hline $\begin{array}{l}2 \text { - Não senti que } \\
\text { estivesse a aprender } \\
\text { mas apenas a brincar }\end{array}$ & 32 & 68,1 & 9 & 19,1 & 2 & 4,2 & 4 & 8,5 & 0 & 0 \\
\hline $\begin{array}{l}3 \text { - Foi uma boa } \\
\text { experiência }\end{array}$ & 0 & 0 & 0 & 0 & 2 & 4,2 & 4 & 8,5 & 41 & 87,2 \\
\hline $\begin{array}{l}4 \text { - Foi uma perda de } \\
\text { tempo }\end{array}$ & 45 & 95,7 & 1 & 2,1 & 0 & 0 & 1 & 2,1 & 0 & 0 \\
\hline $\begin{array}{l}5 \text { - Esta tarefa } \\
\text { contribuiu para } \\
\text { melhorar os meus } \\
\text { resultados }\end{array}$ & 2 & 4,2 & 1 & 2,1 & 13 & 27,6 & 19 & 40,4 & 12 & 25,5 \\
\hline $\begin{array}{l}6 \text { - Esta atividade } \\
\text { deveria ser feita mais } \\
\text { vezes nas aulas porque } \\
\text { se aprende muito }\end{array}$ & 1 & 2,1 & 0 & 0 & 7 & 14,9 & 19 & 40,4 & 20 & 42,6 \\
\hline
\end{tabular}

Ainda sobre a realização da história, houve um participante que não ouviu a leitura das histórias realizadas. Quase todos $(93,6 \%)$ indicaram que tinham curiosidade de ler essas mesmas histórias, havendo 3 alunos que responderam não ter curiosidade. Dos que leram as histórias $(74,5 \%)$, referiram que essa leitura contribuiu para aumentar os seus conhecimentos e a mesma percentagem indicou ter gostado de as ler (Tabela 5.21). 
Tabela 5.21 - Opinião sobre as histórias realizadas pelos outros participantes $(n=47)$

\begin{tabular}{|c|c|c|c|}
\hline \multirow{2}{*}{\multicolumn{2}{|c|}{ Opinião sobre as histórias realizadas pelos colegas }} & \multicolumn{2}{|c|}{ Participantes } \\
\hline & & \multirow{2}{*}{$\begin{array}{c}\mathrm{f} \\
44\end{array}$} & \multirow{2}{*}{$\begin{array}{c}\% \\
93,6 \\
\end{array}$} \\
\hline \multirow{3}{*}{$\begin{array}{l}1 \text { - Tinha curiosidade de ler os trabalhos dos meus } \\
\text { colegas }\end{array}$} & Sim & & \\
\hline & Não & 3 & 6,4 \\
\hline & Não li & 0 & 0,0 \\
\hline \multirow{3}{*}{$\begin{array}{l}2 \text { - Ler os trabalhos dos meus colegas contribuiu para } \\
\text { aumentar mais os meus conhecimentos }\end{array}$} & Sim & 35 & 74,5 \\
\hline & Não & 11 & 23,4 \\
\hline & Não li & 1 & 2,1 \\
\hline \multirow{4}{*}{$\begin{array}{l}3 \text { - Gostei de ler as histórias criadas pelos meus } \\
\text { colegas }\end{array}$} & Sim & 35 & 74,5 \\
\hline & Mais ou menos & 11 & 23,4 \\
\hline & Não & 0 & 0 \\
\hline & Não li & 1 & 2,1 \\
\hline
\end{tabular}

Na questão de resposta aberta sobre a elaboração da história, constatam-se comentários cheios de entusiasmo (55,3\% referem que gostaram muito), de motivação promovida pelo trabalho desenvolvido (14,9\%), que entendem como produtivo e uma forma de aprenderem mais $(38,3 \%)$ e consideram que foi uma experiência inovadora (14,9\%) (Tabela 5.22), destacam-se alguns comentários, mais detalhados, sobre a importância que terá tido para eles a criação da história sobre o 25 de abril:

- Gostei bastante da experiência com a utilização do Book Creator e a construção de uma história. Foi uma maneira inovadora e original de aprender a matéria e acho que melhorei os resultados.

- Utilizar o Book Creator faz com que tenhamos a noção da construção de uma história. Ajuda-nos a perceber os nossos erros e elabora o nosso trabalho como se fosse um verdadeiro livro.

- Foi uma experiência muito boa e acho que é uma atividade que deveria ser realizada com mais frequência, pois para além de tornar as aulas mais divertidas também simbolizam os tempos modernos que ligam a educação à tecnologia. 
- Gostei bastante. Foi uma forma de aprender mais porque, de certa maneira, ao tentar construir uma boa história, tivemos de estudar bem os conteúdos.

- Com esta aplicação considero que o estudo desta matéria se tornou mais fácil, tendo, esta experiência, tornando-se numa motivação ao estudo desta matéria.

Apesar do sucesso que parece ter sido, um dos participantes indicou também que "foi uma experiência interessante que adorei. Mesmo assim, prefiro estudar pelo manual" e houve ainda seis alunos que não escreveram nada sobre a elaboração da história.

Tabela 5.22 - Opinião relativa à elaboração da história $(n=47)$

\begin{tabular}{|l|c|c|}
\hline \multirow{2}{*}{\multicolumn{1}{|c|}{ Categorias }} & \multicolumn{2}{c|}{ Participantes } \\
\cline { 2 - 3 } & $\mathrm{f}$ & $\%$ \\
\hline Gostei muito & 26 & 55,3 \\
\hline Aprendemos mais & 18 & 38,3 \\
\hline Foi motivador & 7 & 14,9 \\
\hline Foi inovador & 7 & 14,9 \\
\hline Ajudou-nos a reviver a História & 1 & 2,1 \\
\hline Prefiro estudar pelo manual & 1 & 2,1 \\
\hline Ajudou-me a perceber os meus erros & 1 & 2,1 \\
\hline No início foi esquisito & 1 & 2,1 \\
\hline Não responde & 6 & 12,8 \\
\hline
\end{tabular}

Em suma, este grupo revelou-se sempre muito motivado para a concretização deste estudo, mostrando-se sempre interessado em colaborar da melhor forma possível. Por isso os seus comentários foram amplamente favoráveis à repetição de trabalhos idênticos, uma vez que consideram que foi uma experiência bastante agradável e divertida através da qual aprenderam muitas coisas novas. Curiosamente, acham que aprenderam melhor mas não sabem se foi efetivamente mais esclarecedor. Como atrás já referimos, julgamos que este grupo ainda se encontra num nível etário onde o apoio e a presença-guia do professor continua a ser demasiado importante nas suas aprendizagens. 
Apesar disso, consideramos satisfatório que também estes alunos indiquem que as diferentes atividades os ajudaram a melhorar as suas competências ao nível da seleção de informação, do trabalho em grupo e também de análise e síntese dessa mesma informação.

A concretização da história, atividade que proporcionou momentos de alguma diversão no espaço da sala de aula, serviu para melhorar os seus resultados, considerando que é experiência a repetir pois se pode aprender bastante através dela. Mesmo a leitura das histórias uns dos outros, terá contribuído para melhorar os seus conhecimentos.

Parece-nos evidente que a motivação para a aprendizagem é um ponto constante em todas as respostas dos questionários de opinião. Havendo alguns elementos mais relutantes, a maioria foi claramente favorável ao desenvolvimento do nosso estudo e vários foram os questionários onde os participantes indicaram, especificamente, que viam neste tipo de trabalho uma ferramenta que potencia a motivação para a aprendizagem.

Verificou-se uma grande evolução do teste inicial para o teste final, sendo este estatisticamente significativo. A melhoria nas competências para a construção do conhecimento histórico pode apenas ser avaliada de uma forma mais genérica, através da observação direta que fomos fazendo e também da forma como os participantes trabalharam na concretização das tarefas intermédias e na construção da história final. O afinco com que procuraram interligar a informação e produzir conteúdos que, apesar de alguns erros, demonstravam algum cuidado e critério, permite-nos dar uma resposta positiva também neste ponto.

Contudo, outro aspecto que nos parece fundamental é que este trabalho permite um aumento qualitativo no acesso às fontes e na própria estruturação de todo o processo de aprendizagem, começando logo na forma como se pode organizar o acesso à informação, passando pela própria estruturação das atividades a desenvolver, que é assumidamente mais clara.

Assim sendo, parece-nos conseguida uma maior eficácia na organização do processo de aprendizagem, para além de que nos parece que se torna muito 
mais fácil fazer a transição entre o consumo e a análise da informação e a produção do novo conhecimento com base nela que é o verdadeiro momento de aprendizagem.

De facto, esta metodologia assente na utilização do programa iTunes $U$ nas aulas de História promove a passagem pelas três fases do processo de aprendizagem: domínio dos conteúdos apresentados, utilização desses mesmos conteúdos, através da concretização de pequenas tarefas e, finalmente, apropriação desses mesmos conteúdos para utilização em novas situações.

É nosso entender que esta última fase é aquela que promove uma aprendizagem efetiva, uma vez que, pela concretização da história final onde, como já referimos, se pretendia que os alunos não só reutilizassem os documentos que lhes tinham sido apresentados, como trabalhassem para criar novos conteúdos, os alunos são levados a apropriar-se da própria História. Para além disso e, pela possibilidade de interação entre as diferentes aplicações presentes nos $\mathrm{iPad}$, estas histórias transformam-se num conteúdo inteiramente novo mas que pode estar ao mesmo nível que outros que eles visualizaram antes no curso no iTunes $U$ e que apresenta, de uma forma por eles sintetizada, informação multimédia nova, intercalada com outra já existente.

Em suma, maior envolvimento (engagement), melhor acesso às fontes, melhor organização dos materiais e possibilidade de recriação dos conteúdos parecem-nos, efetivamente, um salto qualitativo no processo de aprendizagem em História, enquanto disciplina de alguma complexidade, e que lida com conceitos que precisam de ser devidamente compreendidos pelos nossos alunos para que estes consigam, de forma plena, construir, de forma crítica, por si próprios, o conhecimento histórico. 
(Página deixada propositadamente em branco) 


\section{O N C L U S Ã O}

Ao realizarmos o nosso trabalho de investigação procurámos criar uma linha de raciocínio que nos guiasse ao longo de um conjunto de ideias teóricas que justificassem a estratégia que delineámos na preparação e execução dos nossos estudos de caso.

No capítulo 1 procedemos a uma revisão dos projetos nacionais e internacionais que visaram a introdução das TDIC nas Escolas e, posteriormente, o seu alargamento no ensino não só no âmbito das infraestruturas como também procurando dotar alunos e docentes de ferramentas e competências que lhes permitissem usufruir ao máximo o que essas tecnologias digitais teriam para oferecer. Pudemos perceber, neste ponto, que Portugal veio acompanhando, tal como tantos outros países, estas medidas, adotando e desenvolvendo variados projetos tecnológicos.

E como a tecnologia digital sofreu, desde há 30 anos para cá, uma enorme evolução, proporcionou também uma certa revolução na maneira como podemos hoje encarar o processo de aprendizagem. Plenamente associado às ideias conectivistas desenvolvidas por Siemens, o Capítulo 2 leva-nos ao mobile learning, o qual vem possibilitar uma aprendizagem muito mais pessoal e praticamente em qualquer lugar (Ally, 2009; Traxler, 2009). Esta mobilidade já havia sido iniciada com o desenvolvimento dos computadores portáteis e, sobretudo, com os laptops, mas foi potenciada com o desenvolvimento dos smartphones e dos tablets que hoje são aparelhos verdadeiramente portáteis e com toda uma diversidade de aplicações que as suas memórias e velocidade de processamento permitem.

A difusão destes dispositivos móveis veio propiciar o desenvolvimento de inúmeros projetos que os introduzem no contexto educativo (nomeadamente, 
Project Tomorrow, Tablets for Schools, Creative Classroom Labs), levando tanto docentes como alunos a perceber que os seus equipamentos, outrora associados apenas ao lazer, podem hoje servir também para aprender. Contudo, apesar de a maioria destes estudos evidenciar o aumento da motivação e da produtividade (Coutinho, 2011; Garcia, 2011; Hutchinson et al., 2012; Moura

\& Carvalho, 2013; Quinn, 2013; Sandvik et al., 2012; Sheppard, 2011), há ainda vários debates e algumas reservas quanto ao efetivo benefício da utilização deste tipo de equipamentos em sala de aula (Observatório de Recursos Educativos, 2014; Traxler, 2010). Entre os principais destaca-se a diminuição do controle que o docente pode ter sobre o que os seus alunos estão a fazer.

Conscientes das opiniões constantes destes estudos, a perspetiva de que poderíamos usufruir da interatividade proporcionada pela tecnologia digital para potenciar a aprendizagem nas aulas de História, levou-nos a introduzir um manual interativo para a plataforma iTunes $U$ (para iPhone e iPad), produzido através da aplicação iTunes $U$ Course Manager.

\section{a) $O$ estudo}

A questão de investigação que determinou a preparação e o desenvolvimento do nosso trabalho relacionava-se com a análise do impacto que têm os novos dispositivos móveis como os tablets, e os ambientes tecnológicos que lhes estão associados, no envolvimento e na aprendizagem dos alunos nas aulas de História.

Sendo a aprendizagem da História uma tarefa que envolve a análise de fontes e documentação variada, é um trabalho que muitas vezes contribui para a desmotivação dos alunos dada a necessidade de relacionar e contrapor perspetivas diferentes. Para além disso, o desenvolvimento de competências em História deve passar não só pela análise de informação mas também pela comunicação em História pelo que, mais do que reproduzir os conteúdos lecionados, cabe ao aluno ser capaz de produzir novos conteúdos a partir do conhecimento que vai adquirindo.

Desta forma, o estudo que desenvolvemos partia de uma matéria cuja aprendizagem é normalmente mais complicada e procurou dotar os alunos 
de ferramentas que lhes permitissem organizar o seu processo de aprendizagem levando-os, através da concretização de diferentes tarefas, a consolidar os conhecimentos adquiridos produzindo, eles próprios, novo conhecimento.

Esse é, para nós, o grande aspeto positivo demonstrado pelo nosso trabalho: o iPad e o iTunes $U$ podem ser bastante benéficos para aumentar o conhecimento histórico dos alunos pois, mais ainda do que aumentar a motivação entre os alunos, têm ao seu dispor, através do $i P a d$, toda uma panóplia de aplicações que lhes permitem ver e rever toda a informação, selecioná-la, organizá-la e apropriar-se dela para a utilizar face a novas situações.

Assim, parecem ter sido alcançados os objetivos que estipulámos para o nosso estudo. Da análise que fizemos dos trabalhos por eles realizados, e do decorrer das sessões, verificamos que os alunos conseguiram ter sucesso no que toca às competências ao nível da construção de conhecimento histórico, das competências de análise e interpretação de fontes bem como de comunicação em História e até mesmo ao nível de conceitos estruturais como o de significância e de evidência.

A escolha da concretização de um trabalho baseado no iTunes $U$ revelou-se para nós acertada pois apesar de esta plataforma ser proprietária, esperamos que sirva como exemplo para o futuro de como se pode desenvolver um ambiente de ensino e de aprendizagem criado para os nativos digitais, ou seja, um ambiente recheado de jogos, aplicativos, vídeos ou músicas online, entre outras possibilidades.

No nosso entender, o iPad consegue ser o eixo de um ecossistema completo, que engloba tanto uma ferramenta para produção dos módulos de aprendizagem, o iTunes $U$ Course Manager, como o canal de distribuição dos conteúdos, o iTunes, e o software para consumo da informação disponibilizada, o iTunes $U$, para além de integrar todo um conjunto de aplicações que permitem tanto a alunos como a professores uma variada e dinâmica interação entre consumo de conhecimento e produção de novo saber.

Se olharmos para os nossos resultados verificamos que os alunos, em larga maioria, se sentem muito mais motivados para a disciplina e veem utilidade nesta nova forma de aprender. De facto, analisados os resultados dos testes de conhecimentos que foram realizados antes e depois do estudo ser desenvolvido, e também das tarefas intermédias que solicitámos aos participantes, 
verificamos que houve sucesso na aprendizagem. Para nós era importante, sobretudo, a análise do trabalho desenvolvido nas sessões, para além do desempenho na concretização das diferentes tarefas, tendo-se verificado, na globalidade, que os alunos demonstraram conseguir atingir as competências que desejávamos ver desenvolvidas.

Assim, e como referíamos na síntese do Capítulo 5, há aqui um todo que funciona em uníssono e que potencia um salto qualitativo na aprendizagem em História: maior envolvimento, melhor acesso às fontes, melhor organização dos materiais e possibilidade de recriação de conteúdos. Nesta mesma síntese referimos precisamente a eficácia na organização do processo de aprendizagem, uma vez que o equipamento que utilizamos permite, através da diversidade e qualidade das aplicações que contém, não só consumo de informação como também organização dessa mesma informação e produção de novo conhecimento. $\mathrm{O}$ iPad revela-se um equipamento bastante dinâmico e cuja interatividade propiciada pela interação entre as mais diversas aplicações permite aos estudantes recriar nova informação que pode ser apresentada ao mesmo nível daquela a que originalmente tiveram acesso.

No Capítulo 2 escrevemos sobre um caso prático desenvolvido nos Estados Unidos no âmbito da disciplina Social Studies (Garcia, 2011), no qual os autores realizaram um estudo de tipo experimental comparando a aprendizagem efetuada, sobre acontecimentos de História contemporânea dos EUA, por dois grupos de alunos, tendo um destes grupos tido acesso a iPads e à aplicação 9/11 e outro cujas aulas decorreram utilizando métodos ditos "tradicionais". Os resultados obtidos veem ao encontro dos que obtivemos com o nosso estudo. Os autores desse trabalho referem que a utilização dos iPads nas aulas veio reforçar o trabalho colaborativo e interativo (potenciado, sobretudo, pelo acesso a fontes primárias) e desenvolver o pensamento crítico destes estudantes. A validação do trabalho destes autores foi feita também através da comparação dos resultados obtidos pelos dois grupos de alunos nos testes realizados antes e depois do estudo, tendo o grupo do mobile learning obtido melhores resultados e respostas de maior qualidade.

Para além disso, se, por um lado, tanto nós como alguns dos participantes do estudo de caso, sentimos que o facto de as idades destes alunos serem 
mais baixas poderia trazer problemas na utilização de uma metodologia como esta, verificamos que acabou por ser um grupo que parece ter beneficiado bastante com o estudo desenvolvido.

Os participantes reconhecem que a motivação para as aulas de História é maior, tendo este tipo de ferramentas ao dispor, as quais facilitam também o processo de aprendizagem. A larga maioria dos estudantes refere que a utilização deste tipo de recurso contribuiu para o desenvolvimento de competências, sobretudo, relacionadas com o trabalho colaborativo e de síntese dos conteúdos. O momento que para nós se revelava mais importante foi a criação de uma história baseada nos conteúdos lecionados que, por ser a fase do trabalho que envolve a aplicação dos conhecimentos a novas situações, foi para os participantes uma forma de aprender ainda mais e de potenciar bons resultados.

Tirando partido das diferentes estratégias que a utilização deste tipo de tecnologia digital permite podemos ir além do estímulo natural propiciado pela utilização de mecanismos que são absolutamente familiares aos alunos e levá-los a desenvolver maior capacidade de trabalho e aumentar a produtividade que pode existir já não só em espaço de aula mas também fora dela. E este é o ponto de partida para investigações futuras.

Contudo, parece-nos importante, sobretudo quando se tratam de alunos mais novos (até ao 3. ${ }^{\circ} \mathrm{CEB}$ ), conseguir controlar a utilização que fazem de equipamentos como o iPad. Durante a realização do nosso estudo, não foi possível fazer a ligação de todos os iPad a um computador, via AppleTV, o que teria permitido autorizar ou restringir o acesso a qualquer App constante de cada $i P a d$, limitando, dessa forma, as possibilidades de distração. No futuro, deve-se optar por esta situação, visto ser benéfico quer para professores quer para alunos.

Depois de verificarmos que é possível aumentar a qualidade da produção de conhecimento histórico entre os nossos alunos, recorrendo às ferramentas ao nosso dispor através dos tablets (e em particular através do iPad), fica este trabalho como uma base a partir da qual novas linhas de investigação podem ser desenvolvidas. 


\section{b) Implicação do estudo no ensino da História}

Através do trabalho que desenvolvemos, foi possível verificar que, apesar da sobrecarga inicial que implica a organização de um manual digital, desde o processo de seleção de materiais à definição das tarefas a realizar, o trabalho pode posteriormente ser devidamente rentabilizado, contribuindo assim para o desenvolvimento de estratégias de aprendizagem bastante dinâmicas.

Através da análise dos dados que obtivemos, é possível afirmar que este tipo de projeto obtém grande receptividade por parte dos alunos, uma vez que estes estão já habituados a lidar com diferentes tecnologias digitais móveis e por isso têm grande facilidade em aprender a trabalhar com este tipo de dispositivos (relembramos também o facto de vários alunos terem pedido para trazer os seus próprios iPads para as aulas).

Indo ao encontro das correntes pedagógicas mais atuais, em particular no que diz respeito às aulas de História, entendemos que este tipo de projetos contribui para desenvolver a autonomia de trabalho dos alunos e, sobretudo, como já atrás referimos, no que diz respeito ao desenvolvimento de competências ao nível da comunicação em História.

Para além disso, tendo em conta que um dos problemas que os professores de História referem para os fracos resultados tem também a ver com a falta de interesse pela disciplina, consideramos que este tipo de estratégia contribui para aumentar o estímulo dos alunos e, consequentemente, promover melhores resultados.

Consideramos também que, apesar de alguns alunos poderem manter-se algo resistentes a este tipo de trabalho, sobretudo por estarem muito habituados aos métodos tradicionais, mais expositivos, isso não quer dizer que não aprendam, efetivamente, através das estratégias associadas ao trabalho com o manual digital.

Tal como mencionámos no ponto anterior, será importante, na utilização dos iPads nas aulas de História, a sua ligação via AppleTV, de forma a conseguir limitar as possibilidades de distração dos alunos, e conseguir assim um maior controlo, por parte dos docentes, de todo o trabalho desenvolvido pelos alunos. 


\section{RE F E R Ê N C I A S B I L I O GRÁ F I CAS}

Alberta Education (2011). iPads: What Are We Learning?: Summary Report Of Provincial Data Gathering Day, October 3. Retirado de: https://education.alberta.ca/ admin/technology/research.aspx (Acessível em 07/04/2014)

Ally, M. (Ed.) (2009). Mobile Learning: transforming the delivery of education and training. Edmonton: AU Press. Retirado de: http://www.aupress.ca/books/120155/ ebook/99Z_Mohamed_Ally_2009-MobileLearning.pdf (Acessível em 15/04/2014)

Alves, L. M. (2009). A função social da História. EF@BULATIONS/ EF@BULAÇÕES. Retirado de: http://ler.letras.up.pt/uploads/ficheiros/7245.pdf (Acessível em 22/01/2014)

Alves, P. (2004). Avaliar competências na aula de História: um novo quadro de referência. In Isabel Barca (org.). Para uma educação histórica de qualidade. Actas das IV Jornadas Internacionais de educação histórica (pp. 115-130). Braga: CIE.

APPLE (2013). iTunesU. In Apple in Education. Retirado de: http://www.apple.com/ education/itunes-u/ (Acessível em 22/01/2014)

Assembleia da República (1996). Lei n. ${ }^{\circ}$ 10-A/96 de 23 de Março. In Diário da República n. $^{\circ} 71 / 96$ I. $^{a}$ Série-A $1 .^{\circ}$ Suplemento, 584-(2) - 584-(69).

Barca, I. (2001a). Concepções de adolescentes sobre múltiplas explicações em História. In I. Barca (ed). Perspectivas em Educação Histórica. Actas das IJornadas Internacionais de Educação Histórica (pp. 29-43). Braga: CIE.

Barca, I. (2007). A educação histórica numa sociedade aberta. Currículo sem Fronteiras, v. 7, n. ${ }^{\circ} 1$, Jan/Jun, 5-9.

Barca, I., Bastos, M. C. \& Carvalho, J. B. (1998). Formar opinião na aula de história - uma experiência pedagógica sobre a guerra colonial. Lisboa: Associação de Professores de História.

Battram, A. (D.L. 2004). Navegando na complexidade: o guia essencial para a teoria da complexidade nos negócios e na gestão. Lisboa: Instituto Piaget. 
Batty, M. (2005). Cities and complexity: understanding cities with cellular automata, agent-based models, and fractals. Cambridge: MIT Press.

Bloch, M. (1993 [1949]). Introdução à História. Mem Martins: Publicações Europa-América.

Blow, F. (1990). Computers, simulation and empathy. In Francis Blow \& Allan Martin, Computers in the history classroom - proceedings of the first international conference on computers in the history classroom. Leeds: Leeds University Press, 144-152.

Borries, B. von (2009). Competence of historical thinking, mastering of a historical framework, or knowledge of the historical canon?. In Linda Symcox \& Arie Wilschut (eds.). National history standards: the problem of the canon and the future of teaching history (pp. 283-306). s. 1.: Information Age Publishing.

Bottentuit Junior, J. (2012). Do computador ao tablet: Vantagens pedagógicas na utilização de dispositivos móveis na educação. EducaOnline, 6 (1) Janeiro/Abril, 125-149. Braudel, F. (1976). História e ciências sociais. Lisboa: Editorial Presença.

Byrne, D. (1998). Complexity theory and the social sciences - an introduction. London; New York: Routledge.

Camacho, M. (2012). Mobile learning en la educación superior: primeros pasos para el diseño y creación de cursos con tecnologías móviles. In Ana Amélia Carvalho. Aprender na era digital (pp. 111-125). Santo Tirso: De Facto Editores.

Carmona, J. [et al.] (1985). Projecto para a introdução das novas tecnologias no sistema educativo. Lisboa: Ministério da Educação.

Carneiro, R., Melo, R., Lopes, H., Lis, C. \& Carvalho, L. (2010). Relatório de resultados e recomendações do Observatório do Plano Tecnológico da Educação. Lisboa: Gabinete de Estatística e Planeamento da Educação (GEPE).

Carretero, M. (1996). Construir y enseñar las ciencias sociales y la historia. Madrid: Visor.

Carvalho, A. A. (1998). Os documentos hipermédia estruturados segundo a teoria da flexibilidade cognitiva: importância dos comentários temáticos e das travessias temáticas na transferência do conhecimento para novas situações. Braga: IEUM. Carvalho, A. A. (2004). A World Wide Web e o ensino da História. In Isabel Barca (org.). Para uma educação histórica de qualidade. Actas das IV Jornadas Internacionais de educação histórica (pp. 233-251). Braga: CIE. 
Carvalho, A. A. (2007). Rentabilizar a internet no ensino básico e secundário: dos recursos e ferramentas online aos LMS. Sísifo - Revista de Ciências da Educação, n. ${ }^{\circ} 3,25-40$.

Carvalho, A. A. (2011). Laptops for students: Strength and weaknesses of the portuguese initiatives. In Maria. A. Flores et al. (orgs.), Proceedings of the 15th Biennial of the International Study Association on Teachers and Teaching (ISATT), Back to the Future: Legacies, Continuities and Changes in Educational Policy, Practice and Research (pp. 878-883), Braga, University of Minho.

Carvalho, A. A. (Ed) (2012). Introdução. In Ana Amélia Carvalho (Coord.). Aprender na era digital (pp.7-10). Santo Tirso: De Facto Editores.

Carvalho, A.A. \& Moreira, A. (2005). Criss-crossing cognitive flexibility theory based research in Portugal: an overview. Interactive Educational Multimedia, 11, 1-26.

Carvalho, A. A. \& Pessoa, M. T. (2012). Politicas educativas TIC en Portugal. In Campus Virtuales: Revista Cientifica de Tecnología Educativa, n. ${ }^{\circ}$ 1, v. 1, 93-104.

Carvalho, J. (1999). O social emergente: sistemas adaptáveis complexos e interpretação histórica. Revista de História das Ideias, vol. 20, 623-688.

Catroga, F. (2009). Os passos do homem como restolbo do tempo: memória e fim do fim da bistória. Coimbra: Almedina.

Chatelet, F. (1962). La naissance de l'histoire - la formation de la pensée historienne en Grèce. Paris : Les Éditions de Minuit, vol. 1.

Clarke, B., Svanaes, S. \& Zimmermann, S. (2013) One-to-one tablets in secondary schools: an evaluation study, Tablets for Schools. http://tabletsforschools.org. uk/wp-content/uploads/2012/12/FKY-Tablets-for-Schools-Stage-2-Full-ReportJuly-2013.pdf (Acessível em 14/04/2014)

Cohen, L. \& Manion, L. (1990). Métodos de Investigación Educativa. Madrid: La Muralla.

Cohen, D. \& Rosenzweig, R. (2006). No computer left behind. Chronicle of Higher Education. 28 de Fevereiro. http://chnm.gmu.edu/essays-on-history-new-media/ essays/?essayid=38 (Acessível em 28/05/2012)

Collins, A. \& Halverson, R. (2009). Rethinking Education in the Age of Technology: The Digital Revolution and the Schools. New York: Teachers College Press.

Comissão da Cultura e da Educação (2013). Projeto de relatório sobre as novas tecnologias e os recursos educativos abertos [2013/2182(INI)]. Retirado do Website do Parlamento Europeu: http://www.europarl.europa.eu/meetdocs/2009_2014/documents/cult/pr/1010/1010424/1010424pt.pdf (Acessível em 03/07/2014) 
Comissão Europeia (1993). Growth, Competitiveness, Employment: The Challenges and Ways Forward into the 21st Century - White Paper. COM (93) 700. Retirado de: http://europa.eu/documentation/official-docs/white-papers/index_en.htm (Acessível em 01/06/2012)

Comissão Europeia (1995a). Livro branco sobre educação e formação: ensinar $e$ aprender: rumo à sociedade cognitiva. COM(95) 590 final. Retirado de: https:// infoeuropa.eurocid.pt/registo/000037230/documento/0001/ (Acessível em 30/05/ 2012)

Comissão Europeia (1996a). Livro verde viver e trabalhar na sociedade da informação: prioridade à dimensão bumana. COM (96) 389 final. Retirado de: http://eur-lex. europa.eu/LexUriServ/LexUriServ.do?uri=CELEX:51996DC0389:PT:NOT (Acessível em 30/05/2012)

Comissão Europeia (1996b). Aprender na sociedade da informação: plano de acção para uma iniciativa europeia na educação 1996-1998: comunicação ao Parlamento Europeu e ao Conselho, ao Comité Económico e Social e ao Comité das Regiões. Luxemburgo: Serviço das Publicações Oficiais das Comunidades Europeias. Retirado de: https://infoeuropa.eurocid.pt/registo/000002965/ (Acessível em $30 / 05 / 2012)$

Comissão Europeia (1999). eEurope - Sociedade da Informação para Todos: comunicação respeitante a uma iniciativa da Comissão a apresentar ao Conselho Europeu Especial de Lisboa de 23 e 24 de Março de 2000. COM (1999) 687. Retirado de: http://ec.europa.eu/information_society/eeurope/i2010/archive/eeurope/index_ en.htm (Acessível em 04/06/2012)

Comissão Europeia (2000a). Relatório da Comissão ao Conselho e ao Parlamento Europeu - pensar o futuro da educação, promover a inovação através das novas TDIC. COM (2000) 23 final. Retirado de: http://eur-lex.europa.eu/COMMonth. do?year=2000\&month=01 (Acessível em 04/06/2012)

Comissão Europeia (2000b). Comunicação da Comissão: eLearning - pensar o futuro da educação. COM (2000) 318 final. Retirado de: http://eur-lex.europa.eu/Result. do?T1=V5\&T2=2000\&T3=318\&RechType=RECH_naturel\&Submit=Search （Acessível em 05/06/2012)

Comissão Europeia (2002). eEurope 2005: Uma sociedade da informação para todos - Plano de Acção a apresentar com vista ao Conselho Europeu de Sevilha de 21 e 22 de Junho de 2002. COM (2002) 263 final. Retirado de: http://eur-lex.europa. 
eu/smartapi/cgi/sga_doc?smartapi!celexplus!prod!DocNumber\&lg=pt\&type_ doc=COMfinal\&an_doc=2002\&nu_doc=263 (Acessível em 05/06/2012)

Comissão Europeia (2003b). Comunicação da Comissão ao Conselho, Parlamento Europei, Comité Económico e Social e Comité das Regiões - Relatório Final sobre o eEurope2002. (COM (2003) 66 final. Retirado de: http://eur-lex.europa.eu/LexUriServ/LexUriServ.do?uri=CELEX:52003DC0066:EN:NOT (Acessível em 05/06/2012)

Comissão Europeia (2005a). Comunicado da Comissão ao Conselho, ao Parlamento Europeu, ao Comité Económico e Social Europeu e ao Comité das regiões - i2010 - uma sociedade da informaçãoo europeia para o crescimento e o emprego. COM (2005) 229 final. Retirado de: http://eur-lex.europa.eu/smartapi/cgi/sga_doc?sma rtapi!celexplus!prod!DocNumber\&lg=pt\&type_doc=COMfinal\&an_doc=2005\&nu_ doc=229 (Acessível em 05/06/2012)

Comissão Europeia (2007a). Organização do Sistema Educativo em Portugal (2006/2007). Bruxelas: Edições Eurydice. Retirado de: http://eacea.ec.europa.eu/ education/eurydice/documents/eurybase/eurybase_full_reports/PT_PT.pdf (Acessível em 23/12/2010)

Comissão Europeia (2009a). Comunicado da Comissão ao Parlamento Europeu, ao Conselho, ao Comité Económico e Social Europeu e ao Comité das regiões - relatório sobre a competitividade da Europa em matéria digital - principais resultados da estratégia i2010 entre 2005 e 2009. COM (2009) 390 final. Retirado de: http:// eur-lex.europa.eu/LexUriServ/LexUriServ.do?uri=CELEX:52009DC0390:PT:NOT (Acessível em 05/06/2012)

Comissão Europeia (2010c). National System overviews on education systems in Europe and ongoing reforms - Spain. Retirado de: http://eacea.ec.europa.eu/edu cation/eurydice/documents/eurybase/national_summary_sheets/047_ES_EN.pdf (Acessível em 23/12/2010)

Comissão Europeia (2012a). Survey of schools: ICT in Education, Country Profile: Portugal. Retirado de: http://ec.europa.eu/digital-agenda/en/survey-schools-ict-education (Acessível em 16/04/2014)

Comissão Europeia (2012b). Comunicação da Comissão ao Parlamento Europeu, ao Conselho, ao Comité Económico e Social Europeu e ao Comité das Regiões, Uma Agenda Digital para a Europa. Retirado de: http://eur-lex.europa.eu/legal-content/ PT/TXT/PDF/?uri=CELEX:52010DC0245\&from=PT (Acessível em 06/06/2014) 
Comissão Europeia (2013). Abrir a Educação: Ensino e aprendizagem para todos de maneira inovadora graças às novas tecnologias e aos Recursos Educativos Abertos [COM (2013) 654 final]. Bruxelas: Serviço de Publicações da Comissão Europeia. Retirado de: http://www.ipex.eu/IPEXL-WEB/dossier/files/download/082dbcc540 a5439001416e35239b249b.do (Acessível em 03/07/2014

Comissão Europeia (2013). Opening up education: Analysis and mapping of innovative teaching and learning for all through new Technologies and Open Educational Resources in Europe [COM(2013) 654 final]. Bruxelas: Serviço de Publicações da Comissão Europeia. Retirado de: http://ec.europa.eu/smart-regulation/impact/ ia_carried_out/docs/ia_2013/swd_2013_0341_en.pdf (Acessível em 11/07/2014)

Conselho de Ministros (2007). Resolução do Conselho de Ministros n. ${ }^{\circ}$ 137/2007, de 18 de Setembro. Retirado de: http://www.pte.gov.pt/idc/idcplg?IdcService=GET_ FILE\&dID=13429\&dDocName=002386 (Acessível em 23/08/2012)

Conselho de Ministros (2011). Resolução do Conselho de Ministros n. ${ }^{0}$ 12/2011, de 8 de Fevereiro. In Diário da República, I $^{\mathrm{a}}$ Série, n. ${ }^{\circ}$ 27, 700-701.

Conselho Europeu, Comissão Europeia (2000). eEurope2002: uma sociedade da informação para todos (plano de acção preparado pelo Conselho e pela Comissão Europeia para o Conselbo Europeu da Feira). Bruxelas, 14/6/2000. Retirado de: http:// ec.europa.eu/information_society/eeurope/i2010/archive/eeurope/index_en.htm (Acessível em 05/06/2012)

Cormier, D. (2008). Rhizomatic education: Community as curriculum. Innovate, 4 (5).

Costa, A., Sobral, C. \& Alves, O. (2009). Exploração do conceito de democracia com alunos do $7 .^{\circ}$ ano de escolaridade. In Isabel Barca \& Maria Auxiliadora Schmidt (eds). Educação Histórica: investigação em Portugal e no Brasil. Actas das VJornadas Internacionais de educação histórica (pp. 159-197). Braga: CIE.

Coutinho, C. P. (2006b). Aspectos metodológicos da investigação em tecnologia educativa em Portugal (1985-2000). Colóquio da Secção Portuguesa da Association Francophone Internationale de Recherche Scientifique en Educacion - "Para um balanço da investigação em educação de 1960 a 2005: teorias e práticas: actas do Colóquio da AFIRSE". Lisboa: Universidade de Lisboa. Retirado de: http://reposito rium.sdum.uminho.pt/handle/1822/6497(Acessível em 25/06/2013)

Coutinho, C. P. (2011). Mobile Web 2.0: New Spaces for Learning. In Lee Chao (Ed.), Open Source Mobile Learning: Mobile Linux Applications (pp.180-195). Estados Unidos da América: IGI Global. 
Crompton, H. (2013a). Mobile learning: new approach, new theory". In Zane L. Berge \& Lin Y. Muilenburg (eds). Handbook of mobile learning (pp. 47-57), New York: Routledge.

Crompton, H. (2013b). A historical overview of mobile learning: Toward learner-centered education. In Zane L. Berge \& Lin Y. Muilenburg (eds). Handbook of mobile learning (pp. 3-14), New York: Routledge.

Cruz, S. (2009). Proposta de um modelo de integração das tecnologias de informação e comunicação nas práticas lectivas: o aluno de consumidor crítico a produtor de informação online, Tese de Doutoramento em Ciências da Educação na área de especialização em Tecnologia Educativa apresentada à Universidade do Minho, 2009.

Cuenca López, J. M. (2004). Iter Itineris: un ejemplo de juego on line para el aprendizaje de la historia. IBER Didáctica de las Ciencias Sociales geografia e Historia,

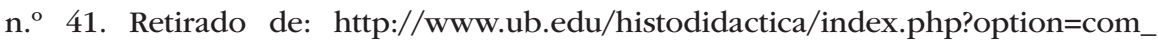
content $\&$ view $=$ article $\& i d=71$ :iter-itineris-un-ejemplo-de-juego-on-line-para-laensenanza-de-la-historia\&catid=16:didactica-con-nuevas-tecnologias\&Itemid= 103 (Acessível em 21/08/2012)

Deleuze, G. \& Guattari, F. (2007). Mil Planaltos. Lisboa: Assírio \& Alvim, $2 .^{\circ}$ volume de Capitalismo e esquizofrenia.

Delors, J. (org. de) (1996). Educação - um tesouro a descobrir. Porto: Edições ASA.

DenBeste, M. (2003). Power point, technology and the web: more than just an overhead projector for the new century?. The History Teacher, vol. 36, n. ${ }^{\circ} 4$, Agosto, 491-504.

Denzin, N. \& Lincoln, Y. (1994). Handbook of qualitative research. Thousand Oaks: Sage Publications.

Devaney, L. (2011). 'Bring your own device' catching on in schools, Posted on April 29, In eSchool News. Retirado de: http://www.eschoolnews.com/2011/04/29/bringyour-own-device-catching-on-in-schools/ (Acessível em 16/04/2014)

Direção Geral do Ensino Básico e Secundário (DGEBS) (1991). Programa de História para o Terceiro Ciclo do Ensino Básico. Lisboa: Ministério da Educação.

Downes, S. (2010). Critical literacies and connectivism. Retirado de: http://www.dow nes.ca/post/53280 (Acessível em 13/12/2011)

Downes, S. (2007). An introduction to connective knowledge. In T. Hug (ed). Media, Knowledge E Education - Exploring new Spaces, Relations and Dynamics in Digi- 
tal Media Ecologies. Proceedings of the International Conference beld on June 25-26. Retirado de: http://www.downes.ca/post/33034 (Acessível em 12/12/2011)

Downes, S. (2011). Connectivism and connective knowledge. Retirado de: http://www. downes.ca/post/54540 (Acessível em 13/12/2011)

Driscoll, M. (2004). Psychology of learning for instruction. Boston: Allyn \& Bacon.

Educause, Learning initiative (2011). Things you should know about... iPad Apps for learning. Retirado de: http://net.educause.edu/ir/library/pdf/eli7069.pdf (Acessível em 16/04/2014)

Ertmer, P. A. \& Newby, T. J. (1993). Behaviourism, cognitivism, constructivism: comparing critical features from an instructional design perspective. Performance Improvement Quarterly, 6(4).

European Commission (2007). eEurope 2005 final evaluation. Stockholm: Ramboll Management AB. Retirado de: ec.europa.eu/dgs/information_society/evaluation/data/pdf/studies/s2005_01/eEurope2005_final_report.pdf (Acessível em $05 / 06 / 2012)$

Eurydice (2007b). Estrutura dos Sistemas de Ensino, Formação Profissional e Ensino para Adultos na Europa: Portugal. Retirado de: http://eacea.ec.europa.eu/education/eurydice/documents/eurybase/structures/041_PT_PT.pdf (Acessível em 23/12/2010)

Gabinete de Informação e Avaliação do Sistema Educativo [GIASE] (2005). Despacho n. ${ }^{\circ} 7072 / 2005$, de 14 de Março. In Diário da República, II. ${ }^{a}$ Série, n. ${ }^{\circ}$ 67, de 6 de Abril, 5463.

Gabinete do Secretário de Estado Adjunto do Ministro da Educação [GSEAME] (1984). Despacho n. ${ }^{\circ}$ 68/SEAM/84, de 9 de Outubro. In Diário da República, n. ${ }^{\circ} 243$, de 19 de Outubro, 9547-9548.

Gago, M. (2008). A identidade e a orientação do "Eu» e do "Nós». In Isabel Barca \& Marília Gago (eds). Estudos de consciência histórica na Europa, América, Ásia e África. Actas das VII Jornadas Internacionais de educação histórica (pp. 55-64). Braga: CIE.

Garcia, E. \& Friedman, A. (2011). <<There's an App for That: >> A Study Using Apple iPads in a United States History Classroom. In Studies in Teaching - 2011 Research Digest. Retirado de: http://www.wfu.edu/education/gradtea/forum2011/research. proceedings.2011.pdf (Acessível em 16/04/2014)

Governo Português (1995). Programa do XIII. ${ }^{\circ}$ Governo Constitucional. 
Grant, M. \& Barbour M. (2013). Mobile teaching and learning in the classroom and online: Case studies in K-12. In Zane L. Berge \& Lin Y. Muilenburg (eds). Handbook of mobile learning (pp. 285-292), New York: Routledge.

Griffin, A. (1963). World Book Encyclopedia. Chicago: Field Enterprises Educational Corp.Guay, L. (2007). Transformation of Teaching Methods by Information and Communication Technologies (ICT). History and Computing. vol. 10, $\mathrm{n} .{ }^{\circ} 1$, Fevereiro.

Harmon, J. (2011). Unlocking Literacy with Ipad. Through Students Eyes Project. s.1., Retirado de: http://www.throughstudentseyes.org/ipads/unlocking_literacy_with_ ipad/ipads_files/unlocking_literacy_ipad.pdf. (Acessível em 03/04/2014)

Haydn, T. (2000). Information and communications technology in the history classroom. In James Arthur \& Robert Philips (eds.). Issues in bistory teaching (pp. 98-111), London: Routledge.

Henderson, S. \& Yeow, J. (2012). iPad in education: A case study of iPad adoption and use in a primary school. In 45th Hawaii International Conference on System Sciences, 78-87.

Hillis, P. (2001). Can multimedia respond to the critics? A report from the history classroom. International Journal of Humanities and Arts Computing. 13, no. 3, 239-252.

Huizenga, J., Admiraal, W., Akkerman, S., \& Dam, G. T. (2007). Learning history by playing a mobile city game. In Dan Remenyi (Ed.), Proceedings of the 1st European Conference on Game-Based Learning (ECGBL) (pp. 127-134), October 2007, University of Paisley, Paisley, Scotland. Reading, UK: Academic Conferences Limited. Hutchison, A., Beschorner, B., \& Schmidt-Crawford, D. (2012). Exploring the Use of the iPad for Literacy Learning.The Reading Teacher, 66 (1), 15-23.

Ireland, G. \& Woollerton, M. (2010). The impact of the iPad and iPhone on Education. In Journal of Bunkyo Gakuin University, Department of Foreign Languages and Bunkyo Gakuin College (10), 31-48.

Jacobson, M. \& Spiro, R. (1994). A framework for the contextual analysis of technology-based learning environments. Journal of Computing in Higher Education, Spring 2004, vol. 5(2), 3-32.

Jennings, G., Anderson, T., Dorset, M., \& Mitchell, J. (2011). Report on the step forward iPad pilot project. Trinity College, University of Melbourne. Retirado de: http:// www.trinity.unimelb.edu.au/Media/docs/iPadPilotReport2011-1b1e1a52-79af-4c7 6-b5b6-e45f92f2c9e9-0.pdf (Acessível em 16/04/2014) 
Johnson, L., Adams, S., \& Cummins, M. (2012). NMC horizon report: 2012 K-12 Edition. Austin, Texas: The New Media Consortium.

Jonassen, D. (2000). Computers as mindtools for schools: engaging critical thinking. New Jersey: Prentice-Hall Inc.

Jonassen, D., Peck, K. L. \& Wilson, B. G. (1999). Learning with technology: a constructivist perspective. New Jersey: Prentice Hall Inc.

Kerr, B. (2007). A challenge to connectivism. Retirado de: http://ltc.umanitoba.ca/wiki/ index.php?title=Kerr_Presentation (Acessível em 12/12/2011)

Kop, R. \& Hill, A. (2008). Connectivism: learning theory of the future or vestige of the past? Retirado de: http://www.irrodl.org/index.php/irrodl/article/view/523/1103 (Acessível em 12/12/2011)

Laouris, Y. \& Eteokleous, N. (2005). We need an Educationally Relevant Definition of Mobile Learning. Atas do 4 th World Conference on mLearning (pp. 25-28). Cape Town, Africa do Sul. Retirado de: http://www.mlearn.org.za/CD/papers/Laouris\%20\&\%20Eteokleous.pdf (Acessível em 14/04/2014)

Le Goff, J. (1982). História e Memória. Lisboa: Edições 70.

Lencastre, J. A. \& Araújo, M. J. (2007). Impacto das tecnologias em contexto educativo formal. In Alfonso Barca et al. (Eds.). Libro de Actas do Congreso Internacional Galego-Portugués de Psicopedagoxía. A.Coruña/Universidade da Coruña: Revista Galego-Portuguesa de Psicoloxía e Educación. 624-632.

Limón, M. (2002). Conceptual change in history. In Margarita Limón \& Lucia Mason (eds.). Reconsidering Conceptual Change: Issues in Theory and Practice. New York: Kluwer Academic Publishers.

Magalhães, O. (2002). Concepções de história e do ensino da história: um estudo no Alentejo. Lisboa: Colibri.

Matta, A. (2001). Procedimentos de Autoria Hipermídia em Rede de Computadores: Um Ambiente Mediador para o Ensino-aprendizagem de História. Dissertação de Doutoramento. Salvador da Bahia: FACED/UFBA.

Mattoso, J. (1999). A função social da História no mundo de hoje. Lisboa: Associação de Professores de História.

Melhuish, K. \& Falloon, G. (2010). Looking to the future: M-learning with the iPad. In Computers in New Zealand Schools: Learning, Leading, Technology, vol. 22(3).

Mendes, C. (coordenadora), Silveira, C. \& Brum, M. (2001). Programa de História A $\left(10 .^{\circ}, 11 .^{\circ}\right.$ e $12 .^{\circ}$ anos), Lisboa: Ministério da Educação. 
Meyniac, J.-P. (2005). Internet et l'enseignement de l'histoire: reflexions d'un clionaute. Les Clionautes. Retirado de: http://www.clionautes.org/spip.php?article219 (Acessível em 21/08/2012)

Ministério da Ciência e da Tecnologia (1999). Portugal na sociedade da informação. Lisboa: Ministério da Ciência e da Tecnologia.

Ministério da Ciência e da Tecnologia (2000). Programa Operacional da Sociedade da Informação 2000-2006. http://www.fct.mctes.pt/pt/programasinvestimento/posi/ posifiles/posi.html (Acessível em 23/08/2012)

Ministério da Ciência, da Tecnologia e do Ensino Superior (MCTES) (2005). Ligar Portugal. Retirado de: http://www.ligarportugal.pt/ (Acessível em 10/07/2012)

Ministério da Educação (1986). Lei de Bases do Sistema Educativo n. ${ }^{\circ}$ 46/86 de 14 de

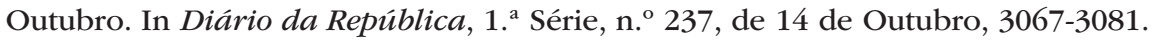

Ministério da Educação (1992). Despacho n. ${ }^{\circ}$ 299/ME/92, de 22 de outubro. In Diário da República, II. ${ }^{a}$ Série, n. ${ }^{\circ} 261$ de 11 de Novembro, 10630.

Ministério da Educação (1994). Programa de desenvolvimento educativo para Portugal. Relatório final de execução. Lisboa: Ministério da Educação.

Ministério da Educação (1996). Despacho n. ${ }^{\circ}$ 232/ME/96, de 4 de Outubro. In Diário da República, II. ${ }^{a}$ Série, n. ${ }^{\circ} 251$ de 29 de Outubro, 15011-15012.

Ministério da Educação (2001). Decreto-Lei n. ${ }^{\circ}$ 6/2001, de 18 de Janeiro. Diário da

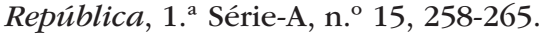

Ministério da Educação (2005a). Despacho n. ${ }^{\circ}$ 16793/2005, de 1 de Julho. In Diário da República, II. ${ }^{a}$ Série, n. ${ }^{\circ}$ 148, de 3 de Agosto. 11099-11100.

Ministério da Educação (2009). Portaria n. ${ }^{0}$ 731/2009, de 7 de Julho. In Diário da República, I. ${ }^{a}$ Série, n. ${ }^{\circ} 129$, de 7 de Julho. 4340-4343.

Missão para a Sociedade da Informação (MSI) (1997). Livro Verde para a Sociedade da Informação em Portugal, Lisboa: MSI-MCT.

Montgomery K. (2007). Generation digital: Politics, commerce, and childhood in the age of the internet, Cambridge: MIT Press.

Morin, E. (D.L. 1995). Introdução ao pensamento complexo. Lisboa: Instituto Piaget.

Mota, J. (2009). Da Web 2.0 ao e-Learning 2.0: Aprender na Rede. Dissertação de Mestrado. Lisboa: Universidade Aberta. Retirado de: http://repositorioaberto.univ-ab. pt/bitstream/10400.2/1381/1/web20_e-learning20_aprender_na_rede.pdf (Acessível em 19/02/2012) 
Moura, A. (2008). A web 2.0 e as tecnologias móveis. In Carvalho, A. A. (org.) Manual de ferramentas da web 2.0 para professores, (pp. 121-146). Lisboa: Ministério da Educação.

Moura, A. (2009). Geração Móvel: um ambiente de aprendizagem suportado por tecnologias móveis para a "Geração Polegar". In Paulo Dias, António J. Osório (org.) Actas da VI Conferência Internacional de TIC na Educação Challenges 2009/Desafios 2009. Braga: Universidade do Minho. 50-78.

Moura, A. (2010). Apropriação do telemóvel como ferramenta de mediação em mobile learning: Estudos de caso em contexto educativo. Tese de Doutoramento. Universidade do Minho.

Moura, A. (2012). Mobile learning: Tendências tecnológicas emergentes. In Ana Amélia Carvalho (Ed.). Aprender na era digital (pp. 127-147). Santo Tirso: De Facto Editores.

Moura, A. \& Carvalho, A. A. (2013). Framework for mobile-learning integration into educational contexts. In Zane L. Berge \& Lin Muilenburg (eds). Handbook of mobile education (pp. 58-69). New York: Routledge.

NAACE, Advancing education through ICT (2012). The iPad as a tool for education. A study of the introduction of iPads at Longfield Academy, Kent. Retirado de: http:// www.naace.co.uk/get.html?_Action=GetFile\&_Key=Data26613\&_Id=1965 （Acessível em 16/04/2014)

Naismith, L., Lonsdale, P., Vavoula, G. \& Sharples, M. (2004) 'Mobile technologies and learning' in Futurelab Literature Review Series, Report N. ${ }^{\circ}$ 11, Futurelab 2004.

Nastu, J. (2011). Mobile learning: Not just laptops any more: New advances in mobile technology could help schools realize the promise of true anytime, anywhere learning, February 25th.

Norris, C. \& Soloway, E. (2013). Substantive educational change is in the palm of our children's hands. In Zane L. Berge \& LinY. Muilenburg (eds). Handbook of mobile learning (pp. 109-118), New York: Routledge.

Observatório dos Recursos Educativos (ORE), Por uma utilização crítica dos recursos digitais em contextos educativos - um balanço de investigações recentes, Porto. Retirado de: http://www.ore.org.pt/filesobservatorio/pdf/EstudoORE_RecursosDigitaisemContextosEducativos.pdf (Acessível em 04/04/2014) 
Ozan, O. \& Kesim, M. (2013). Rethinking scaffolding in mobile connectivist learning environments. In Zane L. Berge \& Lin Y. Muilenburg (eds). Handbook of mobile learning, New York: Routledge, 166-175.

Paiva, J. (2003). As tecnologias de informação e comunicação: utilização pelos alunos. Lisboa: Ministério da Educação.

Parlamento Europeu (2014). Resolução do Parlamento Europeu, de 15 de abril de 2014, sobre novas tecnologias e recursos educativos abertos (2013/2182(INI)). Retirado de: http://www.europarl.europa.eu/sides/getDoc.do?pubRef=-//EP//TEXT+ TA+P7-TA-2014-0395+0+DOC+XML+V0//PT (Acessível em 12/11/2012)

Pearson Foundation (2012). Survey on students and tablets. Retirado de: http://pearsonfoundation.org/downloads/PF_Tablet_Survey_Summary_2012.pdf (Acessível em 16/04/2014)

Petrocelli, H. (2012). Portland's "Refugee from Occupied Hollywood": Andries Deinum, his Center for the Moving Image, and Film Education in the United States. Tese de Mestrado em História. Portland State University.

Ponte, J. P. (1994). O Projecto MINERVA: introduzindo as NTI na Educação em Portugal, Lisboa: DEPGEP Ministério da Educação.

Prensky, M. (2001). Digital natives digital immigrants, part 1. On the Horizon, 9 (5), October.

Prensky, M. (2010). Teaching digital natives: partnering for real learning. Retirado de: http://oetmanhattan.wikispaces.com/file/view/Prensky--Teaching+Digital+Na tives-in+press6.pdf (Acessível em 14/04/2014)

Prensky, M. (2013). Our brains extended. In Technology-Rich Learning. 70(6). 22-27

Proença, M. C. (1989). Didáctica da história. Lisboa: Universidade Aberta.

Project Tomorrow (2012). Mapping a Personalized Learning Journey - K-12 Students and Parents Connect the Dots with Digital Learning (online). Retirado do Website do Project Tomorrow: http://www.tomorrow.org/speakup/SU11_April_Report.html (Acessível em 04/07/2014)

Quinn, C. N. (2000). mLearning: Mobile, Wireless, In-Your-Pocket Learning, In Marcia Conner LINEZine. Retirado de: http://www.linezine.com/2.1/features/cqmmwiyp. htm (Acessível em 25/07/2011)

Quinn, C. N. (2011). Designing mLearning: Tapping into the Mobile Revolution for Organizational Performance. São Francisco: Pfeiffer. 
Quinn, C. N. (2013). The Mobile Academy: MLearning for Higher Education. s.1.: Jossey-Bass.

Ribeiro, A. I, Nunes, J. P. A., Cunha, P. (2014). Metas curriculares de História - Terceiro Ciclo do Ensino Básico. Lisboa: Ministério da Educação.

Ribeiro, A. I. \& Trindade, S. D. (2017). O ensino da História e tecnologia - conexões, possibilidades e desafios no espaço das Humanidades Digitais. In C. Porto e J. A. Moreira (coord.), Educação no ciberespaço. Novas configurações, convergências e conexões (pp. 145-159). Aracaju: Editora Universitária Tiradentes.

Ribeiro-Geraldes, M. \& Morais, C. (2007). A internet como meio de promoção de competências em contexto educativo, Revista Educare-Educer. Ano XIII, n. ${ }^{\circ}$ 20, 262-274.

Rilley, M. A. (2011). We are Pando: Rhizomatic learning. Retirado de: http://maryannreilly.blogspot.com/2011/09/we-are-pando-rhizomatic-learning.html (Acessível em $14 / 12 / 2011)$

Rivero Garcia, M. P. (2011). El aprendizaje multimedia de la Historia: valoración de una experiencia de aula. In R. López Facal (Coord.), Actas del I Congreso Internacional sobre Enseñanza de la Historia: Pensar históricamente en tiempos de globalización. (pp. 167-173). Santiago de Compostela: Universidad de Santiago de Compostela-Comunicación.

Rodrigues, M. C. M. (1981). Consequências pedagógicas da informática no ensino da bistória. Lisboa: Assembleia Distrital de Portalegre.

Roldão, M. C. (1995). As histórias em educação - a função mediática da narrativa. Ensinus 3, 25-28.

Roldão, M. C. (2002a). Gestão curricular na área da história. In Emanuel Medeiros (ed), I Encontro de Didácticas no Açores (pp. 133-145).

Rosen, L. (2010). Welcome to the iGeneration!. Education Digest, 75 (8), 8-12.

Rosen, L. (2011). Teaching the iGeneration. Educational Leadership, 68 (5). Retirado de: http://www.steveclarkprincipal.com/uploads/1/6/5/2/16527520/teaching_the_ igeneration.pdf (Acessível em 21/02/2014)

Santos, M. I. (2006). A Escola Virtual na aprendizagem e no ensino da Matemática, Mestrado em Educação área de especialização em Tecnologia Educativa. Braga: Universidade do Minho. Retirado de: http://www.ore.org.pt/filesobservatorio/pdf/ teseescolavirtual.pdf (Acessível em 17/11/2010)

Sawyer, R. K. (2005). Social emergence: societies as complex systems. Cambridge: Cambridge University Press. 
Sharples, M. (2005) Learning As Conversation: Transforming Education in the Mobile Age. Paper presented at Conference on Seeing, Understanding, Learning in the Mobile Age, Budapest, Hungary, April 2005.

Sheppard, D. (2011). Reading with iPads - the difference makes a difference. Education Today, 11(3).

Siemens, G. (17/10/2003). Learning Ecology, Communities, and Networks - Extending the classroom. Retirado de: http://www.elearnspace.org/Articles/learning_communities.htm (Acessível em 12/12/2011)

Siemens, G. (12/12/2004). Connectivism: A learning theory for the digital age. Retirado de: http://www.elearnspace.org/Articles/connectivism.htm (Acessível em $12 / 12 / 2011)$

Siemens, G. (2005c). The network is the learning. Retirado de: http://www.connectivism.ca/?p=13 (Acessível em 12/12/2011)

Siemens, G. (2006a). Connectivism: Learning Theory or Pastime for the Self-Amused? Retirado de: http://www.elearnspace.org/Articles/connectivism_self-amused.htm (Acessível em 13/12/2011)

Siemens, G. (2006b). Knowing Knowledge. Retirado de: http://www.elearnspace.org/ KnowingKnowledge_LowRes.pdf (Acessível em 12/12/2011)

Siemens, G. (2008a). New structures and spaces of learning: The systemic impact of connective knowledge, connectivism, and networked learning, Encontro sobre Web 2.0, Braga: Instituto de Educação da Universidade do Minho. Retirado de: http:// elearnspace.org/Articles/systemic_impact.htm (Acessível em 13/12/2011)

Siemens, G. (2008b). What is the unique idea in connectivism? Retirado de: http:// www.connectivism.ca/?p=116 (Acessível em 12/12/2011)

Siemens, G. (2009). What is Connectivism? Week 1: CCKO9 (online course). Retirado de: https://docs.google.com/View?docid=anw8wkk6fjc_14gpbqc2dt\&pli=1 (Acessível em 12/12/2011)

Silva, B. D. (2001). A tecnologia é uma estratégia. In Paulo Dias \& Varela de Freitas (org.). Actas da II Conferência Internacional Desafios 2001 (pp. 839-859). Braga: Centro de Competência da Universidade do Minho do Projecto Nónio.

Silva, B. D. \& Silva, A. M. C. (1999). Um olhar sobre a avaliação do programa Nónio no âmbito da intervenção do Centro de Competência da Universidade do Minho. In Paulo Dias \& Varela de Freitas (orgs.), Actas da I Conferência Internacional Desa- 
fios'99 (pp. 54-573). Braga: Centro de Competências da Universidade do Minho do Projecto Nónio.

Silva, B. D. \& Silva, A. M. C. (2002). Programa Nónio Século XXI: o desenvolvimento dos projectos das escolas do centro de competência da Universidade do Minho. Braga: Centro de Investigação em Educação.

Spiro, R. (2002). Pioneering a New Way of Learning in a Complex and Complicated World. New Educator, Spring. Retirado de: http://www.educ.msu.edu/neweducator/spring02/faculty1.htm. (Acessível em 03/11/2010)

Stake, R. (1994). Case Studies. In Norman K. Denzin \& Yvonna S. Lincoln (eds). Handbook of qualitative research. California: SAGE.

Staley, D. J. (2003). Computers, visualization, and history - how new technology will transform our understanding of the past. New York: M. E. Sharpe.

Stephenson, K. (1998). What knowledge tears apart, networks make whole. Internal Communication Focus, n. ${ }^{\circ}$. 36. Retirado de: http://www.netform.com/html/icf.pdf (Acessível em 12/12/2011)

Swanborn, P. (2010). Case study research: what, why and how?. London: SAGE.

Tavares, A. (2009). As novas tecnologias no ensino da história. Retirado de: http:// acessibilidadeblog.blogspot.pt/2009/04/as-novas-tecnologias-no-ensino-da.html (Acessível em 27/01/2014)

Terras, M. \& Ramsay, J. (2012). The five central psychological challenges facing effective mobile learning. British Journal of Educational Technology, vol 43 (5). 820-832.

Thomas, D. \& Brown, J. S. (2011). A new culture of learning: Cultivating the imagination for a world of constant change. Retirado de: http://www.morristownhighschool.org/wp-content/uploads/2011/09/newcultureoflearning.pdf (Acessível em 14/12/2011)

Traxler, J. (2005). Defining Mobile Learning, In IADIS International Conference Mobile Learning 2005 (pp. 261-266).

Traxler, J. (2009). Learning in a Mobile Age, In David Parsons (ed.) International Journal of Mobile and Blended learning, Vol. 1, Issue 1. Retirado de: http://www. academia.edu/171500/Learning_in_a_Mobile_Age (Acessível em 15/02/2014)

Trindade, S. D. (2015). o passado na ponta dos dedos: o mobile learning no ensino da História no $3 .^{\circ}$ CEB e no Ensino Secundário (Tese de Doutoramento em Letras, área de História, especialidade de Didática da História). Coimbra: Universidade de Coimbra. 
Trindade, S. D. \& Ribeiro, A. I. (2016). Universidade de Coimbra digital: visitas de estudo guiadas por tablets. In N. Pedro, A. Pedro, J. F. Matos, J. Piedade, M. Fonte (orgs.), Digital Technologies \& Future School - Atas do IV Congresso Internacional TIC e Educação 2016 (artigos selecionados) (pp. 179-188). Lisboa: Instituto de Educação da Universidade de Lisboa.

Trindade, S. D. \& Moreira, J. A. (2017a). A Emergência do Mobile Learning e os Novos Desafios Formativos para a Docência em Rede. In P. Torres (org.). Redes e Mídias Digitais (pp. 41-57), Curitiba: APPRIS.

Trindade, S. D. \& Moreira, J. A. (2017b). Tecnologias Móveis e a Recriação Digital na Construção do Conhecimento Histórico. Revista Eletrônica de Educação. V. 11 (2), jun-ago, 637-652.

Trindade, S. D.; Carvalho, J.; \& Carvalho, A. A. (2014). "Do iTunes U para as aulas de História - um estudo no 3. ${ }^{\circ}$ CEB". In A. A. Carvalho, S. Cruz, C. Marques, A. Moura \& I. Santos (orgs.) Atas do $2 .^{\circ}$ Encontro de Jogos e Mobile Learning (pp. 185-198). Braga: CIEd.

Trindade S. D., Carvalho, J. \& Carvalho, A. A. (2013). "History at the fingertips". In N. Reynolds \& M. Webb (eds). WCCE 2013: Learning while we are connected. 10th IFIP world conference on computers in education, vol. 2: practice papers (pp. 51-60). Torún: Nicolaus Copernicus University Press.

Trindade S. D., Carvalho, J. \& Carvalho, A. A. (2013). "Do iTunes U ao iPad nas aulas de História”. In M. J. Gomes, A. J. Osório, A. Ramos, B. D. Silva \& L. Valente (orgs). Challenges 2013: Aprender a qualquer hora e em qualquer lugar. Atas da VIII Conferência Internacional de TIC na Educação (pp. 93-110). Braga: Centro de Competência da Universidade do Minho.

Trindade. S. D. (2011). "As novas tecnologias ao serviço da complexidade no ensino de História”. in P. Dias, A. J. Osório (eds). Challenges 2011: actas da Conferência Internacional de TIC na Educação (pp. 1725-1729), 7. Braga: Centro de Competência da Universidade do Minho.

UNESCO (2014). O futuro da aprendizagem móvel: implicações para planejadores e gestores de políticas. Brasília: UNESCO.

Verhagen, P. (2006). Connectivism: a new learning theory? Retirado de: http://elearning.surf.nl/e-learning/english/3793 (Acessível em 12/12/2011)

Vosloo, S. (2012). UNESCO policy guidelines for mobile learning. Version 2.1: Draft. UNESCO Retirado de: http://www.unesco.org/new/fileadmin/MULTIMEDIA/ 
HQ/ED/pdf/UNESCO_Policy_Guidelines_on_Mobile_Learning_DRAFT_v2_1_ FINAL_2_.pdf (Acessível em 22/02/2014)

White, C. (1999). It's not just another new thing: Technology as a transformative innovation for social studies teacher education. In Journal of Technology and Teacher Education, 7(1), 3-12.

Willey, J. \& Ash, I. K. (2005). Multimedia learning of history. In Richard Mayer (ed.). The Cambridge handbook of multimedia learning (pp. 375-392). Cambridge: Cambridge University Press.

Yin, R. (1993). Applications of case study research. Thousand Oaks: Sage Publication.

Yin, R. (2003). Case study research: design and methods. Thousand Oaks: Sage Publications.

Zhao, Y. (2004). Social studies teachers' perspectives of technology integration. Dissertação de Doutoramento. Retirado de: http://athenaeum.libs.uga.edu/bitstream/handle/10724/7484/zhao_yali_200405_phd.pdf?sequence=1 (Acessível em 21/08/2012) 
Sara Dias-Trindade - Doutora em História e pós-doutora em Tecnologias da Educação e da Comunicação pela Universidade de Coimbra. Docente na Faculdade de Letras (DHEEAA) da Universidade de Coimbra. Investigadora no CEIS20-UC, integrando, atualmente, a equipa de coordenação do referido Centro. É também investigadora na UMIELO da Universidade Aberta e em vários grupos de pesquisa de diferentes universidades brasileiras. Tem participado em diferentes projetos internacionais relacionados com as Tecnologias Educativas e com a Formação de Professores. As suas áreas de interesse e investigação são: Didática, Formação de Professores, Tecnologias Educativas e Cinema na Educação.

Joaquim Ramos de Carvalho - Doutor em História pela Universidade de Coimbra. Docente na Faculdade de Letras (DHEEAA) da Universidade de Coimbra e coordenador do Grupo Humanidades Digitais do CEIS20-UC. Exerceu funções de Vice-reitor da Universidade de Coimbra entre 2011 e 2019. Foi conselheiro ECTS junto da Comissão Europeia e membro do Comité de Coordenação da Rede de Excelência CLIOHRES. net ( $6^{\circ} \mathrm{PQ}$ ). Participou em atividades do Coimbra Group (onde é membro do Executive), programas Erasmus Mundus (onde coordenou recentemente o projeto ALISIOS-Ação 3) e Tempus, ações Marie-Curie e projetos europeus no domínio do património, criatividade e tecnologia. 
Série Investigação

Imprensa da Universidade de Coimbra

Coimbra University Press

2019

12 (10.19 9 ONIVERSIDADE P

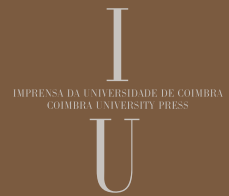

